\title{
NATURAL MONUMENTS: \\ RETHINKING ARBOREAL HERITAGE \\ FOR \\ TWENTY-FIRST-CENTURY \\ AOTEAROA NEW ZEALAND
}

Susette Goldsmith

A thesis submitted to Victoria University of Wellington in fulfilment of the requirements for the degree of Doctor of Philosophy

Victoria University of Wellington

2018 



\begin{abstract}
The twenty-first century is imposing significant challenges on nature in general with the arrival of climate change, and on arboreal heritage in particular through pressures for building expansion. This thesis examines the notion of tree heritage in Aotearoa New Zealand at this current point in time and questions what it is, how it comes about, and what values, meanings and understandings and human and non-human forces are at its heart. While the acknowledgement of arboreal heritage can be regarded as the duty of all New Zealanders, its maintenance and protection are most often perceived to be the responsibility of local authorities and heritage practitioners. This study questions the validity of the evaluation methods currently employed in the tree heritage listing process, tree listing itself, and the efficacy of tree protection provisions.
\end{abstract}

The thesis presents a multiple case study of discrete sites of arboreal heritage that are all associated with a single native tree species - karaka (Corynocarpus laevigatus). The focus of the case studies is not on the trees themselves, however, but on the ways in which the tree sites fill the heritage roles required of them entailing an examination of the complicated networks of trees, people, events, organisations, policies and politics situated within the case studies, and within arboreal heritage itself. Accordingly, the thesis adopts a critical theoretical perspective, informed by various interpretations of Actor Network Theory and Assemblage Theory, and takes a 'counter-'approach to the authorised heritage discourse introducing a new notion of an 'unauthorised arboreal heritage discourse'.

The thesis introduces alternative examples of arboreal heritage to the contemporary heritage canon paving the way for other forms of heritage that may remain mired in the expectations of the twentieth century's authorised heritage discourse. In doing so it elevates arboreal heritage as a valid part of physical heritage and a worthy topic for further critical heritage study. The research findings show that in contemporary Aotearoa New Zealand trees have been active in forging links between the past, the present and the future in new and powerful ways transcending the received evaluation methods and establishing a new rhetoric of arboreal indigeneity. Through the lens of tree registers, the research contributes to a better understanding of both natural heritage and heritage in general and, while firmly placed in the New Zealand context, provides a basis for critical heritage studies of related subjects elsewhere. 
Little has been written about arboreal heritage in Aotearoa New Zealand. As the first academic study of the topic, the thesis fills gaps in academic and professional knowledge of the tree heritage process. It introduces interdisciplinary ideas, from both the sciences and the humanities, and draws attention to tree heritage as a significant historical, social, economic, cultural and environmental contributor to the well-being of New Zealanders. The case studies demonstrate that effective, contemporary stewardship requires a revised 'tree sense' that acknowledges that arboreal heritage is founded on complex and various values, meanings and understandings, and is manifest in many different forms. Drawing on the archival, documentary and empirical research undertaken, the thesis proposes a democratisation of arboreal heritage decision-making, and contributes a set of principles to facilitate the negotiation of arboreal heritage acknowledgement and protection by communities, local authorities and heritage practitioners. 


\section{ACKNOWLEDGEMENTS}

First and foremost, I thank my family—Paul Goldsmith, Rupert Goldsmith, Celia Goldsmith, Katie Blackstock, Ari Stevens, Ann Cameron and Fergus Goldsmith-for their constant moral and practical support during this project. In particular I thank Paul who has accompanied me on my tree forays, endured countless breakfast- lunch- and dinner-time discussions of tree matters and been patient well beyond the call of duty. I acknowledge my parents Pat and Ray Drewery who taught me, in their separate ways, the worth of trees; my Māori and Pākehā farming and gardening forebears who have embedded in my DNA a deep appreciation of the natural world; and Jessica Goldsmith and her legacy of a fine redwood forest.

I consider myself extremely fortunate to have worked with Conal McCarthy as my primary supervisor and Kate Hunter as my secondary supervisor. As well as their wit and wisdom, they have brought to our meetings unwavering interest in and enthusiasm for my research. I sincerely thank them both. I also thank, for their friendship and practical help negotiating university rules and regulations, Annie Mercer and Pippa Wisheart. For the empathy and friendship that only fellow PhD students can provide, I thank Kay Hancock, Michelle Horwood, Samuele de Stefani and Lisa Terreni.

For their assistance in many different and extremely valuable ways, I wholeheartedly thank the following: archivists at City Archives (Wellington) and Museum of New Zealand Te Papa Tongarewa; Athfield Architects; Brad Cadwallader; Murray Dawson; librarians at the Wellington City Library, the Beaglehole Room (Victoria University of Wellington), the Alexander Turnbull Library and the Alister McIntosh Memorial Library (Heritage New Zealand); Justin Maxwell; Bruce McFadgen; Terese McLeod; officers of the Hastings District Council, the Palmerston North City Council and the New Plymouth District Council; the Parliamentary Commissioner for the Environment; Tim Porteous; Tony Quinn; Lee Rauhina-August; Trevor Thompson; Aaria Dobson-Waitere and Wraight Associates. I especially thank Brigitte Hegner and Megan Wraight for 'Being There'with me. Last but not least I acknowledge the assistance of my two retrievers, Rita and Plum, who made sure I never sat at my desk for too long. 


\section{CONTENTS}

$\begin{array}{ll}\text { List of Figures } & \text { p. } 7\end{array}$

$\begin{array}{ll}\text { List of Tables } & \text { p. } 9\end{array}$

$\begin{array}{ll}\text { Glossary } & \text { p. } 11\end{array}$

$\begin{array}{ll}\text { Abbreviations } & \text { p. } 13\end{array}$

$\begin{array}{lr}\text { Introduction: Natural Monuments } & \text { p. } 17\end{array}$

$\begin{array}{ll}\text { Chapter One: Research Design } & \text { p. } 65\end{array}$

$\begin{array}{lr}\text { Chapter Two: The Cyberforest: Heritage Trees } & \text { p. } 77\end{array}$

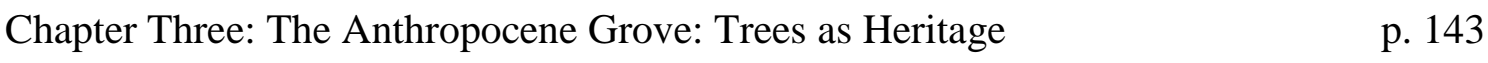

$\begin{array}{ll}\text { Chapter Four: The Dendroglyph Trees: Heritage as Trees } & \text { p. } 179\end{array}$

$\begin{array}{lr}\text { Chapter Five: Case Study Discussion } & \text { p. } 211\end{array}$

Conclusion: Rethinking Arboreal Heritage for the Twenty-first Century p. 233

$\begin{array}{ll}\text { Bibliography } & \text { p. } 245\end{array}$ 


\section{LIST OF FIGURES}

$\begin{array}{ll}\text { Map of Aotearoa New Zealand showing tree locations. } & \text { p. } 15\end{array}$

$\begin{array}{ll}\text { Karaka's distinctive drupes and leaves. } & \text { p. } 69\end{array}$

Mature karaka (Corynocarpus laevigatus). p. 70

$\begin{array}{lr}\text { Cover of RNZIH's June } 1940 \text { Journal. } & \text { p. } 83\end{array}$

$\begin{array}{lr}\text { Pōhutukawa ANZAC memorial, Eastbourne. } & \text { p. } 85\end{array}$

$\begin{array}{ll}\text { “A Giant Kauri” one-shilling centennial stamp. } & \text { p. } 88\end{array}$

“The Progress of Transport” four-penny centennial stamp. p. 88

Cover of "The Forest", vol.1, no.9, Making New Zealand. p. 90

$\begin{array}{ll}\text { Tree planting at Khandallah School, Wellington, } 1940 . & \text { p. } 94\end{array}$

$\begin{array}{lr}\text { RNZIH tree label. } & \text { p. } 102\end{array}$

Cover of Great Trees of New Zealand, $1984 . \quad$ p. 104

$\begin{array}{lr}\text { Year for Urban Trees poster, } 1984 . & \text { p. } 107\end{array}$

$\begin{array}{lr}\text { New Zealand Tree Register home page. } & \text { p. } 112\end{array}$

$\begin{array}{lr}\text { Karaka at } 32 \mathrm{Kuku} \text { Street, Te Awanga. } & \text { p. } 122\end{array}$

$\begin{array}{lr}\text { Karaka at } 28 \text { Kuku Street, Te Awanga. } & \text { p. } 122\end{array}$

$\begin{array}{lr}\text { Sculptures at the Palmerston North grove entrancer } & \text { p. } 125\end{array}$

$\begin{array}{lr}\text { The Palmerston North grove. } & \text { p. } 126\end{array}$

$\begin{array}{lr}\text { Cut-outs on the pou. } & \text { p. } 127\end{array}$

$\begin{array}{ll}\text { Life-like insects attached to the pou. } & \text { p. } 127\end{array}$

$\begin{array}{ll}\text { The three pou. } & \text { p. } 127\end{array}$

The buttress 'feet' of the New Plymouth karaka. p. 130

$\begin{array}{ll}\text { The two trunks and the canopy's dapple effect. } & \text { p. } 131\end{array}$

$\begin{array}{ll}\text { The karaka's canopy. } & \text { p. } 131\end{array}$

$\begin{array}{ll}\text { View north of the Anthropocene Grove. } & \text { p. } 144\end{array}$ 
Te Aro Pa 1842/1843.

p. 148

Subdivision of Te Aro Pā 1842/43.

p. 150

Overlooking Te Aro, 1857.

p. 156

Taranaki Wharf planting plan, 2010.

p. 166

Kupe Group.

p. 168

The Anthropocene Grove.

p. 172

Early Taranaki Wharf proposal illustration.

p. 177

Map of Parangarahu Lakes Area.

p. 184

Adkin's map showing locations of Dendroglyph Trees.

p. 188

Sketch plan showing Dendroglyph Trees, and sketches of dendroglyphs.

p. 188

Māori group roasting karaka berries, 1908.

p. 192

Planting day at Parangarahu Lakes Area.

p. 200

Dendroglyph Tree and the fish form.

p. 201

Dendroglyph Tree with hollow trunk.

p. 202

Sketch plan of karaka groves, Cape Palliser coast.

p. 203

Map showing karaka groves.

p. 204

Extant karaka grove, Palliser Bay Road.

p. 204

Remaining karaka at Te Roro Stream.

p. 205

Lake Kohangatera karaka grove.

p. 206

Dendroglyph Tree.

p. 207 


\section{LIST OF TABLES}

Table 1: STEM classifications and evaluations, 1996.

Table 2: Comparison of native and exotic tree entries in lists 1943-2016.

Table 3: Comparison of native and exotic tree entries in the Cyberforest.

Table 4: Comparison of native and exotic heritage tree lists in three council district plans.

Table 5: The heritage assemblage of Taranaki Wharf.

Table 6: Comparison of tree sites according to core domains of arboreal heritage.

p. 228

Table 7: Principles for the acknowledgement and protection of arboreal heritage in Aotearoa New Zealand. 


\section{GLOSSARY}

ahi kā. Rights of occupation.

iwi. Extended kinship group, tribe.

kāinga. Home, village.

kaitiaki. Guardian.

kaitiakitanga. Guardianship, protection.

kaumātua. Elders, persons of status.

kawanatanga. Authority, government.

korowai. Cloak.

mana. Prestige, authority.

mana whenua. Territorial rights.

Māori. Indigenous New Zealander.

Māoritanga. Māori culture, practices and beliefs.

mauri. Life force.

moemoeā. Vision.

pā. Fortified village.

Pākehā. New Zealander of European descent.

pātaka. Storehouse.

pou whenua. Post marker of ownership.

rāhui. Device for separating people from things that are tapu.

rākau momori. Carved memorial trees of Rēkohu Chatham Islands.

rangatira. Chief.

raukura. Feather.

rongōa. Medicine.

tāngata. People. 
tangata whenua. Local indigenous people.

taonga. Prized possessions, precious resources (tangible and intangible).

taonga tuku iho. Heirlooms, heritage.

tapu. Sacred, prohibited.

te reo Māori. Māori language.

tikanga. Cultural practices.

tino rangatiratanga. Full authority.

tohunga. Priest, healer.

tupuna. Ancestors.

wāhi tapu. Sacred places.

waiata. Song, chant.

waka taua. War canoe.

whakairo. Carving.

whakapapa. Genealogy, lineage.

whanaunga. Kin.

whare tapere. Place for entertainment.

wharekai. Dining hall, café.

wharewaka. Waka house.

whenua. Land.

Current New Zealand English conventionally uses macrons to indicate a double vowel in Māori words. This convention is followed here unless in the titles of, for example, books and organisations, and in historical archival sources and texts where no macrons or double vowels are used intentionally. 


\section{ABBREVIATIONS}

AAHD. Authorised Arboreal Heritage Discourse.

AHD. Authorised Heritage Discourse.

ANT. Actor Network Theory.

CCC. Community Consultative Committee (Wellington).

GWRC. Greater Wellington Regional Council.

HDC. Hastings District Council.

MIRO. Mainland Island Restoration Operation.

NPDC. New Plymouth District Council.

NTNZ. Notable Trees New Zealand.

NZArb. New Zealand Arboricultural Association.

NZHPT. New Zealand Historic Places Trust (now Heritage New Zealand Pouhere Taonga).

NZIH. New Zealand Institute of Horticulture (now Royal New Zealand Institute of Horticulture).

NZNTT. New Zealand Notable Trees Trust.

PNBST. Port Nicholson Block Settlement Trust.

PNCC. Palmerston North City Council.

RMA. Resource Management Act, 1991.

RNZIH. Royal New Zealand Institute of Horticulture.

STEM. Standard Tree Evaluation Method.

TEM. Tree Evaluation Method.

UAHD. Unauthorised Arboreal Heritage Discourse. 

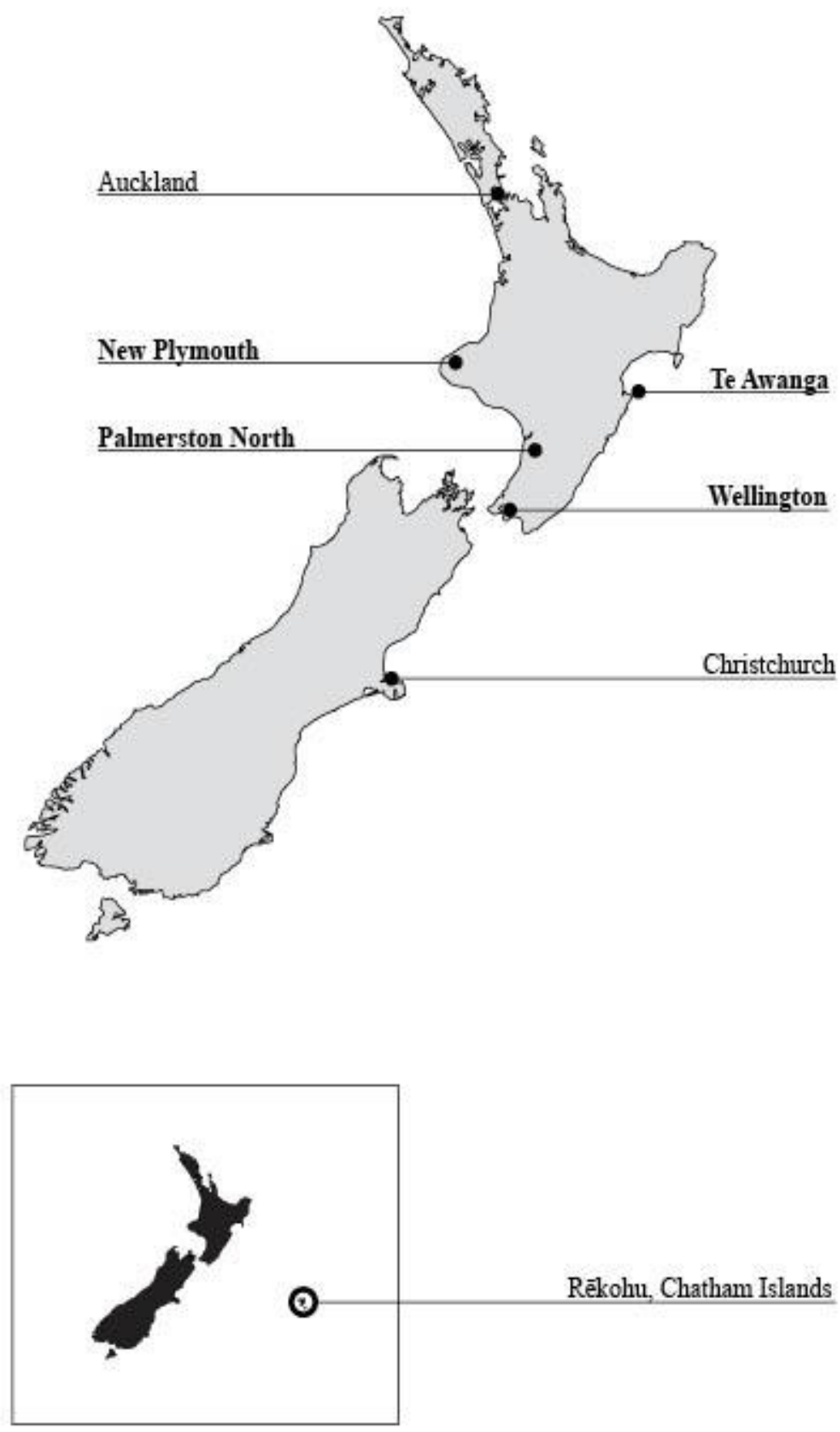

Figure 1: Aotearoa New Zealand showing tree locations of importance to the thesis. 


\section{INTRODUCTION: NATURAL MONUMENTS}

Heritage is that part of the past which we select in the present for contemporary purposes, be they economic, cultural, political or social. The worth attributed to these artefacts rests less in their intrinsic merit than in a complex array of contemporary values, demands and even moralities. ${ }^{1}$

\section{Research Topic}

The tree destruction or protection quandary has been argued by different voices from different perspectives coloured by one or more of economic, environmental, cultural, historical, scientific, political and personal concerns throughout the long and fraught history of arboreal heritage. The twenty-first century has imposed its own significant challenges on nature in general, with the arrival of climate change, and on tree heritage in particular, through pressures for building expansion. The first challenge has introduced multidisciplinary discussions and conceptual ideas appropriate to any contemporary considerations of nature and natural heritage, and the second has shaken the authority of tree heritage listing and protection. At the same time, Aotearoa New Zealand's ${ }^{2}$ tree heritage has evolved as it has adapted to political and societal changes and community expectations. All of these developments contribute to my claim that this study of arboreal heritage is particularly timely. This thesis examines the notion of arboreal heritage at this current point in time and establishes new ways of thinking about it and negotiating its acknowledgement and protection appropriate to twenty-first-century New Zealand. The research has taken a multiple-case-study approach, examining one indigenous tree species, karaka (Corynocarpus laevigatus), within three discrete cases:

The Cyberforest (the digital New Zealand Tree Register)

The Anthropocene Grove (an urban planting on Wellington's waterfront)

The Dendroglyph Trees (carved trees at Lake Kohangapiripiri, Wellington). Through archival, documentary and empirical research into the backgrounds of and current heritage practice at the selected tree sites, this study defines arboreal heritage and its processes, and determines the influences that continue to shape New Zealand's arboreal heritage today.

\footnotetext{
${ }^{1}$ Brian Graham, G. J. Ashworth, and J. E. Tunbridge, A Geography of Heritage: Power, Culture and Economy (London: Arnold, 2000). 17.

${ }^{2}$ Although not formally recognised, the double appellation 'Aotearoa New Zealand' is used widely. It is employed here when directly quoting from texts, discussing thesis questions or for emphasis. Elsewhere the country is referred to as 'New Zealand'.
} 
Arboreal heritage is an uncommon topic for academic study, which ordinarily focuses on built heritage, and little has been written about it. Because of this, and because the topic has roots in both natural and cultural heritage, this thesis includes research drawn from other disciplines in both the sciences and the humanities. This shift has introduced contemporary ideas to this discussion which were not foreseen at the beginning of the research. In particular, these relate to the intricate nature-society network of the twenty-first century and the understanding and responsibilities this calls for today. This is a critical heritage studies inquiry — rather than an environmental study_enriched by acknowledgement of these interdisciplinary ideas and ethical considerations which have introduced an environmental dimension to the discussion and influenced the research approach.

While the acknowledgement of arboreal heritage can be regarded as the duty of all New Zealanders, its maintenance and protection are most often perceived to be the responsibility of local authorities and heritage practitioners. This study calls into question the validity of the evaluation methods currently employed in the tree heritage listing process, tree listing itself, and the efficacy of arboreal heritage protection provisions and introduces alternative examples of arboreal heritage to the contemporary heritage canon. It proposes a democratisation of decision-making concerning arboreal heritage and introduces a set of principles for the successful engagement of communities, local authorities and heritage practitioners when negotiating its acknowledgement and protection.

\section{Research Context}

At the beginning of my preparations for this study, a curiously appropriate event occurred. My neighbour on the opposite side of the road fired up his chainsaw and proceeded to 'trim' a young, self-sown pōhutukawa (Metrosideros excelsa) that was growing on the footpath outside his house and leaning into the nearby power lines. It was, he believed, impeding the performance of his computer by brushing against the wires. The neighbour to my immediate right and also opposite the tree called out to the tree-trimmer to "cut the whole thing down" as it was spoiling her otherwise unrestricted view. Alarmed, I spoke up in defence of the tree which, I reasoned, had a right to live and, besides, provided a welcome green frame for my own view. The tree trimmer, somewhat bemused by the interference of his neighbours but keen to satisfy everyone, opted for a compromise - the branches closest to the wires were cut and the others were left alone. The right-hand neighbour had a view with less greenery, I had 
a view with a ragged frame, the tree trimmer had newly liberated power wires and the tree was still alive.

That might have been an end to it. However, a few weeks later, notices appeared in our letter boxes from our local authority reprimanding whoever was responsible for "illegally pruning" vegetation on public land under bylaw part 17 (Public Places). Once more, that might have concluded the affair. But, no. After several more weeks, a council truck arrived at the scene, several men equipped with a chainsaw and brooms got out and cut down what was left of the tree, picked up the branches, stowed them on the truck, swept the footpath around the remaining tree stump and drove away. Intrigued by the latter proceedings, in view of the fact that we had all been told off for vandalising the tree and because I was currently engrossed in matters arboreal, I emailed the signatory of the notice asking what the reason was behind the council's action. A month went by before I received a reply from the customer liaison arborist who apologised for the delay in responding. She explained that it was council policy to remove all trees on public property whose roots threatened the structure of nearby crib walls, and thanked me for my interest in public trees. A little later I reported all of this to my neighbour to the left, who had been away at the time of the events and whose house is also opposite the tree but is elevated sufficiently to secure tree-free views. She was not at all surprised that the council had cut down the tree, she said, because it was threatening the power wires and, anyway, it wasn't a "real tree", which I took to mean that it hadn't been planted with human intent. Real tree or not, the pōhutukawa has proved to be resilient. Three and a half years later, the fuss has died down and the stocky little tree stump has put out many very healthy branches.

The point of this story is not to cast blame: none of the parties — including the tree-was at fault. My interest in the proceedings stems from the fact that each of the protagonists in our small suburban drama — including the tree-was acting from a vastly different viewpoint. All were, as Cronon puts it, "defending their corner of Eden". ${ }^{3}$ Of particular interest to me is the fact that the differences in our opinions about the fate of the single pōhutukawa tree clearly show that there was more than one tree at work here and that the various trees subscribed to were measured by individual people according to idiosyncratic and anthropocentric values. If,

\footnotetext{
${ }^{3}$ William Cronon, "Introduction: In Search of Nature," in Uncommon Ground: Rethinking the Human Place in Nature, ed. William Cronon (New York: W. W. Norton, 1996). 39.
} 
as Cronon has written, our views of nature are important factors in defining who we think we are and the kind of lives we wish to lead, this episode was not just about the tree, in fact it was about us - what we individually believe in and stand for. ${ }^{4}$ Similarly, contemporary heritage theory suggests that what we decide to protect in the name of 'heritage' represents, and is an expression of, our cultural and social values and meanings which are not inherent in the items or events themselves. ${ }^{5}$ Where heritage has often been determined by past experts engaged in, what Smith describes as, an 'authorised heritage discourse' (AHD), with its predilection for values of history and beauty, current thinking has bucked the system. Heritage, today, is viewed as intangible and as a cultural process of meaning and value production. ${ }^{6}$ The term, 'process', is particularly important to this thesis. Not only is the word used to define heritage but it also signposts the path for my research. Process, West points out, "stands for the thoughts and actions that join the tangible remains of the past with contemporary meanings and practices ... [and] is a powerful route towards understanding why heritage is identified, cherished and celebrated in such diverse ways". 7 The aim of this thesis is to understand the thoughts and actions that join the tangible remains of the past with contemporary meanings and practices through the lens of arboreal heritage.

\section{Research Questions}

This study of the heritage process with a focus on trees builds on a literature review and critical heritage studies theory. The empirical research undertaken shows how this process transforms some individual trees into official arboreal heritage but withholds the privilege from others; it examines the associated roles that both humans and non-humans play and questions how trees can be heritage in ways that differ from the parameters of the AHD. Trees in New Zealand are ubiquitous - they dominate our indigenous 'bush', our botanical gardens and parks and our 'leafy suburbs' - and as such are in danger of being neglected by academia. This research introduces a fresh approach to their place in the natural heritage canon and addresses the following primary questions:

\footnotetext{
${ }^{4}$ Ibid.

${ }^{5}$ Laurajane Smith, Uses of Heritage (London: Routledge, 2006).

${ }^{6}$ Laurajane Smith, "General Introduction," in Cultural Heritage: Critical Concepts in Media and Cultural Studies, ed. Laurajane Smith (Oxford: Routledge, 2007). 4.

${ }^{7}$ Susie West, ed. Understanding Heritage in Practice (Manchester: Manchester University Press, 2010). 1.
} 
What is arboreal heritage in Aotearoa New Zealand?

How do trees become arboreal heritage?

What values, meanings and understandings, and human and non-human forces have shaped and continue to shape Aotearoa New Zealand's arboreal heritage today?

While these questions are addressed within the context of New Zealand the omnipresence of trees worldwide suggests that the research findings will provide a basis for comparison with other countries' arboreal heritage.

\section{Research Background}

This topic has grown out of my previous research for a Master's thesis in Museum and Heritage Studies, Turning Over Old Ground: Investigating Garden Heritage in Aotearoa New Zealand, in which several relevant strands of heritage were noted and called for further investigation. The first of these strands is that despite New Zealand's focus on conserving only its built heritage, since the first interest in preserving colonial buildings in the early twentieth century, special dispensation has been afforded to trees. A clean-up-the-groundsbut-save-the-trees approach was typical of the, then, New Zealand Historic Places Trust's $(\mathrm{NZHPT})^{8}$ mid-twentieth-century conservation practice despite a general disregard for the conservation and/or authenticity of the remaining curtilage of historic places. ${ }^{9}$ It can be argued that where it did occur, the preservation of large and/or old trees was aimed primarily at creating an impression of deep time at historic places and, in part, was at the expense of the conservation of the associated curtilage and outdoor artefacts. Efforts to protect the trees appear to have distracted the agency from any more comprehensive protection of historic places and, to some extent, to have replaced it. As long as the very visible historic heritagebuildings and trees - had been conserved then the job of protection was considered to be done. ${ }^{10}$

The second strand is that several agencies, independent of the NZHPT, have energetically attempted to protect New Zealand's historic trees. Following early twentieth-century actions by the Scenery Preservation Board to reserve substantial areas of "magnificent but

\footnotetext{
${ }^{8}$ Now called 'Heritage New Zealand Pouhere Taonga'.

${ }^{9}$ This is not intended as criticism but is an indication of common heritage practice of the time.

${ }^{10}$ Susette Goldsmith, "Turning over Old Ground: Investigating Garden Heritage in Aotearoa New Zealand" (MA, Victoria University of Wellington, 2014). 52.
} 
uncontentious and unproductive" 11 land, moves to formalise the protection of individual trees began in earnest in the 1930s and are now enshrined within the local authority tree registers maintained under the Resource Management Act, 1991 (RMA). The Royal New Zealand Institute of Horticulture (RNZIH) established a list of notable and historic trees "for the purpose of cataloguing and registering New Zealand's tree heritage" in the 1970s which developed into the online New Zealand Tree Register launched in 2009. ${ }^{12}$ This register is now administered by the New Zealand Notable Trees Trust (NZNTT), which was established by the RNZIH and the New Zealand Arboricultural Association (NZArb) in 2007, and is studied in this thesis as the Cyberforest.

A third strand has arisen from the fact that these moves to conserve arboreal heritage, described above, are in stark contrast with the determined actions from the mid-nineteenth century to the early twentieth century to transform the country from a landscape that was densely forested to one dominated by pasture. ${ }^{13}$ Seduced by promises of rich fertile soils suitable for farming on readily procurable lands, nineteenth-century Pākehā (New Zealanders of European descent) settlers were alarmed to discover on arrival that the new home they had signed up for was far from the South Seas Eden they had imagined. ${ }^{14}$ The settlers set to, energetically draining wetlands, ploughing the tussock growing on land previously cleared of indigenous forest and burning vast tracts of the forest that remained. By the beginning of the twentieth century, four million hectares of New Zealand had been converted to grass ${ }^{15}$ through what artist Alfred Sharpe describes as "arboricidal profanation". ${ }^{16}$ Geographer Kenneth Cumberland wrote in 1941 that where New Zealand's transformation to grasslands had been accomplished within a single century it had taken Europe twenty centuries and

\footnotetext{
${ }^{11}$ David Young, Our Islands Our Selves: A History of Conservation in New Zealand (Dunedin: Otago University Press, 2004). 124.

${ }^{12}$ http://www.notabletrees.org.nz. Accessed 2 November 2012.

${ }^{13}$ Giselle Byrnes, Boundary Markers: Land Surveying and the Colonisation of New Zealand (Wellington: Bridget Williams Books, 2001). See also Geoff Park, Ngā Uruora: The Groves of Life (Wellington: Victoria University Press, 1995); Theatre Country: Essays on Landscape and Whenua (Wellington: Victoria University Press, 2006).

${ }^{14}$ Rollo Arnold, "British Settlers and the Land," in Te Whenua Te Iwi: The Land and the People, ed. Jock Phillips (Wellington: Allen and Unwin and Port Nicholson Press, 1987); James Belich, Making Peoples: A History of the New Zealanders from Polynesian Settlement to the End of the Nineteenth Century (Auckland: Allen Lane, the Penguin Press, 1996); Evan Eisenberg, The Ecology of Eden (New York: Alfred A. Knopf, 1998); Carolyn Merchant, Reinventing Eden: The Fate of Nature in Western Culture (London: Routledge, 2004); Park, Theatre Country.

15 Tom Brooking and Eric Pawson, "The Contours of Transformation," in Seeds of Empire: The Environmental Transformation of New Zealand, ed. Tom Brooking and Eric Pawson (London: I. B. Tauris and Co. Ltd, 2011). 13-14.

${ }^{16}$ Quoted in Roger Blackley, “Alfred Sharpe,” in Art at Te Papa, ed. William McAloon (Wellington: Te Papa Press, 2009). 96.
} 
North America four centuries. ${ }^{17}$ Brooking and Pawson point out that at the heart of this transformation was a "preoccupation evidenced all over the European settler world: the drive to construct new landscape out of 'unimproved' territories. Landscape was a product of culturally specific ways of seeing". ${ }^{18}$ Mitchell describes the act of 'improvement' as an ideological, material and technical project. ${ }^{19}$ Pākehā were not alone in slashing and burning the indigenous forest, however, nor were the lands they found 'unimproved'. Prior to the arrival of Pākehā settlers in New Zealand in the nineteenth century, Māori (indigenous New Zealanders) had been involved in the loss of 50 per cent of the original forest. ${ }^{20}$ Land was cleared for hunting and gardening, and to create spaces for fortifications and other structures much of the native forest had been pushed back from the coastal edge. This thesis is not an inquiry into the events that led to the destruction of New Zealand's forests but acknowledges them as forces that potentially have influenced the arboreal heritage process, and still do.

A further and very topical subject for discussion concerns the future of the world's ecology and the importance of nature to human life and well-being. This is an ongoing, multidisciplinary discourse that engages academics from both the sciences and the humanities, raises questions concerning a more ethical consideration of non-human entities, and encourages a review of the relationships between non-humans and humans. It is in this context that this study presents arboreal heritage as having not only past and present but also future environmental significance.

This thesis has its genesis in the neighbourhood event and the heritage issues outlined above. As there is little literature that deals with the construction of heritage in New Zealand, ${ }^{21}$ this research contributes to a better understanding of both natural heritage and heritage in general. It aims to fill gaps in academic and professional knowledge of the tree heritage process, and both to deepen general appreciation of arboreal heritage and to elevate it as an important field

\footnotetext{
${ }^{17}$ Kenneth B. Cumberland, "A Century's Change: Natural to Cultural Vegetation in New Zealand," Geographical Review 31, no. 4 (1941). 529.

${ }^{18}$ Eric Pawson and Tom Brooking, "Introduction," in Seeds of Empire: The Environmental Transformation of New Zealand, ed. Tom Brooking and Eric Pawson ((London: I. B. Tauris and Co. Ltd, 2011). 8.

${ }^{19}$ W. J. T. Mitchell, "Imperial Landscape," in Landscape and Power, ed. W. J. T. Mitchell (Chicago: University of Chicago Press, 1994). 5-34.

${ }^{20}$ Atholl Anderson, "A Fragile Plenty: Pre-European Maori and the New Zealand Environment," in Making a New Land: Environmental Histories of New Zealand, ed. Eric Pawson and Tom Brooking (Dunedin: Otago University Press, 2013). 36.

${ }^{21}$ An exception is Alexander Trapeznik, ed. Common Ground? Heritage and Public Places in New Zealand (Dunedin: University of Otago Press, 2000).
} 
of critical heritage studies. Deciding whether or not to conserve trees is a recurring dilemma faced by communities and their heritage agencies in New Zealand and often arouses strong emotions. It is hoped that this thesis will provide a better understanding of arboreal heritage, the processes that have led to it in its various forms and the values, meanings and understandings that support it, and that it will prompt a more informed discussion and a more intelligent appraisal of our contemporary tree heritage that is broader in scope.

While trees have been examined, for example, as agents of both memorialisation ${ }^{22}$ and identity, ${ }^{23}$ these discourses tend to present heritage as something preordained rather than as a cultural construct that is in flux and subject to both human and non-human influences. This thesis offers an alternative reading of arboreal heritage with particular reference to the changing narratives, values and principles associated with the transformation of karaka to arboreal heritage within the three cases studied. While considering the materiality of trees it will also, in keeping with contemporary theory, approach heritage as performative and examine arboreal heritage in relation to cultural identity, feelings of belonging and the play of memory and duration which Crouch refers to as 'heritaging'. ${ }^{24}$ He writes that heritage, together with time and memory, is always emergent, open, full of possibilities and never reliably constrained, "Heritage is too rich to be so constrained. Heritage is not deferential; it is in and of life". ${ }^{25}$ By considering them as the product of changing relationships in which they are placed trees can be regarded as "performed". ${ }^{26}$

\footnotetext{
${ }^{22}$ For example: Paul Cloke and Eric Pawson, "Memorial Trees and Treescape Memories," Environment and Planning D: Society and Space 26, no. 1 (2008); John Dargavel, "More to Grief Than Granite: Arboreal Remembrance in Australia," Journal of Australian Studies 24, no. 64 (2000); Katie Pickles, "Mapping Memorials for Edith Cavell on the Colonial Edge," New Zealand Geographer 62 (2006). See also Yukiko Numata Bedford, "The 'Peace Gardens', Featherston, South Wairarapa and the Chor-Farmer," http://environmentalhistory-a-nz.org/wp-content/up[loads/2011/01/ENNZ_2010_v5_n2. Accessed 2 November 2012.

${ }^{23}$ For example: Kylie Mirmohamadi, “Talking About Native Plants,” (2006), http://www.colloquy.monash.edu.au/issue12/mirmohamadi.pdf. Accessed 7 January 2012. "Designing Bush Landscapes: History and Place in Eltham and Castlecrag," Studies in the History of Gardens and Designed Landscapes 31, no. 2 (2011); Katie Holmes, "Growing Australian Landscapes: The Use and Meanings of Native Plants in Gardens in Twentieth-Century Australia," ibid.; Philip Smith, "Genius Loci: Identity and the New Zealand Garden," New Zealand Garden Journal 7, no. 1 (2004).

${ }^{24}$ David Crouch, "The Perpetual Performance and the Emergence of Heritage," in Culture, Heritage and Representation: Perspectives in Visuality and the Past, ed. Emma Waterton and Steve Watson (Surrey: Ashgate, 2010).

${ }^{25}$ Ibid. 68-69.

${ }^{26}$ Cloke and Pawson, "Memorial Trees and Treescape Memories.” 109.
} 


\section{Literature Review}

This literature review provides a theoretical framework for the research into arboreal heritage in New Zealand. As noted above, in surveying the relevant literature I have cast a wide net across numerous disciplines. These include: social ecology; environmental history; philosophy; ethics; and geography. The reasons for this multi-disciplinary approach are threefold. First, critical heritage studies itself is a hybrid, interdisciplinary field concerned with ideas about the composition and management of both natural and cultural heritage. Second, arboreal heritage, as a cultural construct of physical entities, stands astride the humanitiessciences divide. Third, such an approach is timely. Late twentieth- and twenty-first-century acknowledgment of and mounting concern about climate change have resulted in discussions about the natural world that have engaged both moral values and scientific principles. This cross-disciplinary discourse has generated innovative thinking about the significance of nature, the contribution of non-human entities to human existence, and the relationships between non-humans and humans. As the fate of trees is often emblematic of the wider environment, ${ }^{27}$ a critical heritage study focused on trees has additional environmental implications. This wide-scoping review of literature aims to provide an up-to-date and theoretically informed contribution to the critical heritage studies field.

\section{Nature, Culture and Critical Heritage Studies}

Numerous writers have addressed, from various perspectives, the ways in which nature and culture work together. ${ }^{28}$ For better or worse, writes Eisenberg, "Our relation to nature can only be cultural. Nature is never just nature. A landscape - even a place that is utterly wildis admired not only for itself but for its links to previous human experience". ${ }^{29}$ Despite this perceived bond, Howard points out, because cultural heritage is traditionally the realm of the

\footnotetext{
${ }^{27}$ Owain Jones and Paul Cloke, Tree Cultures: The Place of Trees and Trees in Their Place (Oxford: Berg, 2002). 2.

${ }^{28}$ For example: Eric Dorfman, ed. Intangible Natural Heritage: New Perspectives on Natural Objects (New York: Routledge, 2012); Peter H. Jr. Kahn, The Human Relationship with Nature: Development and Culture (Cambridge, Massachusetts: MIT Press, 2001); Kenneth R. Olwig, "Introduction: The Nature of Cultural Heritage, and the Culture of Natural Heritage-Northern Perspectives on a Contested Patrimony," in The Nature of Cultural Heritage and the Culture of Natural Heritage: Northern Perspectives on a Contested Patrimony, ed. Kenneth R. Olwig and David Lowenthal (Oxford: Routledge, 2006); Mere Roberts et al., "Kaitiakitanga: Maori Perspectives on Conservation," Pacific Conservation Biology 2 (1995); Anne Salmond, "Ontological Quarrels: Indigeneity, Exclusion and Citizenship in a Relational World," Anthropological Theory 12, no. 2 (2012); Anthony Weston, "Is It Too Late?," in An Invitation to Environmental Philosophy, ed. Anthony Weston (Oxford: Oxford University Press, 1999); Richard White, "Discovering Nature in North America," The Journal of American History 79, no. 3 (1992).

${ }^{29}$ Eisenberg, The Ecology of Eden, 244. See also S. E. Larsen, "Is Nature Really Natural?," Landscape Research 17, no. 3 (1992) and Simon Schama, Landscape and Memory (New York: Alfred A. Knopf, 1995).
} 
humanities and nature conservation has been almost exclusively the subject of scientists, anything that bridges both is in danger of being overlooked. Overriding the many problems of definition that fray the boundaries of heritage categories, he proposes a single field of enquiry that includes natural and cultural heritage, "If only to ensure that each group stops neglecting the other aspect". ${ }^{30}$ While this thesis considers both nature and culture-specifically arboreal heritage - it is firmly located within the discipline of critical heritage studies which is open to multi-disciplinary consideration and, therefore, is well placed to provide the single field of enquiry, as advocated by Howard, and is particularly appropriate to this study. A second advantage of the discipline of critical heritage studies for this investigation is its ability to operate from a contemporary viewpoint rather than from a primarily historical focus. The attention of critical heritage studies is drawn not so much to the past as it is to what we do today with the objects and the ideas that we have inherited. ${ }^{31}$ The presence of trees in our everyday lives ensures that arboreal heritage has an immediate influence on us-even if it is not universally recognised. The here-and-now quality of critical heritage studies means that its focus can be informed by contemporary circumstances and individual academic interests providing a third advantage for this study. The value of heritage, Eriksen argues, is not defined by age or historical consequence, but by the "interest of some living subject who takes on the role as heir". ${ }^{32}$ Heritage, by this definition, requires a contemporary champion to further its interests and its merit is measured by current values and conditions. The single field of enquiry undertaken in this thesis is arboreal heritage. The approach adopted is that of critical heritage studies which Macdonald points out leads to "interrogation of why and how some things come to count as 'heritage' and the consequences that flow from this". ${ }^{33}$ Why, how and by whom the cause of arboreal heritage has been and is still promoted, which parts do not make the cut, and what values and conditions are at play are topics discussed here. As a study of arboreal heritage, rather than, say, built heritage, this thesis has required the application of additional, particular considerations of the peculiar characteristics of its topic. Trees are living entities; they are non-portable; situated outdoors and in both public and private realms; ubiquitous and a vital part of our sensory landscapes, and they operate in "their own ecological time which is rather different from the typical time-scales of human-

\footnotetext{
${ }^{30}$ Peter Howard, Heritage: Management, Interpretation, Identity (London: Continuum, 2005). 55.

${ }^{31}$ Barbara Kirshenblatt-Gimblett, "Theorizing Heritage," Ethnomusicology 39, no. 3 (1995); Howard, Heritage; Anne Eriksen, From Antiquities to Heritage: Transformations of Cultural Memory (New York: Berghahn, 2014).

${ }^{32}$ Eriksen, From Antiquities to Heritage. 149.

${ }^{33}$ Sharon Macdonald, Memorylands: Heritage and Identity in Europe Today (London: Routledge, 2013). 17.
} 
centred analysis". ${ }^{34}$ One of the most important accomplishments of heritage, Macdonald writes, is to turn the "past from something that is simply there, or has merely happened, into an arena from which selections can be made and values derived. We might even put this as heritage turning the past into The Past". ${ }^{35}$ How critical heritage studies theory can be applied to the study of arboreal heritage, which is peculiarly grounded in both time and place and can be regarded as both tangible and intangible, is discussed in the following section.

\section{Critical Heritage Studies as a Mode of Enquiry}

If, as alluded to above, trees cannot reasonably be uprooted and exhibited within museums how are they to be displayed for universal heritage consumption? If materiality is not absolutely essential to the work of heritage, ${ }^{36}$ is the 'heritageness' of the tree adversely affected by its physical absence? While it is important to the understanding of the role that trees play in the construction of heritage, their physical being is not the prime focus of this thesis. However, to what extent the heritageness of the trees studied here relies on their living materiality is discussed further in the cross-case analysis in Chapter Five. The subject of our heritage gaze, writes Smith, "is not so much a 'thing' as a set of values and meanings. 'Heritage' is therefore ultimately a cultural practice, involved in the construction and regulation of a range of values and understandings". ${ }^{37}$ Smith's definition of heritage underpins this thesis, however, in its specific application to trees, the terms 'values', 'meanings' and 'understandings'require further clarification as, within the particular theoretical framework of this research, they are not necessarily human generated. In accordance with recent moves by scholars away from an anthropocentric approach towards the employment of methodologies that 'study up' rather than 'study-down', this research has been guided by what Plumwood describes as "shifting the onus of proof from inclusion to exclusion"38 and what Nader defines as "asking "common sense' questions in reverse". 39 The values and meanings considered in this study might, therefore, be derived from a non-human source. These approaches are mediated by an acknowledgement of Harrison's "continuous and integrated way of understanding" past-present and human-non-human relationships and the "thorough mixing or entanglement of objects and humans in the process of 'creating'

\footnotetext{
${ }^{34}$ Jones and Cloke, Tree Cultures. 54.

35 Macdonald, Memorylands. 18.

36 Kirshenblatt-Gimblett, "Theorizing Heritage."; Smith, Uses of Heritage.

37 Smith, Uses of Heritage. 11.

${ }^{38}$ Val Plumwood, Environmental Culture: The Ecological Crisis of Reason (London: Routledge, 2002). 11.

${ }^{39}$ Laura Nader, "Up the Anthropologist: Perspectives Gained from Studying Up," in Reinventing Anthropology, ed. Dell Hymes (New York: Vintage Books, 1972). 289.
} 
heritage, and the ways in which both are equally implicated in a process of producing the past in the present". ${ }^{40}$

Heritage, Kirshenblatt-Gimblett argues is a "mode of cultural production in the present that has recourse to the past" ${ }^{41}$ This is the working definition of heritage for this study, enabling the thesis to challenge receive ideas of heritage and investigate alternative examples. The phrase "mode of cultural production" highlights the applied nature of critical heritage studies and reinforces the usefulness to this thesis of the set of principles at its conclusion which is intended to be a practical guide designed for heritage in practice. Furthermore, KirshenblattGimblett adds, a key to heritage productions is "their virtuality, whether in the presence or the absence of actualities". ${ }^{42}$ I argue in this thesis that, in arboreal heritage terms, Kirshenblatt-Gimblett's actualities and virtualities can be translated into the listing and classification of actual, living — but mortal—objects within virtual, accessible — but comparatively immortal—registers. ${ }^{43}$ The New Zealand Tree Register's online presence lends it another-literal-level of 'virtuality' and makes it a useful heritage instrument for investigation as a tree-site (the Cyberforest). There are other virtualities at work here and contained in what Eriksen defines as an experience of temporality that can be called 'presentist' and allows "values of the present to invade and define the past not merely when it comes to selecting what is important, but also concerning the way this procedure is carried out". ${ }^{44}$ Similarly, Macdonald introduces the notion of 'past presencing' as "the empirical phenomenon of how people variously experience, understand and produce the past in the present". ${ }^{45}$ The sub-section that follows, titled 'Towards Ethical Mindfulness', discusses a recent turn towards a more ethical nature-culture relationship in which writers advocate the move away from anthropocentrism. ${ }^{46}$ How this turn might influence contemporary attitudes

\footnotetext{
${ }^{40}$ Rodney Harrison, Heritage: Critical Approaches (London: Routledge, 2013). 39.

${ }^{41}$ Barbara Kirshenblatt-Gimblett, "Theorizing Heritage”. 370. See also Steve Watson and Emma Waterton, "Introduction," in Culture, Heritage and Representation: Perspectives in Visuality and the Past, ed. Emma Waterton and Steve Watson (Surrey: Ashgate, 2010).

${ }^{42}$ Kirshenblatt-Gimblett, "Theorizing Heritage." 375.

${ }^{43}$ The term 'comparatively' is used advisedly here as registers can be subject to change as illustrated in Chapter Two.

${ }^{44}$ Eriksen, From Antiquities to Heritage. 149. See also Macdonald, Memorylands.

${ }^{45}$ Macdonald, Memorylands. 52.

${ }^{46}$ For example: Stephen R. Kellert, "The Biological Basis for Human Values of Nature,” in The Biophilia Hypothesis, ed. Stephen R. Kellert and Edward O. Wilson (Washington DC: Island Press, 1993); Weston, "Is It Too Late?."; Jane Bennett, The Enchantment of Modern Life: Attachments, Crossings, and Ethics (Princeton: Princeton University Press, 2001); Lawrence Buell, Writing for an Endangered World: Literature, Culture and Environment In the U.S. and Beyond (Cambridge, Massachusetts: Harvard University Press, 2001); Tatjana Merchant, Reinventing Eden; Angelika Krebs, Ethics of Nature: A Map (Berlin: Walter de Gruyter, 1999); Char Miller and Hal Rothman, "Introduction," in Out of the Woods: Essays in Environmental History, ed. Char Miller
} 
towards the selection and management of arboreal heritage is investigated in the cross-case analysis in Chapter Five and is incorporated in the principles that conclude the thesis.

Kirshenblatt-Gimblett introduces the notion of "hereness" as part of the production of heritage which, at a basic level, might be seen to be achieved in the online tree register by photographic records of the individual trees selected as worthy of note, and by the progressive measurements of the height, girth and crown spread of the trees which are documented in an ongoing record of growth and/or decline. A further example of 'hereness' which, as Kirshenblatt-Gimblett argues depends on further virtualities and links heritage and tourism as "collaborative industries", can be associated with other instances of arboreal heritage. ${ }^{47}$ Kirshenblatt-Gimblett describes how heritage converts locations into destinations and tourism rendering them economically viable as exhibits of themselves:

Locations become museums of themselves within a tourism economy. Once sites, buildings, objects, technologies, or ways of life can no longer sustain themselves as they once did, they 'survive' - they are made economically viable - as representations of themselves. They stage their own rebirth as displays of what they once were, sometimes before the body is cold. ${ }^{48}$

Through the lens of arboreal heritage, new plantings of native trees at frequently-visited sites where once they would have grown naturally can be read as 'past-presenced' representations of themselves. The Anthropocene Grove of karaka situated on the hard-paved surface of Wellington's busy waterfront and strategically located between the Museum of New Zealand Te Papa Tongarewa (Te Papa) and Te Raukura, the wharewaka (waka house) and its neighbouring Karaka Café, provides an ideal focus for what Urry describes as the "tourist gaze". ${ }^{49}$ The modifier 'Anthropocene' used for this tree site is derived from its application to "the current geological epoch to emphasize the central role of humankind in geology and ecology"50 and from Byrne and Ween's reference to "concrete, bitumen and other artifactual

and Hal Rothman (Pittsburgh: University of Pittsburgh Press, 2014); Holmes Rolston III, "Ethics on the Home Planet," in An Invitation to Environmental Philosophy, ed. Anthony Weston (Oxford: Oxford University Press, 1999); Peter Scheers, "Human Interpretation and Animal Excellence," in Is Nature Ever Evil? Religion, Science and Value, ed. Willem B. Drees (London: Routledge, 2003); John Rennie Short, "Alternative Geographies: From Cosmography to Geography," in Sacred Landscapes and Cultural Politics: Planting a Tree, ed. Philip P. Arnold and Ann Grodzins Gold (Aldershot: Ashgate, 2001)

${ }^{47}$ Kirshenblatt-Gimblett, "Theorizing Heritage." 371.

48 Ibid.

49 J. Urry, The Tourist Gaze (London: Sage, 1990).

${ }^{50}$ Will Steffen, Paul J. Crutzen, and John R. McNeill, “The Anthropocene: Are Humans Now Overwhelming the Great Forces of Nature?," AMBIO: A Journal of the Human Environment 36, no. 8 (2007). 615. 
strata" - as employed on the waterfront site—as "Anthropocene rock". ${ }^{51}$ As a 'rebirthed' tree-place the Anthropocene Grove illustrates "historical theming", as defined by Macdonald, and is a site "publicly imbued with time-depth through reference to historical narratives". 52 Consequently, it has proved to be another ideal subject for this study.

Both the conflation of heritage and tourism and the conceit of locations as "museums of themselves" are apposite to any study of arboreal heritage and can draw from a long history in New Zealand. Scenic landscapes in New Zealand have been regarded as worthy of protection since the establishment of the first national parks in the country in $1887 .{ }^{53}$ Legislation under the 1903 Scenery Preservation Act focused initially on largely unmanaged and visually impressive sites and archaeological pā sites, which had the effect of promoting, "the beautiful, awesome and sublime ... [and marginalising] ordinary nature". ${ }^{44}$ Efforts to nourish the tourism industry-beginning with the Scenery Preservation Society's nineteenthcentury activities and extending to Tourism New Zealand's twentieth-century-initiated ' $100 \%$ Pure New Zealand ${ }^{55}$ brand-have focused on promoting the country's natural attractions including its indigenous forests. As living 'actualities' and as representatives of forests, and therefore of 'nature', newly-planted native trees, too, can very effectively assist in the rebirth of locations in this country. While the intangible natural heritage values surrounding them are certainly heritage, can the trees themselves be regarded as heritage? In KirshenblattGimblett's terms, these newly-planted trees are 'instruments' for adding value to the heritage production. Examination of both the instruments - in this case, trees - and the assumptions that underlie them is important to understanding heritage, she writes, because the interface between traditions and tourism is "a critical site for the production of meanings other than the 'heritage' message'. 56

\section{The Authorised Arboreal Heritage Discourse (AAHD)}

Mention to anyone that you are studying arboreal heritage and the response will almost always contain descriptions of magnificent and/or venerable and/or rare trees which the

\footnotetext{
${ }^{51}$ Denis Byrne and Gro Birgit Ween, "Bridging Cultural and Natural Heritage," in Global Heritage: A Reader, ed. Lynn Meskell (Chichester: Wiley Blackwell, 2015). 95.

${ }^{52}$ Macdonald, Memorylands. 4.

${ }^{53}$ Gavin McLean, "Where Sheep May Not Safely Graze: A Brief History of New Zealand's Heritage Movement 1890-2000," in Common Ground?: Heritage and Public Places in New Zealand, ed. Alexander Trapeznik

(Dunedin: University of Otago Press, 2000). 27.

${ }^{54}$ Park, Ngā Uruora, 318.

${ }^{55}$ New Zealand's global marketing brand launched by Tourism New Zealand in 1999.

${ }^{56}$ Kirshenblatt-Gimblett, "Theorizing Heritage." 374.
} 
speaker believes should be considered for close inspection. While these responses are, undoubtedly, intended to be helpful they are both predictable and incongruous. They are, by Crouch's definition, typical of "elite thinking" and neatly illustrate the paradox that is heritage:

Heritage is distanced and detached, whilst at the same time it is identified and found in communication as a component of belonging. Heritage becomes signified; produced and constituted in cultural contexts; communicated in cultural mediation; consumed, further reified, and 'held onto' as a sense of belonging. Heritage is, by such means, ritualized in cultural practise inscribing a particular world view that is circulated in mediated popular culture. ${ }^{57}$

Because trees are so much present in New Zealand's quotidian existence they are largely taken for granted as the unremarkable furnishings of urban civic spaces, rural landscapes and leafy suburbs. In general, we notice their absence rather than their presence, unless their presence is evidenced by magnificence, venerability or rarity. These attributes of size, age and singularity, along with provenance, are the main ingredients of the popular world view of arboreal heritage and, to some extent, are the focus of, to borrow from and customise Smith's term, the 'authorised arboreal heritage discourse' (AAHD). The New Zealand Tree Register (the Cyberforest) and the various tree registers maintained by local authorities rely on set criteria for determining which trees should be specially noted and/or protected. These lists are largely governed by principles of stature, time depth, rarity or association with a prominent person or event, and their contents are most often selected by 'experts'. In this, the registers are typical manifestations of what Smith describes as a "hegemonic discourse about heritage", or the AHD ${ }^{58}$ Smith's notion of the AHD is generally regarded to be one of the linchpins of contemporary heritage discourse, and is typified by the common practice of "rounding up the usual suspects to conserve and 'pass on' to future generations", writes Smith, which promotes "a certain set of Western elite cultural values as being universally applicable". ${ }^{59}$ As a result of this discourse, the practices and performances of both popular (as illustrated by the imaginary conversation above) and expert (as evidenced in the tree registers) constructions of heritage are validated, and alternative and subaltern ideas about heritage are undermined. ${ }^{60}$ Furthermore, Smith argues, the work done by heritage as a social and cultural practice is obscured by the AHD:

\footnotetext{
${ }^{57}$ Crouch, "The Perpetual Performance and the Emergence of Heritage." 57-58.

${ }^{58}$ Smith, Uses of Heritage. 11.

${ }^{59}$ Ibid.

${ }^{60} \mathrm{Ibid}$.
} 
The 'authorized heritage discourse' privileges monumentality and grand scale, innate artefact/site significance tied to time depth, scientific/aesthetic expert judgement, social consensus and nation building. It is a self-referential discourse, which has a particular set of consequences. ${ }^{61}$

One consequence of the AHD, Smith writes, is power which resides in both the experts and the institutions they represent and leads to top-down processes of selection and valuation leading from the expert via the heritage site or artefact to the visitor or observer. The AHD is a helpful analytical device for examining arboreal heritage. References to 'monumentality', 'site significance', 'time depth', 'expert judgement', 'social consensus' and 'nation building' all appear in this literature review and the following case studies. The term 'self-referential' is particularly apposite given that the thesis prises open the AHD in order to scrutinise alternatives, and self-referentiality is highlighted in Chapter Two by descriptions of the criteria employed in the cataloguing of trees. A 'particular set of consequences' is illustrated by the commonly-held misconceptions about tree listing which are discussed at the end of the same chapter. This latter phrase paves the way for comparison of the consequences of other ways of perceiving arboreal heritage and a consideration of the democritisation of heritage. This thesis argues that the AHD's cousin, the AAHD, shares the familial traits outlined by Smith and is alive and well in New Zealand. It proposes another analytical device — an unauthorised arboreal heritage discourse (UAHD)——which is explored in Chapters Three and Four.

\section{Trees as Natural Monuments}

At a meeting of the RNZIH ${ }^{62}$ executive council in 1940, a remit was introduced by the Forest and Bird Protection Society urging the institute to gather information in order to preserve the nation's trees along with other "natural monuments ${ }^{63}$, such as those of an ethnological, geological or biological nature". ${ }^{64}$ The drive for New Zealanders to list trees and to ascribe them monumental status, when fifty years earlier they were vigorously engaged in what Park describes as the "tremendous violence and waste that attended the furious, meticulous work of Britain's mission in New Zealand", is pivotal to this thesis. ${ }^{65}$ The use of the word 'monument' is significant and has lent this thesis its title. In order to discuss this further,

\footnotetext{
61 Ibid.

62 The New Zealand Institute of Horticulture became the Royal New Zealand Institute of Horticulture in 1939.

${ }^{63}$ This term, while not often heard in contemporary New Zealand, is a commonly used term on signs in German-speaking countries as 'naturdenkmal' and denotes protected trees.

${ }^{64}$ H. H. Allan, "Historic Trees in New Zealand," RNZIH Journal (1940). 19.

${ }^{65}$ Park, Ngā Uruora. 21.
} 
literature concerning the concepts of monuments and monumentality, memory and materiality is examined here.

\section{What is a Monument? What is Monumentality?}

In this discussion of 'monuments' and 'monumentality' these terms are used interchangeably in the sense of 'monumental' as "serving as a monument" rather than the more common sense of great in importance, extent or size. The terms are differentiated here from 'monumentalism' which is defined as construction, especially of buildings, on a grand scale. It is important to note, also, that most of the discourse on monuments and monumentality referred to here is premised on their definition as cultural constructs and is applied most often to constructions rather than natural, living entities, such as trees. A monument, as defined in its oldest and most original sense, Riegl writes, "is a human creation, erected for the specific purpose of keeping single human deeds or events (or a combination thereof) alive in the minds of future generations". ${ }^{66}$ It follows, therefore, that much of the theory examined in the following text, for the purposes of this study of arboreal heritage, is drawn from writing on the built environment.

Numerous writers have concerned themselves with defining monumentality and discussing the issues that surround it. ${ }^{67}$ Monumentality, writes Loukaki, is "a social construct that corresponds to very basic social needs for symbolism and abstraction, stimulation of the imagination of social agents, narrativization of the human experience, and mythopoesis". ${ }^{68}$ As "symbols of highly prized public virtues, and of special relations in specific social formations" monuments are described as having a variety of social functions:

They operate to remind us '.. of the antiquity of the dynasty, the power of the regime, the wealth of the community, the truth of its ideology, or of some event $-\mathrm{a}$ military victory or successful revolution - that demonstrated such wealth, power or truth'. They also help to fortify social bonds through the cultivation of social consensus, held together by common respect for powerful symbols. They are aesthetic

\footnotetext{
${ }^{66}$ Alois Riegl, "The Modern Cult of Monuments: Its Character and its Origin," in Cultural Heritage ed. Laurajane Smith (London: Routledge, 2007). 114. Riegl's article was written in 1903 but remains relevant. ${ }^{67}$ For example: Francoise Choay, The Invention of the Historic Monument, trans. Lauren M. O'Connell (Cambridge: Cambridge University Press, 2001); Robert S. Nelson and Margaret Olin, "Introduction," in Monuments and Memory, Made and Unmade, ed. Robert S. Nelson and Margaret Olin (Chicago: University of Chicago Press, 2003); Richard K. Wittman, "Local Memory and National Aesthetics: Jean Pagès's EarlyEighteenth-Century Description of the 'Incomparable' Cathedral of Amiens," in Monuments and Memory: Made and Unmade, ed. Robert S. Nelson and Margaret Olin (Chicago: University of Chicago Press, 2003); Michael Hunter, "The Fitful Rise of British Preservation," in Preserving the Past: The Rise of Heritage in Modern Britain, ed. Michael Hunter (Phoenix Mill: Alan Sutton Publishing, 1996).

${ }^{68}$ Argyro Loukaki, Living Ruins, Value Conflicts (Aldershot: Ashgate, 2008). 47
} 
statements of a specific people, time and place, but with claims to generality and universality. ${ }^{69}$

Nelson and Olin observe that, while the term 'monumentality' suggests, qualities of “inertness, opacity, permanence, remoteness, distance, preciosity and grandeur", monuments are prized because they are also "living, vital, immediate, and accessible" to many, and their protection is paramount: ${ }^{70}$

To be vital, the monument must exist within an actual, present-oriented network of relationships. Unlike a lifeless art object suspended on the white walls of a museum, the monument does not privilege the past at the expense of the present. Rather it engages both to make claims for and against the future. ${ }^{71}$

Considering the "actual, present-oriented network of relationships" attached to each of the tree sites is part of the work undertaken in each of the case studies in order to answer the third thesis question and determine the values, meanings and understandings that shape New Zealand's arboreal heritage.

Riegl, wrestling, in 1903, with the practicalities of monument preservation, differentiates "intentional" monuments, whose commemorative value has been determined by their makers, from "unintentional" monuments whose significance has been realised later. ${ }^{72} \mathrm{He}$ ascribes three commemorative values to monuments: historical value that, "singles out one moment in the developmental continuum of the past and places it before our eyes as if it belonged to the present"; intentional commemorative value that "aims to preserve a moment in the consciousness of future generations, and therefore to remain alive and present in perpetuity"; ${ }^{73}$ and age-value that "appreciates the past for itself" and rests on the visible traces of its eventual disintegration. ${ }^{74}$ It is age-value, Riegl points out, that raises the issue of protection of animals and the environment that "extends to individual plants and forested areas and even demands legal protection for "monuments of nature"". ${ }^{75}$ The notions of differentiation between intentional and unintentional monuments, and variation in commemorative values, described by Riegl, contribute significantly to the comparison of the

\footnotetext{
69 Ibid. 48.

${ }^{70}$ Nelson and Olin, "Introduction." 3.

${ }^{71}$ Ibid. 6.

${ }^{72}$ Riegl, "The Modern Cult of Monuments." 117.

73 This is referred to later as 'memorialisation'.

${ }^{74} \mathrm{Riegl,}$ "The Modern Cult of Monuments." 130.

75 Ibid. Note to 125.
} 
tree sites in Table 6 of Chapter Five, and its conclusion that arboreal heritage is dynamic and influenced by time-related circumstances.

Loukaki describes monumentality in terms of our need for symbols that, by definition, can serve both as instruments of power and sources of aesthetic or moral qualities. Monuments, she writes, live in a "climate of constant social awareness of both their spatiality and their temporality. Their spatiality is defined by both themselves and their relationship with their context. Their temporality is quite idiosyncratic, because their present contains their long past and the social will for them to "live long"" ${ }^{76}$ The longevity of monuments does not depend only on their physical characteristics and their solidity but is itself a social construct. Because monuments as symbolic forms participate in both the power and the aesthetic level of social reality, Loukaki argues, any "redefinitions" of them involve heated ideological and aesthetic struggles from which non-experts are largely excluded. ${ }^{77}$

While recognising the significance of trees as monuments and, therefore, symbolic forms ${ }^{78}$ it is important to keep in mind the fact that symbolism is only one form of the impact brought by trees. They maintain, as well, an ability to create and adapt their habitats, communicate changing sensory data and contribute to the relational agency of the places they occupy. ${ }^{79}$ In their account of the social significance of trees, Jones and Cloke remark that trees are culturally constructed, representing a "form of social nature, but they are also living, active, creative, physical presences. This mix of the cultural, the material and the living presents interconnected agency and performance wherever trees are to be found" ${ }^{80}$ The concept of monumentality deployed as a domain of arboreal heritage for cross-case analysis in Chapter Five, therefore, takes on characteristics additional to those typical of other forms of heritage. Furthermore, with respect to trees as monuments it is significant that many of the writers quoted above refer to a monument's contemporary relevance: "To be vital, the monument must exist within an actual, present-oriented network of relationships"; 81 "to preserve a moment in the consciousness of future generations, and therefore to remain alive and present

\footnotetext{
${ }^{76}$ Loukaki, Living Ruins, Value Conflicts. 49.

${ }^{77}$ Ibid. While Loukaki is writing about buildings as monuments, her words are particularly apposite for any discussion of trees as monuments.

${ }^{78}$ For a comprehensive discussion on trees as symbols see Laura Rival, "Trees, from Symbols of Life and Regeneration to Political Artefacts," in The Social Life of Trees: Anthropological Perspectives on Tree Symbolism, ed. Laura Rival (Oxford: Berg, 1998).

${ }^{79}$ Cloke and Pawson, "Memorial Trees and Treescape Memories." 109.

${ }^{80}$ Jones and Cloke, Tree Cultures. 74.

${ }^{81}$ Nelson and Olin, "Introduction." 6 . The italics in this and the following two quotations are mine.
} 
in perpetuity", 82 and to "live in a climate of constant social awareness of both their spatiality and their temporality". ${ }^{83}$ Trees are mortal and, therefore, issues of time depth, materiality and replacement of arboreal heritage are of interest to this study and are discussed within the three case studies.

\section{Monuments, Memory and Materiality}

The English word 'monument' comes from the Latin monumentum derived from monere (to remind) ${ }^{84} \mathrm{~A}$ monument was initially a "reminder, a memory sign, part of a society's symbolic background". ${ }^{85}$ Because a monument calls upon the faculty of memory, Choay writes, the affective nature of its purpose is essential. "It is not simply a question of informing, of calling to mind a neutral bit of information, but rather of stirring up, through the emotions, a living memory." ${ }^{86}$ Nelson and Olin argue that memory and monument "are to each other as process and product, although not necessarily as cause and effect, for circularity often obtains". ${ }^{87}$ Of particular relevance to monuments, as readily accessible public entities, they argue, is collective memory which is a "mingling of the public and the private". 88 Halbwachs describes collective memory as the depository of tradition shared by a particular social group living together in a discrete time and place. ${ }^{89}$ This shared recollection of the group's past plays an integral part in the group's present identity and is sustained by the place where its members have lived together. Place, Halbwachs theorises, offers the memory a stable, external reminder of the past of the group. As Hayden points out:

Identity is intimately tied to memory: both our personal memories (where we have come from and where we have dwelt) and the collective or social memories interconnected with the histories of our families, neighbors, fellow workers, and ethnic communities. Urban landscapes are storehouses for these social memories because natural features such as hills or harbors, as well as streets, buildings and patterns of settlement, frame the lives of many people and often outlast many lifetimes. $^{90}$

\footnotetext{
${ }^{82}$ Riegl, "The Modern Cult of Monuments." 130.

${ }^{83}$ Loukaki, Living Ruins, Value Conflicts. 49.

84 The English 'monument' has cognates in French, Italian and other Romance languages. The German denkmal (monument), however, is derived from the root 'to think'.

${ }^{85}$ Loukaki, Living Ruins, Value Conflicts. 47.

${ }^{86}$ Choay, The Invention of the Historic Monument. 6.

${ }^{87}$ Nelson and Olin, "Introduction." 4.

${ }^{88}$ Ibid. 3.

${ }^{89}$ Maurice Halbwachs, The Collective Memory (New York: Harper \& Row, 1980). See also Macdonald, Memorylands.

${ }^{90}$ Dolores Hayden, The Power of Place: Urban Landscapes as Public History (Cambridge, Massachusetts: MIT Press, 1997). 9.
} 
Urban renewal and redevelopment, however, have obliterated the important collective memories of many communities. In other instances, as demonstrated by Parr, large-scale projects transform settings and practices of everyday life and alter the ways in which people know themselves and their place. ${ }^{91}$ As non-portable heritage, monuments are grounded in place. Tree monuments, as living entities, rely on the place in which they are grounded for life and growth. They can be intentional or unintentional, are living memories both literally and figuratively and are particularly vulnerable to the developer's chainsaw.

'Place' is a complex "configuration of highly flexible subjective, social, and material dimensions", ${ }^{92}$ and a thorough examination of its complexity is beyond the remit of this thesis. However, in relation to this discussion of trees as natural monuments, it is important to consider the relationship between place and memory, to what extent memory relies on materiality and the "powerful yet often unnoticed roles which trees play in the construction of places and landscapes", referred to by Jones and Cloke. ${ }^{93}$ Halbwachs differentiates history, as opposed to memory, as an intellectual and critical treatment of the past that relies not on the experience of place but on its documentation in writing. Wittman, picks up this idea and asks, "what happens to one's experience of a place when the paradigmatic community is dispersed, gathering only conceptually in the pages of books?"94 Elsner tackles the question from another direction by asking, "Can we say that memory inheres in the materiality of a monument?"95 Both these questions are valuable to my study of the processes leading to the establishment of the New Zealand Tree Register and its digital version, the Cyberforest. Of further, and more widely applicable value to the Cyberforest as a digital record, to the Anthropocene Grove as a representative planting and to the Dendroglyph Trees as cultural redress, is Nora's notion of "lieux de mémoire" or sites of memory. Like Halbwachs, Nora separates history as "a representation of the past" from memory as "a perpetually actual phenomenon, a bond tying us to the eternal present". ${ }^{96}$ Lieux de mémoire, he writes originate

\footnotetext{
${ }^{91}$ Joy Parr, Sensing Changes: Technologies, Environments, and the Everyday, 1953-2003 (Vancouver: UBC Press, 2010).

92 Buell, Writing for an Endangered World. 60.

93 Jones and Cloke, Tree Cultures. 73.

94 Wittman, "Local Memory and National Aesthetics." 271.

95 Jaś Elsner, "Iconoclasm and the Preservation of Memory," in Monuments and Memory, Made and Unmade, ed. Robert S. Nelson and Margaret Olin (Chicago: Chicago University Press, 2003). 209.

96 Pierre Nora, "Between Memory and History: Les Lieux De Mémoire," Representations 26 (1989). 8. See also Macdonald, Memorylands. 13-14. Macdonald argues that a differentiation between history and memory tends to direct attention to veracity and points out that the line between them can be blurred. She highlights as more important issues the specific contexts, motives and frameworks of production of the various accounts and their forms of veracity.
} 
with the sense that there is no spontaneous memory, "we must deliberately create archives, maintain anniversaries, organize celebrations, pronounce eulogies, and notarize bills because such activities no longer occur naturally". ${ }^{97}$ Memory, he argues, is constantly besieged by history which acts to organise the past. It is this "push and pull" between history and memory that produces lieux de mémoire "moments of history torn away from the movement of history, then returned; no longer quite life, not yet death, like shells on the shore when the sea of living memory has receded". 98

Elsner's question regarding the materiality of monuments is derived from a preoccupation with iconoclasm directed at built monuments. Answering his own hypothetical question, he writes that the preserved and damaged object "signals both its predamaged state-a different past, with potentially different cultural, political, and social meanings - and its new or altered state. ${ }^{99}$ In part, the meaning of the 'new' monument is defined by its difference from (that is by the changes to) the 'old' monument". ${ }^{100}$ He differentiates three kinds of memory: the commemoration envisaged by the first builder of the monument; memory acquired over time; and the memory of absence brought about by active, purposeful and collectively performed "forgetting"101 illustrated by the ancient Roman practice of damnatio memoriae. ${ }^{102}$ The deliberate airbrushing out of elements of monuments or entire monuments, described by Elsner, above, is reliant on cultural rather than physical change, and on time as much as place. As Loukaki explains:

... monumentality is really a time-specific social moment, in its content and the kinds of obligations it imposes on the social body. Such transpositions of both content and limits to respect of the monumental are due to the changing relevance of the past, the values attributed to monumentality, the evolution of archaeology, and the social understanding of heritage and tradition. ${ }^{103}$

While all monuments are, to some extent, mortal, ${ }^{104}$ tree monuments die in the literal, rather than metaphorical, sense. The manner in which 'natural' rather than 'constructed'

\footnotetext{
${ }^{97}$ Nora, "Between Memory and History." 12.

98 Ibid.

${ }^{99}$ See also Harrison, Heritage.

${ }^{100}$ Elsner, "Iconoclasm and the Preservation of Memory." 210.

${ }^{101}$ Ibid. 211.

${ }^{102}$ Damnatio memoriae refers to the deliberate erasure of memory through destruction of physical remnants, often the removal from monuments of images of people no longer in favour and is distinct from de facto damnatio memoriae where the destruction is not deliberate.

${ }^{103}$ Loukaki, Living Ruins, Value Conflicts. 50.

${ }^{104}$ Robert S. Nelson and Margaret Olin, "Destruction/Reconstruction,” in Monuments and Memory, Made and Unmade, ed. Robert S. Nelson and Margaret Olin (Chicago: Chicago University Press, 2003); Elsner, "Iconoclasm and the Preservation of Memory."; Loukaki, Living Ruins, Value Conflicts.
} 
monuments 'die' as the result of deliberate destruction can, therefore, be regarded differently according to one's own beliefs regarding the sanctity of life and the sentience of non-human life forms. ${ }^{105}$ The effects of death, however, can be much the same. Nelson and Olin argue that the effect of the 'destruction' of a monument, or its state of being "under erasure"106 is not necessarily oblivion, but a preliminary stage towards another level of monumentality where its former meaning is erased but the signs of erasure serve as a new form of communication. ${ }^{107}$ Arboreal examples of erasure and successive levels of monumentality are exemplified by the trees of the sacred hill, Maungakiekie One Tree Hill, a volcanic peak and former major pā (fortified village) site in Auckland. Their story begins with a seventeenthcentury sacred tōtara (Podocarpus totara), continues with a single pine tree, various illegal plantings and protests and now awaits a final planting decision for the most recently bare peak popularly known as 'None Tree Hill'. ${ }^{108}$ Maungakiekie One Tree Hill is a place where trees have lived, died, been planted and destroyed and not-planted as non-material or material signifiers of a series of apolitical and political, historical and contemporary narratives. Such "processes of monument making and unmaking and the orchestration of memory and forgetting", Phillips argues, designate "major shifts in regimes of power". ${ }^{109}$ The trees of Maungakiekie One Tree Hill further illustrate that rather than diminishing the tree's monumental status or its ability to communicate memory its mortality introduces additional powerful qualities. For as long as they live, individual trees can play the associated roles of witnesses of history, living sign posts of historic places, and "windows onto landscapes we will never see". ${ }^{110}$ In dying, whether as a result of damnatio memoriae or de facto damnatio memoriae, heritage trees highlight the passage of time and, through their new or altered states, can be potent signifiers and memory prompts of shifts in cultural, political and social values, meanings and understandings. These changes are noted further in this thesis in

\footnotetext{
${ }^{105}$ Consideration should be given also to the processual way in which trees die. Parts of slow-growing trees have already died while the tree continues growing: wood comprises both dead and live cells. Rival, "Trees, from Symbols of Life and Regeneration to Political Artefacts." 22-23.

${ }^{106}$ Robert S. Nelson and Margaret Olin, "Destruction/Reconstruction.” 205.

${ }^{107}$ Ibid. 205-6.

${ }^{108}$ A grove of three tōtara and six pōhutukawa and a shelter belt of native shrubs were planted in 2016 . The strongest tree will be selected from the grove and the others removed, leaving a single tree standing once more. Mayor Len Brown reportedly announced that the loss of the pine tree was "a symbol of what divided us. The return of a tree is a symbol of what unites us". "One Tree Hill to Get Its Tree Back," The New Zealand Herald, 20 October 2015.

${ }^{109}$ Ruth B. Phillips, "Settler Monuments, Indigenous Memory: Dis-Membering and Re-Membering Canadian Art History," in Monuments and Memory, Made and Unmade, ed. Robert S Nelson and Margaret Olin (Chicago: University of Chicago Press, 2003). 281.

110 Tim Low, The New Nature (Camberwell, Australia: Viking, 2002). 306.
} 
relation to the 'death' of arboreal heritage through the deaccessioning of tree sites in tree registers and the evolution of the various sites brought about by social and political change.

\section{Nature and Culture}

Modifying the term 'monument' with the adjective 'natural', as achieved in the 1940 RNZIH remit, neatly illustrates the complexity of the nature-culture dualism. The term 'nature' itself carries multiple meanings. As Eisenberg argues, “depending on context, 'nature' may mean all living things on the planet Earth; or all living things except for humans; or the genetic tendencies of living things, as opposed to their cultural expression, or everything in the universe". ${ }^{111}$ For the purposes of this proposal, 'nature' is taken to mean the collective phenomena of the physical world, namely, the plants animals, landscape and other products and features of the earth as opposed to humans and human creations. Visak, in her consideration of the terms 'nature' and 'natural' introduces, as one characteristic of nature, the idea of 'spontaneous blossoming' which stands for "all spontaneous development" in nature and, therefore, includes decay. Spontaneous blossoming, she argues, can happen at different levels: "There might be trees that grow and develop spontaneously in a forest that as such has been planned and managed. There might be a tree that was planted but which from this point on shows spontaneous growth and development". ${ }^{112}$ The significance to this thesis of these close examinations of nature lies not only in their differentiation of nature and culture but in their recognition that there are variable levels of separation. Sexson asks, "... can we see the trees as we erase the forests? Does landscape — or the decorative and commemorative tree on the disciplined lawn of the campus - bestow image or iconoclastic treatment of image?"113

\section{Nature, Culture, Otherness and Agency}

The circular relationship between nature and culture and the associated concepts of otherness and agency have been topics of discussion for many writers. ${ }^{114}$ Schama conflates nature and

\footnotetext{
${ }^{111}$ Eisenberg, The Ecology of Eden, xx.

112 Visak, "The Moral Relevance of Naturalness," in Is Nature Ever Evil? Religion, Science and Value, ed. Willem B. Drees (London: Routledge, 2003); . 42.

${ }^{113}$ Lynda Sexson, "Isaac and the Elk: Nature's Unnatural Acts," in Sacred Landscapes and Cultural Politics: Planting a Tree, ed. Philip P. Arnold and Ann Grodzins Gold (Aldershot: Ashgate, 2001). 10.

${ }^{114}$ For example: White, "Discovering Nature in North America."; Schama, Landscape and Memory; Buell, Writing for an Endangered World; Michael Pollan, The Botany of Desire: A Plant's-Eye View of the World (New York: Random House, 2002); Plumwood, Environmental Culture; Paul Cloke and Owain Jones, "Grounding Ethical Mindfulness for/in Nature: Trees in Their Places," Ethics, Place \& Environment 6, no. 3 (2003); Merchant, Reinventing Eden; David Lowenthal, "Natural and Cultural Heritage," International Journal
} 
culture by pointing out that, although we are accustomed to separating nature and human perception into two realms, they are, in fact, indivisible. He writes that rather than being "a repose" for the senses, "landscape is the work of the mind. Its scenery is built up as much from strata of memory as from layers of rock". ${ }^{115}$ Buell describes the nature-culture distinction itself as an "anthropogenic product" which is derived from our transition from nomadism to settlement and, today, provides a both distorting and necessary lens with which to view the world's physical environment. Our environment, he argues, is on the one hand “increasingly refashioned by capital, technology, and geopolitics, with so-called nature consumed or reproduced as lawns, gardens, theme parks, habitat zoos, conservancies, and so on". On the other hand, he points out, this process has made, "tracts of (relatively) unfabricated nature in some quarters more salient and, in general, all the more crucial both as concept and as term of value: as a way of designating what has not yet been greatly transformed by pollution, climate change, and the like; as a way of dramatizing the violence and excess of techno-transformation; and as a way of underscoring the importance of the however-modified nonhuman world to the maintenance of life". ${ }^{116}$ Human beings, Buell argues, are "ecosystemically" constrained as much as the non-human world is constrained by human influence. ${ }^{117}$

Developing this idea of human constraint on the non-human world, Cronon introduces the concept of hierarchical categorising of nature and, in particular, of trees, which is a central concern of this thesis. He reflects on the divide between trees in cultivation and trees in the forest, and calls for a dismissal of the arboreal hierarchy, and promotes a fusion of the concepts of nature and culture. ${ }^{118}$ Cronon emphasises the need to embrace a single natural landscape that is also cultural and includes the city, the suburb, the pastoral, and the wild on equal footing. 119 "We need to honor the Other within and the Other next door as much as we

\footnotetext{
of Heritage Studies 11, no. 1 (2006); Ken Taylor and Jane Lennon, "Cultural Landscapes: A Bridge between Culture and Nature?," International Journal of Heritage Studies 17, no. 6 (2011); William Cronon, "The Trouble with Wilderness: Or, Getting Back to the Wrong Nature," in Out of the Woods: Essays in Environmental History, ed. Char Miller and Hal Rothman (Pittsburgh: University of Pittsburgh Press, 2014); 115 Schama, Landscape and Memory. 6-7.

${ }^{116}$ Buell, Writing for an Endangered World. 5-6.

${ }^{117}$ Ibid. 6. Plumwood argues that our current "ecological crisis" is breaking down the nature/culture dualism and forcing us to realise that we are, "positioned equally and along with the whole cast of non-humans in the drama of the ecological world of populations, species, and the flows of the food chain". Plumwood, Environmental Culture. 51-52.

${ }^{118}$ Cronon, "The trouble with Wilderness." Plumwood refers to this as "unnecessary species-ranking" and calls for "an interspecies egalitarian ethic". Ibid. 169.

119 The division between cultivated trees and those found in the wild, is discussed further in Merchant, Reinventing Eden and Eisenberg, The Ecology of Eden.
} 
do the exotic Other that lives far away." ${ }^{120}$ In a similar spirit of inclusiveness, Pollan describes the relationship between humans and plants as a "coevolutionary drama, a dance of human and plant desire that has left neither the plants nor the people taking part in it unchanged". ${ }^{121}$ Employing this definition of coevolution, he demonstrates how particular plants and people engage in reciprocal relationships to the betterment of both. "All these plants, which I'd always regarded as the objects of my desire, were also, I realized, subjects, acting on me, getting me to do things for them they couldn't do for themselves." ${ }^{22}$ If, as Pollan describes, trees can be promoted as agents of memorialisation (for example, the 2015 WWI commemorative planting of Australian eucalypts at the Pukeahu National War Memorial Park in Wellington), ${ }^{123}$ and if they can be utilised in identity-making (for example, the contemporary, urban landscaping throughout the country by local authorities introducing assemblages of New Zealand's native trees and shrubs) who is responsible for these allocations of responsibility? Who has agency? Is it the trees themselves or the humans who have employed plants in these ways? Pollan's answer would be 'both'. By applying his logic of mutualistic relationships, and by taking an Actor Network Theory (ANT) approach, trees can be seen to furnish the availability, longevity, endemicity and magnificence of stature suited to these metaphorical tasks: the human input can be viewed as ensuring their veneration (and, ultimately, their protection and procreation). These qualities can best be defined as 'intangible natural heritage'.

\section{Trees and Intangible Natural Heritage}

Discussions of intangible natural heritage have developed out of the 2003 UNESCO Convention for the Safeguarding of the Intangible Heritage's identification of intangible

\footnotetext{
${ }^{120}$ Cronon, "The Trouble with Wilderness." 49.

${ }^{121}$ Pollan, The Botany of Desire. 243.

122 Ibid. XV.

${ }^{123}$ For related discussions of commemorative tree planting and the influence of societal change see Eric Pawson, "The Memorial Oaks of North Otago: A Commemorative Landscape," in Glimpses of a Gaian World, ed. Geoff Kearsley and Blair Fitzharris (Dunedin: University of Otago, 2004); Pickles, "Mapping Memorials.”; Dargavel, "More to Grief than Granite." and John Stephens, "Remembrance and Commemoration through Honour Avenues and Groves in Western Australia," Landscape Research 34, no. 1 (2009).
} 
cultural heritage ${ }^{124}$ and its legitimisation as a UNESCO heritage category. ${ }^{125}$ Intangible cultural heritage, under the umbrella of the convention, is seen to be manifest in oral traditions and expressions, performing arts, social practices rituals and festive events, knowledge and practices concerning nature and the universe, and traditional craftsmanship. ${ }^{126}$ The term 'safeguarding' refers to, "measures aimed at ensuring the viability of the intangible cultural heritage, including the identification, documentation, research, preservation, protection, promotion, enhancement, transmission, particularly through formal and nonformal education, as well as the revitalization of the various aspects of such heritage". ${ }^{127}$ While the definition of intangible cultural heritage includes a reference to "knowledge and practices concerning nature and the universe", thinkers in the field of natural history (for example, members of the International Committee for Museums and Collections of Natural History's [NATHIST] 2004 general assembly in Seoul and delegates to the 2006 annual NATHIST conference in New Zealand $)^{128}$ have made a case for a separate intangible natural heritage framework for "acknowledging and fostering human relationships with the environment, not only for the benefit of society but for the ongoing conservation of nature". ${ }^{129}$ In summarising their essay collection on the topic of intangible natural heritage, Dorfman and Carding argue that the notion requires, "a linking of the intangible phenomena of the natural world with a human interrelationship and includes the natural phenomena being seen as valuable and so worthy of preservation" and they propose a draft definition:

\footnotetext{
${ }^{124}$ Intangible cultural heritage is defined as: "The practices, representations, expressions, knowledge, skills - as well as the instruments, objects, artefacts and cultural spaces associated therewith - that communities, groups and, in some cases, individuals recognize as part of their cultural heritage. This intangible cultural heritage, transmitted from generation to generation, is constantly recreated by communities and groups in response to their environment, their interaction with nature and their history, and provides them with a sense of identity and continuity, thus promoting respect for cultural diversity and human creativity. For the purposes of this Convention, consideration will be given solely to such intangible cultural heritage as is compatible with existing international human rights instruments, as well as with the requirements of mutual respect among communities, groups and individuals, and of sustainable development". UNESCO, "Convention for the Safeguarding of the Intangible Cultural Heritage," http://www.unesco.org/culture/ich/en/convention. Accessed 5 June 2015.

${ }^{125}$ Prior to this, at its sixteenth session on 16 November 1972, the General Conference of UNESCO adopted the Convention Concerning the Protection of the World Cultural and Natural Heritage. Cultural heritage under this 1972 convention includes monuments, groups of buildings, and sites: natural heritage is defined as including natural features, geological and physiographical formations and precisely delineated natural areas of special value. UNESCO, "Recommendation Concerning the Protection, at National Level, of the Cultural and Natural Heritage," http://portal.unesco.org/en/ev.php-URL_ID=13087\&URL_DO=DO_TOPIC\&URL_SECTION=201.html. Accessed 5 June 2015.

${ }^{126}$ UNESCO, "Convention for the Safeguarding of the Intangible Cultural Heritage," http://www.unesco.org/culture/ich/en/convention. Accessed 5 June 2015.

${ }^{127}$ Ibid.

${ }^{128}$ Eric Dorfman, "Foreword," in Intangible Natural Heritage: New Perspectives on Natural Objects, ed. Eric Dorfman (New York: Routledge, 2012). xi.

${ }^{129}$ Ibid.
} 
Intangible Natural Heritage - the environmental forces that create biological and geological entities, the phenomena that these entities produce, and their interaction with humans and human communities. Particularly included are those phenomena and interactions that are repeatable, rather than isolated incidents, are compatible with legal frameworks, and are consistent with sustainable development that does not diminish the natural world for future generations. ${ }^{130}$

Of particular significance to this thesis is the way in which the discussion of intangible natural heritage firmly links humans with the intangible phenomena of the natural worldand potentially, by association, with the intangible phenomena of the arboreal worldrecognises the existence and worth of such phenomena, and signals the possibility that they have values, meanings and understandings independent of human intervention. The discussions that centre on the dichotomy or commingling of nature-culture and tangibleintangible are complex and intrinsic to any study of the meanings, values and understandings of the process of arboreal heritage. While the intangible quality to be acknowledged and protected may be a product of the natural world, its ascribed value is, as many scholars point out, in itself a product of culture. ${ }^{131}$ The "identification, documentation, research, preservation, protection, promotion, enhancement, transmission, particularly through formal and non-formal education, as well as the revitalization of the various aspects of such heritage", ${ }^{132}$ as prescribed by UNESCO, are clearly, as writers argue, cultural acts. ${ }^{133}$ The concept of natural heritage as cultural in origin, as described in the scholarly discussions above, is fundamental to this thesis; as is the idea that the values, meanings and understandings associated with both natural and cultural heritage are closely intertwined. As Munjeri states, the three "pillars" of societies, norms and values, are "in an equilateral triangle relationship to form a smart partnership that sustains cultural heritage. However, they work within a larger equilateral triangle of natural heritage, cultural heritage and spiritual heritage". 134

\footnotetext{
${ }^{130}$ Eric Dorfman and Janet Carding, "Discussion: Towards a Unified Concept of Intangible Natural Heritage," ibid. 172.

${ }^{131}$ Schama, Landscape and Memory; Eisenberg, The Ecology of Eden; Dorfman, "Intangible Natural Heritage."; Cronon, "The Trouble with Wilderness."

132 UNESCO, "Convention for the Safeguarding of the Intangible Cultural Heritage".

${ }^{133}$ White, "Discovering Nature in North America."; Lowenthal, "Natural and Cultural Heritage."; Cronon, "The Trouble with Wilderness."

${ }^{134}$ Dawson Munjeri, “Tangible and Intangible Heritage: From Difference to Convergence,” in Cultural Heritage: Critical Concepts in Media and Cultural Studies, ed. Laurajane Smith (London: Routledge, 2004). 329.
} 


\section{Towards Ethical Mindfulness}

Merchant, in examining the relationships humans have forged with nature, emphasises the need for a more ethical nature-culture relationship. This would rely, she argues, not on an eco-centric ethic (where humanity is only one of a number of equal parts), nor on biocentrism (where value is grounded in life itself rather than being centred on humanity), but on a partnership ethic that, "posits nature and humanity as equal, interacting, mutually responsive partners". ${ }^{135}$ Both mainstream Western culture's traditional assertion of human dominion over nature ${ }^{136}$ and its alternative approach of stewardship smack of anthropocentrism, she argues. "Stewardship is a caretaker ethic, but it is still anthropocentric inasmuch as nature is created for human use. Moreover, Nature is not an actor, but is rendered docile." ${ }^{\prime 137}$ In a similar, but more moderate argument, Buell advocates a mutual constructionist version of the nature-culture distinction, extending a non-species-specific version of 'nature' to embrace a cultural element and re-emerge under the umbrella term of 'physical environment'. Monist, dualist and technocultural constructionist theories or myths, he argues, are, "likely to prove less convincing than a myth of mutual constructionism: of physical environment (both natural and human-built) shaping in some measure the cultures that in some measure continually refashion it". ${ }^{138}$ Under Merchant's microscope, Dorfman and Carding's suggested definition of intangible natural heritage as, "phenomena and interactions that are ... consistent with sustainable development that does not diminish the natural world for future generations" might be construed as anthropocentric: under Buell's eye it might qualify as mutual constructionism. Short adds to the discussion by championing the application of alternative geographies to our consideration of nature. The environment, he argues, has become:

One of the grand metanarratives that has helped to fill the god-shaped hole that lies at the heart of the postmodern world. Alternative geographies are ways of reinterpreting the environment in the light of the success and failures of the modernist enterprise. We now have accurate measurement of the world but realize that more mathematics is not what we need. Rather, we need more sympathy for the earth, a widening of our understanding of the world that incorporates feeling with thinking, moral values as well as scientific principles. ${ }^{139}$

The writings of Bennett (political theory), Buell (American literature), Merchant (environmental history, philosophy and ethics) and Short (geography) quoted above are

\footnotetext{
${ }^{135}$ Merchant, Reinventing Eden. 26.

${ }^{136}$ The term "dominion over nature" appears regularly in discussions of the relationship between nature and culture and is derived from Genesis 1:26-28.

${ }^{137}$ Merchant, Reinventing Eden. 25. See also Plumwood, Environmental Culture.

138 Buell, Writing for an Endangered World. 6.

139 Short, "Alternative Geographies." 34.
} 
multi-disciplinary and represent an ethical turn which, Cloke and Jones write, reflects a, "critique of anthropocentrism and points towards moves to non-anthropocentric frames in which the othernesses and ethics of difference are shaped by an acknowledgement that human and non-human agency are relationally bound and assembled in networks and places". ${ }^{140}$ This turn, they point out, requires a "more sensitive 'ethical mindfulness' which is grounded in particular space-time contexts". ${ }^{141}$ Similarly, Plumwood writes that the "Otherisation of nature bears on a key question of justice - the concern with obstacles to justice, especially forms of partiality and self-imposition that prevent us from giving others their due". ${ }^{142}$ Her analysis of anthropocentrism suggests that one approach to justice involves: studying up rather than studying down, shifting the onus of proof from inclusion to exclusion and moving the ethical focus from the evaluated item and the dubious question of their 'qualifications' for ethical inclusion and attention (studying down) to the different and largely neglected question of the ethical stance of the human evaluator (studying up) and their own moral status. ${ }^{143}$

Critical philosophical engagement, in the context of anthropocentric culture, she writes, should be applied to self rather than to other: "the limits imposed by the human rather than the nature side of the ethical relationship, the ethical stance of closure rather than the ethical stance of openness". ${ }^{144}$ Visak, in her study of nature and naturalness draws on recognition of species-specificity as a means of providing a moral guideline for our dealings with nature. She argues that non-humans and humans have 'species-specific' ways of living that can be observed when unconstrained in their natural (species-specific) environments. The capability of moral reasoning, she points out, is species-specific to humans:

If we want to show any respect for others we should at least pay attention to their species-specific way. As humans we can use our capability of sympathy and moral reasoning ... 'Naturalness' in the sense of [a] 'species-specific way' appears to be very appropriate as a moral guideline. More than other guidelines it helps us with the setting of goals and limits for our species-specific way of using technology. Respect for the species-specific way of other beings can even guide our human tendency to recreate nature. ${ }^{145}$

\footnotetext{
${ }^{140}$ Cloke and Jones, "Grounding Ethical Mindfulness for/in Nature.” 195. Miller and Rothman describe the widening of environmental historians' frames of reference in the twenty-first century to include, among other perspectives, "environmental justice and its corollary, eco-racism" Miller and Rothman, "Out of the Woods." xv. See also Krebs, Ethics of Nature: A Map.

${ }^{141}$ Cloke and Jones, "Grounding Ethical Mindfulness for/in Nature." 195. See also Robin Attfield, "The Good

of Trees," The Journal of Value Inquiry 15, no. 1 (1981).

${ }^{142}$ Plumwood, Environmental Culture. 11.

${ }^{143}$ Ibid.

144 Ibid.

145 Visak, "The Moral Relevance of Naturalness." 43.
} 
And Bennett argues that sensory receptivity to "the marvellous specificity of things" fosters enchantment, which, in turn, leads to ethical generosity. ${ }^{146}$ Continuing this discussion of means with which to apply ethical mindfulness, Scheers advocates the stance of the 'benevolent interpreter' in communicating non-human versions of otherness. The term, derived from the eighteenth-century notion of hermeneutische billigkeit, or hermeneutical fairness, originally required a reader to begin and continue examining a text in the expectation of finding meaning and truth. Scheers argues that the benevolent interpreter, as applied to nature rather than texts, should at least be willing to probe the possibility of finding meaning and excellence in non-human others:

An authentic benevolent interpreter would be inclined to extend the search for original meaning as far as possible. Capabilities may create duties. We are capable of interpreting nature. It would therefore be immoral not to try to interpret nature truthfully. The ethics of interpretation implies the duty to interpret. ${ }^{147}$

This discussion has introduced a range of terms and theoretical position statements: 'enchantment with ethical potential'; 148 'mutual responsiveness';149 'mutual constructionism'; 150 'alternative geographies';151 'studying up rather than studying down' and adopting the 'ethical stance of closure rather than the ethical stance of openness'; 152 'speciesspecificity'; 153 and 'benevolent interpretation'. ${ }^{154}$ Their common thread-which is of particular value to this thesis - is a willingness to consider nature not simply as a cultural construct, as previously described by Schama, ${ }^{155}$ but as a non-human, dynamic system in which it is possible that "even plants possess a kind of agency" 156 and which invites interdisciplinary study guided by ethical considerations and an inclusive approach. ${ }^{157}$ Associated issues of species-specificity, recognition of non-human agency and natural or

\footnotetext{
${ }^{146}$ Bennett, The Enchantment of Modern Life. 3-5. In a parallel discussion, Gell links our relationship with social order to art processes as the "technology of enchantment" which is founded on the "enchantment of technology". Alfred Gell, "The Technology of Enchantment and the Enchantment of Technology," in Anthropology Art and Aesthetics, ed. Jeremy Coote and Anthony Shelton (Oxford: Clarendon Press, 1992). 4344.

${ }^{147}$ Scheers, "Human Interpretation and Animal Excellence." 56-57.

148 Bennett, The Enchantment of Modern Life.

149 Merchant, Reinventing Eden.

${ }^{150}$ Buell, Writing for an Endangered World.

${ }^{151}$ Short, "Alternative Geographies."

152 Plumwood, Environmental Culture.

${ }^{153}$ Visak, "The Moral Relevance of Naturalness."

${ }^{154}$ Scheers, "Human Interpretation and Animal Excellence."

155 Schama, Landscape and Memory.

156 Bennett, The Enchantment of Modern Life. 170.

${ }^{157}$ See also Weston, "Is It Too Late?." and Rolston, "Ethics on the Home Planet."
} 
cultural origins of the tree sites studied here are explored in the following case studies and the cross-case analysis in Chapter Five.

For an example of the practical application of an ethical approach to the study of trees I refer to the work carried out by Cloke and Jones. ${ }^{158}$ They research the interconnections between trees and places that occur within four separate 'tree-places' - an urban square, an urban cemetery, a heritage trail and an orchard - "which provide grounded contexts of encounter and potential for ethical mindfulness". ${ }^{159}$ While my fieldwork is focused on the heritaging of one specific tree species (karaka) within three specific case studies (the Cyberforest, the Anthropocene Grove and the Dendroglyph Trees), rather than Cloke and Jones' non-specific tree species drawn from specific locations, their research has direct relevance to my thesis for many reasons. First, it draws together several of the threads of the nature-culture discussion as outlined above and identified as being significant to my own study_-non-human agency, otherness and relational ethics. Second, it examines groups of trees in separate and specific frames of both time and space and acknowledges the significance of context in examining human and non-human relationships and the related values, meanings and understandings created by and contained within them, which are primary concerns of my study. Third, it acknowledges the appropriateness of a non-anthropocentric stance for research on trees, and, finally, Cloke and Jones' study provides a counterpoint to my own proposed fieldwork investigation of selected tree sites in which karaka is located.

\section{Intangible Natural Heritage in New Zealand}

In the, then, New Zealand Historic Places Trust's 2007 discussion paper on heritage landscape values, McClean describes trees as an "important aspect of the natural, historic and cultural environment" of New Zealand. ${ }^{160}$ Most Heritage New Zealand-registered trees are listed as part of recorded historic places or areas. McClean notes that trees are particularly important to Māori as markers of events, historic sources of food, boundary markers or wāhi tapu (sacred places), and, today, trees are recorded by Heritage New Zealand as archaeological sites, for example, trees with dendroglyphs (tree carvings) and trees associated with cultivation such as cabbage trees (Cordyline australis) and karaka. Heritage trees at

\footnotetext{
${ }^{158}$ Cloke and Jones, “Grounding Ethical Mindfulness for/in Nature.” See also Jones and Cloke, Tree Cultures.

${ }^{159}$ Cloke and Jones, "Grounding Ethical Mindfulness for/in Nature." 195.

${ }^{160}$ Robert McClean, "Sustainable Management of Historic Heritage: Discussion Paper No. 3: Heritage Landscape Values," (Wellington: New Zealand Historic Places Trust 2007). 24.
} 
historic sites may, for example, be associated with events of persons of importance to the country's history, they may have symbolic, commemorative or wāhi tapu values. While trees have finite lives, McClean points out, protection and commemoration should be afforded to the tree-sites through interpretation or by the planting of a new tree in the vicinity of the old "to maintain continuity of landscape values when the old tree dies". ${ }^{161}$ Several topics of interest pertinent to the case studies emerge from the discussion paper: the intangible heritage values of trees in New Zealand; the ephemerality of trees and its effects and authenticity. The issue of heritage authenticity is considered further in Chapter Five.

Lowenthal, in discussing divergent concerns for nature and culture, writes that nature, "seems essentially other than us; we may yearn to feel at one with its life-supporting fabric, but unlike certain aboriginal and tribal peoples we seldom put ourselves in nature's place or project ourselves into non-human lives". ${ }^{162}$ In contrast, he argues, cultural heritage promotes "empathy ... However deeply we may love nature, most of us identify more easily with human relics and rise more readily to their defence". ${ }^{163}$ Three aspects of Lowenthal's statement stand out here. First, it should be noted that Lowenthal's essay is contained within a book that reflects the "position of authors working in the north of Europe, where nature has long been a mark of national distinction for societies located on the periphery of a European civilisation centred toward the south". ${ }^{164}$ Second, it is significant to note that the term "we" in Lowenthal's statement implies that his audience is confined to people who are not, "certain aboriginal and tribal peoples". Third, it is important to point out, in the context of this thesis, how alien it is for many, if not most, New Zealanders to be differentiated as 'we' and 'the other'; Lowenthal's comments are included here to illustrate that there are, indeed, varying attitudes towards nature and culture. Of special interest to this thesis is McClean's statement that "trees are particularly important to Māori as markers of events, historic sources of food, boundary markers or wāhi tapu" and the Heritage New Zealand definition of wāhi tapu as, "a place sacred to Māori in the traditional, spiritual, religious, ritual, or mythological sense". ${ }^{165}$ While the cosmogonic theories of different tribal districts and major thinkers vary, ${ }^{166}$ two

\footnotetext{
${ }^{161}$ McClean, "Sustainable Management of Historic Heritage." 25.

162 Lowenthal, "Natural and Cultural Heritage." 86.

163 Ibid.

164 Olwig, "Introduction" 2.

165 www.heritage.org.nz. Accessed 2 June 2015.

${ }^{166}$ Anne Salmond, "Maori Epistemologies," in Reason and Morality, ed. J. Overing (London: Tavistock, 1985). 244.
} 
aspects fundamental to Māori cosmogony are whakapapa (genealogy, lineage) and the personification of natural phenomena. ${ }^{167}$ As Roberts et al. describe:

Everything in the universe, inanimate and animate, has its own whakapapa, and all things are ultimately linked via the gods to Rangi and Papa. ${ }^{168}$ There is no distinction or break in this cosmogony, and hence in the whakapapa between supernatural and natural. Both are part of a unified whole. ${ }^{169}$

Significantly, there is no distinction made in Māori cosmogony between animate and inanimate, as illustrated by Salmond's interpretation of a Māori cosmological chant:

Thought, memory, the mind-heart and desire generate Te Pō, the ancestral realm, and the wind of life, which creates the elements of Te Ao Mārama, the everyday world of light. Here, there is no radical disjuncture between mind and matter, thought and emotion, subject and object, the ideal and the real. Because everything is animated by hau tupu and hau ora, the winds of growth and life, including objects and people (ahau means 'I' in Māori), animate and inanimate phenomena are not distinguished. ${ }^{170}$

From a Māori point of view, the 'protection and commemoration' of arboreal heritage is provided through kaitiakitanga (guardianship, protection) which encompasses:

Atua [supernatural ancestors], tapu [sacred, prohibited], mana [prestige, authority]. It involves whakapapa and tika [truth, correctness]; to know 'kaitiaki' [guardian] is to know the Maori world. Everybody on this planet has a role to play as a guardian. But if you use the word kaitiaki, that person must be Maori because of the depth and meaning of the word, and the responsibilities that go with it. The reason is that to be a kaitiaki means looking after one's own blood and bones-literally. One's whanaunga [kin] and tupuna [ancestors] include the plants and animals, rocks and trees. We are all descended from Papatuanuku; she is our kaitiaki and we in turn are hers. ${ }^{171}$

An example of kaitiaki in relation to trees is provided by Marsden who describes the Māori practice of pure rākau before a tree was felled for canoe-making or house-building. In order to propitiate Tāne, god of the forest, a fire was first lit under the tree and the first chip was burnt together with mauku. ${ }^{172 ~ " T h e ~ s c e n t, ~ r e p r e s e n t i n g ~ t h e ~ e s s e n c e ~ o f ~ t h e ~ t r e e, ~ w a s ~ o f f e r e d ~ u p ~}$ to propitiate Tāne for the slaying of this forest child of Tāne."173

\footnotetext{
${ }^{167}$ Roberts et al., "Kaitiakitanga." 8.

${ }^{168}$ Ranginui is the Sky Father; Papatūānuku is the Earth Mother.

${ }^{169}$ Roberts et al., "Kaitiakitanga." 9.

170 Salmond, "Ontological Quarrels." 120.

${ }^{171}$ Roberts et al., "Kaitiakitanga." 13.

${ }^{172}$ Hen and chickens fern (Asplenium bulbiferum).

${ }^{173}$ Te Ahukaramū Charles Royal, ed. The Woven Universe: Selected Writings of Rev. Māori Marsden (Ōtaki:

Estate of Rev. Māori Marsden, 2003). 8.
} 
It is not my intention to provide anything like a definitive description of Māori cosmogony that illustrates the relationships between nature and culture and between humans and nonhumans. As de Castro writes, using traditional dichotomies in this way carries the obvious risk of distortion, "since it is unlikely that any nonmodern cosmology can be adequately described either by means of such conceptual polarities or as a simple negation of them (as if the only point of a nonmodern cosmology were to stand in opposition to our oppositions)". ${ }^{174}$ The point I make here is that despite Lowenthal's assertion, in New Zealand wāhi tapu-and in association, arboreal heritage — and their traditional, spiritual, religious, ritual, or mythological elements are recognised and sanctioned both officially ${ }^{175}$ and unofficially. Furthermore, Jeffrey Sissons describes a process of State "systematisation of Maori tradition" which began in the 1970s and 1980s and politicised and codified Māori tradition. ${ }^{176}$ Its intention was to reduce, and ideally eliminate, ethnic inequalities, and its implementation formally recognised Māoritanga (Māori culture, practices and beliefs) and included, what Sissons terms, the "“juridification" of tradition" that allowed the Waitangi Tribunal to hear land claims dating back to $1840 .^{177}$

Smith argues that de-privileging the physical aspects of heritage illuminates the elements that link heritage with identity and social and cultural values and meanings:

These elements include the importance of acts of remembering and memory making, the dissonant nature of heritage, and the political power that can be invested in heritage processes, sites and objects, as well as the performativity of heritage and ways in which this is used to signal and demarcate moments of identity and value creation or recreation and negotiation. ${ }^{178}$

To what extent and as a result of what processes the values, meanings and understandings of arboreal heritage within the case studies are recognised are investigated in this thesis, and to what extent the tree sites examined here rely on living materiality is considered in the crosscase analysis in Chapter Five.

\footnotetext{
${ }^{174}$ Eduardo Viveiros de Castro, "Exchanging Perspectives: The Transformation of Objects into Subjects in Amerindian Ontologies," Common Knowledge 10, no. 3 (2004). 464.

${ }^{175}$ For example, the 1991 RMA acknowledges that the principles of the Treaty of Waitangi must be accommodated in the management of the country's natural resources.

176 Jeffrey Sissons, “The Systematisation of Tradition: Maori Culture as a Strategic Resource," Oceania 64, no. 2 (1993). 99.

${ }^{177}$ Ibid. 101. See also Margaret Kawharu, "Measuring Progress: Reflections on the Ground" in The Treaty on the Ground: Where We Are Headed, and Why It Matters, ed. Rachael Bell, et al. (Auckland: Massey University Press, 2017).

${ }^{178}$ Smith, Uses of Heritage. 307.
} 


\section{Out of the Forest and into the Register ${ }^{179}$}

The RNZIH remit concerning natural monuments, described above, was proposed in 1940, the year of the country's centennial celebration, and referred to both a tree-listing project begun by the institute in 1938 and a similar project sponsored by the Commissioner of State Forests. While the official centennial celebrations centred on the completion of the new Parliament buildings, the writing of historical surveys and the running of celebratory events including a national exhibition in Wellington, many New Zealanders were planting trees as monuments and local memorials and the RNZIH and the Commissioner of State Forests were compiling a catalogue of natural monuments. ${ }^{180}$ Riegl argues that the value of monuments lies in their uniqueness and their representation of and reference to the changes that constitute history. ${ }^{181}$ While intentional monuments are erected specifically to mark special persons or events, he asserts, unintentional monuments rely for their existence on a modern understanding of history — which he equates with development and progress - and a modern experience of temporality. Regarded in this light, a list of natural monuments could contribute much to the country's "deliberate act of national self-definition" that celebrated one hundred years of organised government, progress, pioneers' achievements and the "attainment of a national maturity". ${ }^{182}$ As Loukaki argues, "every nation needs a national memory in order to survive and remain independent, and that national self-awareness is shaped and strengthened not only through the knowledge of its political history, but through the activation of monuments as vehicles of national memory". ${ }^{183}$

The NZIH had petitioned the government for support for its scheme to protect the country's arboreal heritage two years before the centennial in 1938, and the Institute's honorary botanist, Harry Allan, had been charged with drawing up a list of one hundred top trees. While it is apparent that the centennial celebrations played a significant part in the initial

\footnotetext{
179 Schuster cites 'schedules', 'inventories', 'lists', 'classifications', surveys', 'registers' 'records' and 'inscriptions' as related terms used for historic preservation, in J. Mark Schuster, "Making a List and Checking it Twice: The List as a Tool of Historic Preservation," in Biannual Conference of the Association for Cultural Economics International (Rotterdam, 2002). 3. In order to simplify matters, the term 'list' is used here to denote both the process of identification and the resulting selection. To avoid confusion with other lists, the capitalised term 'Register' refers to the New Zealand Tree Register.

${ }^{180}$ In 1959 the NZHPT, New Zealand Forest Service, Auckland University and Department of Lands and Survey all had independent files on the country's historic trees. It was not until 1967 that the RNZIH and S. W. Burstall of the Forest Research Institute shared their lists.

${ }^{181}$ Riegl, "The Modern Cult of Monuments."

${ }^{182}$ Kynan Harley Gentry, "Associations Make Identities: The Origins and Evolution of Historic Preservation in New Zealand, 1870-1954” (PhD, University of Melbourne, 2009). 247.

${ }^{183}$ Loukaki, Living Ruins, Value Conflicts. 55.
} 
work towards a heritage tree register, other influences should also be considered. Writing about the beginnings of heritage registers in Britain, Saint theorises that listing in that country was closely allied to an enthusiasm from the 1920s to the 1940s about broad environmental issues and, in particular, about planning. ${ }^{184}$ "Listing was, as it remains, umbilically connected to the planning process," he argues. ${ }^{185}$ While New Zealand's RMA was not passed until 1991, the inclusion of trees in the resulting district plans suggests that similar influences may have been in play earlier. Other events, including the imminent outbreak of war, may have influenced the plans for a national tree register also. Loukaki cites WWII as the turning point for a "new monumentality" which moved away from the "monumentality of the exceptional to that of the humble, the quaint and the repetitive". ${ }^{186}$ The events of that war, she argues, heightened appreciation of the "rarity, irrevocability and fragility of tangible historical evidence ... in conjunction with the environmental issue and the dislike of what were perceived as the built excesses of Modernism". ${ }^{187}$ The description that follows in Chapter Two of the 1940 centennial tree-planting projects carried out during WWII bears out Loukaki's supposition.

Harrison describes lists and hierarchical categories of physical objects as embodying "the values, spirit and history of the nation". ${ }^{188}$ Heritage lists, he writes, resemble "offshoots of the concept of 'the canon"” which raises a number of questions. ${ }^{189}$ Who determines what is and what isn't on the list? What values underlie the judgements specifying what should be represented? How do we assess which are the great heritage objects and which are not? How does creating a list include and exclude the values of different members of society? Mitchell observes that the idea of a canon represents the narratives, values and principles on which particular visions of nationhood are founded. ${ }^{190}$ Any study of a class of objects perceived to

\footnotetext{
${ }^{184}$ Andrew Saint, "How Listing Happened," in Preserving the Past: The Rise of Heritage in Modern Britain, ed. Michael Hunter (Phoenix Mill: Alan Sutton Publishing, 1996). 115.

185 Ibid. 131.

${ }^{186}$ Loukaki, Living Ruins, Value Conflicts. 56.

187 These comments refer to developments in Europe. For discussions on commemorative tree plantings in New Zealand and Australia see Dargavel, "More to Grief than Granite: Arboreal Remembrance in Australia."; Cloke and Pawson, "Memorial Trees and Treescape Memories."; Pickles, "Mapping Memorials."; Pawson, "The Memorial Oaks of North Otago."; Stephens, "Remembrance and Commemoration Through Honour Avenues and Groves in Western Australia." and Chris Maclean, Jock Phillips, and Debbie Willis, The Sorrow and the Pride: New Zealand War Memorials (Wellington: New Zealand Department of Internal Affairs: Historical Publications Branch, 1990).

${ }^{188}$ Rodney Harrison, "What Is Heritage?," in Understanding the Politics of Heritage, ed. Rodney Harrison (Manchester: Manchester University Press, 2010). 14.

189 Ibid.

${ }^{190}$ W. J. T. Mitchell, "Canon," in New Keywords: A Revised Vocabulary of Culture and Society, ed. Tony Bennett, Lawrence Grossberg, and Meaghan Morris (Oxford: Blackwell Publishing, 2005). 21.
} 
be the greatest expression of a nation's culture must, therefore, reveal the narratives and values deemed most worthy by that nation and controlled by the experts it sanctions. ${ }^{191}$ Through linking these two concepts of canon and register, the secondary questions 'which narratives, values and principles does today's Cyberforest reflect?', 'have they changed over time?' and 'who are the experts?' become highly relevant to this research. A heritage register can also be viewed as a type of collection in the sense of "specially designated groups of artefacts", ${ }^{192}$ and the Cyberforest draws attention online to its "unique collection". As McClellan notes, who collects what and when, and how what is collected is organised and presented to the world, are matters of deep cultural and historical interest. ${ }^{193}$ The effects on the listed objects of cataloguing is another aspect of the register that demands inquiry.

Wittman refers to the "blanching" of a monument that occurs when it is abstracted "from the very concerns that made it so valuable" in order that it might take its place in a "universal aesthetic category". ${ }^{194}$ Similarly, Lenzerini warns that authenticity can be lost when the selected heritage is required to adapt to the needs of the list and the requirements of those who safeguard it. ${ }^{195}$ Of particular relevance in this regard is Cloke and Pawson's argument that trees are especially susceptible to imaginative social and cultural constructions and can alter dramatically within and between cultural contexts. ${ }^{196}$ As Park notes while mourning the historic loss of so much of New Zealand's indigenous forest, it is ironic that advertisers in New Zealand today use the tree to "symbolise rootedness and stability". 197

\section{Why List?}

Modern memory, writes Nora, is, above all, archival and "relies entirely on the materiality of the trace, the immediacy of the recording, the visibility of the image". ${ }^{198}$ Our obsession with archiving marks our age and is an expression of our fear of a rapid and final disappearance combined with anxiety about the meaning of the present and uncertainty about the future. The less memory we experience from the inside the more it exists only through "its exterior

\footnotetext{
${ }^{191}$ Harrison, "What is Heritage?" 15.

192 Sharon Macdonald, Behind the Scenes at the Science Museum (Oxford: Berg, 2002). 43.

${ }^{193}$ Andrew McClellan, The Art Museum from Boullée to Bilbao (Berkeley: University of California Press, 2008).

${ }^{194}$ Wittman, "Local Memory and National Aesthetics." 274.

${ }^{195}$ Federico Lenzerini, "Intangible Cultural Heritage: The Living Culture of Peoples," European Journal of International Law 22, no. 1 (2011).

${ }^{196}$ Cloke and Pawson, "Memorial Trees and Treescape Memories."

197 Park, Ngā Uruora. 324.

198 Nora, "Between Memory and History." 13.
} 
scaffolding and outward signs". ${ }^{199}$ The archive has become the "deliberate and calculated secretion of lost memory. It adds to life - itself often a function of its own recording - a secondary memory, a prosthesis-memory". ${ }^{200}$ Like other heritage artefacts, trees considered worthy are archived in heritage registers and lists, studied here as the Cyberforest and the heritage lists of three local authorities. Lists, Gass writes, lie at the heart of the archive and achieve the "purposeful coming together of names like starlings to their evening trees". ${ }^{201}$ They tend to confer equality on objects, detach them from their place in the world and enumerate them elsewhere. ${ }^{202}$ The list is no stranger to the arboreal world. Since Linnaeus invented modern biological classification in the eighteenth-century, scientists have examined, grouped, regrouped and labelled trees and filed their categories in manageable, conceptual lists from 'species' to 'kingdoms'. 203

Goody identifies three broad kinds of lists: the retrospective "inventory" of persons, objects or events (the most common list form); the "shopping list" (a plan and guide for future action where items are struck off as they are dealt with); and the "lexical list" (an inventory concerned primarily with concepts; a "proto-dictionary or embryonic encyclopaedia"). ${ }^{204}$ The list, he argues, relies on discontinuity rather than continuity. It depends:

on physical placement, on location; it can be read in different directions, both sideways and downwards, up and down, as well as left and right; it has a clear-cut beginning and a precise end, that is, a boundary, an edge, like a piece of cloth. Most importantly it encourages the ordering of the items, by number, by initial sound, by category, etc. And the existence of boundaries, external and internal, brings greater visibility to categories, at the same time as making them more abstract. ${ }^{205}$

All lists deal with information, but their organisation differs, and any one list can have more than one organisational system. Gass notes four organising principles: as encountered, found, remembered or needed (an informal list); as arranged by an already ordered external system (sometimes alphabetically or numerically and possibly hierarchical); as dictated by the order of the objects themselves (for example, the contents of a book); and as rated in terms of some principle of value or importance. Lists, he writes, are "juxtapositions, and exhibit many of the qualities of collage. The names which appear on them lack their normal syntactical

\footnotetext{
199 Ibid.

200 Ibid. 14.

${ }^{201}$ William H. Gass, "I've Got a Little List," Salmagundi Winter-Spring, no. 109/110 (1996). 21.

${ }^{202}$ Ibid. 21-22.

${ }^{203}$ Edward O. Wilson, Consilience: The Unity of Knowledge (New York: Alfred A. Knopf, 1998). 3.

${ }^{204}$ Jack Goody, The Domestication of the Savage Mind (Cambridge: Cambridge University Press, 1977). 80.

205 Ibid. 81.
} 
companions. Most lists are terse, minimal, bald; they are reminders, commands, aspirations". ${ }^{206}$

Why are heritage items gathered together in lists? Schuster theorises that "the ultimate intent of the list in historic preservation is to assure the preservation of identified properties". ${ }^{207}$ But listing can be a double-edged sword. While the listing of historic artefacts can provide the means for attracting funding it can also trigger regulations regarding maintenance, renovation, use, public access, transfer or demolition. Listing can also, according to some writers, lead to too much of a good thing. Gass points out that the list is the "fundamental rhetorical form for creating a sense of abundance, overflow, excess", ${ }^{208}$ a sense which, Schuster claims, causes list-loving preservationists to say "My, our list is long! We must have a considerable and valuable architectural and natural heritage" and encourages further additions. ${ }^{209}$ Lists can be used also by others for diametrically opposed purposes, through the provision of inventories for the unwelcome attention of vandals and iconoclasts. ${ }^{210}$

Gass describes a list as a "purposeful collection" which invites interrogation. ${ }^{211}$ What, then, is its purpose? How is it ordered? What are the accessioning requirements and deaccessioning principles? These are questions pertinent to this study of national and regional tree lists. While lists are documented, Muller-Wille and Charmantier argue, they are not stable but can be manipulated through reordering thereby producing a dialectical effect. ${ }^{212}$ As Goody points out, they can represent "an abstraction, a decontextualisation, a game - and sometimes a conceptual prison. But at the same time, they crystallise problems of classification and lead to increments of knowledge, to the organisation of experience". ${ }^{213}$ Using the example of an apple, Gass demonstrates how 'reordering' of a list can compose quite a different object by re-arranging its properties:

... according to some experiential order (where shape, stem, color and skin, would come first), or in terms of desire (then its flood of juice and quash of tart pulp between the teeth might lead the imagination), or by stressing symbolic factors instead (Eve,

\footnotetext{
${ }^{206}$ Gass, "I've Got a Little List." 23. See also Liam Cole Young, "Un-Black Boxing the List: Knowledge, Materiality, and Form," Canadian Journal of Communication 38 (2013). 501.

207 J. Mark Schuster, "Making a List and Checking It Twice: The List as a Tool of Historic Preservation," in Biannual Conference of the Association for Cultural Economics International (Rotterdam, 2002). 5.

${ }^{208}$ Gass, "I've Got a Little List." 35.

${ }^{209}$ Schuster, "Making a List and Checking it Twice." 11.

${ }^{210}$ Ibid. $14-15$.

${ }^{211}$ Gass, "I've Got a Little List." 29.

${ }^{212}$ Staffan Muller-Wille and Isabelle Charmantier, "Lists as Research Technologies," Isis 103, no. 4 (2012). 744.

${ }^{213}$ Goody, The Domestication of the Savage Mind. 94.
} 
tree, worm), or by concentrating on the way the language moves, (fancying a phrase like "voluminous juice," in my mouth, more than the apple's taste. ${ }^{214}$

Muller-Wille and Charmantier's "reordering” becomes 'classification' under the scrutiny of Bowker and Star and is defined as a "spatial, temporal, or spatio-temporal segmentation of the world". ${ }^{215}$ "To classify is human ... Our lives are henged round with systems of classification, limned by standard formats, prescriptions, and objects." ${ }^{216}$ Along with the act of classification goes the imposition of standards; "any set of agreed-upon rules for the production of (textual or material) objects". ${ }^{217}$ Attempting to understand the classifications and standards embedded in our systems of information begs three questions: 'What work do they do?'; 'Who does that work?' and 'What happens to the cases that do not fit?' all of which contribute to the enquiry of the second thesis question 'How do trees become arboreal heritage? Classifications and standards are powerful territory, Bowker and Star argue, because they can advantage or disadvantage any individual, group or situation. "We need to consistently explore what is left dark by our current classifications ("other" categories) and design classification systems that do not foreclose on rearrangements suggested by new forms of social and natural knowledge." ${ }^{218}$ In arboreal heritage terms, classifications and standards equate to the categories and tree evaluation methods that formulate The Cyberforest and the associated regional tree lists.

\section{Digitisation of lists}

In 1977 the RNZIH established a national register of notable trees "for the purpose of cataloguing and registering New Zealand's national tree heritage". ${ }^{219}$ In 2004 the formerly hardcopy Notable New Zealand Trees database was launched online as the digitised New Zealand Tree Register, now administered by the NZNTT and referred to here as the 'Cyberforest'. ${ }^{220}$ The aim of this new online presence was to "allow public access and wider recognition of New Zealand's tree heritage". ${ }^{221}$ The process of digitising the register is not a prime concern of this study, nor is an argument for or against its application, but literature

\footnotetext{
${ }^{214}$ Gass, "I've Got a Little List." 34.

${ }^{215}$ Geoffrey C. Bowker and Susan Leigh Star, Sorting Things Out: Classification and its Consequences (Cambridge, Massachusetts: MIT Press, 2000). 10.

${ }^{216}$ Ibid. 1.

${ }^{217}$ Ibid. 13.

218 Ibid. 321.

${ }^{219}$ https://www.notabletrees.org.nz. Accessed 2 June 2015.

${ }^{220}$ Online national registers of trees are known to have been established by Australia, Ireland, United States and United Kingdom and regional registers document trees of Tasmania, California and the Eastern United States.

${ }^{221} \mathrm{http}: / /$ www.notabletrees.org.nz. Accessed 2 June 2015.
} 
that discusses some of the possible effects of this process is useful for understanding how the register operates as a heritage tree site. Digitisation adds a further contextual dimension to lists. A list in writing, Young argues, can be grasped all at once and, depending on its size or scope, it can either intimidate or comfort the reader. In contrast, an online list does not abide by the same visual logic and presents the reader with new challenges for comprehension:

The structural limitations of computer monitors ensure that the horizon of online lists is continuously deferred and elusive. Items are either scrolled through, with those at the top disappearing to make room for those coming into view at the bottom, or the list is navigated item by item via Next or Previous buttons. One can never examine, let alone comprehend, such a list all at once. Thus, certain information is lost to the reader (i.e. the size or length of the list, one's navigational progress, the ability to compare entries that are further apart than a computer screen will allow, etc.). The loss of a visible horizon produces an unsettling effect in the reader. ${ }^{222}$

Increasingly museums and other heritage caretakers are digitising their collections with the aim of introducing new audiences to the contents. The benefits of a virtual interface, they argue, range from easier language conversion to faster access for the disabled. The motivations, de Groot points out, include a "shifting definition of the dynamic, context and purpose of 'the visit",223 and competition for visitors' attention:

In a very real sense, the online museum has to actively compete with other attractions for the attention of the visitor and must bend their will in terms of access, route and duration of visit. They are no longer able to physically impart meaning to an object, in the same way that the object is no longer experienced physically in any sense at all. The 'museum' as physical repository is replaced by the cybermuseum, a more negotiable space in all senses of the word. The engagement with the particular artefact is no longer the most important element of the 'visit'. ${ }^{224}$

It should be pointed out that although a register can be likened to a museum, in that both are responsible for collections, they cannot be regarded equally as "physical repositories", as described by de Groot. While a museum traditionally displays and cares for physical objects, a register can only display their images and list them as objects worthy of preservation.

Digitisation of a register, therefore, does not incur the same level of changes to visitor engagement with its artefacts. It does, however, enable similarly appreciable changes to the accessibility of its contents. At the press of a key, any online visitor to the Cyberforest can now view information on each of the trees deemed to be 'notable' in any of nineteen areas of

\footnotetext{
${ }^{222}$ Young, "Un-Black Boxing the List." 511-12.

${ }^{223}$ Jerome de Groot, "Historiography and Virtuality," in Culture, Heritage and Representation: Perspectives on Visuality and the Past, ed. Emma Waterton and Steve Watson (Surrey: Ashgate, 2010). 91.

${ }^{224}$ Ibid.
} 
New Zealand regardless of their geographical location or the weather at the tree site. The locations of most of the trees are indicated by aerial photographs and some trees are pictured at ground level: names, measurements and ages are recorded and some historical details are included. Three examples of karaka are listed currently in the Cyberforest - tree sites at Te Awanga, Palmerston North and New Plymouth. Who visits the online New Zealand Tree register and why, and whether "wider recognition of New Zealand's tree heritage" has been achieved are unclear from the information presented on the web site. However, my observations indicate that the Register — whether digital or analogue — is largely unknown by the general public.

Of particular interest to any research into the effects of digitisation on the Register as a heritage tree site is the application of curatorial filters. Relevant questions include: 'how are tree entries selected?' 'can trees be deaccessioned?' 'what relationship does this national register have with the registers administered by local authorities?' 'what happens to the individual entries when the registered trees die?' and, to borrow from Bowker and Star, 'what is left "dark"?"225 As Wellington and Oliver argue, the act of choosing what to digitise and make available online is "not a value-neutral activity". ${ }^{226}$ Of further interest to this study is the suggestion that the "normative" 227 nature of digitisation of museum collections, and the effortless accessibility to countless digital manifestations of objects throughout the world at any time of day might, in fact, work to increase the importance of the actual—rather than virtual - visit as a physical sensory experience. Wellington and Oliver point out that "the ease with which we participate digitally with our cultural heritage, along with the transitory nature of that engagement, paradoxically places more emphasis on, and, perhaps surprisingly, elevates the notion of the physical". ${ }^{228}$ In response to this notion, and as part of my empirical research, I visited each of the five tree sites contained within the three case studies and document these experiences.

'Register' is a polysemic word that includes references to music, language, printing and retailing. The term, as used here, is generally defined as an official list or record. The

\footnotetext{
${ }^{225}$ Bowker and Star, Sorting Things Out. 321.

${ }^{226}$ Shannon Wellington and Gillian Oliver, "Reviewing the Digital Heritage Landscape: The Intersection of Digital Media and Museum Practice," in The International Handbooks of Museum Studies: Museum Practice, ed. Conal McCarthy (Chichester: Wiley Blackwell, 2015). 592.

${ }^{227}$ Ross Parry, "The End of the Beginning: Normativity in the Postdigital Museum," Museum Worlds: Advances in Research 1 (2013).

${ }^{228}$ Wellington and Oliver, "Reviewing the Digital Heritage Landscape." 595.
} 
Cyberforest by this definition is an official list or record of trees in this country. The adjective 'official' is a crushing term that repels change and suggests that any register, such as the Cyberforest, is unassailable. The discussion in my literature review, however, particularly concerning concepts of otherness, agency, intangible natural heritage, affective nature and the ethical mindfulness turn, suggests that a more comprehensive record of arboreal heritage might contain much more than classifications and standards based on measurements of age, height, girth and crown spread. It might aspire to becoming the type of list that Goody describes as serving to "crystallise the state of knowledge, but to raise problems of classification and to push at the frontiers of a certain kind of understanding". 229

\section{Alternative Forms of Listing}

To investigate this further, I refer to two contemporary examples of alternative heritage documentation that take a 'counter-' approach. In the first, Rodney Harrison describes how the social values of place in Australia and the United Kingdom have been recorded by "counter-mapping" which, he writes, gives "voice to politically marginal and subaltern understandings of the past and present". ${ }^{230}$ The processes of counter-mapping, Harrison writes, "allow minority groups to challenge some of the 'taken for granteds' of heritage management, but also encourages [sic] people to celebrate their experiences of the everyday". 231 The second example of a counter-approach to heritage documentation is the establishment of parish maps that record significant events and sites within small places “defined from within" as part of the United Kingdom's Common Ground project. ${ }^{232}$ In striving to "articulate the importance of everyday surroundings to local people in a professional world driven by concern to protect the rare, the endangered, the spectacular", Common Ground followed a counter-approach by encouraging communities to produce their own local maps. ${ }^{233}$ The point highlighted by the parish maps was that "everyday nature, unwritten history, and vernacular buildings were significant and in danger; that the special

\footnotetext{
${ }^{229}$ Goody, The Domestication of the Savage Mind. 93-94.

${ }^{230}$ Rodney Harrison, “'Counter-Mapping' Heritage, Communities and Places in Australia and the United Kingdom,” in Local Heritage, Global Context: Cultural Perspectives on Sense of Place, ed. John Scholfield, Rosy Szymanski, (Surrey: Ashgate, 1988). 79.

231 Ibid. 91.

${ }^{232}$ Sue Clifford, "Local Distinctiveness: Everyday Places and How to Find Them," in Local Heritage, Global Context: Cultural Perspectives on Sense of Place, ed. John Scholfield and Rosy Szymanski (Surrey: Ashgate, 1988). 15.

${ }^{233}$ Ibid. 13.
} 
would never survive without the ordinary, that everyday surroundings and their inhabitants were important anyway". 234

If 'mapping' is defined as associating a group of elements or qualities with another group according to a particular formula or model then counter-mapping as a model for a 'counterAAHD' can be seen as not too great a stretch. My investigation of the UAHD requires an appropriately agile tool — counter-heritaging — that endorses the introduction of the Anthropocene Grove and the Dendroglyph Trees as alternative forms of arboreal heritage that have no place in conventional registers. This thesis argues that a counter-AAHD - the UAHD - approach that incorporates the concepts of otherness, agency, intangible natural heritage, affective nature and the ethical mindfulness turn, as outlined above, can contribute to a contemporary rethinking of New Zealand's arboreal heritage. This study builds on the work of Jones and Cloke who have examined the interconnections between trees and place at four separate United Kingdom sites. ${ }^{235}$ My study similarly considers concepts such as nonhuman agency, otherness, relational ethics and the significance of temporal and spatial context but examines the interconnections between a single tree species and heritage at five sites in New Zealand. My research has resulted in three separate, bounded and fine-grained case studies and a cross-case analysis.

\section{Literature Review: Conclusion}

From the literature review it is clear that much has been written about the broad heritage topics of monumentality, nature, culture, registers and their relevant sub-topics, all of which have informed my research. Professional practice and academic research on heritage in New Zealand has focused largely on the built environment prompting Janelle Warren-Findley, in her study of heritage management in New Zealand, to refer to a historic buildings" "bias" in many urban areas of the country which has led to conservation efforts to focus on buildings that are architecturally or aesthetically interesting at the expense of their historic context. ${ }^{236}$ New Zealand's garden history has been documented in books ${ }^{237}$ and a plethora of on-site

\footnotetext{
234 Ibid.

235 Jones and Cloke, Tree Cultures.

${ }^{236}$ Jannelle Warren-Findley, "Human Heritage Management in New Zealand in the Year 2000 and Beyond," (Wellington: Fulbright New Zealand, 2001).

${ }^{237}$ For example, James Beattie, "Growing Chinese Influences in New Zealand: Chinese Gardens, Identity and Meaning," New Zealand Journal of Asian Studies 9, no. 1 (2007); James John Beattie and Katie Holmes, "Reflections on the History of Australasian Gardens and Landscapes," Studies in the History of Gardens and Designed Landscapes 31, no. 2 (2011); Matthew Bradbury, ed. A History of the Garden in New Zealand (Auckland: Viking, 1995); Bee Dawson, A History of Gardening in New Zealand (Auckland: Random House,
} 
brochures. Informative essays on New Zealand's landscape ${ }^{238}$ and environmental histories ${ }^{239}$ have provided both physical and historic contexts for heritage sites. While there have been significant publications on individual native tree species, ${ }^{240}$ there is a gap in the literature concerning arboreal heritage in New Zealand. If heritage is "related to cultural identity, feelings of belonging and the play of memory and duration", ${ }^{241}$ as argued by Crouch, and if heritage signifies "the organization of a new historical moment in the workings of historical time", ${ }^{242}$ as described by Schwarz, a study such as this is both appropriate and prescient.

This review of relevant literature has demonstrated the appropriateness of critical heritage studies as a field for examining the processes and effects of arboreal heritage. Because it concerns itself with both nature (trees) and culture (heritage), and, therefore, might be viewed through the lenses of both science and humanities, arboreal heritage calls for a multidisciplinary approach and, as Howard proposes, a single field of enquiry. ${ }^{243}$ As a field of enquiry that deals with the composition and management of both natural and cultural heritage, critical heritage studies is well placed for this task. In particular, the adoption of a tailored version of the AHD — the AAHD - along with the notion of intangible natural heritage and its affective properties, and a counter-AAHD approach — the UAHD — situate the study firmly amid contemporary heritage discourse while introducing arboreal heritage as a sub-category of physical heritage in its own right. The literature examined here in relation to trees as monuments, prompted by the title of the thesis, has been drawn largely from writing about built heritage but has proved to be neatly apposite to a study of trees. Discussions about mortality of memory and its effects; intentionality or unintentionality of monuments; and the relationships of history, memory and place willingly migrate to a study of natural heritage and in doing so pose secondary questions to be investigated including: 'To what extent does memory rely on materiality?' 'Can newly-planted trees in heritage places be regarded as

2010); Helen Leach, 1000 Years of Gardening in New Zealand (Wellington: Reed, 1984); “Analysing Change in the New Zealand Home Garden: by Style or Element," New Zealand Garden Journal 1, no. 2 (1996).

${ }^{238}$ For example, Park, Ngā Uruora; Theatre Country; Janet Stephenson, Mick Abbott, and Jacinta Ruru, eds., Beyond the Scene: Landscape and Identity in Aotearoa New Zealand (Dunedin: Otago University Press, 2010). ${ }^{239}$ For example, Jock Phillips, ed. Te Whenua Te Iwi-the Land and the People (Wellington: Stout Research Centre, 1987); Eric Pawson and Tom Brooking, eds., Making a New Land: Environmental Histories of New Zealand (Dunedin: Otago University Press, 2013); Brooking and Pawson, Seeds of Empire.

${ }^{240}$ For example, Philip Simpson, Pohutukawa and Rata: New Zealand's Iron-Hearted Trees (Wellington: Te Papa Press, 2005); Totara: A Natural and Cultural History (Auckland: Auckland University Press, 2017).

${ }^{241}$ Crouch, "The Perpetual Performance and the Emergence of Heritage." 57.

${ }^{242}$ Bill Schwarz, "Heritage," in New Keywords: A Revised Vocabulary of Culture and Society, ed. Tony Bennett, Lawrence Grossberg, and Meaghan Morris (Malden, USA: Blackwell, 2005). 156.

${ }^{243}$ Howard, Heritage. 55. 
'heritage'?' 'Trees are monuments to what?', 'Does monumentality equate to protection?', 'Can trees survive death or deaccessioning and continue to be monuments?' and 'How well can the archiving of trees keep memories of them intact?' The literature concerned with the listing and cataloguing of heritage objects has proved also to be directly relevant to this thesis not only because one of the cases studied (the Cyberforest) is associated with archiving, but also because the archiving process itself is predicated on values, meanings and understandings - a central concern of this study — and, as Gass points out, a list can be defined as a purposeful collection which invites interrogation. ${ }^{244}$ Studying the Cyberforest as a 'purposeful collection' has opened it up to further questions such as: 'Who determines what is or isn't included?' 'What values underlie these decisions?' and 'What purposes do these collections serve?'

My study of the literature that deals with the relationship between nature and culture has introduced to the discussion of arboreal heritage concepts of otherness and agency, species specificity and a general move away from anthropocentrism and towards the concept of ethical mindfulness. Much of this discourse has emerged out of a recognition that the world currently faces environmental threats of global significance and proportions. The twentyfirst-century "ecological crisis", Plumwood argues, has positioned humans and non-humans in an equal relationship that is subject to ethics as much as ecology; "we can no longer retain the comfortable human-centred illusion of separate casts of characters in separate dramas. Our disciplinary structures must reflect that knowledge". ${ }^{245}$ It is important to note again that this thesis is not an environmental study; rather it is an examination of the values, meanings and understandings formed and regulated in the process of trees becoming arboreal heritage. However, it is also pertinent to recognise that it is the consideration of the environment and the relationship of nature and culture, as described above, which provokes many questions that are relevant to this study. As Weston points out, the fear of an ecological crisis has given rise to a growing environmental awareness and, perhaps, has resulted in an awakening of "some deep sort of remembrance of nature" and introduced "some sense of wild possibility". 246

\footnotetext{
${ }^{244}$ Gass, "I've Got a Little List." 29.

${ }^{245}$ Plumwood, Environmental Culture. 51-52.

${ }^{246}$ Anthony Weston, "Introduction," in An Invitation to Environmental Philosophy, ed. Anthony Weston (Oxford: Oxford University Press, 1999.) 3.
} 
This thesis is in seven parts: this Introduction; Research Design; three case studies (the Cyberforest, the Anthropocene Grove and the Dendroglyph Trees); Case Studies Discussion; and the Conclusion. The Introduction frames the research and reviews the literature that contributes to the theoretical framework. Chapter One outlines the methodology employed and concludes with an explanation of the significance of the thesis. The three case studies are documented in chapters Two, Three and Four. Chapter Two discusses the historical background to the Cyberforest (the online New Zealand Tree Register) from 1937. It describes the three embedded heritage tree sites-Te Awanga, Palmerston North and New Plymouth — and their status in the heritage tree registers of their local authorities-Hastings District Council (HDC), Palmerston North City Council (PNCC) and New Plymouth District Council (NPDC) respectively_ - and compares the numbers of entries of native and exotics in the tree lists examined in the thesis. Chapter Three focuses on the development and current heritage role of the Anthropocene Grove (an urban planting on Taranaki Wharf, Wellington ${ }^{247}$ ) and Chapter Four describes the genesis and ongoing heritage nature of the Dendroglyph Trees (carved trees at Lake Kohangapiripiri, Wellington). The Case Studies Discussion in Chapter Five employs a cross-case analysis method using seven domains of arboreal heritage to identify similarities and differences in the five tree sites included in the three cases. The term 'domain' indicates that each section of the cross-case analysis refers to a clearly defined area of knowledge applied here specifically to the arboreal heritage under examination and not necessarily applicable to heritage in a more general sense. The domains are: species specificity, cultural or natural origins, agency, authenticity, social and political change, monumentality and materiality. The Conclusion draws together the research findings in order to answer the three primary thesis questions and, in line with the applied nature of critical heritage studies, formulates a set of ten principles designed for negotiating the acknowledgement and protection of arboreal heritage.

${ }^{247}$ Officially named Taranaki Street Wharf but popularly known as Taranaki Wharf. 


\section{CHAPTER ONE: RESEARCH DESIGN}

\section{Methodology}

Appropriate theoretical concepts emerge from the literature review to form the basis for developing and carrying out the research and are outlined here. Underpinning the study and ensuring its contemporary relevance is the concept of ethical mindfulness in relation to nature which, in a multitude of forms, has permeated the work of many disciplines over recent years and has been motivated and nurtured by a growing global awareness of the current threats to the environment. It is in consideration of this concept that I chose to adopt a critical theoretical perspective informed by various interpretations of ANT, ${ }^{1}$ which introduces the notion of relational agency to arboreal heritage, and Assemblage Theory, which helps clarify the complicated networks of assemblages and assemblers.

Exploring heritage as a production of the past, writes Harrison, "leads to a reassessment of who and what is involved in the process of 'making' heritage, and 'where' the production might be located within contemporary societies. This directly invokes the question of agency". ${ }^{2}$ Consequently, agency is recognised not as an individual act of will but as something distributed across collectives, or assemblages, of humans and non-humans. ${ }^{3}$ The most useful means of disentangling the many institutions and individuals (human and nonhuman), actions and reactions, values, meanings and understandings that operate within the arboreal heritage process in this country is an approach based on ANT.

Hitchings defines ANT not as a theory but as an attitude. Under ANT, he writes, "people, objects, plants, animals and ideas all jostle against each other, and it is through these interactions that society takes shape and our understandings of this society find form". 4 Appropriately for a study where trees are the focus, an ANT perspective strips away

\footnotetext{
${ }^{1}$ Bruno Latour, Reassembling the Social: An Introduction to Actor-Network-Theory (Oxford: Oxford University Press, 2005); Russell Hitchings, "People, Plants and Performance: On Actor Network Theory and the Material Pleasures of the Private Garden," Social and Cultural Geography 4, no. 1 (2003); Jane Bennett, "The Force of Things: Steps Towards an Ecology of Matter," Political Theory 32, no. 3 (2004); Harrison, Heritage; John Law, "After ANT: Complexity, Naming and Topology," in Actor-Network-Theory and After, ed. John Law and John Hassard (Oxford: Blackwell, 1999); Jones and Cloke, Tree Cultures; Gay Hawkins, "The Politics of Bottled Water: Assembling Bottled Water as Brand, Waste and Oil," in Assembling Culture, ed. Tony Bennett and Chris Healy (London: Routledge, 2011).

${ }^{2}$ Harrison, Heritage. 32.

${ }^{3}$ Ibid.

${ }^{4}$ Hitchings, "People, Plants and Performance." 100.
} 
anthropocentrism and smudges the line between nature and culture by awarding equal instrumentality to all 'actants' —-Latour's term — and democratically defining both human and non-human actors. ${ }^{5}$ This is a particularly apt stance to take when trees, which are alive but not human, are the principal actants to be studied. Jones and Cloke, while supporting ANT's notion of relational agency argue not only for a move away from treating human agency as "separate, privileged and ontologically unique" but also for a disaggregation of the notion of agency itself in order to show how non-humans, including trees, exercise their own peculiar form of agency. ${ }^{6}$ Trees, they write, collectively have a "bewildering range of skills and/or uses, and they are embedded in a plethora of relationships, both with humans and other nonhumans. Equally with humans they are embedded in a vast range of cultural, social, technological and economic networks, as well as being highly visible in local, national and global disputes over the "environment".?

Actants, Latour points out, are mediators not intermediaries and are associated with each other through making others "do things". ${ }^{8}$ This is similarly described by Pollan as a "coevolutionary drama". ${ }^{9}$ The term 'network' in Actor Network Theory refers not to these associations themselves but to the tool used in order to describe them. An ANT approach avoids any focus on the groups themselves involved in the heritaging activities and instead concentrates on the changing processes of group formations without a determinable starting point. ${ }^{10}$ It is an approach in which, Latour argues, "by following circulations we can get more than by defining entities, essences or provinces". ${ }^{11}$ By adopting an ANT "attitude" this study has been able to introduce the Anthropocene Grove and the Dendroglyph Trees as tree heritage distinct from the received AAHD model and to consider more nuanced relationships between human and non-human actants. ANT is also "diasporic", in that it readily converts itself into a range of different practices. ${ }^{12}$ Despite criticism that assigning agency to nonhumans is absurd and that ANT denies power imbalances, it remains an approach well-suited to my study of trees as living entities. As well, in line with the concept of heritage as "a mode

\footnotetext{
${ }^{5}$ Latour, Reassembling the Social.

${ }^{6}$ Jones and Cloke, Tree Cultures. 54.

${ }^{7}$ Ibid.

${ }^{8}$ Latour, Reassembling the Social. 107.

${ }^{9}$ Pollan, The Botany of Desire. 243.

${ }^{10}$ Latour, Reassembling the Social.

${ }^{11}$ Bruno Latour, "On Recalling ANT," in Actor Network Theory and After, ed. John Law and John Hassard (Oxford: Blackwell, 1999). 20.

12 Law, "After ANT." 10.
} 
of cultural production in the present that has recourse to the past", ${ }^{13}$ ANT addresses different temporal and spatial parameters, well suited to the characteristics of trees and draws from a range of disciplines, an approach appropriate to current discussions of the contribution of trees to human well-being. The robust "jostling" in this study of people, objects, plants, animals and ideas in the case studies, as described by Hitchings, has resulted in a fresh understanding of tree heritage in New Zealand. However, the point made by Jones and Cloke for a disaggregation of agency to accommodate the particular qualities of trees is well made and acknowledged here. With this in mind, establishing the associations engaged in the process of arboreal heritage and documenting the transformative work of the mediators has been the work of the research. In addition, by directing attention more to the processes that create heritage than to the finished products themselves, this thesis has taken an Assemblage Theory perspective on heritage. ${ }^{14}$

Adopting an assemblage means of examining heritage, Macdonald writes, results in an "emphasis on the "multiple, heterogeneous and often highly specific actions and techniques that are involved in achieving and maintaining heritage"; a revelation of "continuities alongside the more usually noted shifts"; and "more nuanced accounts of complexes of interrelationships". ${ }^{15}$ Assemblage Theory is a useful part of the theoretical framework for this study of complicated networks of trees, people, events, organisations, policies and politics situated within each of the three case studies and within arboreal heritage as both an assemblage and an assembler. Bennett's notion of 'thing-power' offers another useful tool for analysis. Thing-Power Theory focuses on performativity and, as such, is closely related to ANT. It falls short of Plumwood's concern with otherisation as an "obstacle to justice"16 but is more generous than ANT in assigning attributes to non-humans through its consideration of "things as being more than mere objects, emphasizing their powers of life, resistance, and even a kind of will". ${ }^{17}$ It is also more tolerant of including groups in its study, as illustrated by Hawkins" comment that, recognising the "thingness of things" is not to "deny the dense web of connections that they are always caught up in. It is simply to be open to the powers of matter and the recognition that there are multiple sites of agency in the world beyond the

\footnotetext{
${ }^{13}$ Kirshenblatt-Gimblett, "Theorizing Heritage." 370.

${ }^{14}$ Sharon Macdonald, "Reassembling Nuremberg, Reassembling Heritage," Journal of Cultural Economy 2, no. 1-2 (2009).

15 Ibid. 118-19.

16 Plumwood, Environmental Culture. 11.

${ }^{17}$ Bennett, "The Force of Things." 360.
} 
human". ${ }^{18}$ Together, these theories enable an approach that broadens any former thinking about arboreal heritage as merely a passive cultural construct and allows a close reading of heritage tree sites as both "social constructions and as real dynamic material entities". ${ }^{19}$

\section{The Case Studies}

To explore possible ways of rethinking arboreal heritage for the twenty-first century this study has focused on a single indigenous New Zealand tree species - karaka - at three very different locations. The choice of case studies has enabled me to present a broad survey of historical events and of changing relationships of nature and society within a heritage framework. The aim of the specific case studies is not to write a complete history of the cases but to discuss the heritaging of trees through the close reading that case studies methodology makes possible. Each study provides historical background; a chronological account of the case's development as heritage that highlights the political and social influences that have shaped it; and a discussion of the case as contemporary arboreal heritage. The focus of the case studies is not on the trees themselves but on the ways in which they fill the heritage roles required of them and the various shifts that have occurred in these heritage roles over time.

The structure of the cases varies as well. While the Anthropocene Grove and the Dendroglyph Trees are individual, holistic case studies the Cyberforest is an embedded case study that includes three separate tree sites in Te Awanga, Palmerston North and New Plymouth. The inclusion of this three-pronged case has increased the number of tree sites within the cases examined from three to five resulting in a more robust and extensive investigation. ${ }^{20}$ It has also led to potential confusion in terminology between 'cases' and 'tree sites' which requires explanation here. The three 'cases' studied are the Cyberforest, the Anthropocene Grove and the Dendroglyph Trees. 'Tree sites' refers to the Anthropocene Grove and the Dendroglyph Trees along with the Te Awanga, Palmerston North and New Plymouth examples which are sub-units of the Cyberforest case. The term 'sites' was selected as a means of diverting attention away from individual trees and focusing it on the connection between the trees and their 'sites' of tangible and/or intangible heritage. ${ }^{21}$

\footnotetext{
${ }^{18}$ Hawkins, "The Politics of Bottled Water." 188.

${ }^{19}$ Jones and Cloke, Tree Cultures. 3-4.

${ }^{20}$ Yin argues that studying sub-units of an embedded case can add "significant opportunities for extensive analysis, enhancing the insights into the single case”. Robert Yin, Case Study Research: Design and Methods (London: Sage, 1994). 44.

${ }^{21}$ The choice of this term also reflects Nora's notion of "sites of memory" (lieux de mémoire) which expresses the various ways in which heritage is attached to material and non-material sites.
} 


\section{Karaka as a Common Focus}

Ko te kaha - Ko te kaha i te toki

Ko te uaua - Ko te uaua i te pakake

Ko te pakari - ko te pakari i te karaka

Mo te tangata kaha enei whakatauki

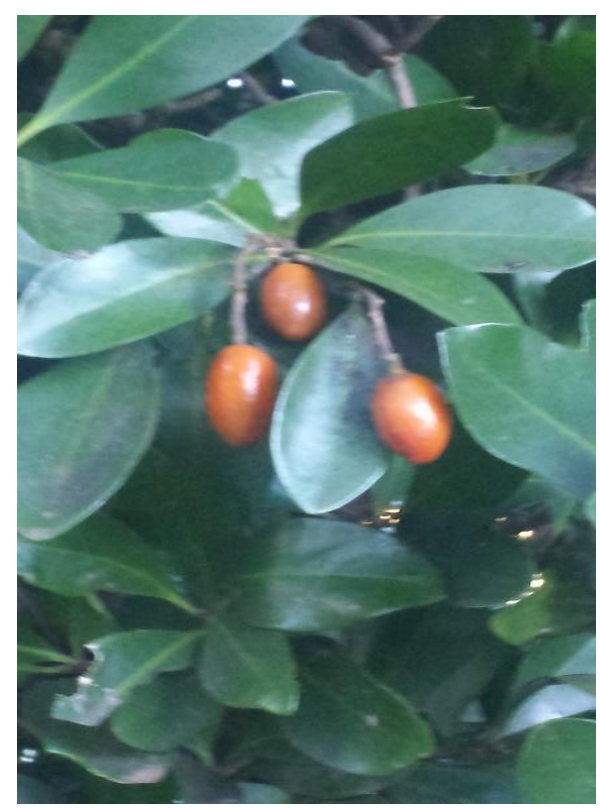

Figure 2: Karaka's distinctive orange drupes and large, glossy leaves. (4 February 2018.)
For strength - strength from the adze For resolution - resolution from the whale For sturdiness - sturdiness from the karaka These sayings concern the resilient man. ${ }^{22}$

Karaka (Corynocarpus laevigatus) ${ }^{23}$ belongs to the family Corynocarpaceae and the genus Corynocarpus which has five species confined to Vanuatu, New Caledonia, New Guinea, Queensland, Australia and New Zealand. ${ }^{24} \mathrm{~A}$ medium-sized tree, it commonly grows to 15 metres tall with a trunk of up to 60 centimetres in diameter and has large, thick and shiny leaves making the trees easily identifiable in indigenous forest and useful as navigational markers. A striking aspect of the tree is the 2.54 centimetre-long, orange-coloured drupes, the flesh of which is edible for humans, as is the poisonous kernel following extensive preparation. They are ingested whole by some birds, notably kererū. ${ }^{25}$

\footnotetext{
${ }^{22}$ Māori whakataukī (proverb) quoted in Elsdon Best, Forest Lore of the Maori: With Methods of Snaring, Trapping, and Preserving Birds and Rats, Uses of Berries, Roots, Fern-root, and Forest Products, with Mythological Notes on Karakia Used etc (Wellington: Te Papa Press, 2005). 48.

${ }^{23}$ Sometimes called 'cow-tree' and 'New Zealand laurel' by nineteenth-century settlers. Referred to as kōpi in Rēkohu Chatham Islands.

${ }^{24}$ John T. Salmon, The Native Trees of New Zealand (Auckland: Reed, 1981). 227. There is, however, some disagreement regarding the number of species and karaka's distribution. Cave and Paddison record only four species, in Yvonne Cave and Valda Paddison, The Gardener's Encyclopaedia of New Zealand Native Plants (Auckland: Godwit, 2003). 196, and Metcalf writes that karaka is found only in New Zealand, Vanuatu and New Caledonia in L. J. Metcalf, The Cultivation of New Zealand Trees and Shrubs (Auckland: Reed, 1991). 104.

${ }^{25}$ Kereru is the only remaining endemic New Zealand bird capable of swallowing the karaka fruit and dispersing the seeds (although some reports indicate tūī have been observed eating the flesh). Kererū are called 'parea' in Rēkohu Chatham Islands.
} 
Karaka is considered to be endemic to New Zealand, although Māori legend suggests that the tree was introduced from legendary Hawaiki. The species is believed to have originated in the northern region of the North Island but was distributed throughout the country by Māori as a winter source of carbohydrates and protein. In addition, the leaves of the species were used for Māori rongoā (medicine) in sealing wounds and treating cuts and grazes. ${ }^{26}$ The tree is frost tender when young and, today, is found often in groves and mainly in coastal areas throughout the North Island and to a lesser extent in the South Island; climate change, however, is expected to increase its range.

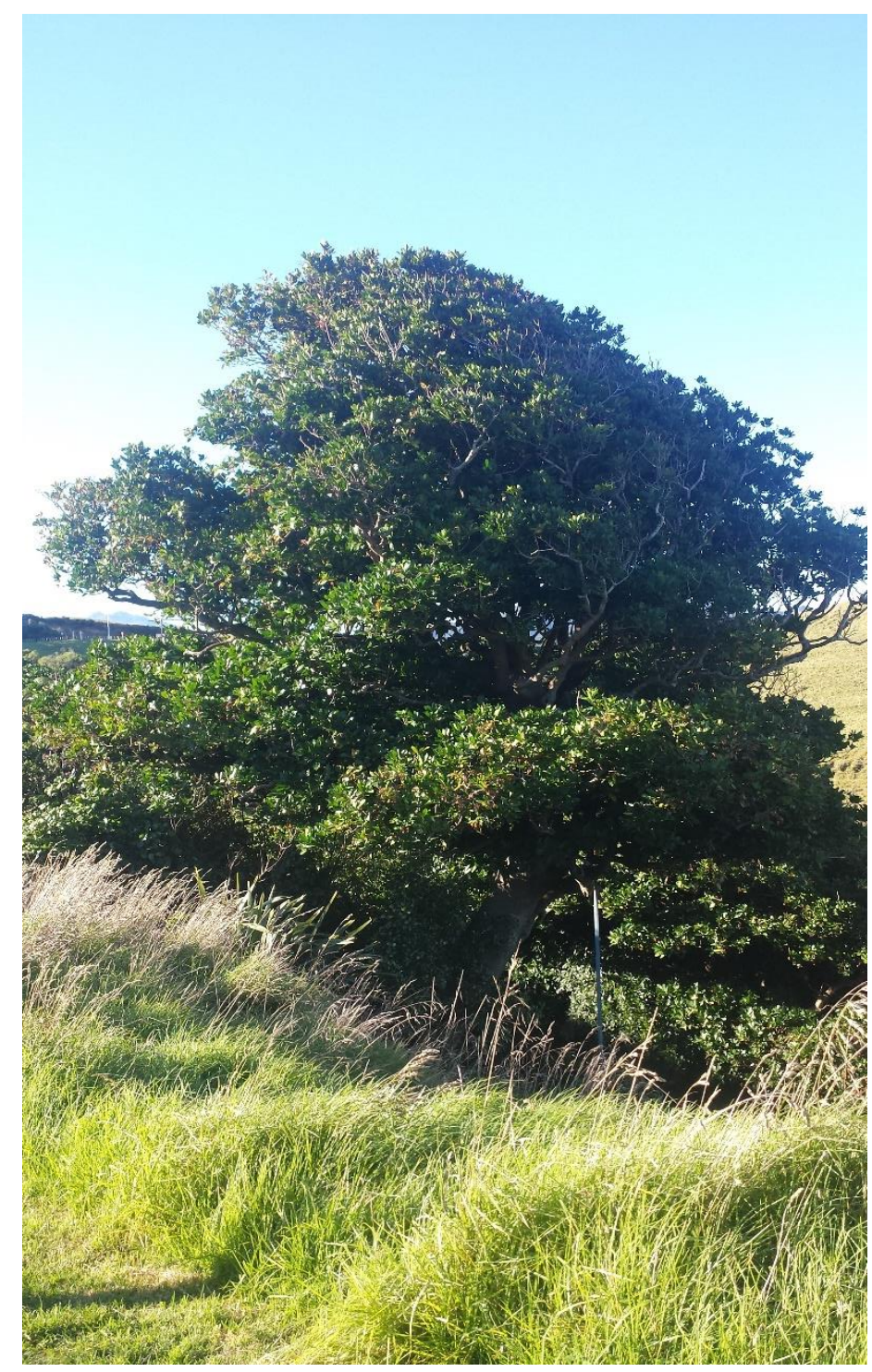

Figure 3: A mature karaka (Corynocarpus laevigatus) growing in the open at Tapuae. (4 February 2018.)

\footnotetext{
${ }^{26}$ P. M. E. Williams, Te Rongoa Maori: Maori Medicine (Auckland: Reed, 1996). 19; Mahinekura Reinfeld, Leonie Pihama, and Naomi Singer, eds., Matarakau: Nga Korero Mo Nga Rongoa O Taranaki: Healing Stories of Taranaki (Taranaki: self-published, 2007). 71; Donna Kerridge, "Rongoa Maori: The Mighty Karaka," http://www.mana.co.nz/heritage/rongoa-maori-the-mighty-karaka.html. Accessed 9 January 2017.
} 
The selection of karaka, for the case study has been made for the following reasons. Karaka has Māori practical (as food, medicine and landmarks) and mythical (ex-Hawaiki and dendroglyphs) significance which gives the study time depth that would otherwise be denied by the choice of an exotic, that is, an introduced species. It is classified as a 'weed' by many domestic gardeners, agriculturists and scientists because of its viability which has been enabled by anthropic intervention (clearing of indigenous forest) and non-human distribution as the food of kererū. Taking the latter uncomplimentary classification and the fact that the Cyberforest contains only three karaka entries out of 1,339 total tree entries,${ }^{27}$ the elevation of the species as the subject of heritage study can be seen to have counter-AAHD undertones and, therefore, is appropriate to the intention of the thesis to rethink arboreal heritage without the constraining values of the AAHD model. The species can also be regarded as an archetypal New Zealand tree in that it is not considered to be iconic ${ }^{28}$ and is, therefore, not bound by well-known symbolism and values, nor is it associated with a 'hot' topic of, what Latour calls "politics of nature". ${ }^{29}$ Karaka has been the subject of recent academic study in a range of disciplines including ethnobotanical research $;{ }^{30}$ botanical research; ${ }^{31}$ and agricultural research ${ }^{32}$ but has not been investigated as a topic of critical heritage studies. Recognition of properties specific to karaka is one domain of arboreal heritage considered in the cross-case analysis in Chapter Five.

\section{Data Providers and Collection}

The empirical research for this thesis includes a range of qualitative methods in order to ensure robust triangulation of data. Each case study draws data from archival, documentary and desktop searches and is supported by interviews and observations. My decisions to follow particular research paths were made on the basis of a priori characteristics identified in the process of my literature review and following initial scoping. My selection of data

\footnotetext{
${ }^{27}$ As at 20 November 2017. To give an idea of the growth of the Cyberforest, the total number of tree registrations on 2 October 2015 was 1224.

${ }^{28}$ Unlike, say, pōhutukawa, kōwhai, tōtara or kauri.

${ }^{29}$ Bruno Latour, "Politics of Nature: East and West Perspectives," Ethics and Global Politics 4, no. 1 (2011). 71.

${ }^{30}$ Helen Leach and Chris Stowe, "Oceanic Arboriculture at the Margins: The Case of the Karaka (Corynocarpus laevigatus) in Aotearoa," The Journal of the Polynesian Society 114, no. 1 (2005).

${ }^{31}$ J. A. Costall et al., "The Endemic Tree Corynocarpus laevigatus (karaka) as a Weedy Invader in Forest Remnants of Southern North Island, New Zealand," New Zealand Journal of Botany 44 (2006).

${ }^{32}$ D. Klinac, R. A. Benton, and S. Rentoul, "Karaka Nuts: A 'New' New Zealand Nutcrop,” (Wellington: Ministry of Agriculture and Fisheries, 2009); David Klinac, "Karaka: A Traditional New Zealand Nutcrop," Indigena (2007).
} 
sources came about through early sampling as a "search for typicality". ${ }^{33}$ While these selections identified some useful key variables other variables remained hidden until the research had begun. ${ }^{34}$ With this in mind I completed considerable research and evaluation before selecting interviewees and carrying out unstructured interviews targeted at specific areas of information. I restricted interviews to small numbers in order to achieve an in-depth study and more textured data on the understanding that quality qualitative research relies on quality interviewing. ${ }^{35}$ Interviewees included heritage practitioners, landscape architects, arboreal specialists, anthropologists and people directly connected to the tree sites studied here. Where possible, interviews were carried out face-to-face and interviewees were briefed by telephone conversation or email message to ensure voluntary participation and informed consent. ${ }^{36}$ Interviews were made up of open-ended questions, recorded in shorthand and transcribed soon afterwards. In order to ensure that I was not directing the research toward my own presuppositions I conducted reflexive research that "reflects upon and questions its own assumptions. Researchers must self-consciously reflect upon what they did, why they did it, and how they did it. The values of the researchers become an explicit part of the research process". ${ }^{37}$ Accordingly, following interviews I re-examined the data in order to draw preliminary conclusions, carried out detailed field work observations of the tree sites and, where appropriate, sought further clarification and/or verification of interview material. Throughout the research I tested ideas on friends and colleagues with the intention of building a data base as broad as possible within my time-frame. Interviewees are listed in the bibliography.

In order to address these areas of inquiry and in line with its interpretivist basis, this study has principally collected qualitative data. Because the multiple-case-study approach calls for the consideration of a mix of archives, documents and interviews, and because qualitative research tends to be a dynamic process, I have used many source providers for data collection and have analysed the data simultaneously. I do not regard this to be a weakness or as lack of direction but as an advantage, in line with Rountree and Laing's advice that the data

\footnotetext{
${ }^{33}$ Malcolm Williams, Making Sense of Social Research (London: Sage, 2003). 74.

${ }^{34}$ Ibid. 84-85.

35 Anne Opie, "Unstructured Interviewing," in Social Science Research in New Zealand: Many Paths to Understanding, ed. Martin Tolich and Carl Davidson (Auckland: Longman, 1999). 225.

${ }^{36}$ Kathryn Rountree and Tricia Laing, Writing by Degrees: A Practical Guide to Writing Theses and Research Papers (Auckland: Longman, 1996). 108.

${ }^{37}$ Martin Tolich and Carl Davidson, Starting Fieldwork: An Introduction to Qualitative Research in New Zealand (Melbourne: Oxford University Press, 1999). 39.
} 
collection process itself assists in progressively focusing the research aims more tightly ${ }^{38}$, and an acknowledgement that my data collection plans might change. This approach has enabled me to set aside, during research, any preconceived notions I might have had about reasons and effects, and to concentrate more fully on results. The research pattern outlined by Tolich and Davidson of (a) data collection; (b) data reduction, i.e. reducing rich data in order to focus further data collection, sampling and methods; (c) data organisation, i.e. collating and categorising; and (d) data interpretation has provided a useful framework for the research. ${ }^{39}$ In order to keep track of this focus-tightening process, I have kept a record of any changes in data collection, sampling and methods, and to keep on top of the organisation of my data and to ensure a clear record of the research process I have maintained a case study database that includes: (a) case study notes, i.e. diary; notes; contacts; observations; analyses, and photographs, and (b) case study documents. I have compiled, during the course of my research, an occasional clippings file of media reports on issues regarding arboreal heritage. This has proved to be much more significant as a research document than originally thought. It ensured that my thinking remained attuned to contemporary issues and contributes to my design of a set of principles for acknowledgement and protection of arboreal heritage which is described in the Conclusion. ${ }^{40}$

\section{Data Analysis}

A widely accepted research method entails early drafting (and re-drafting) of themes and continual filing (and re-filing) of data into theme files as the data collection progresses. ${ }^{41}$ As I am working on a complex multiple case study with many variables, and a variety of interviews and data providers, I have followed this method. One specific piece of analysis that was not anticipated at the beginning of the thesis arose from this research method and became a significant finding. By filing the heritage tree lists relevant to the study and examining them for themes early in the research process I was able to draw a comparison of native and exotic tree entries which are illustrated by Tables 2, 3 and 4 in Chapter Two. This analysis reflects the concerns for native species I record when tracing the earliest discussions

\footnotetext{
${ }^{38}$ Rountree and Laing, Writing by Degrees.

39 Tolich and Davidson, Starting Fieldwork.

40 This idea was taken from an interdisciplinary seminar on the theme "Reinventing Nature" held at the University of California's Humanities Research Institute in 1994 which resulted in the book Uncommon Ground: Rethinking the Human Place in Nature edited by William Cronon.

${ }^{41}$ Tolich and Davidson, Starting Fieldwork; Yin, Case Study Research; Gary D. Bouma, The Research Process (Melbourne: Oxford University Press, 1993).
} 
for tree listing and protection and has led to my discussion of a systematised indigenous arboreal heritage in Chapter Five.

In order to compare the three case studies and establish convergent evidence with which to reach a thesis conclusion I approach them as three separate and whole cases within two discrete groups according to their characteristics of an authorised arboreal heritage discourse (AAHD) (the Cyberforest with its three embedded tree sites) and an unauthorised arboreal heritage discourse (UAHD) (the Anthropocene Grove and the Dendroglyph Trees). To consider their similarities and differences in a cross-case analysis I draw on seven core domains of arboreal heritage which emerge from the data and are reflected in the literature review. The results of this cross-case analysis are summarised in Table 6 in Chapter Five. The cross-case analysis demonstrates that the empirical data both supports and challenges the AAHD/UAHD-logic model. While the Cyberforest tree sites exhibit some of the characteristics of the AAHD, as expected, two of the sites show affiliations to the UAHD. What distinguishes these two is the date of their entrance in the Cyberforest. As this is a thesis that rethinks arboreal heritage for twenty-first-century New Zealand, this temporal difference is a significant finding.

\section{Observation: 'Being There'}

In his collection of essays, talks and articles, Being There, Malouf describes the importance of "attending" to things, that is, "the gathering of all our powers of looking and listening, of recording, understanding, feeling" and "to be present, as when we speak of 'attending' a performance. To give our whole being to an event or object outside us is to be ourselves most fully present, most fully there". ${ }^{2}$ "On the whole, modern living is not very conducive to this sort of activity", he continues, "the size of collections and exhibitions, makes browsing almost inevitable". I have pointed out that trees are ubiquitous in New Zealand and, as a result, tend to be taken for granted and overlooked. In this word-based study on arboreal heritage the tree sites studied have been documented in words and photographs but are not necessarily experienced by the reader. To reflect what it is to 'attend' to these tree sites, to better inform readers of this thesis and to add to my consideration of the materiality of tree heritage, I have provided descriptions entitled, to borrow from Malouf, 'Being There'. I made four trips to visit the least accessible sites-Te Awanga, Palmerston North, the Dendroglyph

\footnotetext{
${ }^{42}$ David Malouf, Being There (Sydney: Random House, 2016). 74.
} 
Trees (twice) - and recorded my own experiences. For the two sites with which I am very familiar, I invited observations from other people - Megan Wraite (the Anthropocene Grove) and Brigitte Hegner (the New Plymouth karaka) — and have included their impressions.

\section{Conclusion: Significance of Thesis}

The occasional clippings file of media reports on issues regarding arboreal heritage which I have compiled during my research has kept me in touch with contemporary attitudes towards tree heritage and associated events as they have occurred. Of particular note have been the adversarial nature of these events, the emotional intensity aroused and the confusion in perceptions of responsibility, all of which strengthened my objective to provide tools for the acknowledgement and protection of tree heritage in New Zealand and have led directly to my design of a set of principles for this purpose.

A typical scenario is the protest that was carried out in West Auckland in March 2015. After spending three days perched in a threatened kauri (Agathis australis), protester Michael Tavares at the Waitakere District Court pleaded guilty to trespassing. ${ }^{43}$ The tree was estimated to be between one hundred and fifty and two hundred years old and was about to be felled, along with an estimated three hundred-year-old rimū (Dacrydium cupressinum), to make way for the construction of two houses in the suburb of Titirangi. Tavares reportedly claimed that his protest had given the trees' community a voice to express the need for their protection which otherwise would have been unheard. However, he added, communities shouldn't have to risk their safety or break the law to protect trees and he called for "better leadership and legislation". His comments, though commendable in their request for better protection of trees, illustrate one of the failings of current attitudes towards arboreal heritage - that trees require rules and official sanction if they are to be valued. Tavares was protecting old trees that had somehow slipped the net of the Auckland Council district plan but would, presumably, have merited a place under the ideology of the AAHD. Writing about the challenges of the concept of wilderness, Cronon points out that, in order to find solutions to environmental dilemmas, we need to abandon the dualism that values one tree (growing in the wild) more highly than another (growing in the garden), and to recognise instead the separate value of both. We are responsible for both, even though we can claim credit for neither, he argues, "our challenge is to stop thinking of such things according to a set of

\footnotetext{
43 "Kauri Protester Calls for Law Change to Save Trees," The Dominion Post, 2 May 2015.
} 
bipolar moral scales in which the human and the nonhuman, the unnatural and the natural, the fallen and the unfallen, serve as our conceptual map for understanding and valuing the world". ${ }^{44}$ Similarly, it would assist our understanding and management of arboreal heritage if we re-considered the dualism that values one tree (noted by AAHD rhetoric in the Cyberforest and/or district plans) more highly than another (not noted in either form of register) and instead recognised that each possesses distinctive values and meanings. This is not to say that registered notable trees should not be protected, nor does it suggest a wholesale moratorium on removing any trees, instead, it promotes a reconsideration of the trees we interact with every day that is not dependent on official sanctions but encourages our own informed understanding of them and awareness and respect for our co-evolution. This thesis, through its case study examination of the process of arboreal heritage encourages this new evaluation as a 'counter-' approach. Chapters Two, Three and Four adopt and apply Hitchings' definition of ANT, not as a theory but as a "general attitude". Accordingly, the three case studies document the historical backgrounds of the cases and the interactions of "people, objects, plants, animals and ideas" and present new ideas concerning tree heritage in New Zealand.

The protection of trees valued by their communities is a complex issue thick with misunderstandings and different viewpoints and values, and news media frequently report infringements of district council rules and conflicts between communities and developers. This thesis does not deal with the topics of leadership and legislation, as advocated by Tavares, but, instead, introduces new ways of thinking about arboreal heritage that are not bound by the ideals of the AAHD but are grounded in an understanding of the cultural and social values and meanings we all attach to trees. In a country that prizes its natural capital, promotes it as a draw-card for tourism and, therefore, profits from its economic contribution, and at a time when we face a global environmental crisis, New Zealand's arboreal heritage should not be regarded as a marginalised sub-field but as a significant topic for research. This discussion of the process that has led to the current values and meanings attached to arboreal heritage aims to bring about a better contemporary understanding and serious consideration of the significance of trees to twenty-first-century heritage management and practice. Critical heritage studies is an applied discipline and this thesis advances towards a set of principles at its conclusion which is intended to be a guide designed for heritage in practice.

\footnotetext{
${ }^{44}$ Cronon, "The Trouble with Wilderness." 49.
} 


\section{CHAPTER TWO: THE CYBERFOREST: HERITAGE TREES}

\section{Introduction}

Opening the Dominion Conference on Bush Preservation and Amenity Tree Planting at Parliament on 2 April 1937, the Governor-General, Lord Galway, reportedly told delegates that one of its main objects was to develop a "'tree sense' in the people from one end of the country to the other". ${ }^{1}$ Planting roadsides, "beautifying" the landscape and restoring "as far as possible the one-time forest beauty of the country by preserving the existing native trees and by replanting others when the opportunity offers" were national concerns, he said. ${ }^{2} \mathrm{He}$ urged property owners to plant their own roadside verges and to observe Arbor Day and added that, while native trees should be the first choice, "the trees of the Old World" might "gladden the eye" in districts more suited to them, and belts of "centenary trees" with nameplates recording the names of the benefactors would be "fine monuments" and "objects of beauty" 3

This case study is in four sections. Following this introduction, the second section (Growing A Tree Sense) describes these and other early events that led towards the establishment of the New Zealand Tree Register (the Register) and its digital form (launched on 19 November 2009 and referred to here as the Cyberforest). It describes the influence of Minister of Internal Affairs, Bill Parry, and Undersecretary, Joe Heenan, who, as Minister in Charge of Centennial Celebrations and chief executive officer and mastermind of the events respectively, encouraged the development of a New Zealand "tree sense" and had significant input into the tree-listing process. It documents the work of Harry Allan in compiling the seminal heritage lists on behalf of the RNZIH ${ }^{4}$ and Bob Burstall's unpublished forest mensuration reports, ${ }^{5}$ Burstall and Edmund Sale's book Great Trees of New Zealand ${ }^{6}$ and Ron Flook's comprehensive list of notable trees in New Zealand ${ }^{7}$ all of which influenced the evolution of the Register and, consequently, the Cyberforest. The second section also

\footnotetext{
1 “Conserving Native Bush: Policy for Future, Important Conference,” Evening Post, 2 April 1937.

2 Ibid.

3 Ibid.

${ }^{4}$ H. H. Allan, "Historic Trees in New Zealand: Consolidated List from Journals of Royal N.Z. Institute of Horticulture June and September, 1940, June 1941," in MS-Papers-1132-286 “J. W. A. Heenan Collection: Trees" (Alexander Turnbull Library, 1943).

${ }^{5}$ S. W. Burstall, "Historic and Notable Trees of New Zealand: Reports 16, 17, 18, 18 (Revised), 19, 20, 21, 22, 23," (Rotorua: New Zealand Forest Service, Forest Research Institute 1970-74 [unpublished]).

${ }^{6}$ S. W. Burstall and E. V. Sale, Great Trees of New Zealand (Wellington: A. H. \& A. W. Reed in association with the New Zealand Forest Service, 1984).

${ }^{7}$ Ron Flook, An Introduction to the Notable Trees of New Zealand (Nelson: Copy Press, 1994).
} 
explains the development of the points-based standard tree evaluation system (STEM) designed by Flook which has played an important role in determining the content of New Zealand's tree lists.

The third section of this case study (The Cyberforest as a Place of Heritage Trees) examines the contemporary heritage tree list with regard to the nomination, selection and evaluation of tree entries and includes profiles of the Cyberforest's three karaka entries and accounts of observations or 'Being There'. These three entries are considered also in relation to their positions within their respective local authorities' heritage tree lists in order to position the Cyberforest within a broad context of contemporary arboreal heritage practice. The political activity in the 1970s and 1980s, designed to encourage legislation that recognised and protected heritage trees, is described in the second section of the case study and connected in the third section to the 1991 RMA and its influence on the change in focus of the Register from protection to collection. In order to gain a more complete understanding of tree lists as sites of arboreal heritage, the entries documented by the twentieth-century lists, the Cyberforest and the three relevant local authorities are reordered according to their numbers of native and exotic trees, and this material is presented in graph form.

The case study concludes (Conclusion: The Hegemony of the List) with a summary of commonly held misconceptions about arboreal heritage listing and introduces the Cyberforest as a flagship of the AAHD.

\section{Growing a Tree Sense}

The 1937 conference, referred to above, was prompted by Galway who had appealed to the government as part of his own campaign to plant more trees throughout the country. The previous year, he had established a cup to be presented to the local authority that planted "the best and most artistic mile of highway". ${ }^{8}$ His call to council action did not go unheeded. The Wairewa County Council, for example, budgeted $£ 200$ for roadside exotic tree planting or bush preservation to mark the centennial, ${ }^{9}$ and Hāwera's mayor, J. E. Campbell, planned a three-mile roadside avenue of trees between Hāwera and Normanby. ${ }^{10}$ The centennial to be

\footnotetext{
8 “Centenary Trees, Lord Galway's Suggestion," Evening Post, 4 August 1936.

9 "Centennial Trees: Few Natives Suitable for Avenues," Akaroa Mail and Banks Peninsula Advertiser, 17 November 1939.

10 “Avenue of Trees: Plan for Hawera," Evening Post, 3 May 1938.
} 
celebrated was the upcoming commemoration of the 1840 Treaty of Waitangi for which planning had begun in 1935, and the monuments Galway was advocating were trees planted as lasting reminders of the event.

Parry ${ }^{11}$ had called the Bush Preservation and Amenity Tree-Planting conference in an attempt to establish a national policy for the protection of the country's native forest. ${ }^{12}$ Members of interest groups and government departments ${ }^{13}$ and individuals were invited including not only promoters of scenery preservation and beautification but also saw-millers and forest company officials, and the Minister of Lands and Commissioner of State Forests, Frank Langstone. While differing widely in their particular objects they all nevertheless laboured towards the same generally admirable end, Parry reportedly said, but despite the good work a "more or less losing battle had been waged". ${ }^{14}$ Parry's interpretation of the "tree sense" required of New Zealanders was more prosaic than Galway's. What end would be achieved by the planting of trees along roadsides, in parks and odd corners, if at the same time people were careless of their God-given heritage? he asked the delegates.

Every summer ... we see whole hill-sides devastated of their beauties through carelessly-thrown matches or cigarette butts: all the year through we see further lands denuded of their natural covering, while lands already cleared and available for use are allowed to run riot with weeds of every description and put to no practical use whatever-land, moreover, of much greater value for agricultural and pastoral purposes than that which in many cases we are now clearing. ${ }^{15}$

First, Parry instructed, the public needed to be educated to put an end to the reproach that "every New Zealander was born with an axe and a fire-stick in his hands". ${ }^{16}$ Second, the

\footnotetext{
${ }^{11}$ Australian-born William (Bill) Edward Parry (1878-1952) was a socialist and one of the founders of the New Zealand Federation of Labour. He joined the New Zealand Labour Party when it was established in 1916, was a close personal friend and political ally of Michael Joseph Savage and joined Savage's government as Minister of Internal Affairs from 1935 until 1949. Gustafson describes him as an administrator rather than an innovative policy maker who relied heavily on his Permanent Undersecretary Joseph Heenan. Barry Gustafson, "Parry, William Edward," Te Ara-the Encyclopedia of New Zealand, http://www.teara.govt.nz/en/biographies/3p12/parry-william-edward. Accessed 17 November 2015.

${ }^{12}$ For a detailed historical account of initiatives to conserve New Zealand's flora, fauna and scenery see Paul Star and Lynne Lochhead, "Children of the Burnt Bush: New Zealanders and the Indigenous Remnant, 18801930," in Making a New Land: Environmental Histories of New Zealand, ed. Eric Pawson and Tom Brooking (Dunedin: Otago University Press, 2013).

${ }^{13}$ These included representatives of the lands, forestry, agricultural, education, railways and post and telegraph departments.

14 “Conserving Native Bush,” Evening Post, 2 April 1937.

15 Ibid.

${ }^{16}$ Ibid. A 'fire-stick' is a burning torch used to light bush and scrub in land clearing. Dianne Bardsley, In the Paddock and on the Run (Dunedin: Otago University Press, 2009) 37. Parry's remark is echoed by the statistic quoted almost eighty years later by Dr Nikolas Stihl, chairman of the global Stihl handheld power equipment company, that New Zealand "racks up more chainsaw sales per capita - both professional and consumer-than
} 
various organisations should be co-ordinated under a national body with a uniform policy and local branches and committees to implement it. Their country, he informed his audience, was suffering from serious floods with economic consequences. Many hillsides, which once carried native bush had "slipped away in a night, ruining thousands of acres of rich land and causing river erosion, terrible to think of in the cost to the country of the damage done. In that sphere of activity alone this conference can help". ${ }^{17}$ Some New Zealanders, despairing of what had gone on for many years, he continued, advocated that absolutely no more native trees should be cut down: others supported cutting native trees and replacing them with quicker-growing exotics. Parry's solution fell between the two extremes and included further cutting of native timber alongside the preservation in perpetuity of selected forest remnants. He called for tolerance on the "vexed question" of natives versus exotics, citing the ready availability of land as a reason for planting exotics - and in particular Australian gums - and asked for private contributions that might supplement the Government purse. $^{18}$

General conference discussion covered the future of existing areas of bush, amenity planting in general, the future of Arbor Day and the powers of local authorities and public bodies both with respect to planting and the welfare of trees. ${ }^{19}$ The delegates agreed that the government should set up an interim committee that would request the views of the various bodies represented, collate the information, and recommend a constitution for adoption by a national organisation that would coordinate the work of interested groups and carry out "much-needed propaganda and educative work". ${ }^{20}$ The members of the, then, NZIH needed no encouragement to demonstrate their own brand of 'tree sense'. They had already been active in the long battle to save the kauri of Waipoua Forest, ${ }^{21}$ had rigorously urged the government to preserve native forests and had a Ministry of Internal Affairs-funded bulletin under way promoting "roadside beautification". ${ }^{22}$ The NZIH's two remits to the conference had urged

\footnotetext{
anywhere else in the world". Nick Grant, "Stihl's Global Boss Calls 'Bullshit' on Govt's Climate Change Response," The National Business Review, 26 February 2016.

17 “Conserving Native Bush,” Evening Post, 2 April 1937.

${ }_{18}$ In 1937, the Lands Department and the Tourist Department held a total 3,980,700 acres in public reserves. The New Zealand State Forest Service was responsible for 4,202,000 acres in permanent State forests and $3,753,000$ acres of provisional State forests.

${ }^{19}$ Appendix to the Journal of the House of Representatives, 1938, H-22, p.4.

${ }^{20}$ Ibid.

${ }^{21}$ The Waipoua Forest in Northland contains the largest remaining stand of kauri and two of the largest of these living trees-Tāne Mahuta and Te Matua Ngahere. The forest became an officially designated sanctuary in 1952.

${ }^{22}$ M. R. Skipworth, "Roadside Beautification in New Zealand," ed. Royal New Zealand Institute of Horticulture (1939).
} 
celebratory plantings of trees along main highways, in anticipation of the coronation of King George III and Queen Elizabeth and the "retention of native bush where possible". ${ }^{23}$ In January 1938, when nothing official was forthcoming as a result of the previous year's conference, the NZIH determined to approach the government "with a view to preserving the trees planted by our pioneers, or other historic trees" 24 and accepted a request from the Lands Department to prepare a preliminary list of historic trees. ${ }^{25}$ An earlier remit, which had been considered at the NZIH's 1938 annual conference, had been forwarded by the Canterbury District Council and stated that, "the Government be approached with a view to preserving the trees planted by our pioneers on estates throughout the Dominion". ${ }^{26}$ As the NZIH's honorary botanist, Allan ${ }^{27}$ was given the job of compiling the draft. ${ }^{28}$ In February 1939, in his presidential address to the NZIH's annual meeting and conference in New Plymouth, F. S. Pope reported that "governmental action in pursuance of the opinions ventilated at the enthusiastic conference held in April, 1937" had still not materialised. 29 "Perhaps it has become evident that the Dominion-wide organisation then envisaged went beyond the practical requirements of the situation", Pope suggested. ${ }^{30}$ Allan, issued a circular throughout the country requesting local information on "historic native trees as well as trees planted by pioneers or those having some special point of interest" to add to a list of trees that "should be preserved", and newspapers took up the cause by requesting nominations. ${ }^{31}$

\footnotetext{
${ }^{23}$ Approximately three hundred coronation commemorative plantings, ranging from a single tree to extensive shrubberies and avenues, including by schools which predominantly planted kauri, tōtara, rimū and oaks, were recorded by the Department of Internal Affairs which noted in its annual report: "The popularity of this method of commemoration on this occasion must result in enhanced beauty of the localities so treated, and augurs well for Centennial memorial plantings in 1940". Appendix to the Journal of the House of Representatives, 1938, H22, p.3.

${ }^{24}$ H. H. Allan, "Historic Trees in New Zealand," Journal of the Royal New Zealand Institute of Horticulture 10, no. 1 (1940). 19.

${ }^{25}$ The government had earlier shown interest in the topic when the Lands Department asked the Christchurch Domains Board for a list of its historic trees and others on which it had information. "Preserving Old Trees," The Press, 28 January 1938.

26 "Remit no, 8," Minutes of the Fifteenth Annual Meeting of the New Zealand Institute of Horticulture, (1938).

${ }^{27}$ Harry Howard Barton Allan (1882-1957) was a teacher, writer and scientist who, following the death of Leonard Cockayne in 1934, was recognised as New Zealand's foremost botanist. He was head of the Botany Section (later Division) of the Department of Scientific and Industrial Research from 1936 until 1948 and was made a CBE for his services. He was President of the Royal Society of New Zealand 1943-1946 and received an honorary PhD and an MA from Uppsala University, Sweden in 1957. His work on native plants was completed and published posthumously in 1961 as the first volume of Flora of New Zealand. Galbreath describes him as a "painstaking, shy and modest man". Ross Galbreath, "Allan, Harry Howard Barton," Te Ara - the Encyclopedia of New Zealand, http://www.teara.govt.nz/en/biographies/5a5/allan-harry-howardbarton. Accessed 17 November 2015.

${ }^{28}$ M. J. O'Sullivan, History of the Royal New Zealand Institute of Horticulture (Royal New Zealand Institute of Horticulture, 1952). 97.

${ }^{29}$ F. S. Pope, "President's Address," (Royal New Zealand Institute of Horticulture, 1939).

${ }^{30}$ Ibid.

${ }^{31}$ James Cowan, "Trees of History and Beauty: An Effort to Preserve Them,” Christchurch Star Sun, 11 November 1939.
} 
In November, 1939, Allan forwarded the first tree list to the, now, RNZIH executive. Aware that the Commissioner of State Forests also had a tree list under way, Captain Ernest Valentine (Val) Sanderson, president of the Forest and Bird Protection Society of New Zealand, ${ }^{32}$ asked the executive to amalgamate the two lists and, seizing the opportunity, requested that "all natural monuments of an ethnological, geological or biological nature" be included. ${ }^{33}$ The Forest and Bird Protection Society hoped the movement towards the listing and preservation of historic trees would follow the example of Britain's expansive National Trust for Places of Historic Interest or Natural Beauty ${ }^{34}$ and protect historic landmarks as well. The RNZIH agreed to the amalgamation with the proviso that the institute retain the right of first publication of the final list of historic trees and published its first list of 122 historic trees in its Journal in June 1940. Allan, who was now both the institute's honorary botanist and editor of the Journal of the Royal New Zealand Institute of Horticulture, described it as "a preliminary contribution": 35

It is not suggested that the list is anywhere near complete, or that all the trees mentioned are of equal importance. Some of them are already well guarded. It is hoped, however, that interest will be still further aroused, and that further information will be forwarded to the Institute as a result. It will then be possible to provide a reasoned statement for the consideration of the Government Departments concerned, with a view to effecting concerted action. The wider field of activities urged by the Forest and Bird Protection Society is deserving of full support by the people of the Dominion, and the preservation of important historic trees will be one definite step forward. We may well learn from the Maori, and instil into ourselves something of his spirit of Tapu. ${ }^{36}$

\footnotetext{
${ }^{32}$ Sanderson had been the driving force behind the 1923 establishment of the New Zealand Native Bird Protection Society which was renamed the Forest and Bird Protection Society of New Zealand in 1935 and is now known as the Royal Forest and Bird Protection Society. He was president of the society from 1933 to his death in 1945. Ross Galbreath, "Sanderson, Ernest Valentine," Te Ara-the Encyclopedia of New Zealand, http://www.teara.govt.nz/en/biographies/4s4/sanderson-ernest-valentine. Accessed 17 November 2015.

${ }^{33}$ Quoted in Allan, "Historic Trees in New Zealand." 19.

${ }^{34}$ Now known as the National Trust.

35 Allan, "Historic Trees in New Zealand." 19.

${ }^{36}$ Ibid. 19-20.
} 


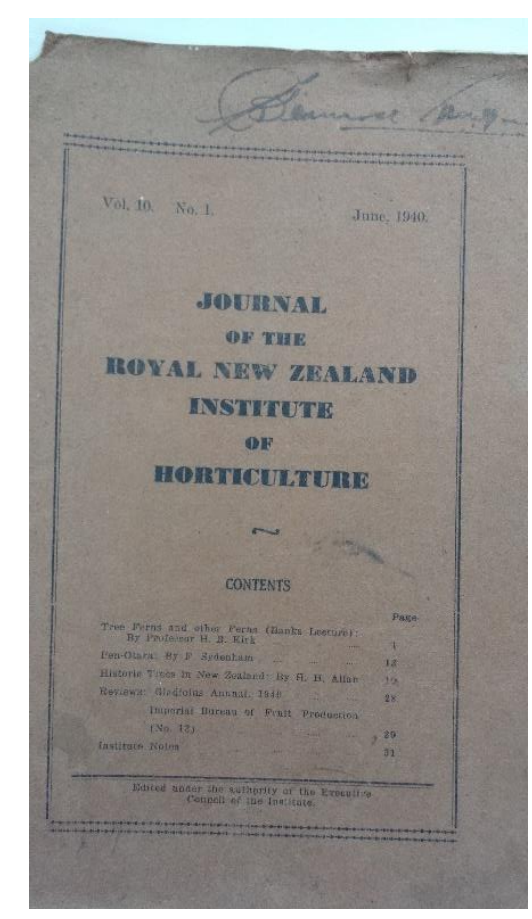

Figure 4: RNZIH's June 1940

Journal that published the first list of 122 historic trees.
This first list is divided into geographical sections setting a precedent for the various lists which followed. ${ }^{37}$ The sections list varying numbers of trees and several entries include more than one tree, for example, "Trees planted by Sir George Grey on Kawau Island". The sections and numbers of entries are: Auckland (36 entries); Bay of Plenty (9); Poverty Bay (2); Hawke's Bay (3); Taranaki (3); Wanganui (14); Wellington (10); Nelson (6); Marlborough (11); Canterbury (20) and Otago, Southland, Fiord District (8). The list records seventy-four exotic species, forty-six native species and two unknown but presumably exotic species $^{38}$ documented in a mix of common, botanical and Māori names.

The trees are variously and multiply noted for their age (62); association with particular people (47); size (35); association with Māori (21); botanical features (8); association with an event (19), group numbers (37). ${ }^{39}$ Not all of the selected trees, however, were in such good health at the time. A kahikatea (Dacrycarpus dacrydioides) near the railway station in Otorohanga, Allan notes, was "lopped some years ago but recovering well", and he lists the tree stumps at Dusky Sound "stated to be remains of trees cut down by Captain Cook". The list is cautious with some provenances noting (my italics) that the pōhutukawa at Taranui Bay "is said to have been used by the Maoris as a place to hang the heads of their human victims" and that "one of the original Maori canoes is alleged to have landed near this tree," but confidently records that the pōhutukawa on both Kawau Island and at Otamatea mark the “scene of cannibal feasts". Wellington's Dominion newspaper reported on Allan's list giving space to the local trees included and providing an overview of the "other notable trees" under the dramatic sub-headings "Shaded Cannibal Picnics" and "Homesick Missionaries," and

\footnotetext{
${ }^{37}$ Allan divided his list into eleven geographical areas; Burstall's forest mensuration lists are in eight geographical areas; Burstall and Sale's 'Notable Trees' section in Great Trees of New Zealand is divided into ten geographical areas; Flook's An Introduction to the Notable Trees of New Zealand is in fifteen geographical areas; and the online New Zealand Tree Register lists entries under nineteen geographical regions.

${ }^{38}$ Although not specified "Trees planted by Sir George Grey on Kawau Island" and "Trees at Appleby where Sir Donald McLean and the Archbishop Redwood family settled in the early days" are thought to probably refer to exotics.

${ }^{39}$ The number of trees in groups, which are noted in individual entries, varies from two to 122 .
} 
preceded a flurry of articles in other newspapers discussing the local need to preserve historic trees. ${ }^{40}$

A month after the Journal was published, Heenan, ${ }^{41}$ in his capacity as undersecretary, congratulated Allan and offered to lend him his personal file of newspaper clippings concerning historic trees. He was very interested in the matter of historic trees, he informed Allan, and had been responsible for the Lands Department's original approach to the NZIH to compile a list. He took the opportunity to inform Allan that one of Nelson's oak trees (number 78 on Allan's list) had been felled recently and since the list was compiled, and enclosed an article from the Nelson Mail reporting the event, remarking, "With all our propaganda and education, which I am happy to say is showing signs of results, there are still local authorities, and individuals as well, whose main object in life seems to be to cut trees down". ${ }^{42}$ He hoped that sometime in the not too distant future "it may be possible to publish a handsome illustrated volume of the more historically important and beautiful trees in the Dominion, and when that time comes, I shall be happy to recommend my Minister to help financially from this Department". ${ }^{3}$

Heenan was not the only member of the Department of Internal Affairs who was keen on historic trees. Parry, apparently unaware of Heenan's earlier letter to Allan, wrote in a memorandum to his undersecretary two days later:

The question raised in the article attached, regarding the protection of notable trees in the Dominion is deserving of full support ... mention might be made of a giant old man pohutukawa which for years has graced the beach at Waiheke ... its history and characteristics should certainly be on record and listed for protection. ${ }^{44}$

\footnotetext{
40 "Historic Trees: Preservation Sought by Horticulturists: Silent Witnesses of Past Events," The Dominion, 23 July 1940.

${ }^{41}$ Joseph (Joe) William Allan Heenan (1888-1951) was born at Greymouth, educated in Wellington, joined the Colonial Secretary's Office (later the Department of Internal Affairs) in 1906, graduated LLB at Victoria College in 1917, transferred to the Office of Law Drafting in 1920 and returned to Internal Affairs as Undersecretary and Clerk of the Writs in 1935 where he served until 1949. He is recognised as a gifted administrator, he was made CBE in 1937 and was knighted in 1949. He was passionate about sport and literature and considered his role as chief executive officer of the New Zealand centennial celebrations and his conception of the centennial publications to be the highlight of his career. Rachel Barrowman, "Heenan, Joseph William Allan," Te Ara-the Encyclopedia of New Zealand, https://teara.govt.nz/en/biographies/4h24/heenanjoseph-william-allan. Accessed 25 March 2016. E. H. McCormick first regarded Heenan as a "vulgarian" but changed his mind when they got down to the business of producing the pictorial surveys. Dennis McEldowney, ed. An Absurd Ambition: Autobiographical Writings: E. H. McCormick (Auckland: Auckland University Press, 1996). 134.

${ }^{42}$ Heenan to Allan, 23 July 1940, Heritage New Zealand General-Trees 22004-001 vol. 2.

${ }^{43}$ Ibid.

${ }^{44}$ Parry to Heenan, 25 July 1940, Heritage New Zealand General-Trees 22004-001 vol. 2.
} 
Allan replied enthusiastically to Heenan assuring him that he would do his best to secure data and illustrations to contribute to the proposed volume. ${ }^{45}$ The next day, Heenan wrote to Allan enclosing Parry's memorandum and describing a "magnificent" pōhutukawa planted —at Heenan's suggestion - at Eastbourne, Wellington on Arbor Day 14 July 1915 as a memorial to the Allies' Gallipoli landing of 25 April the same year and claimed as the "first ANZAC memorial anywhere in the world". 46

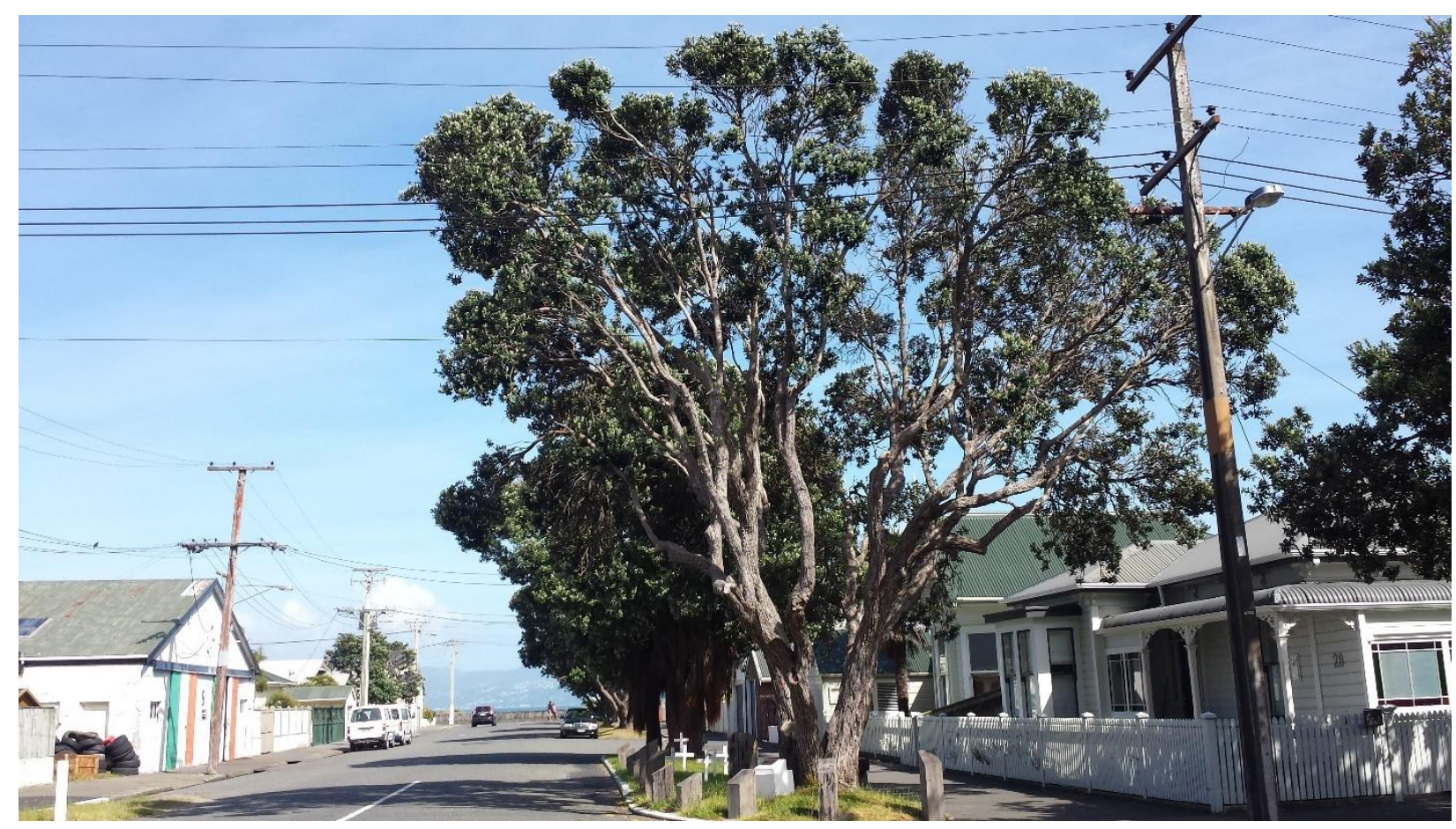

Figure 5: Pōhutukawa ANZAC memorial, Eastbourne. (29 November 2015.)

Heenan added, in confidence, that he believed electric power boards were the "champion vandals of the whole country" who deliberately took powerlines over trees in order to find an excuse to chop the trees down. He followed up during the next two months by sending Allan two collections of newspaper cuttings relating to historic trees, and, in September, Allan published another list in the RNZIH's Journal noting the demise of the previously listed oak in Nelson and including Parry and Heenan's pōhutukawa of Waiheke Island and Eastbourne in the list of twenty-nine additional trees. The new entries expand six of the geographical sections from the earlier list: Auckland (3); Bay of Plenty (1); Poverty Bay (2); Taranaki (11); Wellington (4) and Nelson (8). Once again, they are a mix of exotic species (20) and native species (9) and are noted variously and multiply for their exceptional age (18); their

\footnotetext{
45 Allan to Heenan, 29 July 1940, Heritage New Zealand General-Trees 22004-001 vol. 2.

${ }^{46}$ Heenan to Allan, 30 July 1940, Heritage New Zealand General-Trees 22004-001 vol. 2. Heenan and his family lived in Eastbourne.
} 
association with particular people (21) (two of these are kauri noted as being planted by Heenan also in Eastbourne as memorials); their size (12); association with Māori (1); botanical features (6); association with an event (5) and/or their number (5).

\section{The Ironies of the 1940 Centennial}

At the time that Allan began gathering information for his task New Zealand was emerging from the Depression, facing the prospect of war and preparing for its 1940 centennial. ${ }^{47}$ As this thesis examines the values New Zealanders attach to their arboreal heritage, close reading of the centennial celebrations and publications, with this context in mind, provides a historical background to the Cyberforest's evolution. ${ }^{48}$ Phillips points out that rather than a celebration of the signing of the Treaty of Waitangi one hundred years earlier, as might be expected given the date, the centennial, unofficially and predominantly became a "tribute to the noble pioneers". ${ }^{49}$ Centennial processions, of which there were many throughout the country often in conjunction with Agricultural and Pastoral Association shows, routinely led with bullock drays, axes and pit saws and concluded with parades of cars and tractors: the pioneer spirit in contradiction with the celebration of material progress. ${ }^{50}$ Viewed through the lenses of native bush preservation, as advocated by Parry in 1937, and the listing of notable trees, as undertaken by Allan, the parades of tree-felling implements take on more potent meaning. They are the villains of the piece, though revered in the context of pageantry. Their part in denuding the land, causing erosion, slips and floods, had contributed to the "terrible" economic consequences Parry had described to the 1937 conference delegates. The material progress and technological advancements in communications, railways, farming and industry

\footnotetext{
${ }^{47}$ Heenan chose the term 'centennial' as he believed the double ' $\mathrm{n}$ ' would avoid the many possible pronunciations of 'centenary,' "a very euphonious word”. New Zealand Centennial News, no.1 (1938). 5. ${ }^{48}$ Despite the war, most of the major centennial events took place, partly because the values they represented were seen, at least by the organisers, to be even more relevant in wartime. In the October-November issue of the New Zealand Centennial News, when war threatened to dampen the celebrations, Parry invoked the WWI principle of 'carry on' to encourage New Zealanders to proceed with their commemorative plans. It was a spirit worthy of the pioneers, he instructed, and any unreasonable slackening of effort by centennial organisations would induce regrets and reproaches.

${ }^{49}$ Jock Phillips, "Afterword: Reading the 1940 Centennial," in Creating a National Spirit: Celebrating New Zealand's Centennial, ed. Bill Renwick (Wellington: Victoria University Press, 2004). 276. The official Government view was that the centennial was "the observance of the one-hundredth anniversary of organized settlement and government in New Zealand". "Summary of Centennial Organization," New Zealand Centennial News, no. 1 (1938). 2.

${ }^{50}$ Phillips describes this as a "whiggish view of settlers conquering a "virgin' land with hard work and modern technology", Phillips, "Afterword.” 277. Barrowman argues that the centennial was fraught with further "ambivalence: between national assertion and colonial deference; between nationalism and internationalism". Rachel Barrowman, "History and Romance: The Making of the Centennial Historical Surveys," in Creating a National Spirit: Celebrating New Zealand's Centennial, ed. Bill Renwick (Wellington: Victoria University Press, 2004). 164.
} 
which were extolled by the centennial film A Hundred Crowded Years were largely achieved at the expense of New Zealand's trees.

Underlying the major contradiction between the values of pioneer spirit and progress is another vividly illustrated contradiction between the values associated with progress and those of environmentalism and aesthetics that New Zealanders ascribed to their trees. While the more than 37,000 lights that lit the Centennial Exhibition buildings at Rongotai in Wellington might have shone a beacon on New Zealand's achievement of domestic comfort courtesy of electricity, at the same time and with another perspective, they represented the ongoing struggle the RNZIH was having with electric power boards and their "unaesthetic onslaughts" $" 51$ on trees throughout the country as they installed posts and lines. Other similar objections to the rampant march of development had been made by the NZIH to the government in 1934 regarding the destruction of native bush to make way for roads, railways and highways, and in 1937 to the Director General of the Post and Telegraph Department regarding the removal of trees on the main highway near Waitara. The progress enjoyed by the 1930s and celebrated at the 1940 centennial, had been anathema to the good health of New Zealand's native forests.

Further reading of the centennial celebrations through the lens of arboreal heritage reveals other ironies. The centennial promoted the country's forested beauty as a tourist attraction and highlighted native trees as a focus of national pride and identity. The one-shilling centennial stamp, designed by Leonard Mitchell, was titled “A Giant Kauri” and featured Tāne Mahuta rising majestically out of Waipoua forest, however, the four-penny stamp, designed by James Berry, was titled "The Progress of Transport" and showed bullock carts passing on a rough track carved from the forest, and ships, a train and an aeroplane. ${ }^{52}$ No emblem more fitting to symbolise New Zealand's history could be found than this giant

\footnotetext{
${ }^{51}$ O'Sullivan, History of the Royal New Zealand Institute of Horticulture. 90.

${ }^{52}$ Selected artists were invited to submit drawings for designs of the centennial stamps to illustrate subjects indicating New Zealand's industrial and historic development as perceived by the National Centennial Historic Committee. Wellingtonians Mitchell and Berry were successful and, between them, designed all thirteen stamps. The other centennial stamps illustrated: the landing of Māori in New Zealand (halfpenny); Captain James Cook, his map and the Endeavour (one penny); British sovereigns of New Zealand (one and a half pence); Abel Tasman, the Heemskerck and his map (twopence); the signing of the Treaty of Waitangi (two and a half pence); settlers landing at Petone Beach in 1840 (threepence); hoisting of the Union Jack at Akaroa (fivepence); the Dunedin's shipment of frozen mutton (sixpence); the Māori Council (sevenpence); the Māori Council reissued in March 1940 when postal rates were changed (eightpence) and gold mining (ninepence). https://stamps.nzpost.co.nz/new-zealand/1940/centennial-officials. Accessed 5 February 2018.
} 


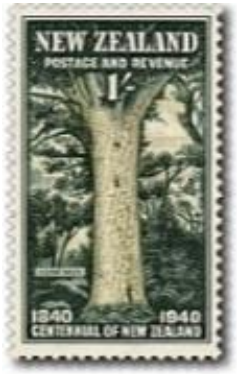

Figure 6: " $A$ Giant Kauri" one-shilling centennial stamp.

kauri, the Centennial News informed its readers, "It has witnessed the development of New Zealand, a modern Dominion of the British Empire, from a land unknown; it has seen bush and swamp turned to rich pasture; it has looked unmoving on the trials and triumphs of a young country elevating itself to nationhood". ${ }^{53}$ If it had been able to speak, Tāne Mahuta might have had something different to say. At the time, public and political, pressure to preserve the Waipoua kauri, halt pine planting in the area and designate some of Northland's remaining kauri forest as a national park was gathering strength. Tāne Mahuta "and other giant kauris in Waipoua State Forest" were number one on Allan's list. ${ }^{54}$ As New Zealanders seized the opportunity of the centennial to closely examine their history and identity their understanding of the history and identity of their trees emerged as a very mixed bag indeed.

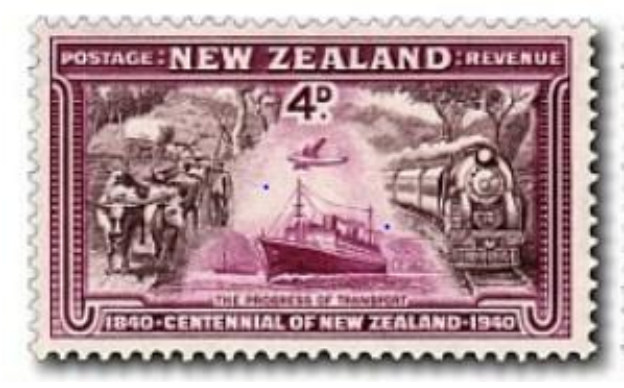

Figure 7: "The Progress of Transport" four-penny centennial stamp.
Given Parry's passionate plea to the 1937 conference to preserve New Zealand's bush, and both his and Heenan's encouragement of Allan to produce his list of historic trees, it is reasonable to assume that the two men might have been conscious of the ironies inherent in the events described above. There were, however, other centennial opportunities to bury the axe and firestick and nurture a tree sense in New Zealanders. ${ }^{55}$

Most notable in this regard were two of the commemorative publications - the highly illustrated Making New Zealand: Pictorial Surveys of a Century and the Department of Internal Affairs' newsletter New Zealand Centennial News. ${ }^{56}$

\footnotetext{
${ }^{53}$ Post and Telegraph Department Acting Inspector General, "The Centennial Postage-Stamp Issue: No. 2. The Fourpenny and the One Shilling Stamps," New Zealand Centennial News, no. 8 (1939). 9.

${ }^{54}$ In 1952 Waipoua Forest was gazetted as a sanctuary under the Forests Act 1949. For more see Michael Roche, “An Interventionist State: 'Wise Use' Forestry and Soil Conservation," in Making a New Land: Environmental Histories of New Zealand, ed. Eric Pawson and Tom Brooking (Dunedin: Otago University Press, 2013). 217-18.

55 See also Monte Holcroft's centennial competition-winning essay The Deepening Stream for observations on relationships with the bush and on the issue of progress versus New Zealand as a scenic wonderland. Monte $\mathrm{H}$. Holcroft, The Deepening Stream: Cultural Influences in New Zealand (Christchurch: The Caxton Press, 1940). Oliver Duff's concluding centennial book survey New Zealand Now includes an account of the influence of the environment on New Zealanders and the reverse effect of settlement on the land: "If enough fools had asked us fifty years ago why we were burning down our children's houses to make room for cows we might have had eight million acres more native forest, and not learnt yet how to spell erosion". Oliver Duff, New Zealand Now, 2nd ed. (London: George Allen and Unwin, 1956). 75.

56 The Making New Zealand surveys were designed for popular consumption. A series of book surveys was intended to provide a more scholarly (though footnotes were not required), topical and chronological
} 
The two-volume, thirty-number series, Making New Zealand recorded the country's first hundred years thematically and was influenced by the contemporary magazine-style series Building America which illustrated life in the United States. The editorial team was headed by Eric Hall McCormick (editor) and included John Pascoe (illustrations editor), David Oswald William Hall (associate editor) and Oliver Duff (advisory editor) and was advised in matters of typography by John Cawte Beaglehole. Parry and Heenan, as minister in charge and undersecretary respectively, supervised as did the National Centennial Historical Committee under the chairmanship of MP and trade unionist, James Thorn. ${ }^{57}$ Various numbers were written by authors commissioned by Heenan — often his own associates — or by members of the editorial committee including Heenan himself. ${ }^{58}$ Making New Zealand, the New Zealand Listener claims, was the first history of the country to place itself firmly in the land itself. ${ }^{59}$ As such it was obligated to address the issues that pertained to its native forests, and in another startling set of ironies, among issues devoted to manufacturing, railways, racing, refrigeration, sea and air and communications, the series includes two numbers of particular interest to this examination of values ascribed to trees. ${ }^{60}$

Number nine in volume one, "The Forest", written by Alexander Hare McLintock, bears a romantic cover photograph by James Walter Chapman-Taylor depicting sun rays slanting through pristine beech forest. The text, however, leaps pragmatically into the fray in the first section, 'The Cost of Settlement', with an admonitory account of the devastation by fire and axe wreaked by Pākehā. The price of progress, McLintock argues, "was the destruction of our native trees, and although we can point with pride to a century of achievement which has transformed New Zealand from a forested wilderness into a rich farming country, we have

commentary on events that had shaped New Zealand of 1940. They included: J. C. Beaglehole, The Discovery of New Zealand, 1939; W. G. McClymont, The Exploration of New Zealand, 1940; J. Cowan, Settlers and Pioneers, 1940; L. C. Webb, Government in New Zealand, 1940; G. T. Alley and D. O. W. Hall, The Farmer in New Zealand, 1941; H. M. Simpson, The Women of New Zealand, 1940; A. E. Campbell, Educating New Zealand, 1941; E. H. McCormick, Letters and Art in New Zealand, 1940; F. L. W. Wood, New Zealand and the World, 1940; S. H. Jenkinson, New Zealanders and Science, 1940; O. Duff, New Zealand Now, 1941. Apirana Ngata was invited to write The Maori which was intended to be the first in the series but was never published.

${ }^{57}$ The National Centennial Historical committee convened in July 1936 to advise on all historical matters related to the centennial.

${ }^{58}$ Heenan and S. V. McEwen wrote Number 28 on horse racing which was one of the most popular of the series.

${ }^{59}$ New Zealand Listener, 14 March, 1941, p. 4. cited in Bill Renwick, "Making New Zealand: Pictorial Surveys of a Century," in Creating a National Spirit: Celebrating New Zealand's Centennial, ed. Bill Renwick (Wellington: Victoria University Press, 2004). 181.

${ }^{60}$ The thirty issues planned for the two volumes were Volume One: The Beginning; The Maori; Navigators and Explorers; Whalers and Sealers; Missionaries and Settlers; The Voyage Out; The Squatters; Gold; The Forest; The Mountains; Pasture Land; Refrigeration; Power; Bread; Manufacturing; and Volume Two: Tracks and Roads; The Railways; Sea and Air; Communications; Houses; Public Buildings; Furniture; Dress; Defence; Recreation; Summer Sports; Winter Sports; Racing; Polynesians; The Changing Land. 
also to remember that some of our forest destruction has been hasty and ill-considered". 61

While New Zealand might boast of its scenery, much of it had been mutilated.

Nature, however, is exacting a penalty. From one end of the country to the other, the clearing of land which should have been conserved has brought in its train a host of tragic consequences. Land-slides and floods, erosion and silting, the spread of scrub and noxious weeds, a serious shortage of native timber-fortunately met by the planting of exotics - are all part of our national legacy of one hundred years of settlement. $^{62}$

In contrast, "The Forest" instructs its readers, Māori fully appreciated and conserved the natural resources of the country before "the European arrived to clear the land by fire and axe ... and Tane's long reign came to its fiery close". McLintock asks in concluding, "Will New Zealand one hundred years hence look back with gratitude on what we are doing to save our

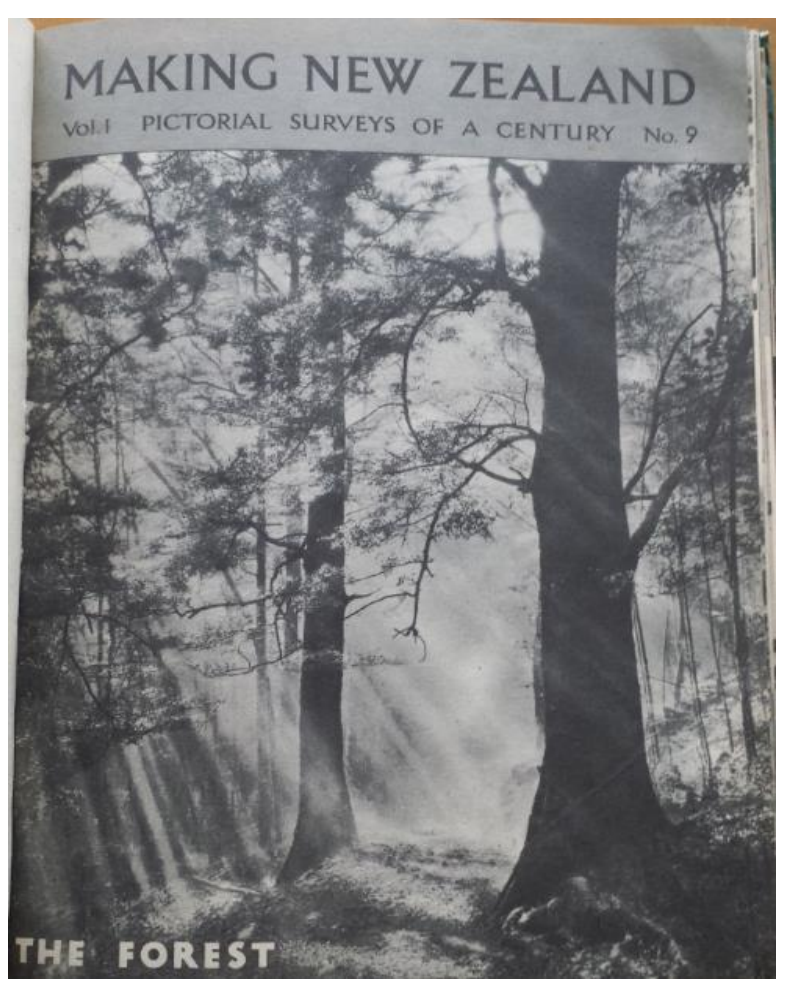

Figure 8: "The Forest". Number nine in volume one of the Department of Internal Affairs' centennial publication, Making New Zealand. country, or will they condemn us for having handed down the legacy of a ruined land?"63 Photographs, art work reproductions, maps and sketches of pristine native forest, milling activities, fire, erosion, washouts and government pine plantations complete the lesson. To provide a suitable finish for the series, Heenan persuaded naturalist, author, farmer and birdwatcher Herbert GuthrieSmith to write "The Changing Land" as a retrospective on the effects of Pākehā intervention on the land. Heenan was an admirer of Guthrie-Smith's book Tutira: The Story of a New Zealand Sheep Station which was first published in 1921, and he regarded it not only as New Zealand's greatest book, but as "one of the world's great books". ${ }^{64}$ The

\footnotetext{
${ }^{61}$ A. H. McLintock, "The Forest," in Making New Zealand: Pictorial Surveys of a Century, ed. McCormick E. H. (Wellington: New Zealand Government, 1939). 2. Succeeding sections are: The Old Forest; The Birds of the Forest; The Maoris and the Forest; The Coming of Europeans; The Milling of Timber; Enemies of the Forest; The Danger of Fire; Loss of Forest Causes Erosion; Types of Erosion; The Fight Against Erosion; Forest Legislation; Our Timber Resources Today; Local Interest in Afforestation; and Forest Policy and the Future.

${ }^{62}$ Ibid. A flash flood had killed twenty-one people at Kōpuawhara on the East Coast on 19 February 1938.

${ }^{63}$ Ibid. 30.

${ }^{64}$ J. W. Heenan, "New Zealand's Greatest Book 'Tutira' by H. Guthrie-Smith: A Talk During Author's Week," (1936). 1.
} 
two men were well known to each other and Heenan had, allegedly, persuaded the author to write for the series in return for assistance in securing a permit to refund funds to Britain for a new edition of Tutira ${ }^{65}$ Guthrie-Smith delivered his text punctually but, when McCormick sometime later came to appraise his work it was considered too brief to be an effective survey. In the meantime, Guthrie-Smith had died. ${ }^{66}$ In order to expand the text to the requisite length, McCormick grafted onto it appropriate sections of Guthrie-Smith's last work, Sorrows and Joys of a New Zealand Naturalist, which is a no-holds-barred assessment of the destruction of the country's environment.

Tutira is an ecological survey of Guthrie-Smith's life on the sheep station north of Napier where he lived and farmed from 1882 until 1940. He was a meticulous observer and recorder of the changes that had occurred on the land over that time including to both fauna and flora, and the final, rather disjointed, essay under Guthrie-Smith's name is founded on his empirical research and begins with the hypothetical removal of all animals and people from twentiethcentury New Zealand - a theme expounded in Tutira. The land would, he speculates, restore itself: native fern, tussock and scrub, woodland and forest would reappear where soil and climate had formerly suited each of them. The few exotic survivors would be confined to domains of edges of slips and banks of river silt. Guthrie-Smith's essay sums up the overall message of the two overtly environmental pictorial surveys that trees are essential to New Zealand's economic, aesthetic and environmental prosperity, and cements the contradiction between New Zealand's centennial celebration of progress and the dire consequences wrought by progress on the environment. Before humans arrived, Guthrie-Smith writes, "ancient New Zealand provided an example of untutored Nature in her wisest mood" ${ }^{67}$ By the time navigators, sealers and whalers, missionaries, the New Zealand Company, goldminers, and acclimatisation societies had had their way with it, New Zealand had declined into "an ashpit". ${ }^{6}$

The second centennial publication important to note in the context of arboreal heritage is the New Zealand Centennial News, a fifteen-issue newsletter produced by the Department of Internal Affairs between August 1938 and February 1941. Parry's signature frequently

\footnotetext{
${ }^{65}$ McEldowney, An Absurd Ambition. 146.

${ }^{66}$ Herbert Guthrie-Smith died at Tutira on 4 July 1940.

${ }^{67}$ Herbert Guthrie Smith, "The Changing Land," in Making New Zealand: Pictorial Surveys of a Century, ed. E. H. McCormick (Wellington: New Zealand Government, 1940). 3.

${ }^{68}$ Ibid. 28.
} 
underlines an introductory column that directly addresses the readers, keeping them up to date and urging them to participate in centennial activities. The newsletter provided an opportunity to press the cause for trees and Parry reported that he encouraged every provincial centennial committee and the interest groups he came in contact with to consider tree-planting as a commemorative event. "Can we conceive any Centennial memorial more enduring, more beautiful, or of greater appeal to this and succeeding generations than the tree?" he preached to the converted of the Wellington Beautifying Society. ${ }^{69}$ Long after the pageantry was over and the exhibition at Rongotai had closed, he instructs his readers, the commemorative trees they had planted would remain as living reminders of the "completion of New Zealand's first century as a British country and the inauguration of another era of progress". ${ }^{70}$ Trees as district memorials, the centennial organisers concluded, were far more appealing than "a monument of stone or marble which may be of indifferent aesthetic merit". ${ }^{71}$

Parry's promotion of tree-planting was multi-faceted. In the Centennial News in 1938 he encourages unofficial competitions in "beautifying operations", suggesting that communities pit one street against another, or one town against another, and emphasising the advantages of "the creation and increase of natural beauty spread throughout the Dominion". ${ }^{72}$ In the next year he assures state cooperation for "active friends of trees" who were attempting to restore the native forests as protection from floods, writing that "those enthusiasts are striving to make New Zealanders properly tree-minded for their own welfare. The instinct of selfpreservation must induce New Zealanders to form strong enduring friendships with forests". ${ }^{73}$ In 1940, under the headline, "Trees to Save the Country", Parry metaphorically draws on New Zealand's preoccupation with the war in Europe insisting that forests must always be the "vanguard of defence against the destructive forces of erosion". ${ }^{74}$ New Zealanders responded to Parry's call for the "planting of trees, more planting, and still more planting". ${ }^{75}$ So much so, that the Centennial News was prompted to offer advice on how and where to plant commemorative trees, warn centennial committees to finalise their planting plans and order their trees early from nurseries or face shortages of available plants, and stress the importance

\footnotetext{
69 “Centennial Tree-Planting for Posterity: A National Appeal,” New Zealand Centennial News, no. 1 (1938). 4.

${ }^{70}$ W. E. Parry, “All Together for the Centennial," ibid., no. 9 (1939). 1.

71 "Desirable Memorials," ibid., no. 1 (1938). 3.

72 “An Opportunity for All," ibid., no. 2 (1938). 1.

73 "Centennial Tree-Planting," ibid., no. 8 (1939). 1.

74 "Trees to Save the Country," ibid., no. 14 (1940). 26.

75 “Centennial Tree-Planting," ibid., no. 8 (1939). 1.
} 
of caring for the trees after the centennial. ${ }^{76}$ At the end of the celebrations it was clear that the planting of trees or establishment of parks had been the most popular form of centennial memorials. $^{77}$

In a parallel thrust for more trees in the country, Christchurch Teachers' Training College agriculture and biology lecturer Lance McCaskill devised a centennial scheme, first presented at the 1937 conference, that encouraged schools, and by association families, to commemorate the year by planting native trees, shrubs, grasses and herbs, the progress of which was tracked in the newsletter. ${ }^{78}$ In 1939 McCaskill had undertaken a Carnegie Travelling Fellowship in the United States studying rural education, nature protection and soil conservation. The operations of the United States Soil Conservation Service and its Civilian Conservation Corps' planting of nearly three billion trees following the dust bowl events of the 1930s was particularly influential on his work in combating erosion. He was passionate about New Zealand's native flora and fauna and while at Christchurch Teachers' Training College, between 1933 and 1944, established a teaching garden of over four hundred native species. ${ }^{79}$ McCaskill is forthright in describing the motivation behind the centennial enterprise, writing that the first hundred years of the development of the country had been a period of destruction of natural resources that had left New Zealanders with a "peculiar psychological heritage". ${ }^{80}$ He berates New Zealanders for believing that nothing that was native to the country should be tolerated, and preferring to be surrounded by only the

\footnotetext{
76 "Centennial Tree-Planting: Careful Preparations Necessary," New Zealand Centennial News, no. 7 (1939). 5. Tree-planting projects reported by Parry in 1938 were in: Auckland (Centennial Avenue with 2,000 native trees); Hamilton (tree-planting along the Hamilton-Cambridge highway); Matamata (a 10-mile Centennial Avenue planting and planting of the domain); Whakatane (Centennial Park at the Whakatane Heads); Hawerta (tree-planting of highway between Hawera and Normanby); Napier exotic tree plantings); Hastings (Centennial Parks throughout Hawke's Bay); Masterton (tree-planting of the Waipoua River banks and the MastertonCarterton highway); Wellington (tree planting of the Wellington-Palmerston North highway); Nelson (reclamation of 100 acres of foreshore as a centennial park); Rangiora (tree planting of the river reserve) and Thames (planted avenue Thames to Kopu).

${ }^{77}$ The final list of memorials approved by the National Centennial Committee, as at 31 March 1941, was: "Treeplanting, parks, play areas, 59; Plunket and rest rooms, 31; historical publications, 27; public halls, 17; swimming baths and pools, 14; Maori meeting houses, 14; memorial gates, 10; beacons, cairns, obelisks, 5; motor camps, 4; community centres, 4; miscellaneous (libraries, rest-rooms, \&c., scholarships, tennis-courts, \&c.) 10. Of these, 95 had been completed and officially opened. Appendix to the Journal of the House of Representatives, 1941, H-22, p.2.

${ }^{78}$ Lancelot William McCaskill (1900-1985) was born in Winchester, South Canterbury and devoted his career to soil conservation, nature protection, scenery preservation and agricultural education. He received many national and international awards and distinctions, was made CBE in 1969 and Honorary Doctor of Science, Lincoln College in 1976. A. P. Thomson, "Lancelot William McCaskill: An Appreciation," The New Zealand Journal of Forestry 30, no. 1 (1985). 7-13.

${ }^{79}$ Ibid.

${ }^{80}$ L. W. McCaskill, "Celebration of the Centennial in Schools: A National Scheme for the Growth and Study of Native Plants," New Zealand Centennial News, no. 2 (1938). 8.
} 
trees, shrubs, flowers and birds of Europe and North America. "So long as this psychological heritage held sway, so long was the development of real nationhood delayed". ${ }^{11}$ McCaskill's sentiment was in sharp contrast to that of the British High Commissioner to New Zealand Sir Harry Batterbee who remarked, when the national flower show opened at the centennial exhibition, that it was a "delight to find in New Zealand flowers that were seen in English gardens because they formed a link between Britain and the Dominion". ${ }^{82}$ McCaskill's scheme introduced children to the history of the plants in their area and was designed to help them understand the challenges of erosion and flooding exacerbated by deforestation, and to encourage them to respect their native trees. The government's Education Gazette provided authoritative horticultural articles to assist teachers, and their students began collecting wild plants, cuttings and seeds appropriate to their geographical location for propagation in school plots. While schools were experienced in horticulture, having customarily worked with the State Forest Service raising eucalypts, pines and cypresses for transplanting, this scheme represented a philosophical shift. The new focus on native plants McCaskill pointed out, introduced a historical motive to horticulture in schools, or at least removed the emphasis on "the grossly material aspect of arboriculture". 83

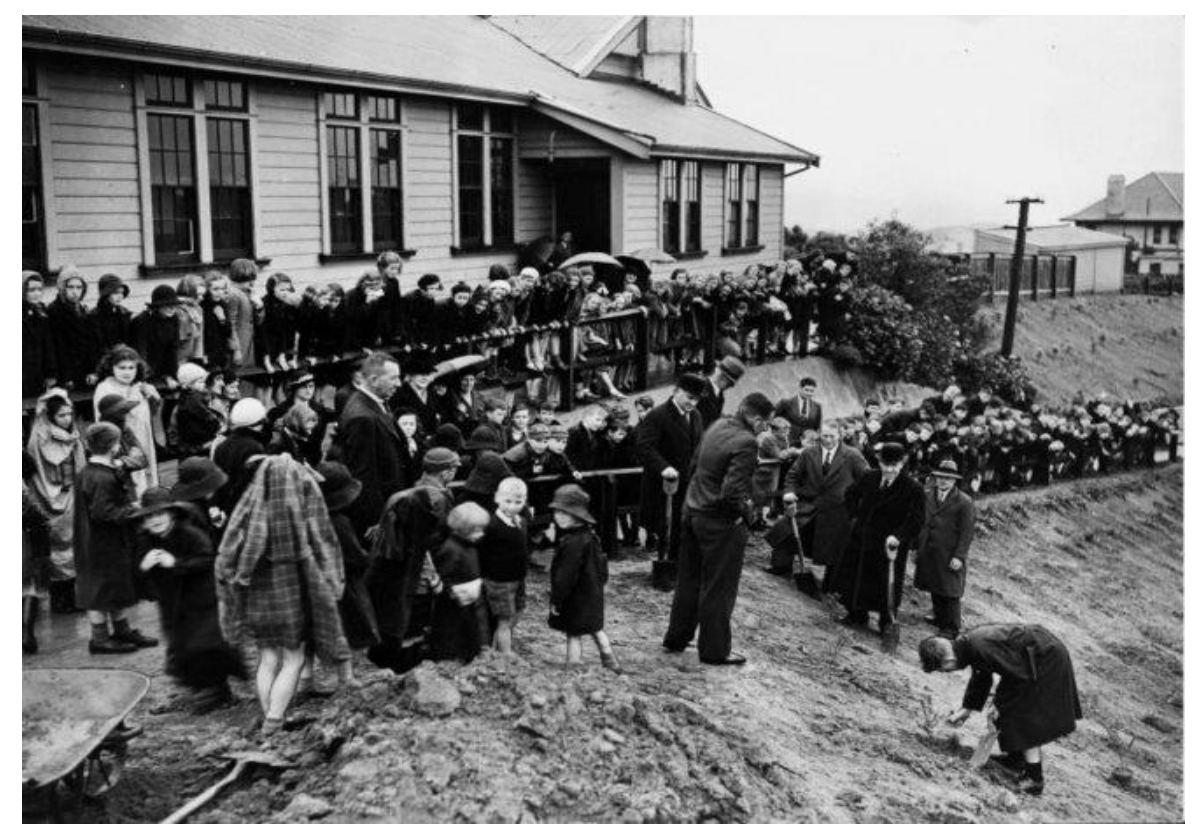

Figure 9: Pupils, staff and visitors at Khandallah School, Wellington during a treeplanting ceremony, 18 October 1940. Ref: PAColl-5927-13 ATL.

\footnotetext{
81 Ibid.

82 “The Centennial Exhibition," http://www.nzhistory.net.nz/culture/centennial/centennial-exhibition. Accessed 4 November 2016.

83 "Centennial Tree-Planting by Schools: A Widespread Programme of Progress," New Zealand Centennial News, no. 10 (1939). 20.
} 
The final issue of the Centennial News published in February 1941 revealed that more than three hundred thousand native plants and many thousands of exotics had been propagated by the schools during the centennial year. In the same year Parry reported that the success of the government's encouragement to local authorities, institutions and individuals throughout the country was evidenced by the fact that "some 220,000 trees were planted for this purpose. In addition, large numbers of trees were planted by educational institutions, beautifying societies, and other public-spirited organizations and by many thousands of private citizens". ${ }^{84}$ Gentry argues that above all else, "the Centennial was not a 'national' celebration, but a large number of regional, provincial and local celebrations of national themes, punctuated by a handful of more broadly national events" ${ }^{85}$ Not everyone could visit the Centennial Exhibition buildings in Wellington and not everyone was motivated to attend the touring National Exhibition of New Zealand Art or read the pictorial surveys. Tree-planting, however, could be undertaken at a district level with an abundance of local sentiment and little expense. By the end of the official centennial period, Parry announced in 1939, "every adult New-Zealander [sic] should be able to say truly, 'I have planted a tree,' or 'I have helped to plant a tree",. ${ }^{86}$

\section{Towards Tree Registration}

Amongst this rousing mix of tree values, when the centennial year was over, the last of the surveys and newsletters were published and as service groups, local governments and schools contemplated how best to maintain their newly acquired forests, Allan's third list appeared in the RNZIH Journal in June $1941 .{ }^{87}$ Only two new trees were added, both exotics: a Norfolk Island pine (Araucaria heterophylla) at Te Wahapū in the Bay of Islands (noted for its size, its age, its connection to surveyor-soldier Gilbert Mair and its survival after severe lopping) and an aspen (Populus tremula) at Tauranga (noted for its size, its age and its connection to a trooper in the Armed Constabulary whose riding switch was believed to have become stuck in the ground and grown to become the tree), bringing the total to 153 tree entries. A subcommittee of Allan (DSIR Botany Division), Walter Reginald Brook Oliver (Dominion Museum), Alexander Robert (Pat) Entrican (State Forest Service) and William Kerr Dallas (RNZIH) was set up the next year to "see how historic trees and other trees could best be

\footnotetext{
${ }^{84}$ Appendix to the Journal of the House of Representatives, 1941, H-22, p.2.

${ }^{85}$ Gentry, Associations Make Identities. 264.

${ }^{86}$ Parry, "All Together for the Centennial." 1.

${ }^{87}$ H. H. Allan, "Historic Trees," Journal of the Royal New Zealand Institute of Horticulture 11, no. 1 (1941). 13.
} 
preserved", and met with further representatives of the State Forest Service and the Lands and Survey Department in Heenan's office. ${ }^{88}$ It was agreed that the records of all relevant government departments would be checked by Allan, a full list of historic trees would be published by the RNZIH as a bulletin, possibly sponsored by Internal Affairs, and the list would be distributed to all local authorities. By the end of that year Allan was reporting in the Journal that "just over 100 native trees are listed, including 11 karakas, 16 kauris, 24 pohutukawas and 11 puriris. Of exotics there are over 150, including 17 Norfolk Island pines, 12 redwoods, 33 gums, 42 oaks". ${ }^{89}$ In July 1943 Allan was still labouring over his project, and wrote to Heenan, "The most interesting account of historic trees at Timaru has reached me, most unfortunately, just as I have finished the rough draft of the bulletin". ${ }^{90}$

The manuscript was finally delivered to Heenan on 28 October 1943 and consolidated the lists published in the June and September 1940 and June 1941 issues of the RNZIH Journal with some changes. ${ }^{91}$ It was not in its final form, Allan wrote, but "sufficiently advanced for you to judge whether it is worthy of publication. If you decide it is, then the matter and manner of publication can be gone into". ${ }^{92}$ He suggested that the final volume should include about twelve illustrations and invited Heenan to write the foreword. Heenan replied with a note of caution. When he had finished reading the manuscript, he wrote, he would pass it to Beaglehole, who was now attached to the Historical Branch of the Internal Affairs Department, before meeting to discuss form, size and illustrations. "You will realise, of course, that just for the moment, in view of the paper situation, immediate publication is out of the question, but you may rest assured that as soon as a favourable opportunity arises, publication will be hastened". ${ }^{93}$ In the meantime, Heenan suggested, Allan might consider including a Christchurch copper beech (Fagus sylvatica 'Purpurea') in the list. He enclosed a photograph.

\footnotetext{
88 "RNZIH Executive Meeting Minutes," 15 October 1941.

${ }^{89}$ H. H. Allan, "Historic Trees," Journal of the Royal New Zealand Institute of Horticulture 12, no. 3 (1942). 54. The final 1943 list includes 152 tree entries comprising fifty-seven natives, ninety-five exotics and two unspecified. Presumably Allan was counting individual trees which he eventually listed in groups.

${ }^{90}$ Allan to Heenan, 30 July 1943, Heritage New Zealand General-Trees 22004-001 vol. 2.

${ }^{91}$ Allan, "Historic Trees in New Zealand: Consolidated List from Journals of Royal N.Z. Institute of Horticulture June and September, 1940, June 1941." The entries in this later list are numbered according to the earlier lists and make it possible to note which are new and which are no longer included.

92 Allan to Heenan 28 October 1943, Heritage New Zealand General-Trees 22004-001 vol. 2.

${ }^{93}$ Heenan to Allan, 4 November 1943, Heritage New Zealand General-Trees 22004-001 vol. 2. During WWII New Zealand experienced a paper shortage.
} 
Allan resigned from the RNZIH executive and from his job as editor of the Journal in 1944 but remained the institute's honorary botanist. In July 1945, the RNZIH secretary L. V. Phillips wrote to Heenan inquiring whether or not the manuscript had been published. ${ }^{94}$ Heenan replied that publication had been held up because acquiring suitable photographs was causing some concern but it had been by no means forgotten and it was "the intention of the Minister as soon as practicable to produce this work in the form it deserves". ${ }^{95}$ Heenan asked William Charles Davies, who had recently retired from his position as curator and photographer at the Cawthron Institute, to take the photographs. ${ }^{96}$ Although initial discussions were positive, Davies returned the manuscript later the next year and Heenan wrote in a file note:

We both agreed that it was not what we wanted, and I said quite frankly that what I visualised was more in the nature of a portfolio of reproductions of photographs of historic trees with short accounts of their historic association. In addition, the portfolio could contain photographs of New Zealand trees to which no history was attached, but which were outstandingly beautiful specimens. ${ }^{97}$

In August 1947 the Internal Affairs Department's Assistant Undersecretary, A. G. Harper, returned the manuscript to Allan with the note, "I think Mr Heenan has already discussed this with you and intimated that the manuscript is not exactly what we had in mind at the time". ${ }^{98}$

The RNZIH's publications committee set up after Allan's resignation unsuccessfully attempted to have the manuscript published in the New Zealand Journal of Science and Technology in 1948 and distributed it to Forest Service conservators and the institute's own district councils for them to inspect and report on the trees. Some reports were sent by the districts but appear to have never been collated with Allan's manuscript. In September 1958 the subject of New Zealand's historic trees received another airing from a new source when the Auckland Star newspaper announced that Richard St. Barbe Baker, founder of the Men of the Trees, ${ }^{99}$ would compile a list of the country's "historic and famous" trees. It was time to record them while early settlers or their descendants could provide historical details, he

\footnotetext{
${ }^{94}$ Phillips to Heenan, 20 July 1945, Heritage New Zealand General-Trees 22004-001 vol. 2.

${ }^{95}$ Heenan to Phillips, 25 July 1945, Heritage New Zealand General-Trees 22004-001 vol. 2.

${ }^{96}$ Heenan to Davies, 4 December 1945, Heritage New Zealand General Trees 22004-001 vol. 2.

${ }^{97}$ Heenan File Note, 19 September 1946, Heritage New Zealand General-Trees 22004-001 vol. 2.

${ }^{98}$ Harper to Allan, 13 August 1947, Heritage New Zealand General-Trees 22004-001 vol. 2. In a parallel venture in 1937, Heenan had proposed to McCormick and Oliver that a manuscript on historic landmarks and monuments by amateur historian Allan Sutherland might be developed into a book. The project was abandoned because the manuscript overemphasised memorials. Cited in Gentry, Associations Make Identities. $273-74$.

${ }^{99}$ Men of the Trees is a conservation organisation founded by Baker in Kenya in 1922 for the planting, maintenance and protection of trees.
} 
reportedly claimed. Baker required nominations of trees with descriptions including "their situation, common or native name, botanical name, height, girth at 4 1/2 ft [1.37 metres] and historical notes - accompanied if possible by photographs" to be sent to Catriona Burnett at Mount Cook Station, Fairlie, who would compile the data. ${ }^{100}$ The rather sketchy book that was published in 1965 is divided into chapters under the headings 'Native Trees', 'The Hardwoods', 'Some Other New Zealand Trees' and 'Introduced Trees', quotes heavily from other publications but does not include footnotes. ${ }^{101}$ In 1959, the Christchurch Star reported an appeal to its readers from Arthur Healy, Assistant Director of the Botany Division of the Department of Scientific and Industrial Research for details of historic native trees in Canterbury ${ }^{102}$ which were to be measured by a committee ${ }^{103}$ against eleven criteria:

- Named by Māori in pre-European times for historic significance

- Associated with Māori tribal custom or ceremony

- Associated with famous Europeans

- Planted by famous Māori in the early days of settlement

- Planted by Europeans in the early days of settlement

- Planted to commemorate some historical event

- Naturally growing and associated with some historic event

- Of large dimensions

- Of great rarity

- Unique because of growth in an anomalous habitat

- Unique as outliers of distribution of the particular species.

Canterbury's exotic historic trees were also to be measured against eleven criteria:

- Planted by famous persons in the early days of settlement

- Planted to commemorate some historic event

- Grown from seed from an overseas locality of historic note

- Already protected by an Act of Parliament

- Of great age

- Of large dimensions

- Having some unique feature in their growth

- Unique from a species point of view

- Unique in strain and variety

- Of significance to forestry

- Of importance in horticulture. ${ }^{104}$

\footnotetext{
100 "Wants Details of Historic Trees," Auckland Star, 16 September 1958.

${ }^{101}$ Richard St Barbe Baker, Famous Trees of New Zealand (Wellington: Reed, 1965).

102 "Historic Canterbury Trees to Be Recorded," Christchurch Press, 2 June 1959. Healy was a previous pupil of Allan's and worked with him at the Department of Scientific and Industrial Research.

103 The committee was formed in 1958 on behalf of the RNZIH Canterbury district council and comprised

Healy; Professor L. W. McCaskill, now Associate Professor of Rural Education at Canterbury Agricultural

College; G. G. Henderson, Secretary of the Canterbury District Council of the RNZIH; D. Combridge and M. J. Barnett.

104 "Historic Canterbury Trees to Be Recorded,” Christchurch Press, 2 June 1959.
} 
Alarmed at the proliferation of tree lists, NZHPT secretary, John Pascoe, wrote to Healy that there was "considerable overlapping of effort by different organisations and agencies". 105 The line-up of historic tree records now included the various interests of Allan; NZHPT; the New Zealand Forest Service; Laurie Henry Millener of the Botany Department at Auckland University; the Department of Lands and Survey; Wairoa nurseryman, Bernard Teague; and G. M. Fowlds of Auckland. In 1960, William Hylton Joliffe and J. Johnson produced a list of historic and notable trees for the New Zealand Forest Service, adding about one hundred trees to Allan's list; and six years later, the Forest Service's A. D. McEwan, under the direction of William John Wendelken, listed six hundred indigenous and exotic historic and notable trees, according to national and local importance, in nineteen regional categories. ${ }^{106}$

From 1954, as he carried out his work measuring exotic forest trees throughout the country for the Production Forestry Division of the Forest Research Institute, Burstall had been noting outstanding trees and recording their dimensions and their histories. ${ }^{107}$ In his own time, he expanded his investigation to include non-forest and native trees. The RNZIH's own efforts, at the time, to compile information on historic trees from all of its district councils had gleaned only eight replies and when offered an article prepared by Burstall, recording 210 'notable' trees measured and recorded during the previous twelve years, the publications committee decided to publish it in the Journal. ${ }^{108}$ Burstall had recorded the trees in alphabetical, rather than in the RNZIH's customary geographical, order. The list was checked by the Forest Service and re-ordered into alphabetical lists within each district and published in the Journal in 1963. The institute's desire to compile a record of the country's 'historic' trees, however, was not satisfied by Burstall's Journal list of 'notable' trees. The records they had to work with now included Allan's list, Burstall's list and the combined records of the Forest Service. Together the documents recorded more than one thousand trees but there were duplications, many of the trees had not been measured since 1939, some were probably no longer in existence, their historical significance was often vague and a working definition of a

\footnotetext{
105 Pascoe to Healy, 8 June 1959. Heritage New Zealand General-Trees 22004-001 vol. 3.

${ }^{106}$ Burstall and Sale, Great Trees of New Zealand, ed. S. W. Burstall and E. V. Sale (Wellington: A. H. \& A. W. Reed in association with the New Zealand Forest Service, 1984). 6.

${ }^{107}$ Stanley Walter (Bob) Burstall joined the Forest Research Institute in 1948 and worked in forest mensuration. From 1958 to 1963 he travelled throughout New Zealand assessing exotic forests and, at the same time, noted particularly large, unusual or old exotic trees and searched records to find out more about them. He extended his research to non-forest and indigenous trees, was assigned to publish his findings and became acknowledged as an expert on notable and historic trees. Gowan Duff, "Preface," in Great Trees of New Zealand. viii. 108 The Forest Service also published the article as Reprint No. 51.
} 
'historic' tree was lacking. In 1964, Forest Service representative on the RNZIH publications committee, M. G. Dunne, came up with a draft definition for the committee to consider:

For a tree to be historic it should qualify for one of the following:

- Significance in Maori Culture

- Significance to Pakeha peoples for its age, or notability for the type of the species

- Have been planted in commemoration and will increase in importance with the passing of time

- Be an outstanding original clone or material which has proved to be a distinct contribution to horticulture. ${ }^{109}$

Two years later, the RNZIH issued to the NZHPT a list of "notable and historic trees" which had been compiled by the Forest Service, and asked the trust to direct its people to check the position and historical details of each tree in their respective districts, to ensure the trees were entered on their town plans as a safeguard against prospective subdivisions and motorways, and to add additional information "provided it is authentic". ${ }^{110}$ The completed list was intended to form the basis of a planned book listing about eight hundred native and exotic trees with a short report on each, its location, historical details and measurements. The covering letter, from the institute's Dominion Secretary, Keith Lemmon, provides a guide that differentiates between the RNZIH's 'historic' trees terminology and Burstall's 'notable' trees usage and tackles definitions of them both:

Historic Trees

Includes those associated in fact with New Zealand history, i.e. have been planted to commemorate an historical event, planted by a member of Royalty or by some person of importance to New Zealand or to the region in which he resided. Trees associated with Maori mythology are also classified as historical.

An attempt has been made to classify the trees further as:

Nationally important; i.e. historical to New Zealand as a whole

Locally important; i.e. planted by an early settler in a particular region or a member of a Provincial Council etc.

Notable Trees

Includes those outstanding for size, botanical interest, or some legend or story which makes a tree interesting but not historical. These are also divided into nationally or locally important, depending on whether the trees are big compared with others in New Zealand, or just big trees in a district, or local landmarks. ${ }^{111}$

\footnotetext{
${ }^{109}$ Royal New Zealand Institute of Horticulture. "Historic Trees," ed. Publications Committee (Wellington: Royal New Zealand Institute of Horticulture, 1964).

${ }^{110}$ Heritage New Zealand General-Trees 22004-001 vol. 3. Underlining in the original.

111 Ibid.
} 
By 1970, now retired and enjoying a reputation as an expert on New Zealand's notable and historic trees, Burstall had almost completed checking the entries in his planned eight regional reports for the Forest Service. ${ }^{112}$ At the RNZIH's combined publications and historic trees committees' meeting in June the next year its members determined to publish Burstall's findings in a single volume containing historic and notable exotic and native trees considered to be of national interest and importance. Furthermore, they decided to seek the services of local botanists to check the nomenclature of the trees and elected to apply for funding from the Internal Affairs Department.

\section{Combatting the "Terrible Pioneer Urge"}

While the work towards the compilation and publication of a definitive list of significant trees now appeared to be making progress, concern was growing about the trees' safety.

Environmental activism beginning in the mid-1960s, involving protest against the country's "rush to destruction", led to the emergence of the Native Forests Action Council and the 1975 Maruia Declaration, which demanded legal recognition of native forests and an end to the logging of them. ${ }^{113}$ Addressing the RNZIH in 1970, Millener reportedly said that there had been "terrible losses" among notable and historic trees. ${ }^{114}$ Auckland had lost an average of one historic tree a year for the past fifteen years not only because of the "explosive growth" of the city, but also through "ignorance of the often unique nature of these trees". The only solution, he said, was to introduce legislation to protect the trees as there was a "terrible pioneer urge" to destroy forests and build homesteads in new countries, and "We are still essentially at the very end of this pioneer stage".

The NZHPT took up the baton and, seizing the opportunity presented by the new Local Government Act and the revision at the time of the 1953 Town and Country Planning Act, put the case for the protection of historic trees to the Department of Internal Affairs in 1974. ${ }^{115}$ While concerned at the fate of the country's significant trees, the NZHPT was not

\footnotetext{
112 The reports covered the following regions: Northland-Auckland; Waikato-Bay of Plenty; Poverty BayHawke's Bay; Taranaki-Wanganui-Rangitikei; Manawatu-Wairarapa-Wellington; Marlborough-NelsonWestland; North and South Canterbury-Chatham Islands; and Otago-Southland. A further national report was planned to include only trees of national importance.

${ }^{113}$ Searle, Graham, Rush to Destruction: An Appraisal of the New Zealand Beech Forest Controversy (Wellington: A. H. \& A. W. Reed, 1975)

114 "Vital to Save Historic Trees," Nelson Evening Mail, 24 September 1970.

115 The Local Government Act 1974 was repealed by the Local Government Act 2002. The Town and Country Planning Act 1977 repealed the Town and Country Planning Act 1953 and its amendments and was itself repealed by the RMA in 1991.
} 
willing to take on the responsibility itself. The trust had customarily concentrated its efforts on the preservation of buildings and sites and cared for its own trees but considered it most appropriate to have significant trees on sites other than its own registered on district schemes under planning legislation rather than under its own Historic Places Act. ${ }^{116}$ Convinced still that listing the trees was an essential part of their protection armoury, the RNZIH set up a notable and historic trees committee in 1977, chaired by Winsome Shepherd, to stimulate public awareness of trees, prepare a national tree register and develop a method of labelling selected trees.

This slim pamphlet, which features on its cover a photograph of the Waimate North oak tree (Quercus robur), the "oldest oak in New Zealand", outlines the voluntary listing scheme. ${ }^{117}$ The pamphlet states that as New Zealand's landscape was constantly changing, trees of "notable and historic importance" require protection because they are: objects of beauty; recognised landmarks; of scientific importance; sources of rare propagating stock, and of historical importance. Labelling the trees with the proprietary green and white enamelled

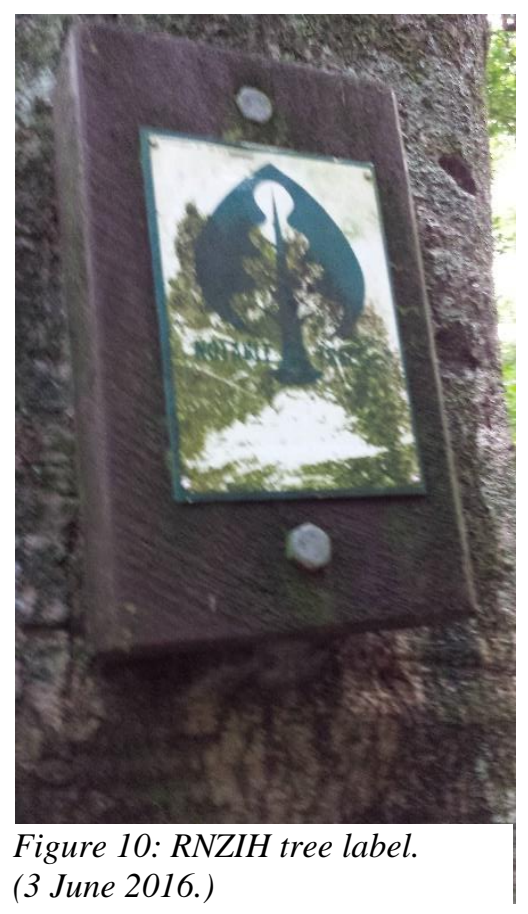
metal plate with a tree symbol ${ }^{118}$ would signify their community importance, would "add status and protection to those trees which are an important part of our heritage," and would encourage local authorities to include them in their district planning schemes, the pamphlet argues. ${ }^{119}$

The registration procedure for each tree began with a proprietary form completed by a qualified horticulturist, landscape architect or arboriculturist which was posted to the Notable and Historic Trees committee for consideration along with a photograph of the tree and a $\$ 2.50$ cheque or postal note. Only trees of national significance would

\footnotetext{
${ }^{116}$ In 1978, the NZHPT had marked only one tree — a kahikatea at Otorohanga-with a standard noticeboard. Luke to Raethel, 30 August 1978, Heritage New Zealand General-Trees 22004-001 vol. 4.

${ }^{117}$ Royal New Zealand Institute of Horticulture. "Notable and Historic Trees: A National Scheme to Register and Promote New Zealand's Notable and Historic Trees," (Wellington: Royal New Zealand Institute of Horticulture, 1977). The publication was supported by philanthropist P. J. Skellerup and a Mobil environmental grant.

118 The tree label was designed by Barbara Cave.

${ }^{119}$ Royal New Zealand Institute of Horticulture. "Notable and Historic Trees." Np. The Town and Country Planning Bill required district schemes to include the "preservation or conservation of trees, bush, plants or landscape of scientific, wildlife, or historic interest, or of visual appeal".
} 
qualify — others were expected to be listed under local initiatives. The guidelines for registering trees which is printed on the back of the forms explains the RNZIH's definitions at the time of 'notable' and 'historic' trees:

Notable Trees and Stands of Trees

- Any tree outstanding in New Zealand for its large diameter, height or canopy spread.

- Any tree of a species rare in New Zealand and outstanding specimens

- Any tree that has national value through its unique location or outstanding functional, strategic or aesthetic significance.

- Any tree that has significant association with other places or objects of national scientific interest such that preservation of the tree will aid in the protection of the associated place or object(s).

- A stand of trees conforming to the above.

Historic Trees or Stands of Trees

- Any tree commemorating a nationally important event either in Maori history or legend or European settlement and development

- Any tree that is regarded as an important landmark and has been acknowledged as such for a significant period of time.

- Any tree that has historic association with a well-known public figure or has had strong public association for some reason

- Any tree that is strongly associated with a national historic feature and which now forms a significant part of that feature. Also, where the preservation of the tree will aid in the protection of the historic feature.

- Age will be a predominant factor in determining historic value and this will normally be in excess of fifty years.

- A stand of trees conforming to the above. ${ }^{120}$

Letters enclosing pamphlets and urging the government to legislate for the recognition and protection of notable and historic trees were sent to the Prime Minister, the Minister of Lands, the Minister of Works, the Commissioner of Works, the Director General of Lands, the Director General of Forests, the Commissioner for the Environment, the Secretary of Internal Affairs and the Department of Lands and Survey. RNZIH district councils were encouraged to appoint tree registration officers to take care of administrative matters, and proposers of trees for consideration were referred to the Forest Research Institute's regional mensuration reports on the historic and notable trees of New Zealand which had by now been completed by Burstall.

\footnotetext{
120 "Royal New Zealand Institute of Horticulture Notable and Historic Trees Registration Form", in Royal New Zealand Institute of Horticulture. "Notable and Historic Trees." Np.
} 
It was not until 1984 that the "handsome illustrated volume of the more historically important and beautiful trees in the Dominion" envisaged by Heenan in 1940 materialised as Great Trees of New Zealand published by Reed in association with the New Zealand Forest Service.

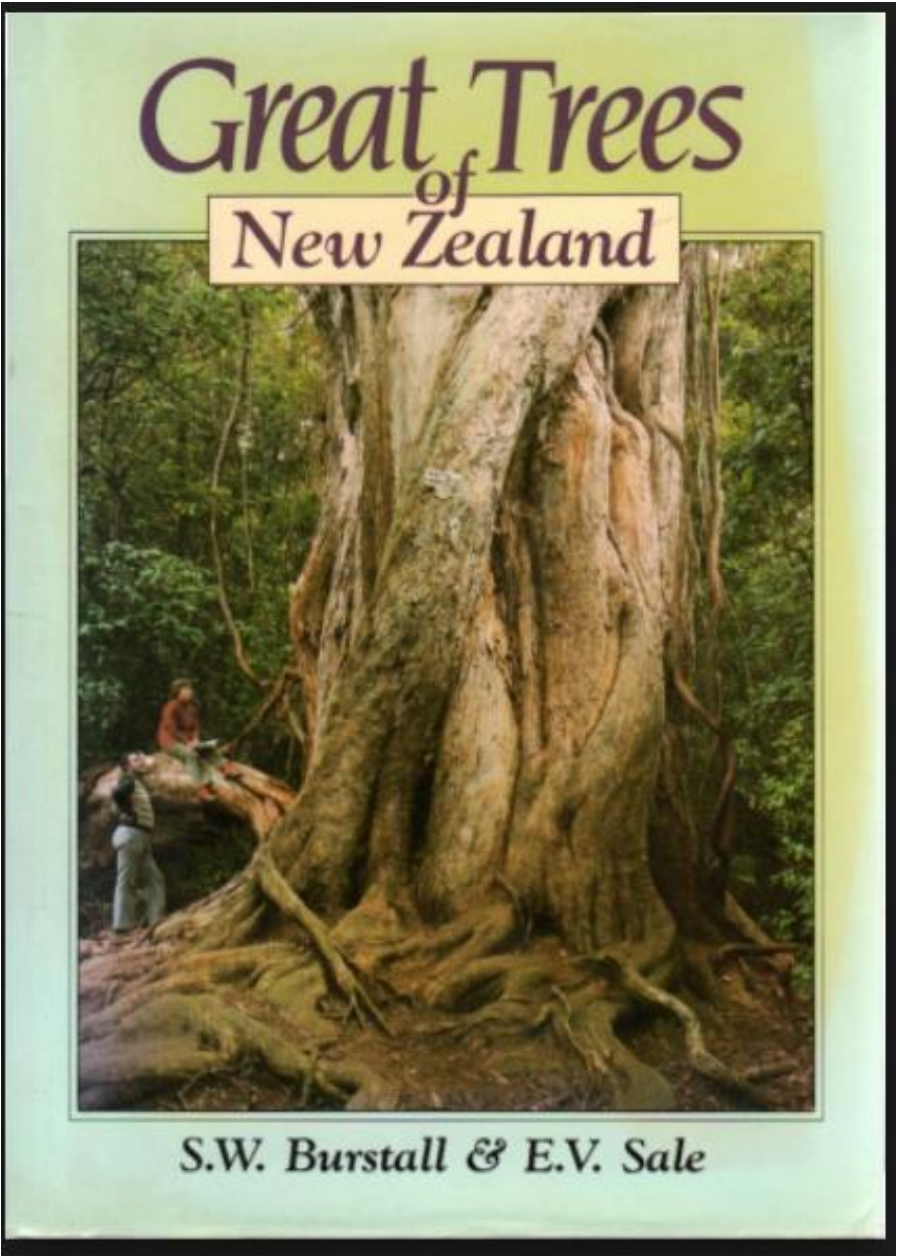

Figure 11. Burstall and Sale's Great Trees of New Zealand published in 1984.
The 288-page, geographicallyordered book by Burstall and Sale generously acknowledges Allan's original list and the RNZIH's 1977 notable and historic trees scheme. ${ }^{121}$ The authors shy away from the term 'historic' instead dividing their text into one hundred 'great trees' followed by a supplementary section covering 'notable trees'. The name 'great trees', the foreword explains, includes those "which may be notable for their beauty as well as for their size, for their occasional rarity as well as an historical association". ${ }^{122}$ The selection is described as "a personal one by the authors" and the also-ran "notable trees' section of 521 entries covers trees "too good to be left out". ${ }^{123}$ All

the measurements are updated to either 1981 or 1982. Just as the authors found that their choices of great trees changed so, they conclude, will the list of great trees continue to change in the future. The original purpose of the book was the protection of significant trees.

Public awareness of trees has been a matter of education rather than enforcement, and the classification of notable trees undertaken by various local authorities has been a major factor in safeguarding those trees that are known. There have been times when notable trees have been cut down or disfigured in full knowledge to develop

\footnotetext{
${ }^{121}$ Edmund Vernon Sale was the author of Quest for the Kauri: Forest Giants and Where to Find Them (Wellington: Reed, 1978); Historic Trails of the Far North (Wellington: Reed, 1981); Four Seasons of Country Diary (Wellington: Reed, 1982) which was a collection of Sale's columns published in the New Zealand Herald illustrated by Gordon Minhinnick; and Saltwater Game Fishing in New Zealand (Wellington: Reed, 1982) with Fred Wilkins.

122 Burstall and Sale, Great Trees of New Zealand. ix.

123 Ibid.
} 
properties the better, but many of the losses or removals have been in ignorance that trees were important. This book may help in part to safeguard some great trees from being felled in future just by listing them. ${ }^{124}$

Fifteen entries in Allan's initial list make it into Burstall's list of one hundred great trees and many more are included or mentioned in passing in the notable trees section. The authors note that, by the time they had drawn up their list, sixty-eight of Allan's 153 trees were known or presumed to have been felled "sometimes unnecessarily" or had succumbed to age or weather. ${ }^{125}$

\section{Growing Political}

Also, in 1984, the Minister for the Environment launched the Year for Urban Trees to address a growing concern that land development pressures were causing the loss of too many trees. ${ }^{126}$ The programme of seminars, publications, school projects and training proposals was managed by the Commission for the Environment. One of the seminars, held at Turnbull House in Wellington on 20 March 1985, focused on the RNZIH's notable and historic trees scheme and led to the formation of a working party and a report recommending that the government establish a national notable trees scheme under an existing act that protected trees by means of covenants, ${ }^{127}$ and was organised and managed by an autonomous board responsible to the Minister of Conservation. ${ }^{128}$ The working party had concluded that it was not possible to run an effective scheme voluntarily without funding, a legal basis for protection, and recognition that notable trees were of national importance. The report

\footnotetext{
${ }^{124}$ Ibid. 4.

${ }^{125}$ Burstall and Sale Noted Cyclone Gisele (1968) and Cyclone Alison (1975) as prime causes of tree destruction.

${ }^{126}$ In Auckland a group called "Friend of Urban Trees" had recently been formed. More than thirty years later, in 2015, University of Auckland researchers Margaret Stanley and Sarah Wyse found that the city's trees had little protection against urban intensification and the Auckland Council's Schedule of Notable Trees was the only tool left for the retention of the few remaining trees listed for protection. "Auckland's Trees Vulnerable to Housing Intensification," University of Auckland, https://www.auckland.ac.nz/en/about/news-events-andnotices/news/news-2015/06/auckland_s-trees-vulnerable-to-housing-intensification.html. Accessed 7 April 2016.

${ }^{127}$ The report argued that a covenant system would be likely to be widely accepted as it was already employed under the Historic Places, Queen Elizabeth II National Trust and Reserves acts. Where covenants were not agreed to by property owners tree protection notices, similar to those issued by NZHPT, could be served on property owners and emergency tree protection notices could be issued to protect significant trees threatened from imminent removal or damage. Royal New Zealand Institute of Horticulture. "Notable and Historic Trees." 1985.

${ }^{128}$ Working party members were: Philip Simpson, chair, Commission for the Environment); Sylvia Allan, (planning consultant); Alan Jolliffe (RNZIH); Winsome Shepherd (National Museum associate in botany); Ron Flook (RNZIH); Lindis Taylor (RNZIH); Jan Simmons (Lower Hutt City Council); Conrad Pharazyn (Wellington Regional Council); Boyden Evans (Queen Elizabeth II National Trust) and Sarah de Renzy (Queen Elizabeth II National Trust).
} 
proposes that notable trees be allocated to the planned Department of Conservation ${ }^{129}$ under the umbrella of 'cultural heritage' alongside the Historic Places and Queen Elizabeth II National trusts and Arbor Day promotions. The report further advocates the inclusion of the protection and preservation of notable trees in district schemes under the Town and Country Planning Act 1977, ${ }^{130}$ rates adjustments for properties with notable trees under the Rating Act 1967, and overriding of rights to trim or remove trees then held under the Public Works Act 1981, Electricity Act 1968, Post Office Act 1959, Soil Conservation and Rivers Control Act 1941 and Property Law Act amendment of 1975. The working party outlines the benefits brought by New Zealand's notable trees including adding beauty and character to the landscape and a sense of identity—particularly historical— to local inhabitants; creating landmarks for successive generations; and providing scientific value as resources of the "very best and oldest genetic systems in the country", and calls on its readers to imagine a tourism route linking the notable trees throughout New Zealand. ${ }^{131}$

Of particular interest to this thesis is the working party's proposed "necessary" valuation system for assessing trees. Here, 'evaluation' is defined as a means of assessment for tree registration: 'valuation' is defined as the monetary value of a tree required as a national standard in the event of legal dispute. The valuation system proposed by the working party follows the principles of the United Kingdom standard of the time-Helliwell. ${ }^{132}$ Under the proposed system, trees would be awarded one to four points at $\$ 2$ per point in seven categories: size (height x crown spread); useful life expectancy; importance of position; presence of other trees; relation to setting; form and special factors. To illustrate the argument, the working party valued the pōhutukawa on the Wellington Club site which had featured on the poster promoting the Year for Urban Trees. ${ }^{133}$ The tree scored $\$ 65,536$.

\footnotetext{
${ }^{129}$ The passing of the 1987 Conservation Act enabled the Department of Conservation to be formed in the following year and integrate some of the functions of the Wildlife Service, the Forest Service and the Department of Lands and Survey.

${ }^{130}$ While the Town and Country Planning Act 1977 made provision for tree protection it was not mandatory for local authorities and only some district planning schemes included it.

${ }^{131}$ Royal New Zealand Institute of Horticulture. "Notable and Historic Trees." 1985. 2.

${ }^{132}$ Helliwell was developed and published in 1967. For more on tree valuation systems see Vadims Sarajevs, "Street Tree Valuation Systems," (Forestry Commission (UK), 2011).

133 The tree had been threatened with severe pruning to make way for the development of the Wellington Club site. Flook notes in the Register that the Wellington City Council required the building to be redesigned and consequently the façade was built to incorporate a curve that accommodated the tree.
} 


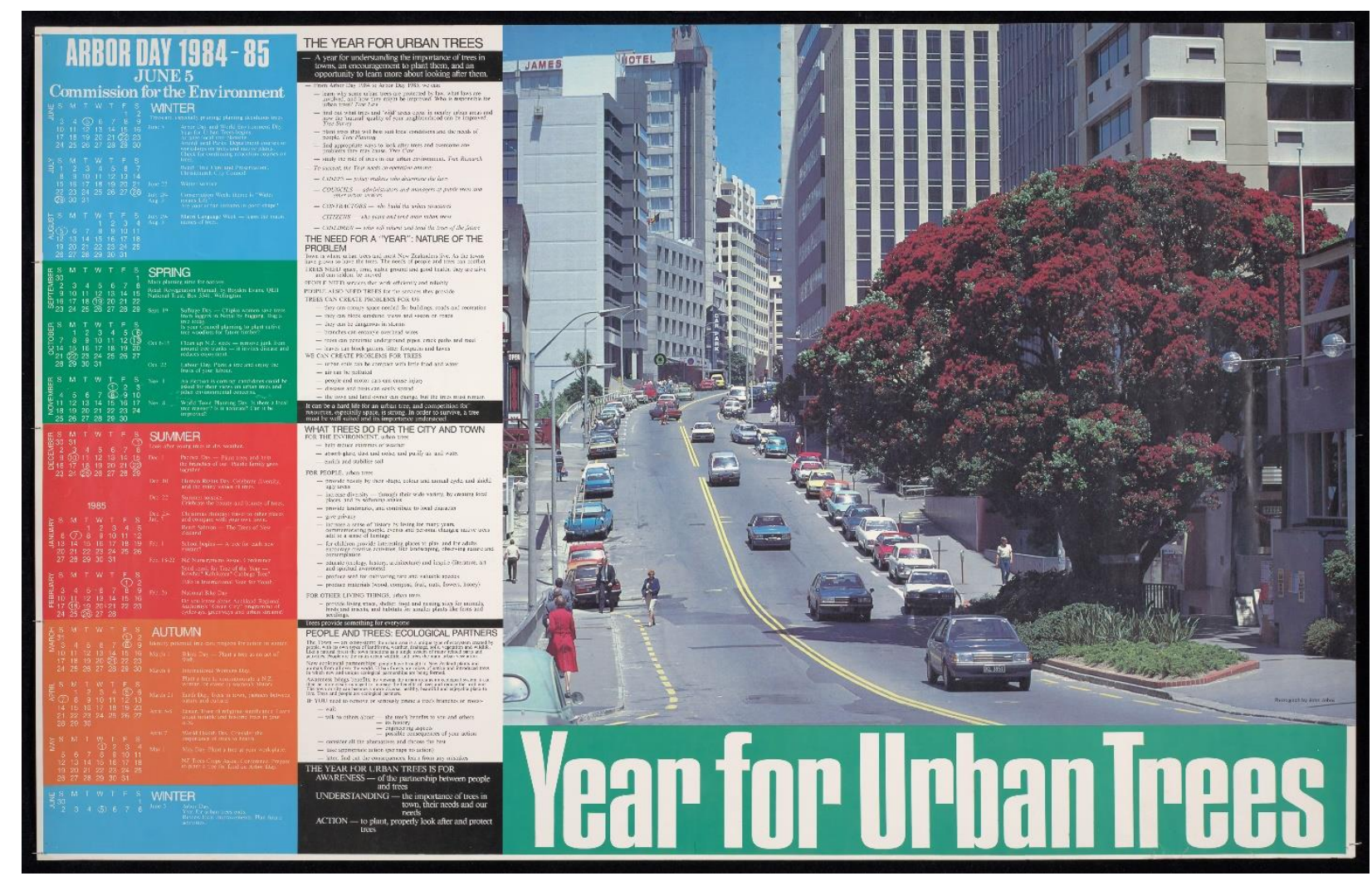

Figure 12: The 1984-1985 Year for Urban Trees poster featuring the pōhutukawa on the Wellington Club site. Photograph: John Johns. Reproduction permission courtesy of the Parliamentary Commissioner for the Environment. Ref: Eph-E-ENVIRONMENT-1984-01, ATL.

Assuming the 160 trees on the RNZIH National Tree Register are of similar value, the report argues, the registered trees can be valued at $\$ 10,485,760$ and the additional 620 trees Burstall had identified as being of national importance can be valued at \$40,632,320. All trees of national importance had not yet been listed, the report concludes "but it is clear that in monetary terms notable trees account for a significant resource heritage". ${ }^{134}$ The Notable and Historic Trees report was circulated in July 1986 to government MPs Russell Marshall, Philip Woollaston, Phil Goff and Ken Shirley; Rosemary Barrington (Research Officer Environmental Committee); and Graham Carroll (Government Research Officer). Reporting to the RNZIH's executive in August, convenor of the Notable Historic Trees Committee Flook ${ }^{135}$ likened the report's response to the "thud of a woodsman's axe" and urged the

\footnotetext{
${ }^{134}$ Royal New Zealand Institute of Horticulture. "Notable and Historic Trees." 1985. 16.

${ }^{135}$ Ronald (Ron) Richard Flook (1932-2006) was born in South Africa. He studied landscape architecture at the Gloucester College of Art and Design and worked for Wellington City Council as senior landscape architect and for consulting firm Boffa Miskell. He was made a fellow of the RNZIH in 1988 and was largely responsible for the establishment of the NTNZ scheme. Maloy, Andrew, "Ronald Richard Flook AHRIH: 14 September-9 January 2006," New Zealand Garden Journal 9, no. 1 (2006).
} 
institute to prioritise arboriculture training in the event of the passing of legislation for the protection of notable trees. ${ }^{136}$

The next year, the Notable and Historic Trees Committee presented their case to the Parliamentary Select Review Committee of the Town and Country Planning Act and were referred to the new Director of Conservation, or "stalled" as Flook writes, and, significantly, the committee proposed to drop the term "historic" and reinvent itself and its scheme as the RNZIH notable trees committee and RNZIH notable trees scheme. ${ }^{137}$ The committee continued to lobby central government for legislation to protect, what they termed, 'trees of national importance'. A meeting with officers from Blenheim and Nelson borough councils in 1987 concerning the evaluation of trees, however, provoked a new two-pronged strategic direction for the committee-lobbying local authorities for tree legislation and providing them with an appropriate evaluation method for tree protection. Flook reported to the executive committee that by running workshops with local authorities, which would account for local geographic conditions and expertise, the RNZIH would receive their backing and would be seen as the "leader in the fight to protect Notable Trees, nationally and locally". 138 The tree evaluation method (later acronymised to TEM), Flook argued, would provide a qualitative classification of trees, from which would emerge the potential trees of national importance; a set of standards especially useful in legal wrangles; and an opportunity for local authorities to press for legislation for tree protection.

The 1991 introduction of the RMA and associated amendment of more than fifty other laws relating to town planning and resource management brought new consideration to effects on natural and physical resources. While trees were not specified, local authorities were now required to maintain inventories of items of local amenity and cultural importance, and many of them adopted Flook's method of evaluation in establishing their tree registers contained within district plans. The Notable and Historic Trees Committee reported in 1992 that its tree registration officers had entered four hundred trees to the list, TEM was successfully being implemented by local authorities in relation to their district schemes and plans were under

\footnotetext{
${ }^{136}$ Ron Flook, "Report to the Royal New Zealand Institute of Horticulture Executive from Notable Historic Trees Committee," (Royal New Zealand Institute of Horticulture, 1986). 2.

${ }^{137}$ While the committee was seen to have dropped 'historic' from its name in 1987, by 1992 it had returned to the title 'Notable and Historic Trees Committee'. It was not until 1997 that the name change to Notable Trees New Zealand was adopted.

${ }^{138}$ Royal New Zealand Institute of Horticulture. "Report to Executive Committee Members," (Wellington: Notable Trees Committee, Royal New Zealand Institute of Horticulture, 1987).
} 
way for publishing the RNZIH's own national tree register. The Register appeared in August 1994 as An Introduction to the Notable Trees of New Zealand in the form of a handbook edited by Flook and supported financially by the Lotteries Grants Board, the Elizabeth Baigent Trust and the Ministry of Forestry. More than two thousand trees are recorded in the list and are organised into the fifteen geographic regions and districts determined by Department of Survey and Land Information maps and include street or rural delivery numbers for easy visitor identification. The entries include dates of origin where known; measurements; dates of registration and names of people who have registered them; and notes often taken from and attributed to Burstall's mensuration reports. Flook notes that trees that had died had been removed from the Register but trees which had been "vandalised or killed by malpractice" remained on the list to "remind us of the vulnerability of our great New Zealand trees". ${ }^{139}$ The record, he writes, is of national importance:

The recording of these significant trees is an attempt to locate and identify one of the great treasures of New Zealand, which is its heritage of venerable trees. By registering and labelling these outstanding trees, public attention will be drawn to them and in this way they receive a measure of protection by being acknowledged as very important. So many trees are lost because their significance is unknown. There are many more significant trees needing registration. ${ }^{140}$

In order for the trees to qualify for registration, the signatures of both the property owner and the local authority were entered on an RNZIH form by a tree registration officer or a concerned member of the public and all the nominations were appraised by tree experts for inclusion as "potential trees of national importance". Trees considered suitable for the Register had to be more than fifty years old and be significant for one or more reasons of stature (size and/or shape); of history (over one hundred years and/or a remnant of an original forest or planting and/or associated with an eminent person or event; and/or commemorating a historic occasion); or of science (part of a collection e.g. an arboretum and/or source of botanical interest and/or rare in circumstances or numbers in New Zealand).

\footnotetext{
${ }^{139}$ Flook, An Introduction to the Notable Trees of New Zealand. 8.

${ }^{140}$ Ibid. 4.
} 
In 2001 Flook, now the national registrar of Notable Trees New Zealand (NTNZ), reported at the RNZIH's annual general meeting that a suggestion that New Zealand should lead an international database of world heritage trees had been declined due to the:

parlous state of support for NTNZ both from RNZIH members and the public at large. The idea remains but the question is how to make it happen? ... There is so much opportunity waiting to be grasped. The elevation of our Institute's image as a leader in this worthwhile cause of Tree protection comes from a sound and readily available knowledge of NZ's Heritage of Notable Trees. ${ }^{141}$

In October 2001 the RNZIH, in association with NZArb ${ }^{142}$, published the Tree Registration Manual, compiled by Flook for national and local authority heritage listing. The manual gives an overview of the work of the RNZIH and NTNZ towards protecting the country's trees and explains how to select notable trees and how to register them. ${ }^{143}$ The country's trees were under threat from the development of urban sites, rural landscapes, forest and tourist areas, the manual warns. Environmental impact assessments were sometimes too late to save resources, and important trees, particularly those that were not recognised and recorded, could be overlooked by assessments. New Zealand's great trees, the manual states, provide an invaluable natural and cultural asset, "They are an important part of our environment for reasons of either their stature, cultural and/or scientific values". ${ }^{144}$ As current legislation was considered to be "inadequate" for the protection of trees NTNZ aimed to identify, list and label the country's native and exotic nationally significant trees; secure statutory recognition through district plans; secure public and private awareness as a means of protecting important trees through education, publicity and labelling trees; add to the Register; and build a national tree database.

\footnotetext{
${ }^{141}$ Royal New Zealand Institute of Horticulture. "Annual Report to the Royal New Zealand Institute of Horticulture," ed. Notable Trees New Zealand (Royal New Zealand Institute of Horticulture, 2001). The suggestion of New Zealand heading an international tree database had been made at the March 2001 Big Tree Symposium in Nagoya, Japan at which NTNZ delivered a paper to more than six hundred delegates at the request of the Japanese Forestry Agency. Flook reported that it had often been repeated at the symposium that New Zealand seemed to have legal protection mechanisms in place and that it had been difficult to explain that these mechanisms were, in the main, not applied.

${ }^{142}$ NZArb became an official supporter of NTNZ in 1997 as part of their tenth anniversary conference in Hamilton.

${ }^{143}$ Ron Flook, Tree Registration Manual: For National and Local Authority District Plan Heritage Listings (Nelson: Royal New Zealand Institute of Horticulture, 2001; repr., 2003). The manual was revised in July 2003 by Flook and Murray Dawson.

${ }^{144}$ Ibid. 1.
} 
In the next year, NTNZ signalled its proposed new directions in a memorandum to the RNZIH chairman and executive. As local authority recording, rather than NTNZ registration, was the only viable tree protection mechanism, national listing had lost its credibility, the memorandum argues. NTNZ was left with "doubts as to our purpose, our record often duplicated, tree protection ineffective and the public reluctant to participate". ${ }^{145}$ Recommendations include the introduction of a 'noble' trees category; ${ }^{146}$ a separate web site for noble trees, with all NTNZ registrations and documentation to be added later; and the establishment of a national botanical tree register with the RNZIH as the recording authority. ${ }^{147}$ The proposed botanical tree register was seen as a development of the work carried out in Burstall's mensuration reports which were still used for botanical reference.

In 2000, the RNZIH's web master Murray Dawson had entered a 'Notable Trees' section on the institute's newly-redesigned web site which included an introductory guide, examples of notable trees and details of notable tree registration. It was the beginning of an online presence that led to the launch in 2004 of the first NTNZ database which allowed public access and aspired to Flook's earlier goal of a wider recognition of the country's tree heritage. Flook died in 2006 and the database became unavailable soon after. In April 2008, however, the RNZIH and NZArb established a charitable trust to continue NTNZ's work, and the following month an RNZIH-organised symposium, Heritage Trees-Our Future Heritage, discussed issues concerning the documentation of the country's tree heritage. ${ }^{148}$ The newly established NZNTT, chaired by David Glenn, began work to create an online notable trees database and integrated management system to streamline access to registrations and images. Existing records were combined with new listings under 'notable' and 'champion' tree categories and the Cyberforest, representing approximately three thousand trees, went live on 19 November 2009 at the NZArb conference in Blenheim.

\footnotetext{
${ }^{145}$ Royal New Zealand Institute of Horticulture. "Notable Trees New Zealand ... New Directions," (Royal New Zealand Institute of Horticulture, 2002). 1.

${ }^{146}$ The new category of 'noble trees' was added to the Register in order to recognise trees of more than 27 metres in height, canopy spread or both.

${ }^{147}$ Royal New Zealand Institute of Horticulture. "Notable Trees New Zealand ... New Directions." 2.

${ }^{148}$ Brad Cadwallader, "The New Zealand Notable Trees Trust Online Database," New Zealand Garden Journal 12, no. 2 (2009). 15.
} 

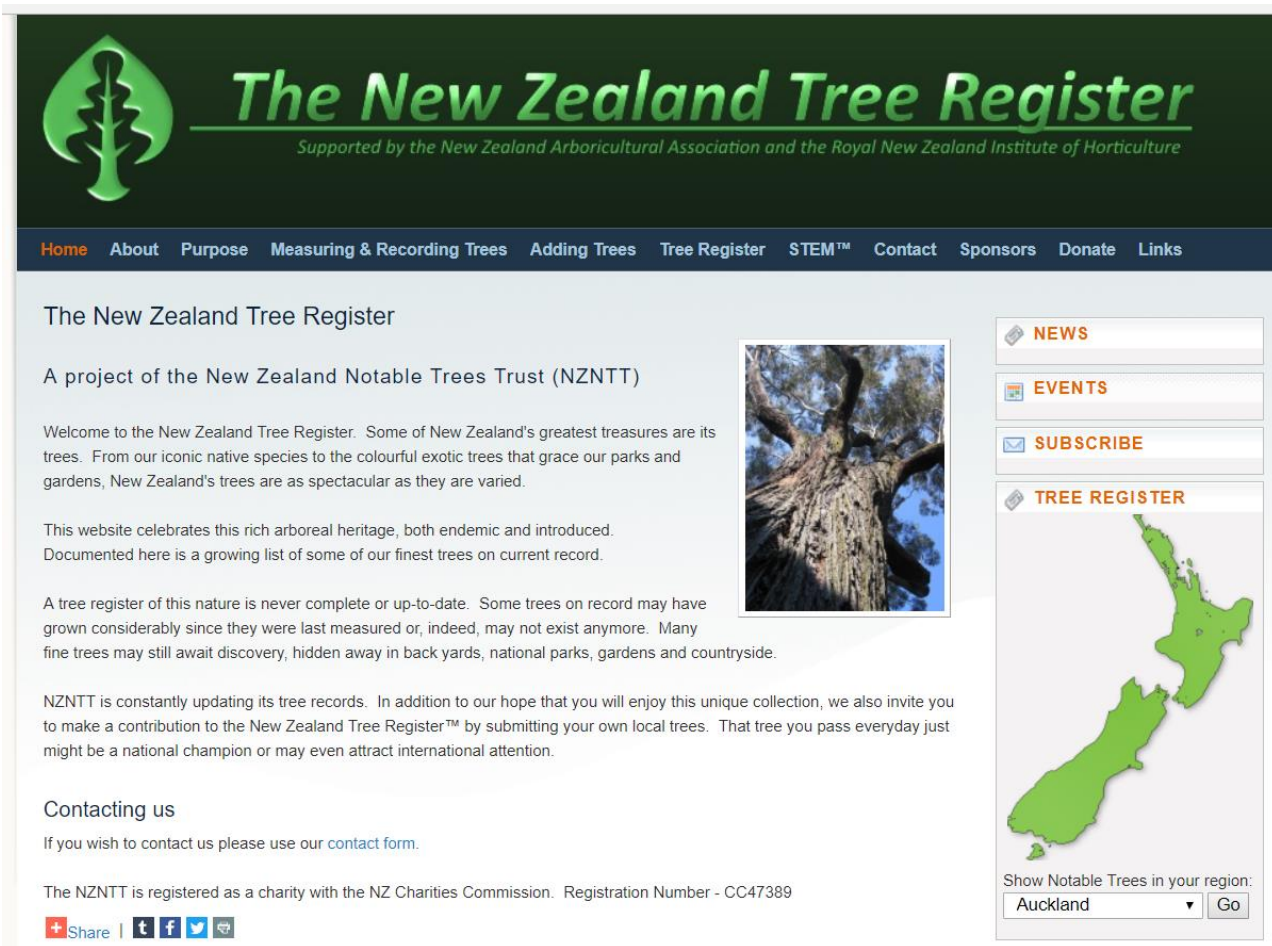

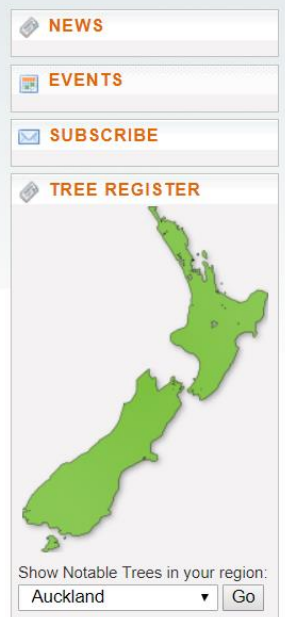

Figure 13: Home page of the New Zealand Tree Register. Reproduction permission courtesy of New Zealand Notable Trees Trust.

\section{The Cyberforest as a Site of Heritage Trees}

The motive behind the 1937 Bush Preservation and Amenity Tree Planting conference that prompted the evolution of the Cyberforest, as described above, was to protect the country from environmental and economic harm by conserving native forests and planting more trees. The subsequent actions of the RNZIH in preparing a list of historic native and exotic trees that should be preserved grew out of this sentiment and the preliminary lists were based on recommendations from New Zealanders who knew their local trees. This section builds on the preceding account of the historical development of the Register and considers both its contemporary place in the arboreal heritage of this country and the values that support it. Today's Cyberforest includes many of those early tree entries and continues to invite nominations from members of the public; its prime concerns, however, are no longer environmental or economic issues nor does it profess to protect the trees it lists. Instead, the Register aims to raise the "profile of significant community trees, foster the centralisation and exchange of tree information, and to encourage people to submit trees that they think are important". ${ }^{149}$

\footnotetext{
${ }^{149}$ http://www.notabletrees.org.nz. Accessed 20 November 2017.
} 
It would be simplistic to claim that there is only one reason for this change in focus from protection to collection. The 1988 formation of the Department of Conservation, a heightened awareness of the significance of the natural environment and a growing acknowledgement of the importance of tourism to the country's economy will have had their own effects. It was, however, the introduction of the RMA in 1991 that most noticeably influenced arboreal heritage registration throughout the country. While the requirements of the new act for local authorities to establish inventories of amenity and cultural importance was primarily directed at built heritage, tree registers appeared in district plans and became supported by a new iteration of TEM — the Standard Tree Evaluation Method (STEM) — introduced by Flook in 1996. Viewing these developments through the lens of the Cyberforest's history, as described above, this change in focus might be interpreted as an overdue response to the RNZIH-led political agitation of the 1970s and 1980s which campaigned for the recognition and protection of arboreal heritage. ${ }^{150}$ To what extent the official recognition of arboreal heritage required by the RMA equates to its protection is one consideration of the following analyses of three tree profiles and contemporary tree lists. A second consideration is the types of trees that qualify for inclusion in the lists. As a means of examining the issue of tree selection the lists are analysed here according to native and exotic tree entries.

While the Cyberforest is not an official government record it does note among its supporters the Ministry for Culture and Heritage and various district councils, and the Register's official name (the New Zealand Tree Register) lays claim to national status. The Register was launched online to "allow public access and wider recognition of New Zealand's tree heritage", however, anecdotal sampling has demonstrated that the Cyberforest remains largely the realm of tree enthusiasts. A more accurate picture of audience response merits further inquiry but is beyond the scope of this investigation which focuses instead on the contribution of the Cyberforest to arboreal heritage and the values that support it. When it first went live in 2009 the Cyberforest might have qualified for the title 'new media'. Today, however, as most recorders of museological or heritage information have resorted to digitisation of their collections, and as the use of digital technology has grown, online

\footnotetext{
${ }^{150}$ The Resource Management Amendment (Simplifying and Streamlining) Act 2009 required local authorities to list protected trees. In 2015, after Tavares' public protest saved the five hundred-year-old Auckland kauri on private land from being felled, Labour pledged to introduce legislation to provide automatic protection to heritage trees. "Labour Proposes Law Change to Protect Heritage Trees," http://www.labour.org.nz/labour_proposes_law_change_to_protect_heritage_trees. Accessed 11 February 2016.
} 
collection presentation can be regarded as the norm or 'postdigital'. ${ }^{151}$ The following discussion takes this into account.

The web site's home page directs its visitors to pages that include instructions for measuring, recording and nominating trees, obtaining copies of STEM and making donations, information on contacts and sponsors and links to selected tree registers and organisations. The site acknowledges the work of Allan, Burstall the RNZIH and Flook that preceded and contributed to the Register's online presence, and notes that it is designed to "celebrate [New Zealand's] rich arboreal heritage, both endemic and introduced", and that it documents "a growing list of some of our finest trees on current record". The web site is efficient, informative and follows a standardised format. A drop-down menu enables access to the tree entry lists of nineteen separate geographical regions. Each tree entry presents a satellite map and location information; details of size, health and age of the tree; general notes including history, photographs if available and any up-to-date observation notes. If a tree is no longer standing this fact is noted and the entry remains: historical records of former trees (with measurements and old photos) can be added. Each of the nineteen lists is viewed independently which means that the arboreal heritage lists of each region are not easily compared. My analysis of the regional entries, however, shows in Table 3 that they vary dramatically in number from Hawke's Bay (165 entries) to Coromandel (four entries). This reflects neither the number of trees in each region nor the number of trees that might make the cut, so to speak, but is simply the number of entries. The web site acknowledges the Cyberforest's limitations in this regard as "never complete or up-to-date ... Many fine trees may still await discovery, hidden away in back yards, national parks, gardens and countryside". What the numbers do suggest, however, is regional variation in enthusiasm for, or perhaps knowledge of, the opportunity to nominate trees for registration.

\section{Registration by Nomination}

Soliciting of nominations for the arboreal heritage list has been standard practice throughout its evolution beginning in 1939 when Allan invited recommendations through newspapers and RNZIH circulars. Burstall too, as he travelled the country gathering records of historic and notable trees, relied on recommendations from local tree enthusiasts to point out suitable

\footnotetext{
${ }^{151}$ Parry, "The End of the Beginning."
} 
trees and to assist in photographing and measuring them. ${ }^{152}$ In Historic and Notable Trees of New Zealand: Otago and Southland, for example, Burstall writes, "On account of the author's limited knowledge of indigenous trees and forests generally and virtually no knowledge of southern forests at all, Mr Geoff Chavasse has kindly written the general notes for these areas". ${ }^{153}$ Each of Burstall's regional forest mensuration reports contains fulsome acknowledgements to his helpers and an appeal to readers for more nominations. In his 1994 An Introduction to the Notable Trees of New Zealand, Flook acknowledges "All those Tree Registration Officers and supporters who work voluntarily in the field". ${ }^{154}$ The regional variation and the entries' reliance on local knowledge and advocacy highlight a weakness in the Cyberforest which purports to be representative of the arboreal heritage of the entire country but, in fact, is patchy in content. It also illustrates a characteristic of heritage where value is not necessarily determined by age or historical significance or any other parameter by which it might be judged, but by the enthusiasm of the champion who supports it. It might also be seen to reflect the bias of the final and official selection. Although public participation in the arboreal heritage identification process has been sought and welcomed since Allan's first forays, it has been the decisions of experts that have determined which trees are worthy of a place in the various lists. In the same manner that Allan and Burstall appealed for suggestions for their heritage tree lists, NZNTT cordially invites visitors to its web site to contribute to the Register "by submitting your local trees. That tree you pass everyday just might be a national champion or may even attract international attention". It is, however, NZNTT administration that moderates the nominations before final registration. When nominations are received, an administrator allocates them to one of the following registration categories:

Notable Tree - International Interest

- A tree associated with an international head of state or other figurehead

- The top five New Zealand indigenous champion trees in any species

- Any exotic tree confirmed to be in the top five in the world

Historic Tree - National Interest

- Trees associated with early Māori and European historical legend/settlement

- Trees associated with a prominent national figure

Historic Tree - Local Interest

- Trees associated with a significant local person or important event (jubilee, centenary etc)

\footnotetext{
152 Fuller interview. George Fuller was curator of Pukekura Park in New Plymouth and advised Burstall on notable trees in Taranaki.

${ }^{153}$ S. W. Burstall, "Forest Mensuration Report No. 23 Historic and Notable Trees of New Zealand: Otago and Southland" (Rotorua: New Zealand Forest Service, Forest Research Institute, 1970 [unpublished]). 6.

${ }^{154}$ Flook, An Introduction to the Notable Trees of New Zealand. 2.
} 
Notable Tree - National Interest

- Trees rare in New Zealand, of the earliest known plantings, and of large diameter, height or canopy spread (in the top ten minus the top five which would be international)

- Remnant of an original forest

- Trees considered nationally as outstanding specimens

Notable Tree - Local Interest

- Largest trees in any one of the three dimensions than any of their species known to the region

- Rare or botanically unique local trees, earliest plantings in the district, prominent or landmark tree

- Generally includes any tree over 50 years old

General Tree - all other trees

Nominating a tree for inclusion in the Cyberforest requires access to and familiarity with computers, some tree knowledge (botanical and common names), appropriate equipment (a 50-metre measuring tape and a clinometer or laser rangefinder are suggested) and commitment to supplying reliable data. Nominations are made by creating an online account and filling in the registration form noting measurements (trunk girth, vertical height and both widest and narrowest crown spread), making various field observations and securing landowner permission if the tree is on private land. Reliance on nominations leaves room for uneven representation of trees according to the enthusiasm and/or knowledge of people in the various regions. An analysis of the number of entries per region in the Cyberforest follows.

\section{Registration by Evaluation}

The entries in the Cyberforest include a space for the STEM score of the tree but only if supplied. STEM was launched at the October 1996 NZArb conference in Auckland and in 2012 NZNTT became its copyright holder. The web site states that the method is currently employed (partly or wholly) by more than thirty local authorities to evaluate trees for their district schemes. ${ }^{155}$ STEM evaluates trees according to three classifications: condition, amenity and notability. The following table illustrates how the nominated trees are classified and evaluated under the original 1996 method.

155 As at March 2018. 
Condition Evaluation

\begin{tabular}{|l|l|l|l|l|l|l|}
\hline Points & $\mathbf{3}$ & $\mathbf{9}$ & $\mathbf{1 5}$ & $\mathbf{2 1}$ & $\mathbf{2 7}$ & Score \\
\hline Form & Poor & Moderate & Good & Very Good & Specimen & \\
\hline Occurrence & Predominant & Common & Infrequent & Rare & Very Rare & \\
\hline $\begin{array}{l}\text { Vigour \& } \\
\text { Vitality }\end{array}$ & Poor & Some & Good & Very Good & Excellent & \\
\hline Function & Minor & Useful & Important & Significant & Major & \\
\hline Age (years) & 10 years + & 20 Years + & 40 Years + & 80 years + & 100 years + & \\
\hline $\begin{array}{l}\text { Subtotal } \\
\text { points }\end{array}$ & & & & & & \\
\hline
\end{tabular}

Amenity Evaluation

\begin{tabular}{|l|l|l|l|l|l|l|}
\hline Points & $\mathbf{3}$ & $\mathbf{9}$ & $\mathbf{1 5}$ & $\mathbf{2 1}$ & $\mathbf{2 7}$ & Score \\
\hline $\begin{array}{l}\text { Stature } \\
\text { (metres) }\end{array}$ & 3 to 8 & 9 to 14 & 15 to 20 & 21 to 26 & $27+$ & \\
\hline $\begin{array}{l}\text { Visibility } \\
\text { (kilometres) }\end{array}$ & 0.5 & 1.0 & 2.0 & 4.0 & 8.0 & \\
\hline Proximity & Forest & Parkland & Group 10+ & Group 3 + & Solitary & \\
\hline Role & Minor & Moderate & Important & Significant & Major & \\
\hline Climate & Minor & Moderate & Important & Significant & Major & \\
\hline $\begin{array}{l}\text { Subtotal } \\
\text { points }\end{array}$ & & & & & & \\
\hline
\end{tabular}

\section{Notable Evaluation}

\begin{tabular}{|c|c|c|c|c|c|c|}
\hline Recognition & Local & District & Regional & National & International & Score \\
\hline Points & 3 & 9 & 15 & 21 & 27 & \\
\hline \multicolumn{7}{|l|}{ Stature } \\
\hline \multicolumn{7}{|l|}{ - Feature } \\
\hline \multicolumn{7}{|l|}{ - Form } \\
\hline \multicolumn{7}{|l|}{ Historic } \\
\hline \multicolumn{7}{|c|}{ - $\quad$ Age $100+$} \\
\hline \multicolumn{7}{|c|}{ - Association } \\
\hline \multicolumn{7}{|c|}{ - Commemoration } \\
\hline \multicolumn{7}{|c|}{ - Remnant } \\
\hline \multicolumn{7}{|l|}{ - Relict } \\
\hline \multicolumn{7}{|l|}{ Scientific } \\
\hline \multicolumn{7}{|l|}{ - Source } \\
\hline \multicolumn{7}{|l|}{ - Rarity } \\
\hline \multicolumn{7}{|c|}{ - $\quad$ Endangered } \\
\hline \multicolumn{7}{|c|}{ Subtotal Points } \\
\hline Total Points & & & & & & \\
\hline
\end{tabular}

Table 1: STEM classifications and evaluations, 1996. Reproduction permission courtesy of New Zealand Notable Trees Trust. ${ }^{156}$

\footnotetext{
${ }^{156}$ Ron Flook, STEM: A Standard Tree Evaluation Method (Nelson: self-published, 1996). 12. The method was produced in consultation with: NZArb; RNZIH; NZ Institute of Landscape Architects; NZ Planning Institute; NZ Recreation Association; NZ Landscape Industries; Department of Landscape Architecture, Lincoln University; NZ Institute of Civil Engineers; NZ Institute of Valuers and many individuals.
} 
In his introduction to the 1996 publication of STEM, Flook spelt out how it should be used:

In the assessment of an organic object, the essential ingredient is objectivity ... STEM is able to set a monetary value for trees based on their evaluated quality. However, it is essential to avoid monetary claims being regarded as unreasonable or excessive. A conservative approach is essential even though it may be emotionally disappointing. ${ }^{157}$

The introduction of a points-based evaluation method was a significant step in the evolution of the tree register. Allan's approach for his first 1940 list was far from “emotionally disappointing". He enthusiastically documented a "beautiful oak" in New Plymouth, two "wonderful Araucaria bidwillii" in Okoia a "fine old pukatea" in Whanganui and "magnificent totara" in Canterbury's Peel Forest. ${ }^{158}$ Burstall, whose long career in forestry had entailed the accurate measurement and assessment of forests for their prospective timber value admitted to his own partiality in the preface to his forest mensuration reports:

Decisions to include or exclude particular trees in the various categories and particularly to include one specimen in preference to another of approximately the same dimensions have sometimes caused difficulties. Inevitably subjective judgments have had to be made with which others may not agree, but the regional reports sometimes list several trees of the same species in a particular locality which could be regarded as co-equal, substitute or replacement individuals. ${ }^{159}$

Burstall and Sale's also-ran list of 521 trees that were "too good to leave out" which followed their top-tree list of one hundred in the 1984 Great Trees of New Zealand is another indicator of a passion for trees that might eclipse any formalised evaluation method. ${ }^{160}$

A second numerical evaluation method operating in the Cyberforest records the "champion tree score' which determines the ranking of single-stemmed trees only for international comparison. The metric measurements recorded in individual tree entries for height, girth and a quarter of the average crown-spread are automatically converted to imperial measurements which conform to a United States formula. The resulting champion tree points can then be compared with equivalent scores in the United States, Canada, Australia and the United Kingdom. Where scores are within ten points of each other they become co-champions. Under the champion tree score method any tree in five countries can be reduced to a number

\footnotetext{
157 Ibid. 14.

158 Allan, "Historic Trees in New Zealand." 19-27.

${ }^{159}$ S. W. Burstall, "Forest Mensuration Report No. 18 (Revised) Historic and Notable Trees of New Zealand:

Poverty Bay, Hawke's Bay," (Rotorua: New Zealand Forest Service, Forest Research Institute, 1974 (unpublished)). 3.

160 Burstall and Sale, Great Trees of New Zealand. ix.
} 
and ranked, and arboreal heritage can be accurately measured and valued according to size. The two evaluation methods determine whether or not a tree will be registered and, if successful, how it will be classified. The application of STEM in evaluating trees, however, is inconsistent. Not all entries in the Cyberforest include a STEM score and many of the local authorities who have adopted the method have adapted it to suit their own tree-listing purposes. The three karaka tree profiles that follow illustrate some ways in which this method has been employed.

\section{Three Karaka Tree Profiles}

As karaka is the focus of this thesis, the karaka registrations in the Cyberforest are of special interest. There are only three. The following section of this case study describes the three entries and their relationship with their respective local authority lists. These profiles are included here in order to provide a fuller understanding of the relationship of arboreal heritage evaluation and registration. The entries are:

HBR/0617 28 Kuku Street, Te Awanga, Hawke’s Bay

MWR/G1155 Batchelar Road, Fitzherbert, Palmerston North, Manawatu

TR/0138 Brooklands Park, Brooklands Park Drive, New Plymouth, Taranaki ${ }^{161}$

\section{Profile One:}

\section{HBR/0617 28 Kuku Street, Te Awanga, Hawke’s Bay}

NZNTR registration category: Notable tree-local interest

STEM score: 143

Champion score: 66

Te Awanga is located on the east coast of New Zealand 16 kilometres south of Napier and 12 kilometres east of Hastings. The Cyberforest records that this karaka was planted circa 1950, however, the HDC's 2015 STEM report ages it as "eighty years or more". ${ }^{162}$ In 2000, the tree was allocated a STEM score of 143 and a champion tree score of 66 by B. G. Allport, and was entered (along with its six neighbouring native trees) into the Cyberforest at the request of the tree's owners. The karaka was, at the time, estimated to be 17 metres tall with a crown spread of 12 metres. The RNZIH requested that the trees be included in the arboreal list of the HDC's district plan and this was achieved as part of a plan change in July 2004. The Kuku

\footnotetext{
161 As at March 2018.

${ }^{162}$ Hastings District Council, "Hastings District Plan Hearings Committee Meeting: Outstanding Trees at 28 Kuku Street, Te Awanga.” 18.
} 
Street karaka is the first tree in a line of mature native trees that runs along the boundary from the roadside to the rear of a private domestic garden. The other trees are (from front to back) pōhutukawa, pūriri (Vitex lucens), tawhai (Nothofagus menziesii), rewarewa (Knightia excelsa), kahikatea and pōhutukawa, and are all of similar height. ${ }^{163}$

Between 2004 and 2015 a series of complaints were made to the HDC by the owner of 32 Kuku Street who claimed that the trees were shading her property and causing bird droppings and damage to her house and driveway. The owners of 28 Kuku Street complained to the council that their neighbour was illegally pruning their listed trees. In 2013 the owner of 32 Kuku Street submitted to the council's draft plan that the trees be struck off the Outstanding Trees List and, as a result, the council removed from the list the three trees at the front of the property - the karaka, the pōhutukawa and the pūriri. The owners of $28 \mathrm{Kuku}$ Street objected and the owner of $32 \mathrm{Kuku}$ Street pressed for all the trees to be removed from the list. In March 2015 arborist, Darryl Judd, evaluated the trees according to STEM and allocated 126 points to the karaka. ${ }^{164} \mathrm{He}$ recommended that the trees be removed from the council's list and advised the council:

While the protected tree list is of great value to us now and to future generations it should be constantly under review as trees decline and fail, such is the cycle of life. At times trees need to be removed from the list therefore the community must be encouraged to put forward candidate trees which will last the test of time. ${ }^{165}$

At a hearing on 22 April 2015, the council decided to remove all the trees from the list of Outstanding Trees "on the basis that they do not meet the criteria for Outstanding Trees as outlined in the District Plan". ${ }^{166}$ To qualify for inclusion in the HDC's arboreal heritage list of Outstanding Trees, the decision report stated, trees must be of:

- important local or landmark significance because of height, size or location.

- historical value because of their age and/or the person who planted them or because they commemorate important historical events.

- $\quad$ special botanic interest because of their scarcity or uniqueness, or because they are a particularly good example of their species. ${ }^{167}$

\footnotetext{
163 The tawhai was removed in 2011 due to poor health.

164 The other scores were: pōhutukawa, 120; pūriri, 120; rewarewa, 114; kahikatea, 132; pōhutukawa, 126.

${ }^{165}$ Hastings District Council, "Hastings District Plan Hearings Committee Meeting." 15.

${ }^{166}$ Hastings District Council, "Proposed Hastings District Plan: Decision Report: Outstanding Trees at 28 Kuku Street, Te Awanga." 4.

${ }^{167}$ Ibid. Appendix. As at March 2018 the Te Awanga tree remains in the Cyberforest.
} 


\section{Being There}

Te Awanga, 8 July 2016

Te Awanga is a seaside town located on the way to the tourist destination of Cape Kidnappers and its gannet colony. There's a casual charm here. There are no footpaths or kerbing and channelling in Kuku Street and the tarmac submits willingly to wide grassy berms. It's raining heavily in the afternoon when my husband and I arrive, and the street is quiet and deserted. Kuku Street is generously leafy but it's not difficult to find the karaka we're here to observe. It's at the front of the line of trees that stretches back from the roadside defining the boundary between numbers twenty-eight and thirty-two. These are tall and imposing trees that dominate the space with a line of varying shapes and textures and dwarf the neighbour's house.

From the roadside the effect is one of a selection of mixed native foliage arranged in a long and inconveniently narrow vase. On closer inspection, rather than providing a shiny full-stop at the arrangement's road edge, the karaka we've come a long way to see looks ragged and partially ill-pruned. On one side of the fence the trees are obviously much respected and allowed to grow as they will: on the other side, it seems, they are classified a nuisance and roughly cut back.

Although the entry in the Cyberforest reveals none of the argument that has swirled around these trees, the council's records show that their neighbour complained about them for eleven years. Under this veneer of casual seaside charm there has been conflict in Kuku Street. I trudge wetly up and down the street trying to find a camera angle that will capture both owners' houses and the tree at the same time but it's not easy. While the neighbour's house is easily seen behind a neat picket fence and presents trimmed lawns and a sensibly sited letter-box, the tree owners' house, garden gate and letter-box are almost completely hidden by a tall hedge of mixed native shrubs that tumble off their boundary and onto the berm. Taking any photographs at all without getting drenched proves another challenge so I settle for one damp-hedge shot and one neighbour's-house shot. The binary nature of my 
photographic record metaphorically sums up the quandary that this suburban karaka and its arboreal co-habitants have posed for the keepers of the HDC's list of "outstanding trees".

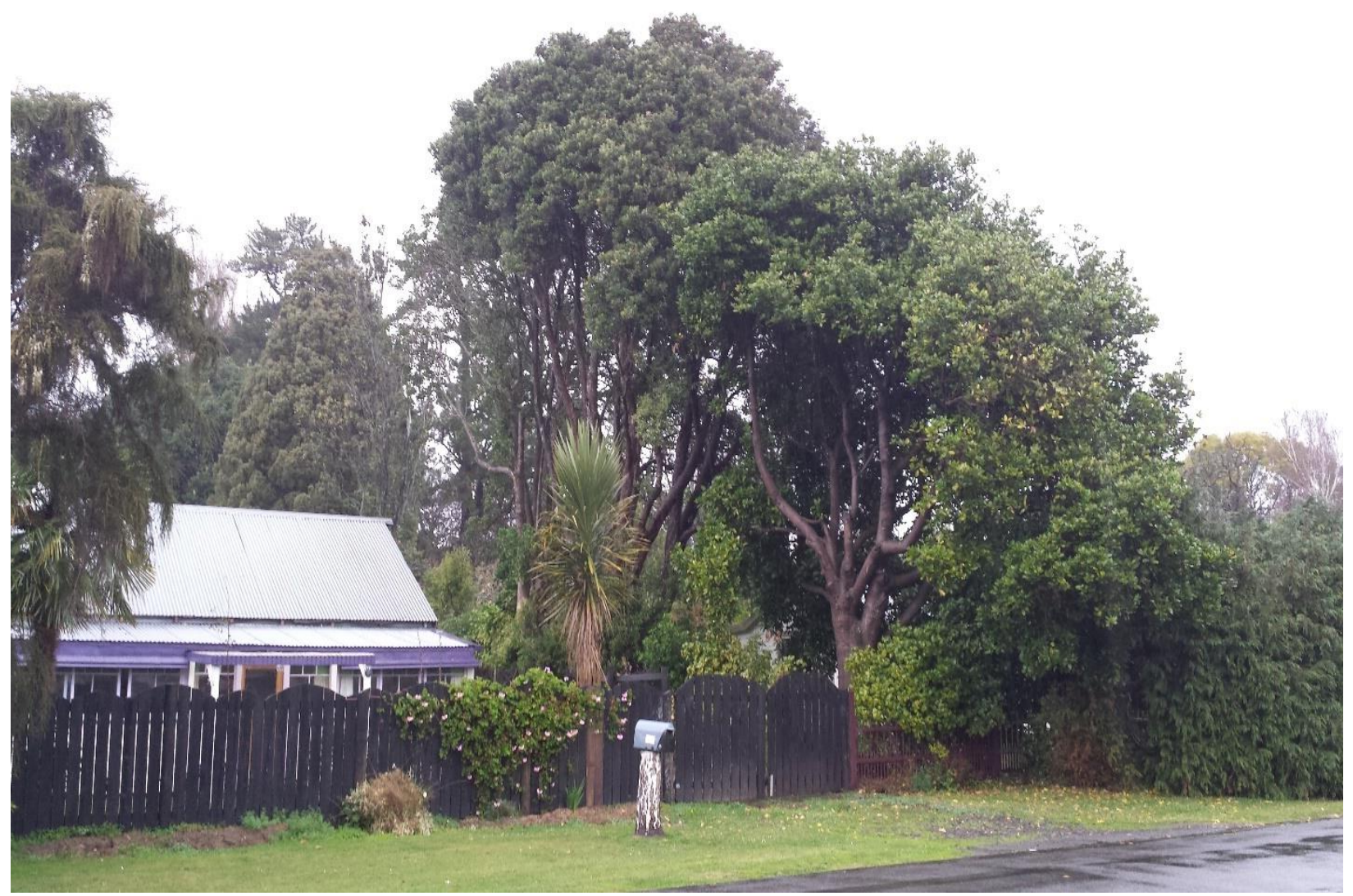

Figure 14: The karaka to the right of 32 Kuku Street showing extensive pruning. (8 July 2016.)

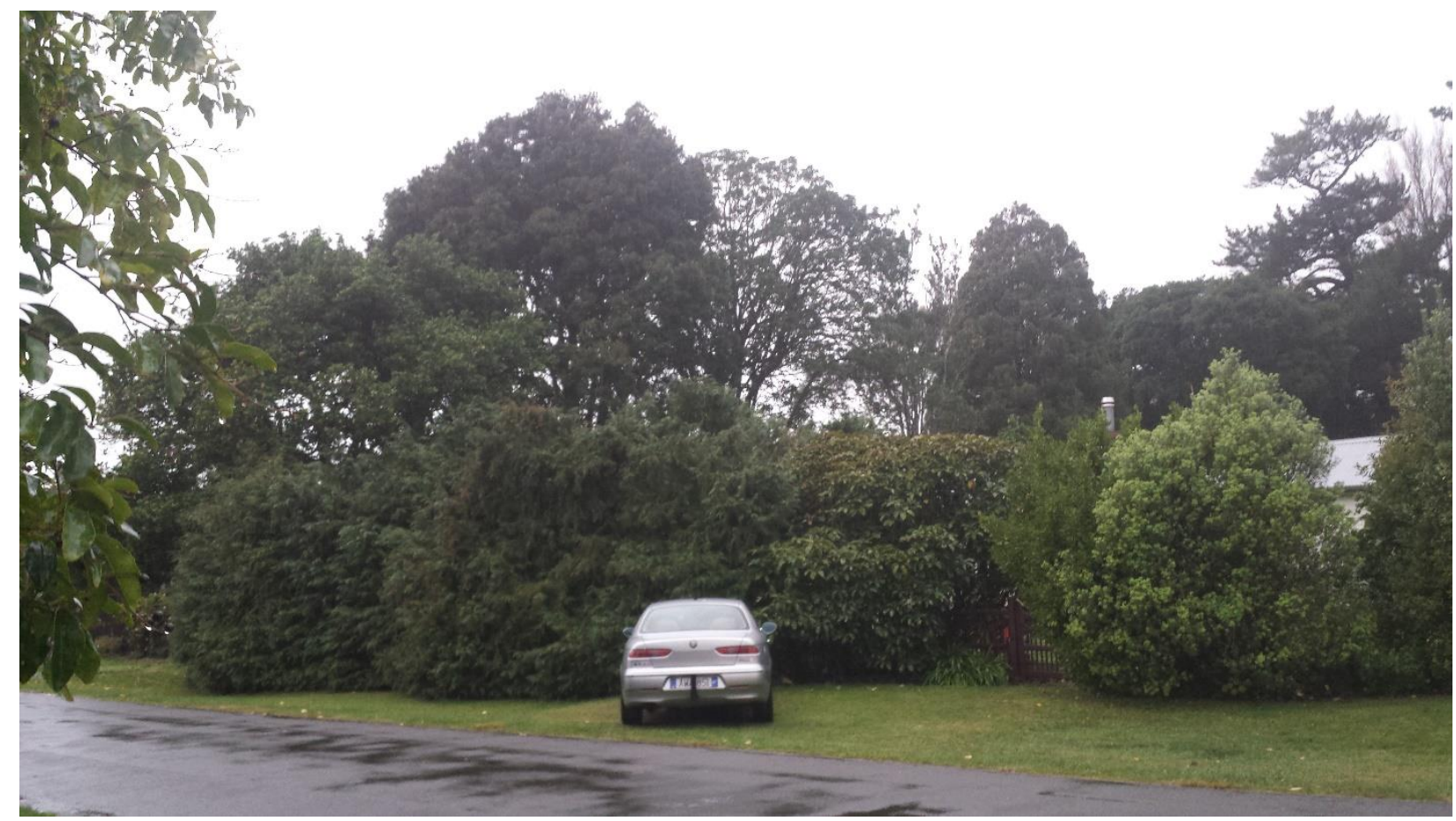

Figure 15: The unpruned karaka at the left of 28 Kuku Street heads the boundary line of native trees. (8 July 2016.) 


\section{Profile Two:}

MWR/G1155 Batchelar Road, Fitzherbert, Palmerston North, Manawatu

NZNTR registration category: Historic tree-local interest

STEM score: None noted

Champion score: None noted

This grove of karaka is located in a reserve between Batchelar Road and the Manawatu River in Palmerston North in the central North Island. The Cyberforest entry notes a grove of forty karaka "established by local tribes to provide a food source ... [and] ... the site of Maori conflict prior to European settlement". The trees are estimated to be planted circa 1800, and in 2013 were described by D. A. Judd as being of "mixed age group and mixed health". The grove was not included by either Allan or Burstall in their early lists. The PNCC district plan has registered the grove in both its Schedule of Objects and Sites of Cultural Heritage Value to Tangata Whenua (local indigenous people) ${ }^{168}$ and its Schedule of Notable Trees, Groups of Trees, and Areas of Significant Indigenous Vegetation (classified under Groups of Trees). ${ }^{169}$

The land on which the grove is situated was originally the home of the Rangitāne tribal group until the late 1860s and was subsequently occupied by John Octavius Batchelar who lived there from 1880 to $1925 .{ }^{170}$ Batchelar learned from Rangitāne chief, Hoani Meihana Te Rangiotu, that several hundred people had died during a battle against invaders on the site in 1820. As a result, he resolved to retain six of the karaka trees that had provided food and shelter for the Rangitāne people as a memorial. In 1926 the land was purchased for Massey Agricultural College and the grove was maintained, it was fenced in 1972 and gardened by the Massey University Department of Horticultural Science from 1981. In 1987 a tōtara carving Te Koha O Te Whenua (the Gift of the Land) ${ }^{171}$ in the style of a pātaka (storehouse on posts), made by John Bevan Ford (Ngāti Raukawa) and Warren Warbrick (Rangitāne), was placed in the grove, and interpretation of the trees and the carving was installed along with a pond in memory of Eileen Earle who had supported the project.

As part of its district plan review in 2011, the council commissioned independent arborists, Wakeling and Associates, to survey the city's notable trees, assessing them for their

\footnotetext{
168 These are sites which have been identified by tangata whenua.

${ }^{169} \mathrm{https} / / /$ www.pncc.govt.nz/plans-policies-and-public-documents/plans/district-plan/ Accessed 29 July 2016.

${ }^{170}$ The following historical information is drawn from the interpretation sign at the entrance of the grove.

${ }^{171}$ The name is based on a Rangitāne waiata (song, chant). For more on the carving See Jill Smith and Peter Smith, Making Connections: John Bevan Ford, Maori Artist (Wellington: Gilt Edge Publishing, 2001).
} 
condition, amenity and notable values according to the council's version of STEM which has been tailored to suit its local context. 'Visibility' of the subjects has been altered to relate to the council roading hierarchy, rather than the distance from which a tree might be seen (as in the original STEM guidelines); 'Stature' has been moved from the Amenity section to the Condition section; and a new criterion 'Public Accessibility' has been added to the Amenity section and noted as "an important factor for local awareness of heritage trees". Wakeling and Associates recommended that the threshold for inclusion in Palmerston North's Schedule of Heritage Trees remain at a score of 160 STEM points, noting that "trees with this score are considered to contribute significantly to the character, identity and history of the city. They are also considered to have a reasonably long and useful life expectancy". ${ }^{172}$ Karaka Grove scored 228 which was the third highest points in the list of ninety single or groups of trees surveyed. ${ }^{173}$ Massey University, as part of its fiftieth jubilee celebrations in 2014, made presentations of fifty karaka seedlings grown from seed harvested from the grove because, Manawatu Campus Registrar, Sandi Shillington, explains in a media release, the grove is "a very real expression of our heritage" and important to local iwi (extended kinship group, tribe), the city and the university. ${ }^{174}$

In 2016, a committee of representatives of Rangitāne, Massey University, PNCC, Horizons Regional Council and the New Zealand Defence Force began to revitalise the grove. The carved pou (posts) which had deteriorated beyond repair were buried at a commemorative ceremony and three new pou were designed and carved by Craig Kawana of Rangitāne and installed in memory of Ford who had died in 2005. The Massey University web site describes the design detail on the pou as representing the pāhiatua, or resting places of the gods, that secure rich harvests. ${ }^{175} \mathrm{~A}$ drinking fountain with an under-planting of native ferns has replaced the pond and the approach to the grove has been planted with pā harakeke (New Zealand flax Phormium tenax) and other native plants. A steel sculpture made by Massey University lecturer, Israel Birch, heralds the entranceway to the grove, and a neighbouring

\footnotetext{
172 Wakeling and Associates, "Survey of Notable Trees for Palmerston North City Council: District Plan Review 2011: Report and Recommendations," 9 June 2011. 6.

173 Top of the list with 234 points is an oak Quercus robur and second with 231 points was a group of four elms Ulmus procera and a deodar Cedrus deodar.

${ }^{174} \mathrm{http} / / /$ www.massey.ac.nz/massey/about-massey/news/article.cfm?mnarticle=karaka-seedlings-to-markmasseys-50th-jubilee-19-02-2014 Accessed 9 February 2017.

$175 \mathrm{http}: / /$ www.massey.ac.nz/massey/about-massey/news/article.cfm?mnarticle_uuid.=C2AA4F15-BE01-09648207-98124Az41D41. Accessed 21 February 2017.
} 
sculpture, carved by Massey University student, Clayton Tansley, acknowledges the surrounding regions of Ruahine, Apiti, Tararua and Manawatū.

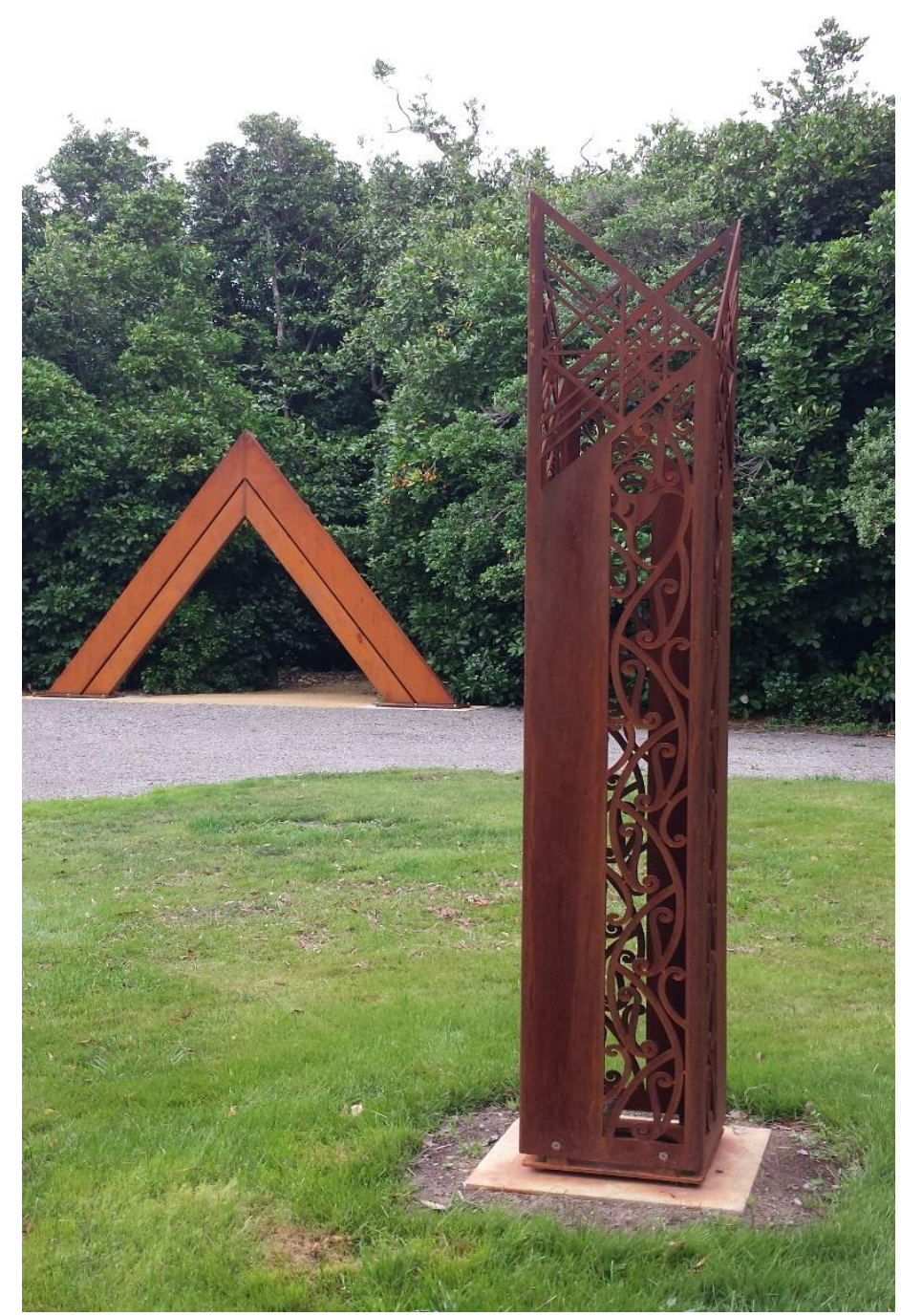

Figure 16: Sculptures marking the entrance to the Palmerston North karaka grove. (19 February 2017.)

\section{Being There}

Palmerston North, 19 February 2017

Finding 'Karaka Grove' in the campus maze of Massey University is comfortingly straightforward as we follow dedicated signs sending us down empty roads flanked by agricultural sheds. It is, therefore, a surprise to be faced with a security camera and a padlocked farm gate obviously blocking entrance to the heritage site to which we have been carefully directed. My husband points out that it is a Sunday, after all, and there are probably weekend security issues surrounding whatever is growing in the sheds. We've driven two hours to get here, however, and we're not going to be put off easily. We smile pleasantly into the camera as proof of our good intentions-and climb over the gate. 
After the impersonal, utilitarian roads and buildings, the introduction to the grove is quite unexpected. A broad lawn is edged with a garden of flax and native shrubs and two large interpretive panels. A tall sculpture on the lawn is slim and delicate and another steel sculpture at the end of a path is contemporary, simple and bold, the exact colour of karaka drupes, and nicely proportioned to slow our pace as we enter the grove. The Cyberforest reports that the grove comprises forty karaka of mixed age and health and is spread over half an acre. But the reality is something quite different. This is a rich and fertile world of large old trees, medium-sized trees and myriad saplings: this is a karaka whānau (family group) that has lived and died here for more than two hundred years.

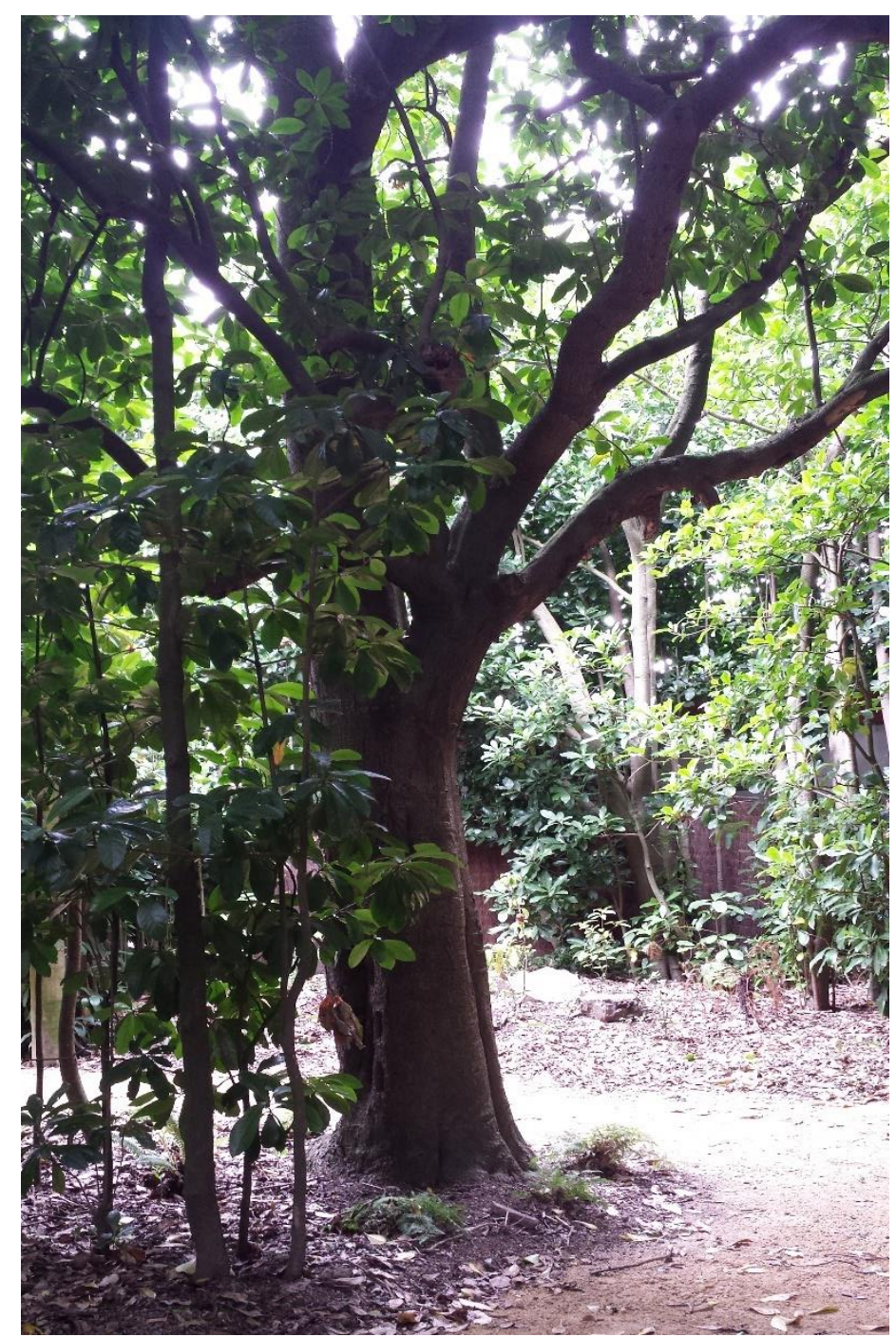

Figure 17: The Palmerston North grove. (19 February 2017.)

The canopy is dense, shiny and complex. There's a greenish light, a cool stillness and an air of sanctity, and we find ourselves speaking softly. The path is informal and threads through the trunks; there's a memorial drinking fountain and an underplanting offerns. There's a wooden bench to sit on and contemplate the trees, the people and the battle that they 
commemorate - and we do. The new pou are wonderful. These respectful, contemporary versions of the Bevan Ford originals feature whimsical black cut-outs and life-like, black insects that serve to leaven the burden of age and violence which this old grove represents. Together, the mature karaka and the young saplings, the pou, the neighbouring sculptures and the flax garden create a very memorable link of past, present and future, and people and place. It's a grove eminently suited to a twenty-first-century university campus.

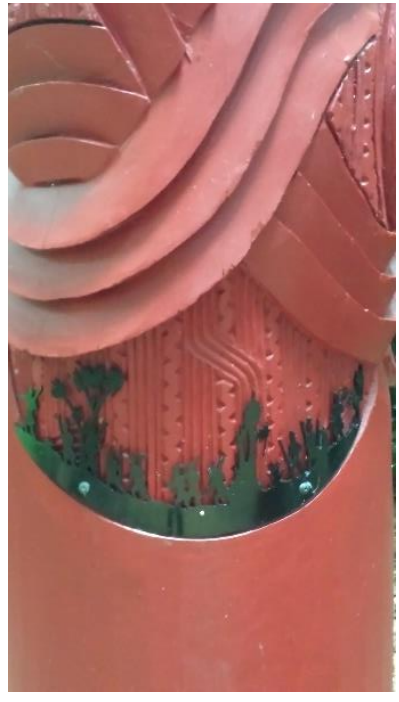

Figure 18: Black cut-outs on the pou represent people and trees.

(19 February 2017.)
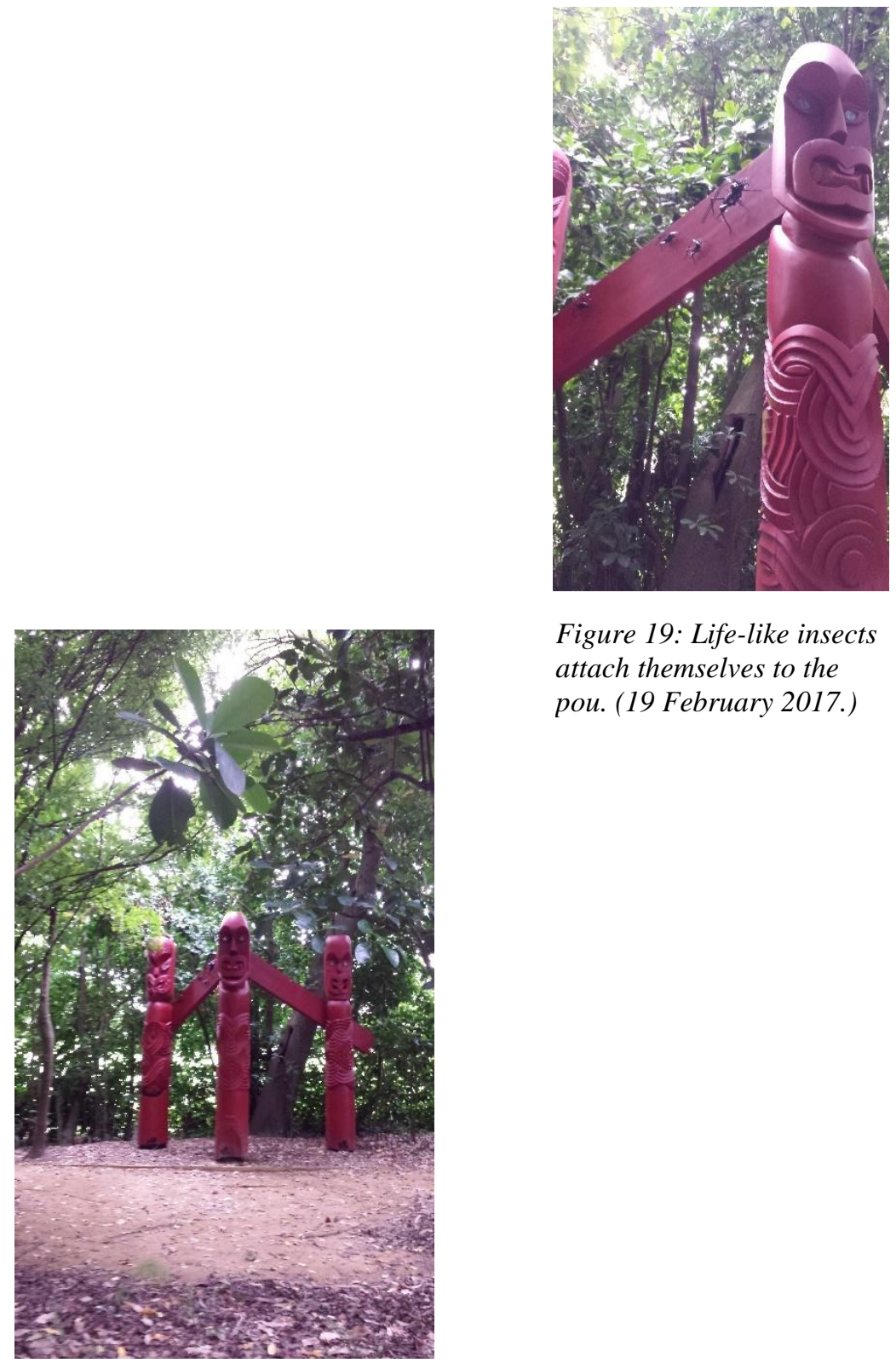

Figure 19: Life-like insects attach themselves to the pou. (19 February 2017.)
Figure 20: The three pou designed and carved by Craig Kawana. (19 February 2017.) 


\section{Profile Three:}

\section{TR/0138 Brooklands Park, Brooklands Park Drive, Brooklands, New Plymouth, Taranaki.}

NZNTR registration category: Notable tree-local interest

STEM score: None noted

Champion score: 210

In 2003 Flook announced at the RNZIH annual general meeting that the one hundredth tree to be entered in the NTNZ database was a karaka in New Plymouth's Brooklands Park. ${ }^{176}$ The tree had been described by Allan as early as 1940 as "a magnificent specimen, fruiting freely" and entered in his list as Number 131. ${ }^{177}$ Burstall later described the tree as an "Indigenous Notable Tree"178 of national interest in his 1973 forest mensuration report and acknowledged Allan's entry; Burstall and Sale included the "veteran karaka" in their supplementary list in Great Trees of New Zealand in 1984 along with "other good trees"; ${ }^{179}$ and Flook listed the tree acknowledging Burstall's comment. ${ }^{180}$ The New Plymouth karaka was entered in the Register by George Fuller who had alerted Burstall to its existence in $1969 .{ }^{181}$

This spectacular tree growing in native bush is registered as 21 metres tall and has two stems that separate at ground level, one of which has a girth of 313 centimetres measured at 1.4 metres and is noted in the Register as the "largest stem recorded". ${ }^{182}$ The current age is "not known”. Despite the frequency with which it appears in tree heritage lists, the Brooklands karaka does not appear in the New Plymouth District Plan's Appendix 13 list of 470 'notable trees' and, although it bears a RNZIH tree label from the 1970s and a number from a now defunct tree trail, it does not have the NPDC protection plaque appended to its trunk as, for example, does the neighbouring pūriri. In reply to inquiries made in person and followed up by email the council advised, "according to our records, this tree is not listed as a Notable Tree in our district plan ... Trees are currently protected on public land by our District Tree

\footnotetext{
${ }^{176}$ Ron Flook, "Report for the R.N.Z.I.H. Executive and A.G.M. Christchurch 2003," (Royal New Zealand Institute of Horticulture 2003). 1.

177 Allan, "Historic Trees in New Zealand." 42. "Historic Trees in New Zealand: Consolidated List from Journals of Royal N.Z. Institute of Horticulture June and September, 1940, June 1941." 6.

${ }^{178}$ S. W. Burstall, "Forest Mensuration Report No. 19 Historic and Notable Trees of New Zealand: Taranaki, Wanganui, Rangitikei, Central North Island" (Rotorua: New Zealand Forest Service, Forest Research Institute, 1973 (unpublished)). 13.

${ }^{179}$ Burstall and Sale, Great Trees of New Zealand. 144.

${ }^{180}$ Flook, An Introduction to the Notable Trees of New Zealand. 70-71.

${ }^{181}$ Fuller interview.

182 The second stem is measured 273 centimetres at 1.4 metres.
} 
Policy. For this reason, we are not intending to include any additional Notable Trees on public land. The current notable trees within Brooklands Park will remain". ${ }^{183}$

The rules in the New Plymouth District Tree Policy, referred to above, apply to the maintenance or removal of notable trees which have been determined by the council's Notable Tree Evaluation Method which is a modified version of STEM that is "relevant to the New Plymouth District context". ${ }^{184}$ Notable trees in the district are classified as category 1 or category 2 according to whether they are considered to be of 'outstanding' or 'significant' historical, botanical landscape, amenity or cultural value. The trees are scored from one to four (lowest to highest) according to the following questions and categories:

- Is the tree a good specimen? (a) stature; (b) form or shape; (c) life expectancy; (d) health and vigour; (e) structural integrity. If the tree scores one it is automatically considered 'not notable'.

- Does the tree have visual/landscape value? (a) prominence of position (b) presence of other trees (c) role in location.

- Does the tree have heritage value? (a) historic (trees that are associated with or have been planted to commemorate an historical event. These include trees that have historic associations with people and places and are important to the city, district or New Zealand). If the tree scores four in this category it is automatically considered to be 'notable'. (b) cultural (this element recognises trees that have spiritual, cultural or other associations (c) approximate age of tree (this element considers the age of the tree. Special merit is given to remnant trees because of their intrinsic value to a particular ecosystem, or when a relict tree exists in an environment that has changed from that which is typical for that tree species)

- Does the tree have botanical/rarity value? (a) occurrence of the species within the local area (b) botanical value. If the tree scores four it is automatically considered to be 'notable'.

- Is the tree manageable in its location? If the tree scores one it is automatically considered to be 'not notable'.

The New Plymouth karaka has been formally documented by the NPDC since at least $1969^{185}$ but, despite my requests to Council staff members, no records were found. The tree does, however, remain in the Cyberforest. ${ }^{186}$

\footnotetext{
${ }^{183}$ Letter from Samantha O'Sullivan, Policy Adviser-District Planning, New Plymouth District Council, 30 September 2016.

${ }^{184}$ www.newplymouthnz.com/Council/Council-Documents/Plans-and.../District-Plan. Accessed 15 September 2016.

${ }^{185}$ Fuller interview.

${ }^{186}$ As at March 2018.
} 


\section{Being There}

New Plymouth, 27 October 2017

I know this karaka well, which is why I've put off writing this section for some time. I decide it needs a second pair of eyes to help me describe it, and I invite a friend to visit the tree with me. We meet at the nearby Brooklands Zoo which is filling up with parents and their happily shrieking pre-schoolers. It's a sunny spring day and the gardeners are watering new begonia beds on the vast, manicured lawn. We set off to the southern bush end of the park, turn right and step off the sealed path onto an informal track and into the cool, green disarray of bush. A young mother with one child in a pushchair and another on a very small tricycle bush-bash their way by-and then it's still and quiet again. My friend used to live nearby, brought her children up there and walked the park with them day after day but thinks she might not know the particular tree I'm taking her to see. As it turns out, she doesn't. She knows the nearby püriri and the gingko, though-they both have council signs on the path. We crunch a little way over fallen leaves and branches along the track and there it is.

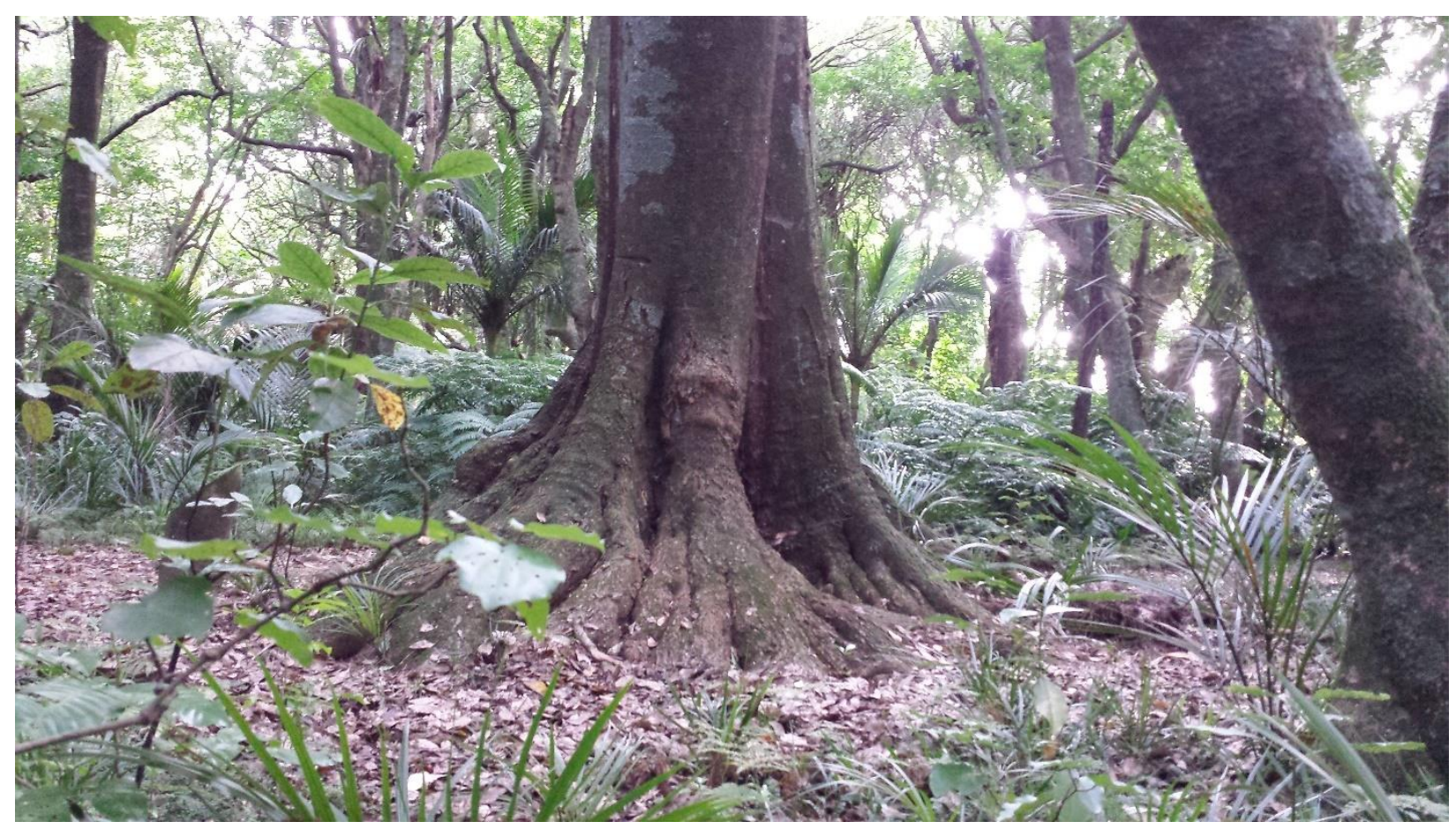

Figure 21: The buttress 'feet' of the New Plymouth karaka. (27 October 2017.) 
My friend is suitably impressed, can't believe it's only one tree, loves its sturdy buttress 'feet' and the dapple-effect the sun casts onto the ground, and she marvels at the way the canopy spreads and spreads and leans gently onto neighbouring and more youthful limbs. She's intrigued by the way the outermost branches curl and spring and ponders the ability of the two such heavy trunks to reach skyward like worshipping arms. We try to remember the name of the yoga pose that does the same action but fail. "Do you hug it when you visit?" she asks? "It's gorgeous." I'm glad she came.

We view the karaka from all angles, examine the saplings that grow at its base, trace the thick roots that thread the ground and gaze up into the green canopy for so long we have sore necks. Next time, she says, she'll bring a cushion and lie down to admire it. Ornithologist David Medway writes that he has observed kererū in the park swallowing karaka fruit whole, and blackbirds transporting fruit to safer ground for pecking. There are no kererū or blackbirds to be seen here today, though. This is tūi-time and, as we leave the bush for the sunshine and the orderliness of the park, I hear one sounding the same clear note over and over like a piano tuner.

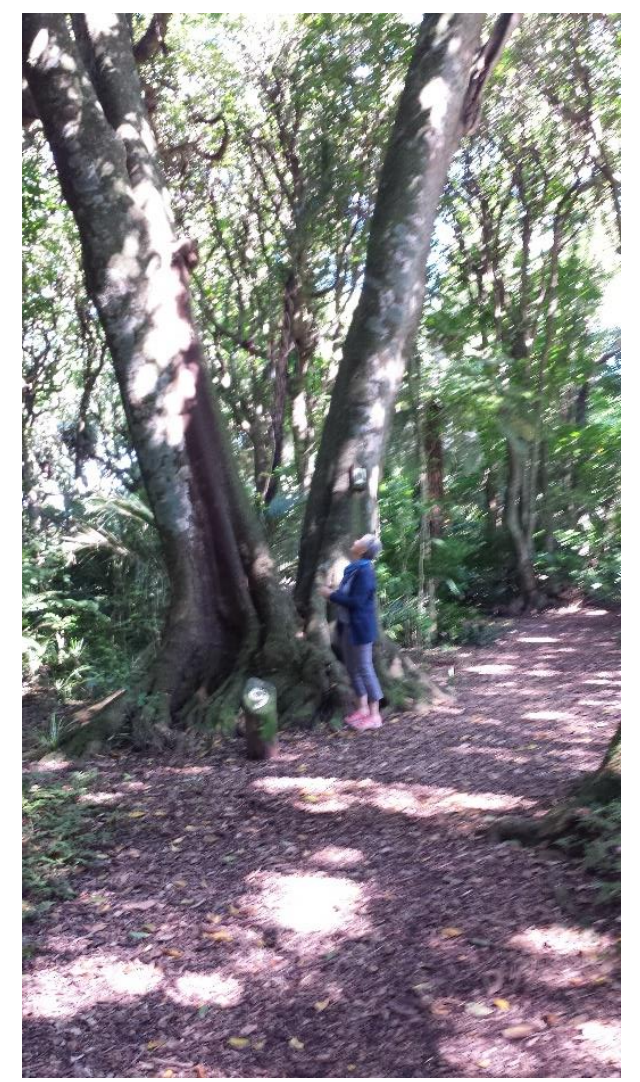

Figure 22: The two trunks and the canopy's dapple effect. (27 October 2017.)

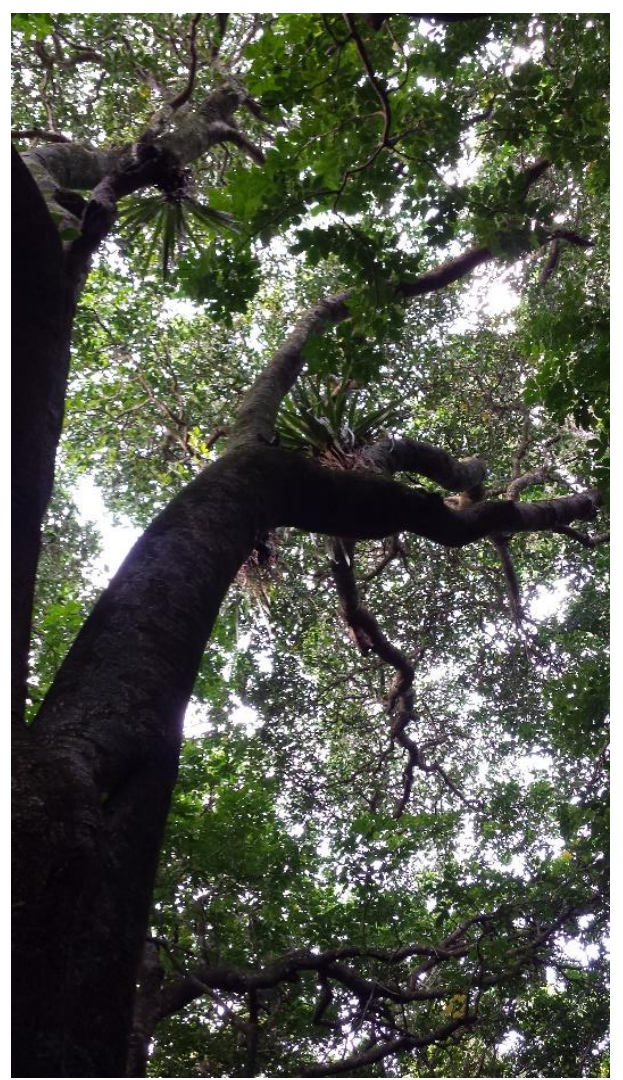

Figure 23: The interlocking canopy. (27 October 2017.) 


\section{Profile Summary}

Profile One: HBR/0617 28 Kuku Street, Te Awanga

Profile Two: MWR/G1155 Batchelar Road, Palmerston North.

Profile Three: TR/0138 Brooklands Park, New Plymouth

While the Cyberforest's three karaka entries all classify the trees as being of local interest and are all drawn from locations generally in the centre of the North Island, they have variable provenances. Profile One is part of a (estimated) sixty-seven-year-old group of mixed species trees in a domestic setting but is registered as a single tree; Profile Two is a privately-owned but publicly accessible group of trees identified and celebrated, by both the landowner, Massey University, and tangata whenua, Rangitāne, as of Māori origin and more than two hundred years old; and Profile Three is a single tree in a park, noted for its size but with no official estimate of age. The manner in which they are recorded in the Cyberforest also differs: only Profile One has a supplied STEM score and only Profiles One and Three have champion scores (champion scores are awarded only to single trees and not to groups of trees).

The most noticeable evaluation and registration differences, however, occur in the local authority lists. The first, and most significant difference, is the omission of Profiles One and Three from the district plans of HDC and NPDC respectively. In contrast, Profile Two is listed in two schedules of the PNCC's district plan. While Profile One was evaluated according to STEM as designed by Flook, Profiles Two and Three have been evaluated by STEM modified to suit their respective local authorities' requirements. The nomenclature of tree classification in the three separate local authorities differs also: Profile One was removed from the HDC's list of 'Outstanding Trees'; Profile Two is classified both as a 'site' and as a 'group of trees' in PNCC's two separate schedules 'Sites of Cultural Heritage Value to Tangata Whenua' and 'Notable Trees, Groups of Trees, and Areas of Significant Indigenous Vegetation'; and Profile Three is missing from the NPDC's list of 'Notable Trees'.

\section{Interrogating the Lists}

This section reorganises the material of the heritage tree lists discussed above, according to the numbers of native and exotic trees registered and presents the results in table form. The purpose of the exercise is to further investigate the similarities and differences of arboreal evaluation and registration. This action is supported by Gass's theory that lists invite interrogation and that reordering a list establishes a quite different entity, as discussed in the 
preceding literature review. ${ }^{187}$ None of the four lists studied here (the Cyberforest, and HDC, PNCC and NPDC tree lists) differentiates between native and exotic trees ${ }^{188}$ which is in the spirit of the original 1937 intention of the NZIH to list both, and follows the listing pattern set by Allan and, subsequently, adopted by Burstall. It is important to note, therefore, that the reordering of the lists imposes new classification on existing lists.

The decision to reclassify the entries by winnowing native trees from exotic trees is based on the evidence discussed in preceding sections. The first example of this evidence is Parry's 1937 reference, in his address at the Bush Preservation and Amenity Tree-Planting conference, to the "vexed question of natives versus exotics" which alluded to the robust discussions taking place in the 1930s concerning the trees best suited for planting in parks and reserves and growing in state forests. Useful background to Parry's remark is provided by the reported comments of the director of Kew Gardens Dr Arthur William Hill who, in 1928, addressed the New Zealand government concerning the indiscriminate planting of exotics in natural reserves which "should be sacred to the native flora". ${ }^{189}$ The New Zealand Herald reported that Hill's warning came, "when sentiment in favour of the purely native is strongly represented in the community and growing ... [his] views will be of great use to those who are fighting to preserve the native flora", and inflamed the debate. ${ }^{190}$ The NZIH's decision to adapt a remit encouraging the government to preserve the "trees planted by our pioneers on estates throughout the Dominion" to a second version urging the government to preserve the "trees planted by our pioneers, or other historic trees", thereby expanding the classification to include naturally growing native trees, suggests that the issue of natives versus exotics was still alive in $1938 .{ }^{191}$ The passionate denunciations of the early destruction of the country's natural environment made by McLintock and Guthrie Smith, and the energetic attempts by $\mathrm{McC}$ askill to encourage native tree planting during the centennial celebrations are further evidence of concern. Another prompt for the reclassification of lists according to native and exotic entries is provided by the three native tree profiles, above,

\footnotetext{
187 Gass, "I've Got a Little List."

${ }^{188}$ However, native trees are singled out in the Cyberforest as being valued as generators of international interest and providers of a "fascinating tour for overseas tree enthusiasts".

189 "National Reserves: Introduction of Exotics: Expert Expresses Fears,” New Zealand Herald, 3 April 1928.

${ }^{190}$ Governor-General, Lord Bledisloe, when opening Brooklands Park in 1934 had continued the discussion by warning its New Plymouth custodians against any temptation to "mix up your native and your exotic trees", "Native Park: Gift to Citizens: New Plymouth Reserve: Opened by Lord Bledisloe," Auckland Star, 12 March 1934. See also letters to the editor, "Native and Exotic Trees," Evening Post, 28 March 1936.

${ }^{191}$ Allan, "Historic Trees in New Zealand." 19. Italics not in the original.
} 
which demonstrate that two of the three karaka entries (Te Awanga and New Plymouth) may have uncertain futures as local authority-registered 'outstanding' or 'notable' trees.

As indigenous trees, which have been distributed, either naturally or culturally, well beyond their endemic range, karaka might be seen to be ubiquitous in the North Island and, as discussed in the introduction to this thesis, are sufficiently successful to be considered by some to be a 'weed'. ${ }^{192}$ When measured by the evaluation methods adopted by their respective local authorities, neither the Te Awanga nor the New Plymouth karaka is able to score highly unless it can claim 'historical' values (HDC) or 'heritage' values (NPDC). The Te Awanga karaka was planted in the early to mid-twentieth century and makes no claim to being associated with a notable person or to commemorate an important historical event: the Brooklands karaka is old, given its size, but no record of age is available and it is unknown whether or not any allowance has been made for its possible "spiritual, cultural or other associations".

Native trees are naturally distributed throughout New Zealand—according to regional climatic and geographical variations - and, therefore, might struggle to qualify for categories of "special botanic interest because of their scarcity or uniqueness" (HDC district plan), or to secure a positive answer to the question "does the tree have botanical/rarity value?" (NPDC district plan). As Bowker and Star point out, classifications are powerful technologies that are embedded in registers and carry out both political and ethical work. ${ }^{193}$ The reclassification of the Cyberforest's three karaka as native or exotic is intended as a tool to understand more fully the heritage tree selection process and, thereby, the contribution of listing to arboreal heritage and some of the values that underlie it.

The tables that follow are indicative rather than definitive. If groups of trees are specifically noted as native or exotic they have been included in the figures: if a native or exotic tree is not specified in a tree group entry the entry has not been included. Total entries in the lists, therefore, may not tally with the numbers of entries shown in the graphs. Table 2 examines the balance of native and exotic tree entries in five arboreal heritage lists discussed here and compiled between 1943 and 2016. Table 3 reorders the Cyberforest as native and exotic tree

\footnotetext{
192 Similar circumstances surround the wide distribution of pōhutukawa beyond its endemic range.

${ }^{193}$ Bowker and Star, Sorting Things Out. 319.
} 
entries for each of the nineteen geographic areas and Table 4 reorders, according to native and exotic entries, the heritage tree lists of the three local authorities associated with the three preceding tree profiles.

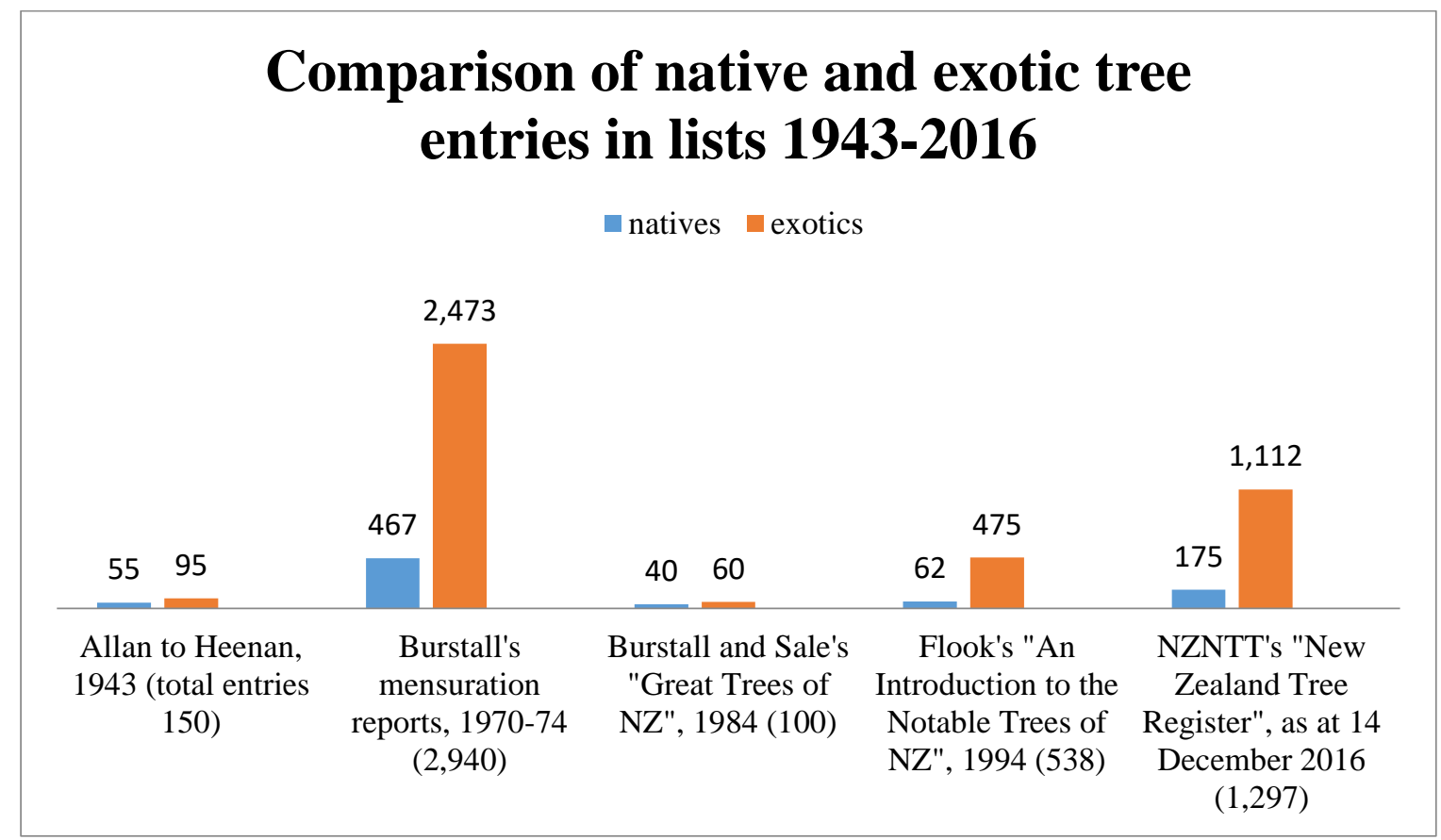

Table 2: Comparison of native and exotic tree entries in lists 1943-2016.

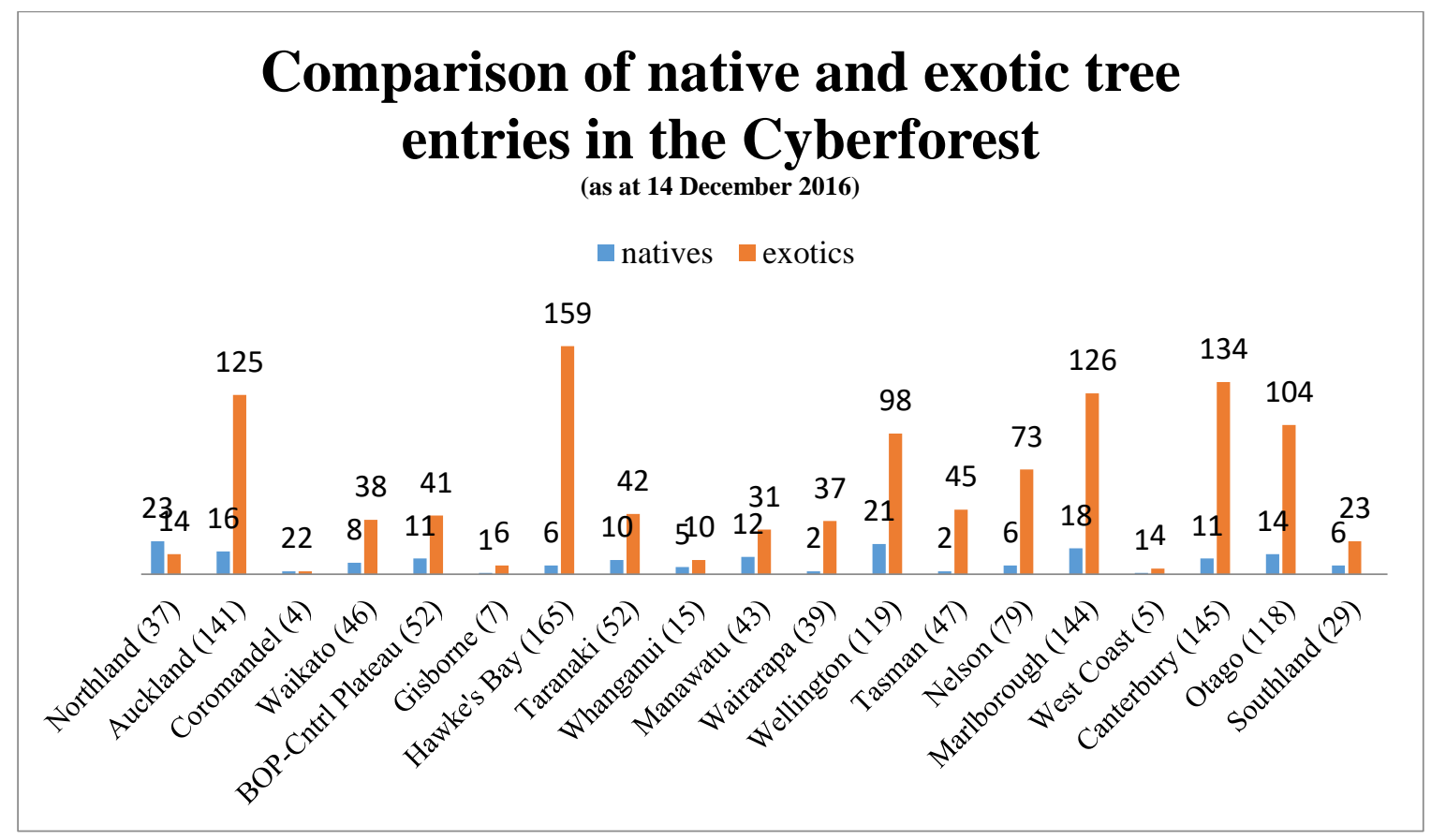

Table 3: Comparison of native and exotic tree entries in the Cyberforest. 


\section{Comparison of native and exotic heritage tree lists in three council district plans \\ (as at 12 February 2017)}

natives $n$ exotics

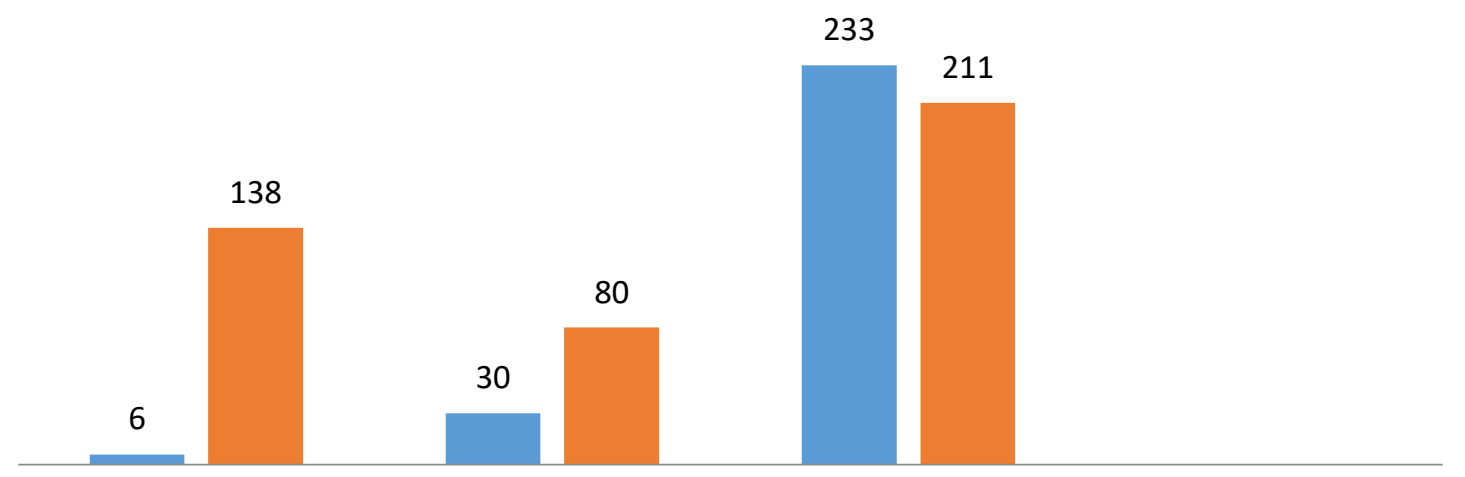

Hastings District Council Palmerston North City New Plymouth District Council Council

Table 4: Comparison of native and exotic heritage tree lists in HDC, PNCC and NPDC district plans.

All three tables demonstrate that predominantly more exotic trees than native trees have been, and are still, registered following a pattern set by Allan's list compiled in 1943 and culminating in the contemporary Cyberforest and the three council district plans. The only exceptions to this trend occur in the Northland and Coromandel regions both entered in the Cyberforest, and in the numbers listed in the NPDC district plan. The numbers of trees generally, however, differ widely across the various lists. ${ }^{194}$

\section{Conclusion: The Hegemony of the List}

Following the 2010 and 2011 Canterbury earthquakes, the Christchurch City Council introduced a replacement district plan that had been designed to enable the city to rebuild, and which proposed a reduction of approximately 84 per cent of the city's original list of significant trees. ${ }^{195}$ The announcement resulted in a public outcry and the establishment of an independent hearing panel to mediate between a group of submitters and the council. As a result of the twenty-one-day hearing, 80 per cent of the 1,623 trees on private land were retained on the new list, 724 trees listed on public land were returned to the new list, and objectives, policies and rules were established "to provide recognition and some protection

\footnotetext{
${ }^{194}$ PNCC's district plan, however, contains a classification of "indigenous status" that gives particular recognition to "New Zealand's unique indigenous trees. Particular recognition is given to those trees that only occur locally or regionally".

${ }^{195}$ Email from NZNTT, 26 November 2016.
} 
for scheduled trees". ${ }^{196}$ In the mediation process the Christchurch Tree Evaluation Method (CTEM) by which the trees were assessed received strong criticism from the Christchurch Civic Trust and allied submitters including RNZIH, NZArb, and NZNTT and was subsequently modified resulting in a significant increase in the number of trees to be assessed for the list. ${ }^{197}$ The Christchurch event illustrates the passion that people feel for their arboreal heritage and the faith they place in arboreal heritage lists. Similar outrage at threats to trees and respect for their registration are noted in the thesis Conclusion. This case study inquiry into the evolution of the Cyberforest, its values and role in arboreal heritage, however, has revealed many misconceptions about arboreal listing that question the basis for public faith in the listing system.

The first is the perennial belief that an arboreal heritage list is synonymous with protection. The evolution of the Cyberforest demonstrates that, although the intention of the first lists was to assist in the protection of trees against the "terrible consequences" brought by the early destruction of the environment, and the political actions of the 1970s and 1980s were aimed at securing protective legislation, contemporary lists can make no claim to guarantee permanent protection of the listed trees. The aim of the Cyberforest is to raise the "profile of significant community trees, foster the centralisation and exchange of tree information, and to encourage people to submit trees that they think are important. By centralising records we can share information with a wider audience and compare them against national and international records". ${ }^{198}$ The HDC endeavours to "protect trees which make an outstanding contribution to the District's amenity and/or heritage" and to "encourage the preservation of trees which make a significant contribution to the District's amenity and/or heritage". ${ }^{199}$ The PNCC includes in its list trees "which Council considers require protection, and any further addition or deletion of a tree from the Schedule will only be considered where a request for a Plan Change has been received". ${ }^{200}$ The NPDC's district plan protects notable trees from "destruction or alteration which will adversely affect their significance or health, except

\footnotetext{
196 Ibid.

${ }^{197}$ Independent Hearings Panel, "Decision 44: Chapter 9: Natural and Cultural Heritage (Part). Topic 9.4Significant Trees," 5. Cadwallader interview.

198 https://www.notabletrees.org.nz. Accessed 23 November 2017.

${ }^{199}$ Hastings District Council, "Hastings District Plan Hearings Committee Meeting." 46. Underlining in the original.

200 https://www.pncc.govt.nz/plans-policies-and-public-documents/plans/district-plan/ Accessed 29 July 2016.
} 
where they pose a threat to property, people or services". ${ }^{201}$ Rather than being concerned primarily with 'protection' contemporary arboreal heritage lists focus on 'collection'.

A second misconception is that arboreal heritage lists are stable. Trees are living entities and therefore grow and die naturally: they are also vulnerable to the axe and the firestick as noted by Parry in 1937, and to the "terrible pioneer urge" described by Millener in 1970. The descriptions of the early tree lists in the second section of this chapter and the profiles of the Cyberforest's three karaka entries in the third section demonstrate that the content of the lists can be dynamic for reasons other than the life span of the trees. Only fifteen entries from Allan's 1943 list made it into Burstall and Sale's list of one hundred great trees and the authors noted that by the time they had compiled their book forty years later sixty-eight of Allan's trees had been felled or had died. A review of Burstall's unpublished mensuration reports on native and exotic trees carried out in 2000 by Wintec (Waikato Institute of Technology) Diploma in Arboriculture students found that 1,171 (29.7\%) of the 3,943 trees documented by Burstall between 1970 and 1974 had been lost. Of these, 667 (53\%) had made way for development; 339 (29\%) had died from natural causes and 210 (18\%) were unable to be found. ${ }^{202}$ Of the three karaka heritage sites profiled here only one has remained secure in its associated local authority list; the remaining two have been deaccessioned although at the time of writing they remained standing. The Cyberforest, however, maintains the memory of deaccessioned or fallen trees it has registered by retaining the entries permanently on its list.

A third misconception is that arboreal heritage lists are truly representative of the region. The variability shown in tables 3 and 4 suggests that the numbers reflect the nominations received and accepted rather than the number of trees that might qualify from all the regions. The Cyberforest makes no claim to being a comprehensive data base but instead states that, "documented here is a growing list of some of our finest trees on current record". ${ }^{203}$

\footnotetext{
201 www.newplymouthnz.com/Council/Council-Documents/Plans-and.../District-Plan. Accessed 15 September 2016.

${ }^{202}$ The Wintec review noted that only $4.2 \%$ of the natives listed by Allan (compared with $44 \%$ of all the trees listed) had been lost to attrition by the time Burstall and Sale had presented their own lists. Furthermore, the review found that $2.5 \%$ of the native trees noted by Burstall and Sale had been lost (compared with $29.7 \%$ of all the trees listed). The review suggests that the lower percentage of native tree loss may be attributed to their frequent location on conservation or reserve land; the superior resilience and longevity of native trees in their natural climate; the reverence paid them by members of the public or the perception that they are protected; a combination of all of the above. Rob Graham et al., "The Notable Trees of New Zealand," Arboricultural Journal: The International Journal of Urban Forestry 34, no. 2 (2012).

203 https://www.notabletrees.org.nz. Accessed 23 November 2017. Italics not in the original.
} 
A fourth misconception is that arboreal heritage lists are impartial documents of the most noteworthy trees. Any collection is subject to curatorial decision-making as to what is included and what is discarded and how the decision is reached. STEM was originally formulated to ensure that lists were objective and that trees could be valued in monetary form if necessary. The method is now employed in pure or modified form by many caretakers of this country's arboreal lists, and evaluations are included in the Cyberforest if supplied by nominators of trees. STEM is a powerful and discriminatory tool. Tables 2, 3 and 4 demonstrate, for example, that native trees tend to register poor scores in the heritage tree lists examined in this thesis. Ministry for Primary Industries' figures record 6.4 million hectares of native forest in New Zealand, and 5.2 million hectares-about 24 per cent of the country's total land area-as protected conservation land. ${ }^{204}$ Given these statistics the results shown in tables 2, 3 and 4 might seem surprising. Some reasons for the discrepancy are inherent in the curatorial values imposed by the evaluation systems. Natural (rather than cultural) native trees might score well, under STEM'S headings of 'form' 'vigour/vitality' (health); 'function' (usefulness including flowers, fruit, foliage, timber and physical and conservation contributions to ecosystems); 'age'; 'stature' (size and shape); 'climate' (shade, shelter and temperature control); 'remnant'; and 'relict' (existence in an environment changed from that typical for the species). However, high scores might prove elusive under the headings 'occurrence' ('very rare' scores maximum points); 'visibility' (distance from which it can be seen); 'proximity' (solitary scores highest), 'role' (aesthetic contribution to its setting); 'source' (species quality or generic derivation), 'rarity', and 'endangered'.

In his evaluation of the Te Awanga karaka Judd concluded that, while all the trees in the group were of value to the streetscape and the local community, it was difficult to measure them according to STEM and achieve the threshold of points to warrant protection. ${ }^{205} \mathrm{Just}$ as the presence of certain curatorial values can be seen to influence arboreal heritage lists, so can the absence of others. As Bowker and Star have pointed out, each standard and each category:

valorizes some point of view and silences another. This is not inherently a bad thing - indeed it is inescapable. But it is an ethical choice, and as such it is dangerous - not bad, but dangerous". ${ }^{206}$

\footnotetext{
${ }^{204} \mathrm{https} / / / \mathrm{www} . \mathrm{mpi}$.govt.nz/growing-and-producing/forestry/indigenous-forestry/ Accessed 16 February 2017.

${ }^{205}$ Hastings District Council, "Hastings District Plan Hearings Committee Meeting." 35.

${ }^{206}$ Bowker and Star, Sorting Things Out. 5-6.
} 
In this respect, STEM barely acknowledges the intangible heritage values of trees'traditional, spiritual, religious, ritual or mythological elements - beyond subheadings of 'association' (with events or people) and ‘commemoration' (of an occasion). ${ }^{207}$

In another example of the variability of classification within heritage tree lists, the Palmerston North City District Plan includes a policy requiring the council to work with tangata whenua to identify sites and objects of significant cultural and natural heritage value according to both physical importance and "metaphysical" importance:

Importance associated with a site or object due to its location, historical setting or commemorative value (this also includes spiritual, symbolic, legendary and political values). Although many sites may no longer exist in a physical form, many of these areas have a Turangawaewae/Taha wairua connection. ${ }^{208}$

Despite this policy, however, PNCC's district plan includes only thirty native tree entries.

Harrison argues that a list of heritage can be viewed as a type of canon which, he writes:

might be understood to represent ideological tools that circulate the values on which particular visions of nationhood are established. Creation of a class of 'things' that are seen to be the greatest expressions of culture promotes, in turn, narratives about the sets of values that are seen to be the most worthy in the preservation of a particular form of state society. The heritage list, like the literary or artistic canon, is controlled by putting the power to establish the canon into the hands of experts who are sanctioned by the state. ${ }^{209}$

The evidence presented in this case study demonstrates similarly that the creation of a class of heritage trees that are seen to be the greatest expressions of nature promotes "narratives about the sets of values that are seen to be the most worthy in the preservation" of particular forms of New Zealand's society.

The Cyberforest and the other arboreal heritage lists examined in this chapter are governed by set criteria based on associated values agreed on largely by experts who assess entries and curate them. In this regard, the lists are typical manifestations of what Smith describes as a "hegemonic discourse about heritage", or the authorised heritage discourse, or AHD. ${ }^{210}$ The arboreal heritage lists studied here predominantly privilege monumental, large, old and rare

\footnotetext{
${ }^{207}$ The New Zealand Tree Register does, however, note any that are known.

${ }^{208} \mathrm{https} / / /$ www.pncc.govt.nz/plans-policies-and-public-documents/plans/district-plan/ Accessed 29 July 2016.

${ }^{209}$ Harrison, "Understanding the Politics of Heritage." 15. See also Mitchell in Bennett "New Keywords".

${ }^{210}$ Smith, Uses of Heritage. 11.
} 
trees, and are curated by experts who pass on the selections and values that support them to their visitors or observers. ${ }^{211}$ This case study, through an examination of the evolution of the Cyberforest, the presentation of three karaka profiles and interrogation of associated arboreal heritage lists, demonstrates that listing of arboreal heritage largely bears the hallmarks of the authorised heritage discourse as defined by Smith—-privileging "monumentality and grand scale, innate artefact/site significance tied to time depth, scientific/aesthetic expert judgement, social consensus and nation building". ${ }^{212}$ The Cyberforest is defined here as a manifestation of the authorised arboreal heritage discourse (AAHD) and as a site of Heritage Trees. The following two chapters employ Harrison's counter-approach by introducing the notion of an unauthorised arboreal heritage discourse (UAHD) represented by the Anthropocene Grove (Trees as Heritage) and the Dendroglyph Trees (Heritage as Trees).

211 The Cyberforest's category General Tree is an exception.

212 Smith, Uses of Heritage. 11. 


\section{CHAPTER THREE: THE ANTHROPOCENE GROVE: TREES AS HERITAGE}

\section{Introduction}

In August 1997, after a year-long moratorium on the development of Wellington's waterfront, prompted by public concern about its direction and management, and following two months of intensive public consultation, the Wellington City Council appointed a multidisciplinary team to produce a waterfront design plan. A team of architects and landscape architects, along with urban designers, advisers and planners, was provided with the results of a city-wide letterbox survey, the recommendations of the city's Community Consultative Committee (CCC $)^{1}, \$ 400,000$ and eight weeks with which to draw up plans of public spaces on the waterfront, predicted costs and planning guidance. The CCC reported that Wellingtonians who had responded to the survey considered heritage to be a "key component of Lambton Harbour's uniqueness and should be a major focus":

Retaining heritage through the restoration of buildings, objects, artefacts and monuments is seen as an important consideration and guiding principle for Lambton Harbour.

Heritage must include both pre- and post-European history. The importance of the waterfront to Maori is an important consideration when heritage trails and other interpretation are developed. ${ }^{2}$

Specific issues identified through the public consultation included an opportunity to "reveal the history of the waterfront, particularly at the Taranaki St Wharf, by peeling back different surface layers to show the historic changes over time" and carrying out archaeological investigations to uncover the wharf building foundations and the old sea wall. ${ }^{3}$ Wellington had started taking more interest in conserving its historic buildings and districts following the construction of the inner-city motorway in the 1960s that had cut a swathe through a large part of the Bolton Street Cemetery and destroyed many of the nineteenth-century cottages between the Tinakori Hills and the harbour. ${ }^{4}$ Large-scale destruction of buildings and entire streetscapes, and the construction of new office buildings in central Wellington along with

\footnotetext{
${ }^{1}$ The CCC was a group of community and business representatives appointed by the Wellington City Council in July 1996 to review development of the waterfront and consult with the community. It presented its findings in November 1996.

${ }^{2}$ Community Consultative Committee, "Report on Lambton Harbour," (Wellington: Wellington City Council, 1996). 47.

${ }^{3}$ Ibid. 49.

${ }^{4}$ David Hamer and Roberta Nicholls, "Introduction," in The Making of Wellington 1800-1914, ed. David Hamer and Roberta Nicholls (Wellington: Victoria University Press, 1990).
} 
the condemnation of historic buildings as earthquake risks had diminished the historic heritage of the city but, at the same time, raised its people's awareness of it. ${ }^{5}$ The Lambton Harbour Public Spaces Concept Plan was unveiled in October 1997, the public was consulted once more, the results were reported by the CCC in December and the design plan, with some modifications, ${ }^{6}$ was adopted by the council the next year. Included in the plan for the Taranaki Street Wharf area on the waterfront was a grove of young karaka to be planted on, what would become known as, Odlin's Plaza. ${ }^{7}$

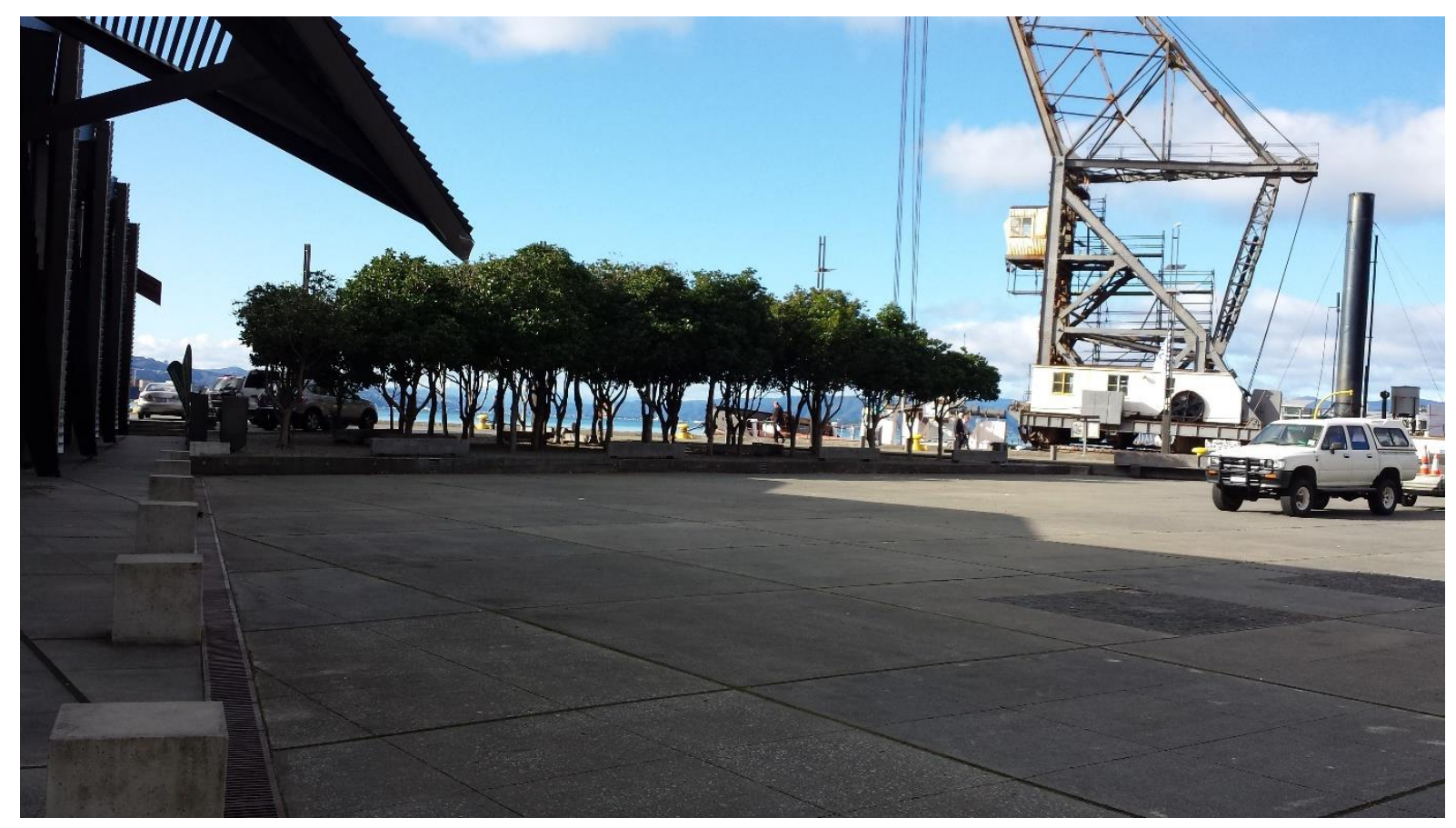

Figure 24: The Anthropocene Grove. View north on Taranaki Wharf from Odlin's Plaza. The historic Hikitia Crane is pictured on the right and Te Raukura is situated to the left. (August 2015.)

This case study focuses on this karaka grove within the heritage landscape of the Taranaki Street Wharf precinct. It outlines the early history of the Wellington waterfront since 1840 and considers matters related to Te Aro Pā, Pākehā settlement and land reclamations as background to a discussion of the karaka grove's contribution to the heritage values of the site. Local and international changes that influenced the regeneration of the city's waterfront

\footnotetext{
${ }^{5}$ Ibid.

${ }^{6}$ Including abandonment of the plan to move the Wellington Free Ambulance Building to the site currently occupied by Te Raukura.

${ }^{7}$ Odlin's Plaza is the site between Te Papa (construction beginning in 1994 and opened in 1998) and the Star Boating Club, Wellington Rowing Club buildings and Whairepo Lagoon (the adjacent Odlin and Wellington Free Ambulance buildings and Shed 22 had been noted by CCC in its December report as heritage to be retained).
} 
and Taranaki Wharf, in particular, are described here. Unlike the Cyberforest, which is examined in Chapter Two as a representative of the AAHD, the Anthropocene Grove is presented here as situated within an unauthorised arboreal heritage discourse (UAHD). The heritage landscape in which the grove is located is a hard-paved surface edging the waters of the harbour. For the purposes of this thesis the grove takes its name from this highly modified context. As noted earlier, the name 'Anthropocene' refers to the current geological era in which, for the first time, humans and our societies have become a global geophysical force. Given both the physical and historical contexts of this karaka grove, the name seems particularly apposite.

This chapter is in four sections. Following this introduction, the second section (Heritage, People and Place) outlines the events of the nineteenth-century settlement of Wellington by both Māori and Pākehā, and the relationships between both groups, and the challenges they both faced. The significance of Te Aro Pā to the development of Taranaki Wharf is foreshadowed by a brief summary of events leading up to the pā's demise. The section concludes with a description of the political and social changes that returned the waterfront to public ownership and decision-making and led to the development of Taranaki Wharf as a heritage landscape.

The third section (Trees as Heritage) provides contextual details for understanding the Anthropocene Grove as a site of trees as heritage, describes its place within the heritage assemblage of Taranaki Wharf and situates the Anthropocene Grove within the UAHD.

The concluding section (Everyday Arboreal Heritage and the Intangible) expands the discussion of the Anthropocene Grove as a manifestation of the UAHD in relation to the process of counter-heritaging and its characteristic expression of tangible and intangible heritage values within everyday experience. The concluding section ends with an account of 'Being There' based on two visits to the site.

\section{Heritage People and Place}

\section{The Settlement of Wellington}

Wellington's colonial settlers arrived from England in 1840 assured by the New Zealand Company that their part of the country would be the first to increase significantly in value. Key to Wellington's success, they were told, was Te Whanganui a Tara Port Nicholson which 
was promoted as the best harbour in New Zealand and guaranteed by its central position to be the centre of the country's coastal and maritime trade. ${ }^{8}$ The settlers were participants in a system of "emigration by private speculation" engineered by Edward Gibbon Wakefield to found colonies by selling land to settlers before they sailed from England. ${ }^{9}$ Wakefield theorised that the land sales would fund the public works essential for the settlement and would sponsor the free passage of labourers whom the land owners would employ on arrival. It proved to be a popular concept and in 1839 the company sold 990 promissory land orders within a month. ${ }^{10}$ Each land order, or 'share' in company parlance, represented a combination of one town acre ( 0.4 hectare) and 100 rural acres (40.5 hectares), and each total land package cost $£ 101 .{ }^{11}$ Each share was allotted a number and the sales were closed once the shares were all sold. The numbers were drawn in a London lottery and matched with other numbers drawn from another box which signified the order in which the owner would be able to select the actual section of land from the map which would be prepared by the company's surveyors. The lottery-style sales gave each purchaser an equal chance to have the pick of the land and the purchasers' taste for a gamble ensured that the company would sell all the shares.

But there were problems with the Wakefield plan. Michael Turnbull describes the New Zealand Company operation as a speculative 'bubble' founded on deception. ${ }^{12}$ First, the land had not yet been purchased from the Māori owners; second, the land had not been surveyed; third, only about half the shares were bought by intending settlers as distinct from absentee speculators; fourth, there were few experienced, practising farmers amongst the owners to develop the rural land (besides, those that had emigrated preferred to employ their family

\footnotetext{
${ }^{8}$ The harbour is said to have been renamed Port Nicholson after John Nicholson the harbourmaster at Sydney by Captain James Herd of the barque Rosanna. It is more commonly known today as Wellington Harbour. The name Poneke is the Māori corruption of Port Nicholson.

${ }^{9}$ Patricia Burns, Fatal Success: A History of the New Zealand Company (Auckland: Heinemann Reed, 1989). 29. For a detailed description of Wakefield's theory and implementation of the systematic colonisation of New Zealand see Michael Turnbull, The New Zealand Bubble: The Wakefield Theory in Practice (Wellington: Price Milburn and Company, 1959). and John Miller, Early Victorian New Zealand: A Study of Racial Tension and Social Attitudes 1839-1852 (Wellington: Oxford University Press, 1974).

${ }^{10}$ New Zealand Company agents searched fifty-two British towns and cities for potential colonists and were paid forty shillings for every married couple and ten shillings for every unmarried adult whom they enrolled in the scheme.

${ }^{11}$ Hamer describes how the 'package' scheme, applied to the settlement of Wellington, preserved the classical form of a colony which included a central urban core and surrounding fields and farms, and was advocated as best practice by surveyors of the time. It was based on the premise that landowners would work in the fields by day and return to the city by night - a situation unlikely to succeed in Wellington where the urban and rural acres were situated far apart. David Hamer, "Wellington on the Urban Frontier," in The Making of Wellington 1800-1914, ed. David Hamer and Roberta Nicholls (Wellington: Victoria University Press, 1990). 232-33.

12 Turnbull, The New Zealand Bubble.
} 
members rather than the intended labourers); and fifth, there was a shortage of both bailiffs to keep order and ambitious farm labourers to carry out the required work. The latter were deterred by the unpredictable dates of sailing, opting instead to serve out their contracts in England and take up land available in the United States or Canada. While Wakefield could be praised as a thinker and a publicist, Turnbull concludes, "as a practical coloniser he was a menace". ${ }^{13}$ John Wood, disappointed with what he found in Wellington, returned to England after twelve months in the new settlement and wrote a book published in 1843 "especially intended for the perusal of intending emigrants". The New Zealand Company, he explains, had deceived Wellington's settlers with "their glowing one-sided representations of the 'Land of Promise,' [that had] induced respectable families to forego the substantial comforts of a home for the dream of independence abroad". ${ }^{14}$

Edward Gibbon's thirty-six-year-old brother William Wakefield was hastily dispatched to New Zealand as the company's agent on the Tory ${ }^{15}$ in May $1839,{ }^{16}$ made the journey in ninety-six days and within a week of entering the harbour had purchased Te Whanganui a Tara and all its surrounding ranges from some Māori in exchange for guns, European clothes and "an array of the traditional rubbish" which he had bought in London, while reserving for Māori one section in ten, or 'the tenths', of the parallelograms into which the area would be divided. ${ }^{17}$ At the time, there were eight major pā situated around the harbour. The people of Te Aro Pā, however, received only a small portion of the goods as they were only a tributary tribe, according to Te Wharepouri the Te Āti Awa chief of Ngauranga Pā who, along with Te

\footnotetext{
${ }^{13}$ Ibid. 36. For a detailed examination of the unravelling of the New Zealand Company's Port Nicholson claim see Rosemarie Tonk, “'A Difficult and Complicated Question': The New Zealand Company's Wellington, Port Nicholson, Claim," in The Making of Wellington 1800-1914, ed. David Hamer and Roberta Nicholls (Wellington: Victoria University of Wellington, 1990).

${ }^{14}$ John Wood, Twelve Months in Wellington, Port Nicholson; or Notes for the Public and the New Zealand Company (London: Pelham Richardson, 1843). 5.

${ }^{15}$ On the ship as well were Edward Gibbon's nineteen-year-old son, Edward Jerningham; Dr Ernst Dieffenbach, a German scientist; Dr Dorset, principal surgeon to the New Zealand Company; Charles Heaphy, the eighteenyear-old official artist; Ngati, a Māori man; Captain Edmund Chaffers, master of the Tory; and Richard Lowry, first mate.

${ }^{16}$ The New Zealand Company's haste was founded on the knowledge that New Zealand's annexation to the Australian colony of New South Wales was imminent and a site for a capital would need to be determined. As an established settlement Wellington would stand a good chance of being chosen. Turnbull, The New Zealand Bubble. 29-30; Hamer, "Wellington on the Urban Frontier." 240-41. Annexation was formalised on 14 January 1840 when William Hobson was appointed Lieutenant-Governor of the new dependency and set about preventing further land speculation and investigating existing purchases. For a full description see Tonk, "A Difficult and Complicated Question."

${ }^{17}$ Burns, Fatal Success. 111. This was only one hundred acres dispersed throughout the town in place of the six hundred acres which Maori had occupied before the arrival of the New Zealand Company, and was reserved for chiefs and their families. See also Miller, Early Victorian New Zealand. 9, 49.
} 
Puni, the Te Āti Awa chief of Pito-one Pā, was supervising the distribution. ${ }^{18}$ William Wakefield, in his haste to purchase the land, dismissed Te Aro as a "slave" settlement and claimed that it was up to the settlers, anyway, to recompense its former owners. ${ }^{19}$ A party of migrants (Te Heke Paukena) comprising Te Āti Awa from Waitara, a part of the Taranaki tribe and some Ngāti Ruanui people had moved to Te Whanganui a Tara in the mid-eighteen thirties and settled between Te Aro and Waitangi streams (now the area between Taranaki Street and Kent and Cambridge terraces) with permission of the Ngāti Mutunga chief Ngātata-i-te-rangi. ${ }^{20}$ These were the people of Te Aro Pā.

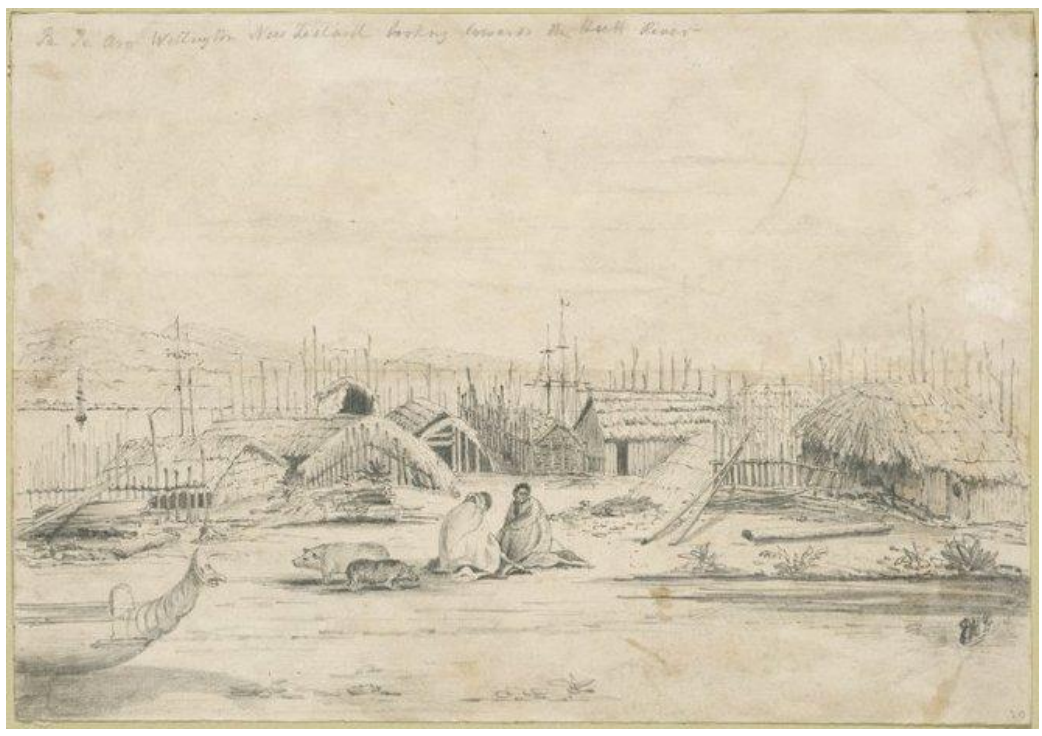

Figure 25: Te Aro Pa 1842/1843. Gilfillan, John Alexander, Norman, Edmund. Attributed works. Ref: A-049-001 ATL.

Describing the Māori occupation between 1800 and 1840, Angela Ballara notes that while relations between the Taranaki tribe at Te Aro with Te Wharepouri were "strained and wary" the tribe could claim legitimate occupation of the harbour as a result of Ngāti Mutunga's transfer of rights to Taranaki and Te Āti Awa in November $1835 .^{21}$ The New Zealand

\footnotetext{
${ }^{18}$ Waitangi Tribunal, "Te Whanganui a Tara Me Ona Takiwa: Report on the Wellington District: Wai 145." (Wellington: Waitangi Tribunal, 2003). Tonk notes that while Te Wharepouri and Te Puni believed the 'sale' of their land would provide them with European protection from their enemies and wealth through trade and employment, like their fellow signatories, they also hoped it would strengthen their positions within the harbour itself. Te Puni had a personal axe to grind too as the Taranaki people had insulted him a few years earlier. Tonk, "A Difficult and Complicated Question." 41-42.

${ }^{19}$ Burns lists only seven pā at Port Nicholson at the time of settlement "Waiwhetu, Pito-one, Nga Uranga, Kaiwharawhara, Pipitea, Kumutoto and Te Aro" omitting Tiakiwai Pā, and states that the people of Te Aro Pā received no goods. Burns, Fatal Success. 115-16. Where discrepancies in information arise, the 2003 Waitangi Tribunal report is taken as the definitive source of information.

${ }^{20}$ Angela Ballara, "Te Whanganui-a-Tara: Phases of Maori Occupation of Wellington Harbour C. 1800-1840," in The Making of Wellington 1800-1914, ed. David Hamer and Roberta Nicholls (Wellington: Victoria University Press, 1990). 25.

${ }^{21}$ Ibid. 30. See also Morris Love, "Te Ati Awa of Wellington," Te Ara-the Encyclopedia of New Zealand, http://www.teara.govt.nz/en/te-ati-awa-of-wellington. Accessed 9 June 2016.
} 
Company deed of purchase, which was written in English, took into account no such niceties. ${ }^{22}$ It described the boundaries of the land purchased and noted that one tenth of that land was reserved for the signatory chiefs and their families. ${ }^{23}$ The harbour's prominent features were renamed after some of the New Zealand Company's directors by William Wakefield before he hurried north to deal with the company's land claims at Kaipara and Hokianga. ${ }^{24}$

The survey team led by William Mein Smith sailed into Whanganui a Tara on the Cuba on 5 January 1840 followed closely by the first combined wave of 811 settlers on the Aurora on 22 January 1840, the Oriental on 31 January, the Duke of Roxburgh on 8 February, the Bengal Merchant on 20 February, and the Adelaide and Glenbervie on 7 March. ${ }^{25}$ The new settlement was in disarray. The settlers, despite early efforts at building temporary huts, were largely dependent on the superior skills and knowledge of Māori for the provision of shelter, food and information. ${ }^{26} \mathrm{In}$ her $\mathrm{PhD}$ thesis, Rebecca Burke describes the existence of a "middle ground" in Wellington, beginning in 1840 and, though diminishing towards the end, lasting until 1860. During this period both Māori and Pākehā benefited from trade, language adoption and knowledge exchange at a private level before issues of land ownership escalated and official power shifted to the new settlers. ${ }^{27}$ In 1840, however, Smith's team had other priorities having just begun work in preparation for selection. Their first plan had to be abandoned. The initial surveying had been carried out on the flat land of the Hutt Valley then,

\footnotetext{
${ }^{22}$ Wakefield's words were translated into Māori by Richard (Dicky) Barrett a whaler whose Māori wife had close relatives in Port Nicholson and by Ngati a Māori man who had travelled from England with William Hayward Wakefield on the Tory. The deed did not include a map of the boundaries. Māori did not realise that they would soon be outnumbered by settlers or that their lands would be redistributed and their resources destroyed. For further information see Miller, Early Victorian New Zealand.

${ }^{23}$ One hundred and sixty-four years later the Waitangi Tribunal found that the deed was "invalid and conferred no rights on the New Zealand Company or its settlers". Waitangi Tribunal, "Te Whanganui a Tara Me Ona Takiwa." xviii.

${ }^{24}$ Burns argues that these further 'purchases' by the New Zealand Company proved "extremely damaging to the future of New Zealand" for two reasons - the representation of Māori as a people longing for Europeans to come and civilise them and Wakefield's ready dismissal of any warnings that the purchases might not be valid. Burns, Fatal Success. 119-20.

${ }^{25}$ Almost 1,500 immigrants had arrived at Port Nicholson by June 1840. Tonk, "A Difficult and Complicated Question." 45. "The First Colony of New Zealand", as named by Petre, comprised about 1,200 immigrants who sailed from England in the autumn of 1839. Henry William Petre, An Account of the Settlements of the New Zealand Company: From Personal Observation During a Residence There (Christchurch: The Caxton Press, 1842, 1971; repr., 5). 7. See also Edward Jerningham Wakefield, Adventure in New Zealand, vol. 1 (London: J. Murray, 1845). 140, 145, 217.

${ }^{26}$ Petre, An Account of the Settlements of the New Zealand Company. 11, 51-52

${ }^{27}$ Rebecca Burke, "Friendly Relations between the Two Races Were Soon Established"?: Pakeha Interactions with Maori in the Planned Settlements of Wellington, Nelson and New Plymouth, 1840-1860" (PhD, Victoria University of Wellington, 2014).
} 
realising that the land was flood prone and the best place for a port was across the harbour, Smith and his team had shifted their work to the opposite southern side. On this new site, the surveyors measured pā and kāinga (homes, villages) and set their pegs in the Te Aro homes, gardens and urupā (burial grounds) as though Māori occupation didn't exist: Māori protested by removing the pegs. ${ }^{28}$ The parallelogram land parcels were completed and duly numbered, the settlers made their selections in the order established by the lottery, the reserves were chosen for Māori without consultation and Te Aro Pā, the owners of which had never signed the deed or purchase, was designated as the centre of commerce for the new town. ${ }^{29}$

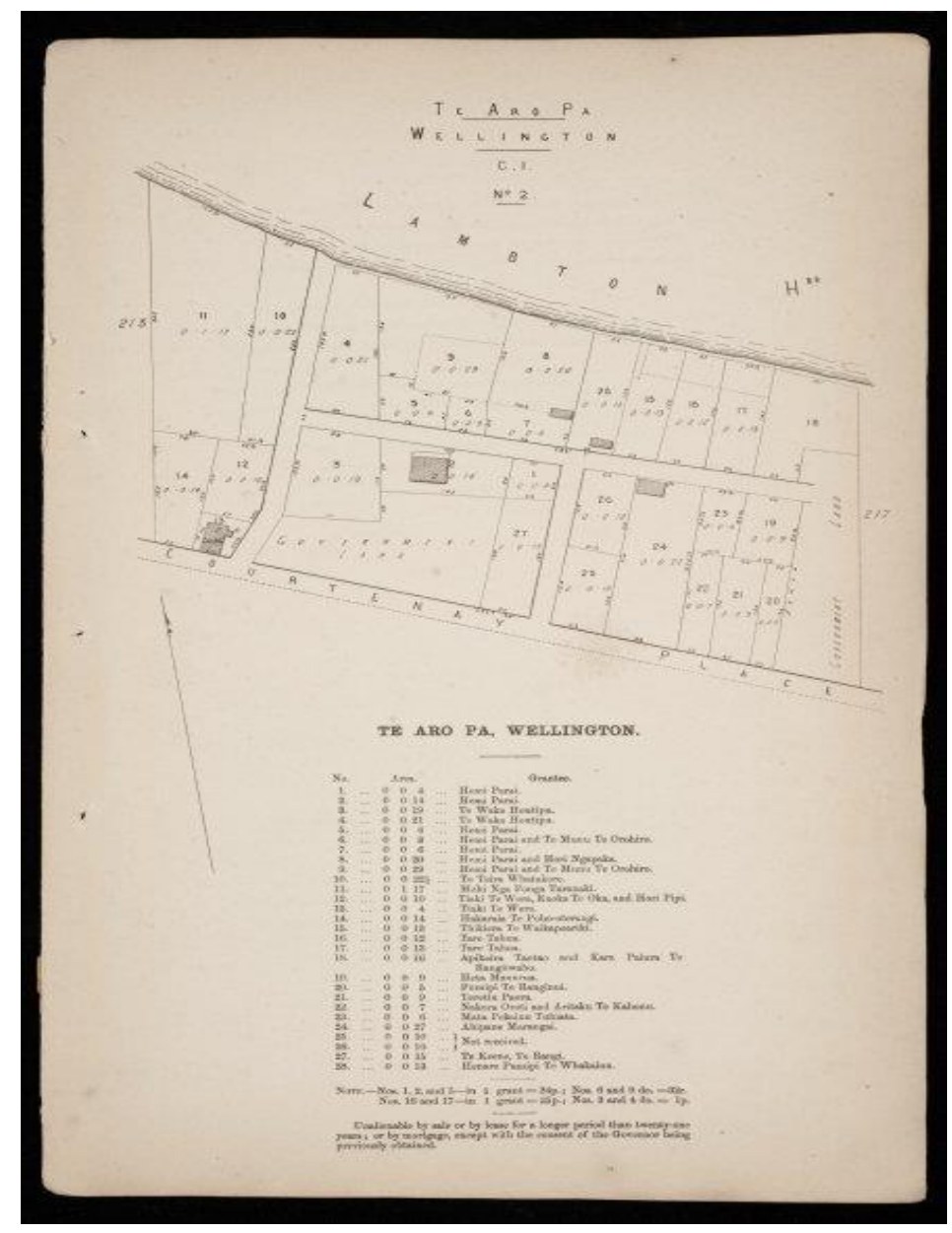

Figure 26: Subdivision of Te Aro Pā 1842/43. Showing subdivisions between Courtenay Place and Lambton Harbour, and names of Māori grantees. Ref: A-049-001, ATL.

\footnotetext{
${ }^{28}$ The people of Te Aro, Pipitea, Kumutoto and Tiakiwai pā made it clear that they had never sold the land and insisted that the Pākehā should be confined to the land bought at Petone and Ngauranga. Tonk, "A Difficult and Complicated Question." 46.

${ }^{29}$ Wellington was the only New Zealand Company town to be surveyed in one-acre lots and was followed by Whanganui which was in quarter-acre sections. B. F. de Vries, "A Site for a Planned Settlement," in Wellington Prospect: Survey of a City 1840-1970, ed. N. L. McLeod and B. H. Farland (Wellington: Hicks Smith and Sons, 1970). 24.
} 


\section{The Urban Frontier}

In The Making of Wellington 1800-1914, David Hamer describes Wellington's relationship with the 'urban frontier' and its Pākehā settlers as "urban pioneers": ${ }^{30}$

The urban frontier was a frontier which had an independent and parallel existence to that of other frontiers. One can detect a flow of people who can be called urban pioneers, who moved from one town to another in search of opportunities and never once, so to speak, set foot upon the soil in between. These were people who did not wish to try to become farmers. Many migrants went to new countries in search of a new urban way of life. Wellington was a settlement on this urban frontier. ${ }^{31}$

Edward Gibbon Wakefield's colonisation theory which drove the settlement of Wellington and was governed by his promotion of the 'sufficient price' encouraged Wellington's urban pioneers to make a commitment to the place they had arrived at. ${ }^{32}$ The sufficient price, he argued, was the sum at which colonial 'waste land' should be sold in order to deter wage earners from becoming landowners and subsequently dispersing over a large geographic area. The high price of land that was fixed would also help build funds for free passage of more wage earners from England to work at developing the town and thereby enable capitalists to turn their attention from working themselves to matters of "taste, science, morals, manners, abstract politics" and "liberal feeling and polished manners". ${ }^{33}$ Wakefield advocated tight control over the development of the town of Wellington which would, he theorised, stimulate growth in a metropolitan society. It was not only the planning, control and supervision of Wellington's settlement by the New Zealand Company, however, that ensured the town's development at the urban frontier. Pioneer farming could be back-breaking, frustrating and slow to provide an income and some settlers who had originally intended to farm their allotted acres turned to business in the town instead. Some professional men, too, changed the course of their careers to take on more profitable and influential urban frontier roles. Hamer cites as examples doctors Isaac Featherston, whose duties as surgeon on one of the

\footnotetext{
${ }^{30}$ The term 'urban frontier' appears in John Reps' study of settlement in the American West and refers to situations where towns precede agricultural or pastoral occupation of newly settled regions. John W. Reps, Cities of the American West: A History of Frontier Urban Planning (New Jersey: Princeton University Press, 1979). See also Richard C. Wade, The Urban Frontier: Pioneer Life in Early Pittsburgh, Cincinnati, Lexington, Louisville, and St. Louis (Chicago: University of Chicago Press, 1976).

${ }^{31}$ Hamer, "Wellington on the Urban Frontier." 228. Italics in the original.

${ }^{32}$ Wakefield wrote and published his theory while in Newgate Prison 1827-1830 after abducting and marrying a fifteen-year-old schoolgirl whose father, he hoped, would help him enter politics. William Wakefield, then twenty-six years old, was sent to prison also for aiding and abetting his older brother who was thirty years old at the time.

${ }^{33}$ Miles Fairburn, "Wakefield, Edward Gibbon," Te Ara-the Encyclopedia of New Zealand, http://www.teara.govt.nz/en/biographies/1w4/wakefield-edward-gibbon. Accessed 25 August 2016.
} 
Company's ships led to his career as a leader of the settlement, and William Fitzherbert, who abandoned medicine and arrived in Wellington with a cargo of goods to trade.

In the path of the Wakefield plan and the aspirations of Wellington's Pākehā settlers was the 'wilderness' - the "swamp" and the steep, bush-clad and windswept hillsides - and the Māori who owned it. John Wood describes his shock at seeing the steep hills of Wellington for the first time:

On the $21^{\text {st }}$ of December the "Mandarin" made the New Zealand coast. Its appearance, as seen from Cook's Straits, was not very promising, but we were elated with hope, and easily persuaded that though frowning mountains fringed the shores, there might be open country beyond them. A strong and favourable wind soon carried us inside the heads of Port Nicholson. The passengers were all on deck straining their eyes to catch a glimpse of civilization. Little was said, though disappointment was visible on the countenance of every one. In whatever direction the eye fell it was on mountains, rising in the blue distance, ridge above ridge in continued succession. ${ }^{34}$

Wood and his friends were dismayed to discover at the surveyor-general's office that their allotted rural lands were 112 miles (180 kilometres) away and their town acres were variously in a swamp and on a windswept hill. New Zealand spontaneously yielded "no edible production but the fern root", 35 and "save Britannia Flat, at the north end of Wellington, and a swampy valley named Te-Aro, near its southern extremity, there was not a level acre in the township". ${ }^{36}$ John Plimmer was similarly disillusioned with Wellington which had been represented as a "veritable Eden":

But alas, how grievously were we disappointed on our arrival. There were beautiful trees descending to the water's edge, the hills were green, the climate delightful, and the bay a splendid sheet of water. But the hills and valleys were covered with primeval forest. What little level land there was, was overgrown with fern and flax, except here and there where the Maoris had cleared a spot to plant their corn and potatoes. Instead of the Eden of our imagination, the wild and stern reality lay before us, and we were here to do the best we could with it. On board the ship we were all associated together, as it were, and could speak freely to each other of our gilded hopes; all was provided for us and we had no thought for the morrow.

But no sooner were we landed than all was changed, and our bright prospects vanished into thin air. We became isolated, and everyone had to provide in the best way he could for himself and those dependent upon him. ${ }^{37}$

\footnotetext{
${ }^{34}$ Wood, Twelve Months in Wellington, Port Nicholson. 9.

${ }^{35}$ Ibid. 5. The windy site was on Wellington Terrace (now the Terrace).

${ }^{36}$ Ibid. 10.

${ }^{37}$ John Young, The Life of John Plimmer, Father of Wellington, with Selections from His Writings (Wellington: Printed by the New Zealand Times Co., 1901). 8.
} 
The New Zealand Company's settlers' "crisis of disenchantment' during the 1840s, John Miller argues, stemmed from unfulfilled contracts; years of waiting, protests and procrastination; the challenges of both forests and floods; confusing surveys, registers and titles; and "shady attempts to evade liabilities". ${ }^{38}$ While Wakefield may have believed that he had legitimately purchased the land, Māori variously interpreted the goods in exchange as gifts for individual people and reward for leaving the survey pegs alone. Relationships between Māori and increasing numbers of Pākehā were generally tense, and the survey continued only after a show of force. ${ }^{39}$ Harried by the settlers who were hunkered down in temporary shelter for almost six months, the surveyors had doggedly spread their blanket of parallelograms over the cramped site between shoreline and hilltops and crafted it according to the instructions Smith had received from the New Zealand Company:

In laying out the plan of the town, you must as closely as possible adhere to the conditions on which the land orders have been sold, as expressed by the enclosed copy of the terms of purchase,- - providing, at all events, that every holder of a land order obtains one full acre of land within the town.

The directors wish that, in forming the plan of the town, you should make ample reserves for all public purposes; such as a cemetery, a market-place, wharfage, and probable public buildings, a botanical garden, a park, and extensive boulevards. It is, indeed, desirable that the whole outside of the town, inland, should be separated from the country sections by a broad belt of land which you will declare that the company intends to be public property, on condition that no buildings be ever erected upon it. The form of the town must necessarily be left to your own judgment and taste. Upon this subject the directors will only remark, that you have to provide for the future rather than the present, and that they wish the public convenience to be consulted, and the beautiful appearance of the future city to be secured, so far as these objects can be accomplished by the original plan,- - rather than the immediate profit of the company. It is of essential consequence that the town lands should be made ready for allotment as soon as possible. ${ }^{40}$

The town acres and the network of roads that made them accessible crept over the flat landincluding Te Aro Pā-and scaled the steep hills. The rectilinear system was the standard form of the time and used to set out many New Zealand towns. While it paid no regard to the topography, resulting in some steep streets and dead ends, it was considered to have many advantages. A grid favoured economic interests by concentrating commerce in its centre or

\footnotetext{
${ }^{38}$ Miller, Early Victorian New Zealand. 195.

${ }^{39}$ Tonk, "A Difficult and Complicated Question." 46.

40 "Extract from the Instructions of the Board of Directors of the New Zealand Land Company, to Lieut. William Mein Smith, Royal Artillery, the Company's Surveyor-General, as Contained in a Letter from the Secretary, Dated Aug. 1, 1839.," New Zealand Gazette and Wellington Spectator, 21 August 1839. The intended marketplace, park and extensive boulevards were never built as they were considered a waste of land that could be better used for making money. New Zealand Productivity Commission, "A History of Town Planning." http://www.productivity.govt.nz/sites/default/files/using-land-draft-report-research-note.pdf. Accessed 1 August 2016.
} 
stretching it out along a main street to attract passing customers; it imposed instant order on the landscape; enabled easy future subdivision of lots; and maintained healthy air flow along streets which, it was believed, could counter air-borne diseases. ${ }^{41}$ Less malleable than the general landscape, however, was the prime real estate of Te Aro Pā on the foreshore. The land south of the pā was intensively cultivated and Māori gardens ascended the hills to Brooklyn and Vogeltown. The waters of the harbour itself and the nearby streams that drained into the harbour and into Waitangi lagoon to the east were rich food sources for the inhabitants of the pā. Smith's grid, however, spread over it all.

Despite the dubious authority of his deed of purchase and the challenges posed to settlement by Wellington's topography, Wakefield had proceeded with the company's intentions and the 'Port Nicholson Deed' had been marked by sixteen Māori signatories on 27 September 1839. Seven months later, in April 1840, the Treaty of Waitangi was signed at Port Nicholson, three months after Lieutenant-Governor William Hobson had proclaimed that the validity of preTreaty land purchases required confirmation by the Crown. In May 1842, Land Claims Commissioner William Spain began his inquiry into the New Zealand Company's claims at Port Nicholson. Giving evidence to the Spain commission in February 1843, Richard (Dicky) Barrett, who had acted as interpreter for Wakefield, provided a list of fourteen signatories, several names spelt differently to those that appeared on the deed, and their pā. Seven of these belonged to Pito-one Pā, two to Waiwhetu Pā, and one each to Ngauranga, Kaiwharawhara, Pipitea, Tiakiwai, and Kumutoto pā, but there was no signatory from Te Aro Pā. ${ }^{42}$ The signatories were described as "the sole and only proprietors, or owners" of Port Nicholson who had sold their "lands, tenements, woods, bays, harbours, rivers, streams, and creeks" to the New Zealand Company "for ever, in consideration of having received as a full, and just payment" various goods. ${ }^{43}$ The Waitangi Tribunal in 2003 concluded that although the boundary of the purchase was described it was scarcely intelligible and impossible to map. According to the deed, the tribunal noted, the signatories had:

\footnotetext{
${ }^{41}$ Ben Schrader, "City Planning," Te Ara-the Encylopedia of New Zealand, http://www.teara.govt.nz/en/cityplanning. Accessed 25 August 2016. Reps points out that the grid form was common to many earlier periods of mass town founding such as "Mediterranean colonization by the Greeks and Romans; medieval urban settlement in southwestern France, Poland and eastern Germany; Spanish subjugation of Latin America; and English occupation of Northern Ireland". Reps, Cities of the American West. x.

${ }^{42}$ Waitangi Tribunal, "Te Whanganui a Tara Me Ona Takiwa." 57.

${ }^{43}$ Ibid.
} 
Bound themselves and their families, tribes, and successors to 'assist, defend, and protect' the company and its shareholders in 'maintaining the quiet and undisputed possession' of the purchased land. Finally, Wakefield and the company promised the signatories that a 'portion of the land ceded by them, equal to one-tenth part of the whole, will be reserved by the ... Company ... and held in trust ... for the future benefit of the said chiefs, their families, and heirs for ever'. In effect, 10 per cent of the purchase was to be reserved for the 16 signatory chiefs and their families. ${ }^{44}$

\section{Te Aro Pā}

Subsequent to the Spain inquiry and in the face of much opposition from the New Zealand Company and Pākehā settlers, Lieutenant-Colonel William Anson McCleverty had reserved some of the pā land for Māori in the course of his duties to settle the claims through deeds of exchange. ${ }^{45}$ The reserved land was located around today's intersection of Courtenay Place and Manners Street and continued north to what was then the harbour shore and is now Wakefield Street. Te Aro Pā represented valuable commercial land that had been allocated to settlers and had been earmarked by the city's developers as the site of a wharf. ${ }^{46}$ For Māori, the ownership and occupancy of this land represented an important means by which they could benefit from the development of Wellington city. However, under the Native Lands Act of 1865 which had individualised Māori land title, thereby freeing up more land for purchase, Te Aro Pā reserve was surveyed into twenty-eight lots. Land sales began in 1873. Plans for reclamation of land in the Te Aro area were afoot and in 1874 the Wellington City Council was granted seventy acres of the Te Aro foreshore and harbour for reclamation. ${ }^{47}$ While it is not known exactly when Te Aro Pā moved completely out of Māori ownership the Waitangi Tribunal report notes that in 1850 there were 186 people living at Te Aro $\mathrm{P}^{48}$ and by 1881 the population had shrunk to only twenty-eight which demonstrated a community in "a state of terminal decline" and unlikely to have lasted very long into the $1890 \mathrm{~s} .{ }^{49}$

\footnotetext{
${ }^{44}$ Ibid. 58.

${ }^{45} \mathrm{McCl}$ everty was appointed commissioner in 1845 to organise a survey and sort out the selection of lands due to Māori and to the settlers.

${ }^{46}$ Hamer, "Wellington on the Urban Frontier." 231.

47 Waitangi Tribunal, "Te Whanganui a Tara Me Ona Takiwa.” 340.

${ }^{48}$ Ibid. 339.

${ }^{49}$ Ibid. 342.
} 


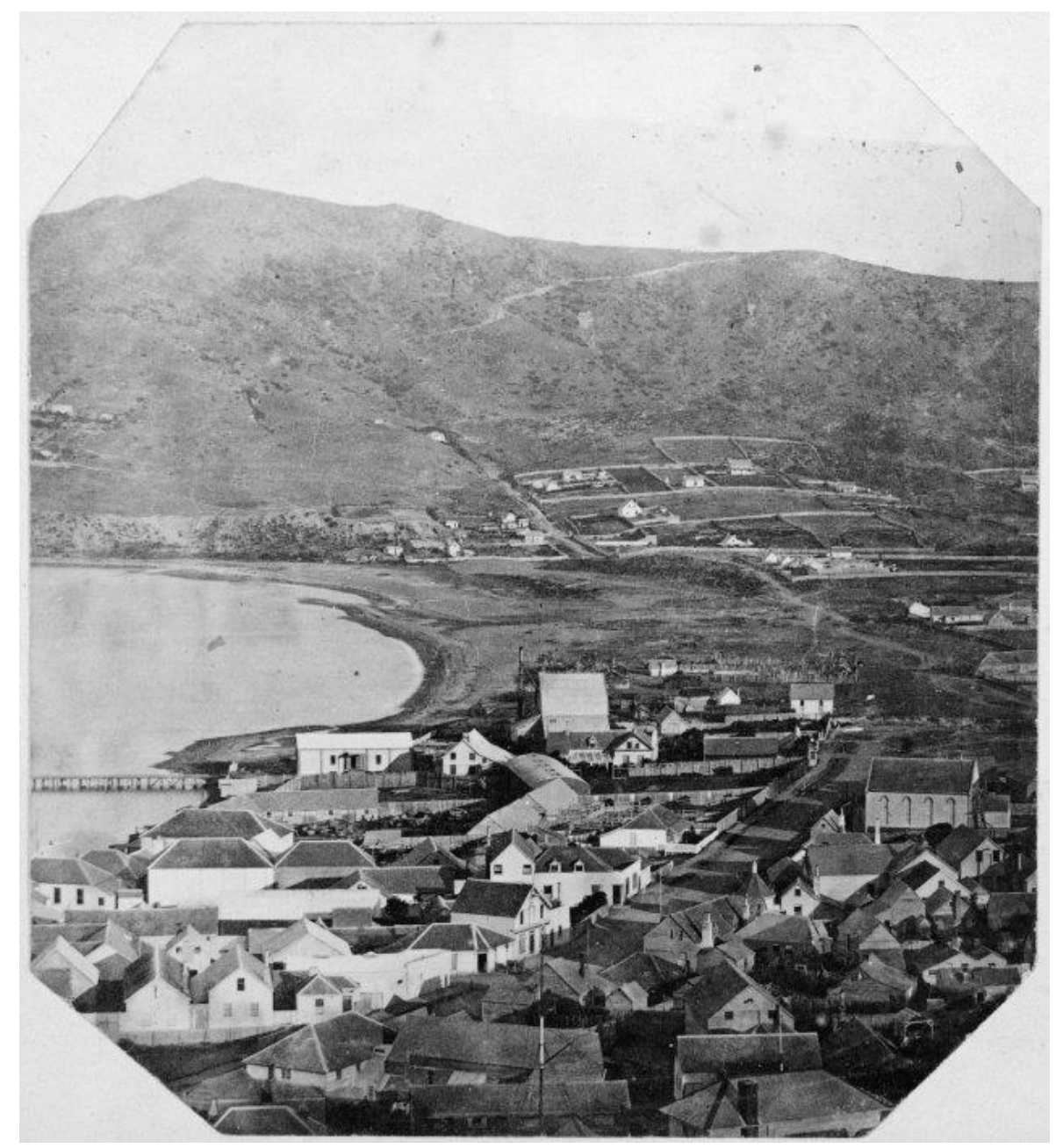

Figure 27: Overlooking Te Aro, 1857. Photographer: S. Thomson. Te Aro Pā is visible in the centre of the photograph. Ref: 1/2-00296-F. ATL.

The process of settlement of new countries, Hamer argues, was universally described as "conquering the wilderness". Nineteenth-century ideas of social evolution assumed that all former 'primitive' aspects of the site would be removed from the urban scene-including the natural landscape and the indigenous people. ${ }^{50}$ The Waitangi Tribunal report has similarly noted that Crown officials wanted to see Māori eliminated from the town and encouraged the alienation of Te Aro Pā to achieve this. Charles Heaphy, when Commissioner of Native Reserves (1869-1881) described Te Aro Pā as a "nest of immorality" and argued that for "moral and sanitary reasons" Māori should be removed from the town and the land passed to Pākehā ownership. ${ }^{51}$

\footnotetext{
${ }^{50}$ David Hamer, New Towns in the New World: Images and Perceptions of the Nineteenth-Century Urban Frontier (New York: Columbia University Press, 1990). 11.

${ }^{51}$ Waitangi Tribunal, "Te Whanganui a Tara Me Ona Takiwa.” 336.
} 
The New Zealand Company's boosters had wooed settlers to its Wellington settlement with two separate enticements: the prospect that geographically central Wellington would eventually become the capital of the country and therefore a profitable investment, and the promise that it would grow to be the centre of trade. Wakefield had been instructed by the New Zealand Company in advance of the Port Nicholson expedition to:

endeavour to make an extensive purchase on the shores of that harbour, which, all things considered, shall appear to offer the greatest facilities as a general trading depot and port of export and import for all parts of the islands, - as a centre of commerce for collecting and exporting the produce of the islands, and for the reception and distribution of foreign goods. ${ }^{52}$

Many of Wellington's colonists were merchants and sailed to the urban frontier equipped with goods to sell, barter or export. Australian wool ships returning from England were expected to discharge English goods at Port Nicholson and transport wheat, wine, olive oil, fruit and vegetables to, then, drought-stricken Australia: emigrant ships from England would return with spars, turpentine, whale oil and raw or manufactured flax. Brisk trade was anticipated and appropriate facilities were required. Squeezed as it was between hills and the shore, Wellington offered little in the way of available land for commercial expansion. Early Wellington was "two knots of settlement, one mainly official but partly commercial [Thorndon], and one mainly devoted to business [Te Aro $]^{53}$ joined by a narrow road along the shore". ${ }^{54}$ The answer to this dearth of foreshore land for development lay in a series of reclamations, the first of which came courtesy of a severe earthquake on 23 January 1855.

The earthquake raised the sea bed of the harbour itself as much as 1.5 metres making reclamation a much cheaper prospect; and raised Te Aro flat, from the harbour, to what is now the Basin Reserve, enabling the land to be drained for building development. ${ }^{55}$ Between the early 1880s and 1925 six reclamations were carried out, mostly by the Wellington City Council, on Te Aro foreshore which most recently had been occupied by boat builders, warehouses and small businesses. For the first substantial council work, a locomotive hauled

\footnotetext{
${ }^{52}$ Hamer, "Wellington on the Urban Frontier." 241. Turnbull argues that the New Zealand Company believed that Port Nicholson was the best harbour in New Zealand and its owner would control the future development of the country. In order to secure this monopoly, a wide belt of unoccupied land was necessary to enable expansion and prevent the establishment of rival settlements. Turnbull, The New Zealand Bubble. 22-23.

${ }^{53}$ Te Aro housed the Customhouse, the Exchange, the Town Hall and a library.

${ }^{54}$ Alan Mulgan, The City of the Strait: Wellington and Its Province, a Centennial History (Wellington: A. H. and A. W. Reed, 1939). 97.

${ }^{55}$ David P. Millar, "Reclamations," in Wellington Prospect: Survey of a City 1840-1970, ed. N. L. McLeod and B. H. Farland (Wellington: Hicks Smith and Sons, 1970). 40. See also Mulgan, The City of the Strait.
} 
fill from a quarry in Oriental Bay below Roseneath along a trestle causeway of wooden piles constructed in 1882 in Te Aro waters. When the work was complete in 1886 nine hectares had been reclaimed and today form the area occupied by Wakefield Street. ${ }^{56}$ Further reclamation was carried out in other parts of the harbour adding, an estimated, more than 155 hectares of land to Wellington's central city area. ${ }^{57}$

Hamer observes that Wellington's reclamation was largely unplanned and while achieving more commercial space it made little allowance for land devoted to public use. Most of the land reclaimed was sold by the provincial government to private interests and a "wall of commercial buildings and, further north, a desert of railroad facilities and lines went up between Wellington and its harbour. Almost all the space created in the 22-acre [9-hectare] Wakefield Street reclamation (1886) was used for commercial purposes". 58

\section{Taking Back the Waterfront}

This thesis does not aim to present a comprehensive history of Wellington's foreshore but has outlined its nineteenth-century development in the vicinity of former Te Aro Pā and presentday Taranaki Wharf from 1839 until 1886 in order to provide a historical context for the following discussion of the area's heritage and its relationship to the Anthropocene Grove. Some twentieth-century events also are pertinent to this discussion and are outlined here.

The Wellington Harbour Board was instituted in 1880 and had systematically developed the harbour into a commercial port with the requisite wharves, docks, sheds and other accoutrements of trade in response to the various changes in the shipping industry and had continued to contribute to the city's prosperity. In 1898, the Board's engineer, William Fergusson, had proposed the construction of a wharf opposite the northern end of Taranaki Street ${ }^{59}$ and plans were prepared in 1901 but it was not until 1906 that the Taranaki Street Wharf was completed by local contractor, Charles Pulley. The 152-metre long and 33-metre wide finger wharf was constructed of Australian hardwood and equipped with ten moveable

\footnotetext{
${ }^{56}$ For a detailed account of Te Aro reclamation see David Johnson, Wellington Harbour (Wellington: Wellington Maritime Museum Trust, 1996). In 1976 the Wellington regional committee of the NZHPT installed fourteen brass plaques along the old shoreline to indicate the extent of reclamation. A Wellington City Council heritage trail guided by a brochure now follows the original shoreline.

${ }^{57}$ Michael Kelly, “Old Shoreline: Heritage Trail,” (Wellington: Wellington City Council, 2005). 1.

${ }^{58}$ Hamer, "Wellington on the Urban Frontier." 239.

${ }^{59}$ Chris Cochran et al., "Coastal Historic Heritage of the Wellington Region: Survey for the Coastal Plan Review," (Wellington, 2012, updated 2014). 197. Cochran et al. note that it is likely that William Mein Smith had proposed a wharf on the same site in 1840.
} 
2-ton and one fixed 20-ton hydraulic cranes and used primarily for transport of coal and timber. In the 1960s, however, the face of the harbour began to alter. David Johnson argues that the changes came from several directions and almost at the same time:

Politically, paternalism and control were thrown aside. Government, including local authority government, was seen as an obstruction to progress and growth if it remained involved in areas where commercial forces could work without government interference. Economically, the shipping industry had no option. It was not making profits and was showing little sign of doing so. The changes wrought by roll on-roll off and containerisation methods swept old traditions aside. Coastal shipping all but disappeared. Employment on the waterfront was cut dramatically. Half the port was no longer needed. Socially, people wanted more access to the harbour. The Board had controlled the area from Oriental Bay to Kaiwharawhara for long enough, filling the shoreline with commercial activity. The citizens of Wellington wanted it back. ${ }^{60}$

Wellington was not the only city to retrieve its "abandoned doorstep" and fashion it into a "new urban frontier". ${ }^{61}$ Peter Hall describes how customary systems dealing with freight and passengers in ports declined in America in the late 1950s and in the rest of the world during the 1960s and 1970s. In addition to the roll on-roll off and containerisation changes cited by Johnson, developments in air transport, new fishing methods, expanded tanker sizes and the recession of the late 1970s and early 1980s resulted in the abandonment of large tracts of northern hemisphere land at the water's edge. The growth in disposable income for recreation, leisure and tourism and a change in attitude towards coastlines and waterfronts, Hall argues, led North American cities to find other uses for their doorsteps; "waterfront revitalisation ... symbolised the 1980 s in the same way that motorway construction and new town building characterised the 1950s and 1960s". ${ }^{2}$ Benson points out that a "growing public awareness of the need for inner-city renewal" was another ingredient for the "global phenomenon" of large-scale dockside and docklands redevelopment. ${ }^{63}$

Boston and Baltimore led the way in America at the end of the 1950s and London's Docklands became the first large-scale redevelopment project in Europe in the mid-1980s. Closer to home, the revitalisation of the Rocks and Darling Harbour, both in Sydney, took

\footnotetext{
${ }^{60}$ Johnson, Wellington Harbour. ix.

${ }^{61}$ Peter Hall, "Waterfronts: A New Urban Frontier," in Waterfronts: A New Frontier for Cities on Water, ed. Rinio Bruttomesso (Venice: International Centre Cities on Water, 1993). 12-20. Many of the chapters in this publication are revised versions of lectures first presented at the Second International Meeting 'Waterfronts: A New Urban Frontier' organised by the Cities on Water Centre in Venice in January 1991. Hall's chapter serves as the book's introduction.

62 Ibid. 19.

${ }^{63}$ Frank L. Benson, "Public/Private Sector Partnerships: The Custom House Docks—a Case Study,” ibid. 7683.
} 
place in the 1970s and 1980s respectively, and Melbourne's Docklands was redeveloped in the late 1990s. In the 1960s, Wellington began to forge its own path toward waterfront regeneration beginning with further reclamation between Queen's Wharf and the seaward side of Taranaki Wharf to form Frank Kitts Park, and the establishment of a smaller version of the present Whairepo Lagoon ${ }^{64}$ to the west of the wharf. ${ }^{65}$ The next decades brought a raft of complex changes which can be seen to further influence the development of Wellington's foreshore and led to the 1997 waterfront plan described in the introduction to this case study. Some of these changes were instigated at a national level and others were the result of issues specific to the Wellington environment. Considered together they illuminate a period of change in the recognition of heritage values that enabled the planting of the Anthropocene Grove.

The Local Government Act 1974 encouraged greater community participation in decisionmaking, and the Town and Country Planning Act 1977 expanded the rights of interested people and groups to object to schemes or planning applications, ${ }^{66}$ introduced public consultation on draft schemes and directed local authorities to acknowledge the culture, traditions and relationships of Māori with their ancestral land. ${ }^{67}$ In 1982 Wellington's harbour board and its city and regional councils collaborated in supporting a two-part design competition. The competition was run by the newly established Wellington Civic Trust, in order to generate ideas for the public use of land that had become redundant for port use because containerisation had moved port activities to the north of the harbour. ${ }^{68}$ The waterfront land in question extended from the railway station to the overseas passenger terminal at the city end of Oriental Parade. A building boom in the 1970s and 1980s had led to the demolition of many of Wellington's historic buildings, before it was slowed by the stock market crash of 1987, and the wreckage had prompted loud protest from new

\footnotetext{
${ }^{64}$ The lagoon has been known variously as 'Frank Kitts Lagoon', 'Frank Kitts Park Lagoon', 'The Lagoon' and 'Aotea Lagoon'. The name 'Whairepo Lagoon' was introduced by the New Zealand Geographic Board in 2015 at the request of Wellington City Council and the PNBST.

${ }^{65}$ Cochran et al. "Coastal Historic Heritage of the Wellington Region." 199.

${ }^{66}$ Rather than granting rights only to individual land owners as required under the Town and Country Planning Act 1953.

${ }^{67}$ New Zealand Productivity Commission, “A History of Town Planning.” 9.

${ }^{68}$ The Wellington Civic Trust was established in 1981 as an advocacy group for Wellingtonians. The design competition was followed by the trust-convened Harbour City Conference in July 1984 and the Harbour City Symposium in November 1985. The Trust continues to organise biennial public seminars on "issues critical to the city's development" and reports the results to the city's planners and decision-makers. "Wellington Civic Trust," http://www.wellingtoncivictrust.org/. Accessed 31 March 2017.
} 
organisations formed to fight for threatened buildings and nurtured a re-evaluation by many people of what was left of the city's historic fabric. ${ }^{69}$

In 1985 the harbour board and the Wellington City Council established the Lambton Harbour Group which, a year later, produced a concept plan for development of the harbour allowing for public spaces and both old and new buildings. ${ }^{70}$ Under a 1986 joint-venture agreement, consistent with the neo-liberal spirit of the time, the board and the council formed two companies to manage and administer the project-Lambton Harbour Overview Limited and Lambton Harbour Management Limited. ${ }^{71}$ Like the inner city developments, many of the proposed new projects were stymied by the stock market crash. The waterfront companies' flagship retail and events centres on Queens Wharf did proceed but were met with public outcry at their visual impact and stimulated vigorous and protracted debate about future developments on the foreshore and the potential loss of public land. Two proposals for further development - a residential complex at Chaffers Bay and a casino planned for the Odlins Building at Taranaki Wharf-caused further public concern ${ }^{72}$ and led to the formation of the lobby group Waterfront Watch in 1995 which called for an immediate halt to waterfront development and lobbied for greater public consultation. In response, Lambton Harbour Management and the council held a public forum in May 1996 which was structured to "encourage wide-ranging debate across all key issues surrounding the development of the waterfront" and to test the public's views on the original plans which, it was pointed out, were supported by the public when the project began. ${ }^{73}$

The robust discussion held at Queen's Wharf illustrated how passionate Wellingtonians were about their harbour and waterfront and confirmed that they intended to be fully engaged in its development. Following the introductions, it was suggested from the floor that the workshop topics should be: public versus private space; heritage versus new development; people

\footnotetext{
${ }^{69}$ For a detailed description of these activities see Julia Gatley and Paul Walker, Vertical Living: The Architectural Centre and the Remaking of Wellington (Auckland: Auckland University Press, 2014).

70 The concept plan was reviewed in 1992.

${ }^{71}$ Local authority restructuring led to the disestablishment of the Wellington Harbour Board and the transfer of assets from the port to the Wellington City Council in 1989. Waterfront Leadership Group, "The Wellington Waterfront Framework: Report of the Waterfront Leadership Group.” Wellington: Wellington City Council, 2001.

72 Ibid.

${ }^{73}$ Lambton Harbour Management media release, 28 March 1996 quoted in Wellington Civic Trust, "On the Waterfront: A Report and Commentary on the Lambton Harbour Forum Held at the Events Centre, Lambton Harbour Sunday 19 May 1996.” Wellington: Wellington Civic Trust, 1996. 2.
} 
versus parking and open versus built. The forum organisers compromised by merging the original topics into two groups: recreation, leisure and retailing; and major projects and living on the waterfront. ${ }^{74}$ In his foreword to the Wellington Civic Trust's report on the forum, trust chair Ian Hunter comments, "The Wellington waterfront has been the scene of many bitter battles and for a time on Sunday 19 May 1996 it looked as though it would add another page to its strifeful history". 75

Instead, the results of the forum and the subsequent surveys organised by the council and Lambton Harbour Management in mid-1996 led to the moratorium on development and the establishment of the Community Consultative Committee ${ }^{76}$ which organised public meetings and focus groups. The CCC's report in November of the same year included more than one hundred recommendations and described a vision for the waterfront as a "special place that welcomes all people to walk our waterfront history through an exciting playground of beautiful and inspiring spaces that connect our city to the sea, and protect our heritage for future generations". ${ }^{77}$ The Wellington City Council adopted and adapted the CCC's vision statement the next year to read, "Wellington's Waterfront is a special place that welcomes all people to live, work and play in the beautiful and inspiring spaces and architecture that connect our city to the sea and to protect our heritage for future generations" and commissioned a design team to produce a concept plan. $^{78}$

The resulting Lambton Harbour Public Spaces Concept Plan, referred to in the introduction to this case study, dealt with the design of open space throughout the waterfront from the railway station to Oriental Bay. ${ }^{79}$ The Taranaki Wharf area, which is the home of the Anthropocene Grove and possessed ready-made built heritage, was selected as stage one of

\footnotetext{
${ }^{74}$ Ibid. 5.

75 Ibid. Np.

${ }^{76}$ The committee was formed in August 1996 and included representatives of: Architectural Centre; Building Owners and Managers' Association; Chaffers Marina; Federation of Wellington Progressive Associations; New Zealand Historic Places Trust (Wellington Branch); New Zealand Institute of Architects (Wellington Branch); Royal Port Nicholson Yacht Club; Tourism Wellington Trust; Victoria University of Wellington Students' Association; Waterfront Watch; Wellington Civic Trust; Wellington Kindergarten Association; Wellington Playcentre Association; Wellington Polytechnic Students' Association; Wellington Regional Chamber of Commerce; Wellington Tenths Trust; and three individuals representing Wellington residents.

${ }^{77}$ Lambton Harbour Management Limited. "Lambton Harbour Public Spaces Taranaki Wharf Stage 1: Applications for Resource Consent.” Wellington: Lambton Harbour Management Limited, 1999. ${ }^{78}$ Ibid.

${ }^{79}$ In 1998 the Lambton Harbour Public Area Design Group was formed as an independent watchdog to ensure public space was developed in accordance with the concept plan, and a community advisory group was set up to represent the concerns of the wider community.
} 
the overall plan and in May 1998 Athfield Architects and landscape architect, Megan Wraight, were commissioned to produce detailed drawings. ${ }^{80}$ More consultation followed. The Wellington Tenths Trust ${ }^{81}$ supported the project and recommended the inclusion of a historical marker on Taranaki Wharf that acknowledged Te Aro Pā, provision of headroom for waka activities and an appropriate Māori protocol event to precede construction; NZHPT expressed concern at the drawings' proposed relocation of the Wellington Free Ambulance Building $^{82}$; the Department of Conservation recommended ongoing public access along the water's edge and protection for penguin nesting sites; and Port Wellington Limited ${ }^{83}$ requested continued rights to berth vessels at Taranaki Wharf. The next section outlines the development of the concept plan and describes the contemporary heritage nature of Taranaki Wharf to provide context for the Anthropocene Grove and its role of trees as heritage.

\section{Trees as Heritage}

The Taranaki Wharf karaka under the microscope here are not included in the New Zealand Tree Register, nor are they noted in the Wellington City Council's Schedule of Heritage and Notable Trees ${ }^{84}$ which, under the city's district plan, are protected because of "their important links with the City's history and tradition, in some cases their ecological importance and because they are a major part of the City's character and amenity". ${ }^{85}$ The Taranaki Wharf area is not currently registered as a historic/heritage area by the Wellington City Council, however, in their report on Wellington's coastal historic heritage for the Wellington Greater Regional Council Cochran et al. note that while it is not presently registered by Heritage New Zealand it is part of a proposed Wellington Wharves Historic Area. ${ }^{86}$ Many of the buildings, objects, artefacts and monuments housed within the area do qualify for heritage status of various degrees and are celebrated as such with a series of easily accessible, attractive and informative interpretive panels. Within Taranaki Wharf, The Odlin's Building, is a Heritage

\footnotetext{
${ }^{80}$ The area covers the space between Te Papa on its south/eastern boundary and the south face of Frank Kitts Park.

${ }^{81}$ The Wellington Tenths Trust was established by the Māori Land Court in 2003 to administer Māori reserve lands. http://www.tekau.maori.nz/WellingtonTenthsTrust/AboutUs.aspx. Accessed 17 March 2017.

82 The suggestion to shift the building to the present location of Te Raukura was met also with vigorous opposition from Waterfront Watch who won an appeal to the Environment Court.

${ }^{83}$ Now named CentrePort.

${ }^{84}$ Trees included in the council's schedule are first evaluated against STEM allocating points to individual trees or groups of trees under the three criteria of condition, amenity and notability.

${ }^{85}$ Wellington City Council. "Wellington City District Plan.” Wellington: Wellington City Council, 2000, amended 2012. 20/4.

${ }^{86}$ Cochran et al., "Coastal Historic Heritage of the Wellington Region”. 205. Wellington Greater Regional Council is responsible for the care of Wellington's foreshore.
} 
New Zealand category 1 Edwardian industrial building which was constructed in 1907 as the warehouse and head office for timber and building hardware merchants C. and A. Odlin Ltd ${ }^{87}$ the art deco, Heritage New Zealand category 1 Wellington Free Ambulance Building was purpose-built in 1931; ${ }^{88}$ and the Heritage New Zealand category 2 Shed 22 was built circa 1921 to store shipping goods. ${ }^{89}$ All three buildings are listed as heritage buildings on the Wellington City Council heritage register along with the Taranaki Street Gates, thought to have been built in $1907,{ }^{90}$ which are listed as a heritage object. The Star Boating Club and the Wellington Rowing Club on the northwest edge of the Taranaki Wharf area are both registered as category 1 buildings with Heritage New Zealand. The Star Boating Club building was constructed for the club in 1885-6 and was originally sited on Jervois Quay, subsequently on a site near the corner of Jervois Quay and Cable Street and shifted to the current site in 1989. The Wellington Rowing Club was built in 1894 as a base for the Wellington Naval Artillery Volunteers; it then became the original home of Wellington Free Ambulance before being taken over by the Wellington Rowing Club in 1931. The floating Hikitia crane, which was commissioned by the Wellington Harbour Board in 1925, has been permanently moored at the wharf since 1990, is believed to be the world's oldest crane of this type still working, and is described by Cochran et al. as “one of the city's most significant maritime relics." 91 Two wharf cut-outs ${ }^{92}$ now reveal the old wharf foundations, and the wharf supports extant steel bollards. Neighbours of the Taranaki Wharf are Te Papa, New Zealand's "forum to present, explore and preserve the heritage of its cultures and knowledge of the natural environment"93 and the Circa Theatre building which incorporates the façade of the former Westport Chambers originally sited on the opposite side of Cable Street.

The following discussion builds on the history of the Taranaki Wharf and its historic heritage elements as outlined above, describes the motives behind the planting of the karaka grove and explores the ways in which the grove contributes to the heritage nature of this area. It asserts that while the karaka grove cannot claim to be made up of 'heritage trees', in the sense of the

\footnotetext{
${ }^{87}$ The building was refurbished in 2005 and is now the home of the New Zealand Stock Exchange, commercial offices and apartments.

88 The Wellington Free Ambulance Building now houses offices and a bar and restaurant.

${ }^{89}$ Shed 22 was refurbished in 2002 and accommodates a brewery, bar and restaurants and offices.

${ }^{90}$ Cochran et al. "Coastal Historic Heritage of the Wellington Region." 198.

${ }^{91}$ Ibid. 200.

92 The timber from the cut-outs has been used to construct the 'timber garden' on Odlin's Plaza.

${ }^{93} \mathrm{https}: / /$ www.tepapa.govt.nz/about/what-we-do/te-papas-vision-and-future. Accessed 29 September 2016.
} 
AAHD, it can be considered as an example of 'trees as heritage' within the counter- concept of the UAHD.

\section{Growing a Heritage}

In 1999 Lambton Harbour Management Limited applied for resource consent to carry out the Taranaki Wharf project at a hearing by the Wellington City and Wellington Regional councils. ${ }^{94}$ The establishment of the karaka grove was included in phase one of the two-phase works schedule. In presenting the design concept for the Taranaki Wharf area Wraight described the design team's strategy to achieve a "sense of place" which she defines as:

the unique identity particular to the Lambton Harbour Waterfront that sets it apart from the global waterfronts and makes it supremely and superbly local. To achieve a 'sense of place' we believe it is necessary to connect to the collective memory of the waterfront. By 'collective memory', I mean the shared richness and range of experiences that remain with a community as a place evolves over time. ${ }^{95}$

The design team's 1999 strategy reflects the CCC's report recommendation made three years earlier that "heritage must include both pre- and post-European history" and "the importance of the waterfront to Māori must be an important consideration" in the development of heritage. The challenge for the design team was how best to represent Māori when no vestige of Te Aro P $\bar{a}$ - the most local of the original p $\bar{a}$ - was in evidence (at the time) and the very ground on which any representation might exist had, in fact, been reclaimed from the sea with the completion of Taranaki Wharf in 1906, and would have been underwater when the last residents had left the pā in the $1890 \mathrm{~s} .{ }^{96}$ In order to "facilitate the reading of the history of the waterfront", Wraight explains, the design followed an "archaeology line" and an "ecology line". The archaeology line proposed to "declaim" some of the reclaimed land returning the water, in part, to its original edge and reinstating it as a finger wharf, and to employ materials of industrial scale and character to reflect the working nature of the port. The ecology line aimed to connect the new landscape to its Wellington coastline context through its selection of plants, aggregates and rocks; a newly-formed coastal headland beside the lagoon; and three grids made up of wharf piles (the 'timber garden'), sculptures of nikau palms (Rophalostylis sapida) and a regimented group of ngaio (Myoporum laetum) trees. ${ }^{97}$ The karaka grove was

\footnotetext{
${ }^{94}$ Land use consents were required from the city council and coastal permits sought from the regional council. Also referred to in the resource application, but not pertinent to this discussion, were the Wellington Regional Policy and New Zealand Coastal Policy statements of the time.

${ }^{95}$ Lambton Harbour Management Limited. “Lambton Harbour Public Spaces Taranaki Wharf Stage 1.” 2.

${ }^{96}$ Remains of Te Aro Pā were uncovered in 2005 and are referred to later in this chapter.

${ }^{97}$ Neither the nikau sculptures nor the group of ngaio trees was achieved.
} 
not intended to be part of the proposed grid colonnade but was designed as an informal element to provide shelter, from the wind and sun and to symbolise "arrival," a "food source" and "encampment" 98 _ pre-European history as prescribed by the CCC.

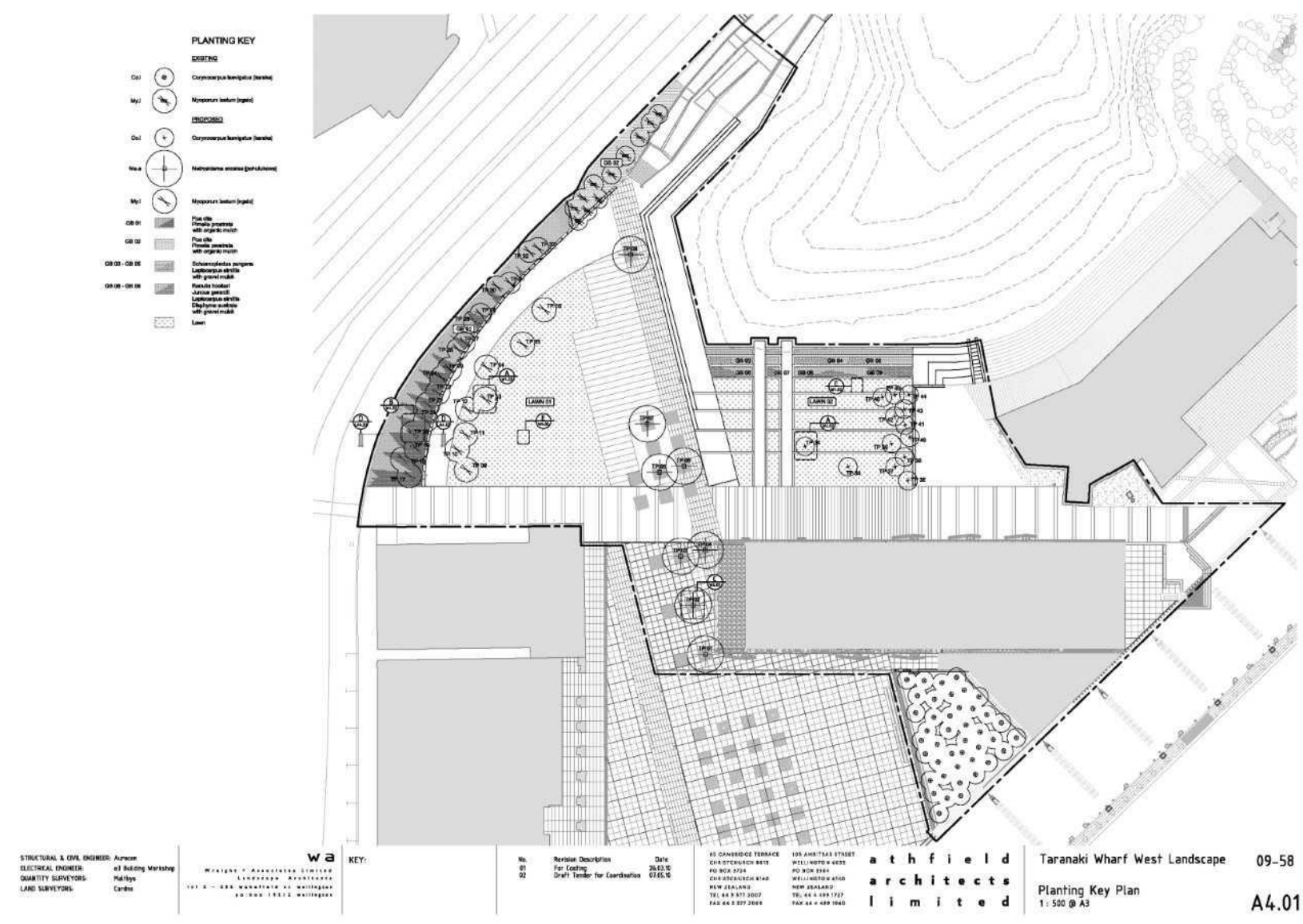

Figure 28: Planting Plan for Taranaki Wharf showing existing and proposed planting, 2010. The karaka grove is shown at the bottom right of the plan and to its left is the timber garden. The building in the centre is Te Raukura. Reproduction permission courtesy of Wraight and Associates and Athfield Architects.

Karaka was selected as a "typical coastal planting of the Wellington region" and the trees were grown from locally sourced material propagated by the Wellington City Council's Berhampore nursery and planted in 1999 when they were about one and a half metres tall. Despite some early doubts from critics who said they wouldn't grow, the trees have thrived with only a few losses which have been replaced successfully. ${ }^{99}$

\footnotetext{
${ }^{98}$ These terms were not included in the resource consent application but are quoted from an interview with Megan Wraight. One aspect of the grove is the noisy nightly arrival and encampment of small birds drawn by the warmth provided by the urban canopy of the karaka grove. Another take on the "arrival" and "encampment" ideas is the use of the area between the grove and Kupe Group as a car parking space for visitors and staff at Te Raukura.

${ }^{99}$ Wraight interview.
} 
While the overall effect of the non-regimented grove is of a 'natural' addition to the Anthropocene surrounds its design is decidedly 'cultural'. First, because the terms "arrival," a "food source" and "encampment" applied to any karaka grove as far south as Wellington are synonymous with intentional planting regardless of the locally sourced origin of the plants. Second, because the trees are growing on reclaimed land they have had to be planted in a below-ground concrete tank to ensure that the soil does not become soaked in salt water. Above ground the specially raised trees are contained in a raised, rectangular bed, composed of locally sourced aggregates, the surrounds of which double as seats. The trees were initially confined in a metal cage designed to both protect them and provide them with shelter, and as the trees have grown they have been limbed up regularly to allow views under their canopies and to ensure the space is safe at night.

\section{Taranaki Wharf as a Cultural Heritage Assemblage}

As well in 1999, the Kupe Group Trust raised the funds necessary to cast in bronze Christchurch sculptor William Trethewey's 1939 plaster work Kupe Group and locate it permanently on the waterfront. As The Coming of the Maori the original plaster sculpture was commissioned and first exhibited in a group of works depicting the country's progress at the 1940 New Zealand Centennial Exhibition at Rongotai, Wellington where it was placed prominently at the main entrance. The Evening Post described the sculpture as representing "the Maori race" and "presenting the discovery of New Zealand by the Maori navigator Kupe, standing at the bow of his canoe ... this work will receive its homage from Maori and pakeha [sic] alike for its faithful detail and the attention that has been paid to weapons, tattoing, and facial characteristics". ${ }^{100}$ When the exhibition closed the proposal to store the sculpture at the Dominion Museum ${ }^{101}$ was turned down and Kupe Group was eventually installed at Wellington's Railway Station where it was damaged by vandals.

In 1986, the sculpture was transferred to the Wellington Show Grounds and was subsequently gifted by the Wellington Show Association to Te Papa in 1997 where it remained until it was recovered by the Kupe Group Trust. The newly cast bronze sculpture was unveiled in March 2000 at a site on Taranaki Wharf just north of the karaka grove. Today Kupe is depicted standing at the prow of the waka (canoe) Matahourua with Hine Te Āparangi his wife

\footnotetext{
100 "Symbolic Statues: An Impressive Panel, Fine Maori Groups, New Zealand Sculptor's Work," Evening Post, 23 August 1939.

${ }^{101}$ The Dominion Museum became the Museum of New Zealand Te Papa Tongarewa in 1992.
} 
pointing towards the Hutt Valley, and Pekahourangi, their tohunga (priest, healer), gazing in the same direction.

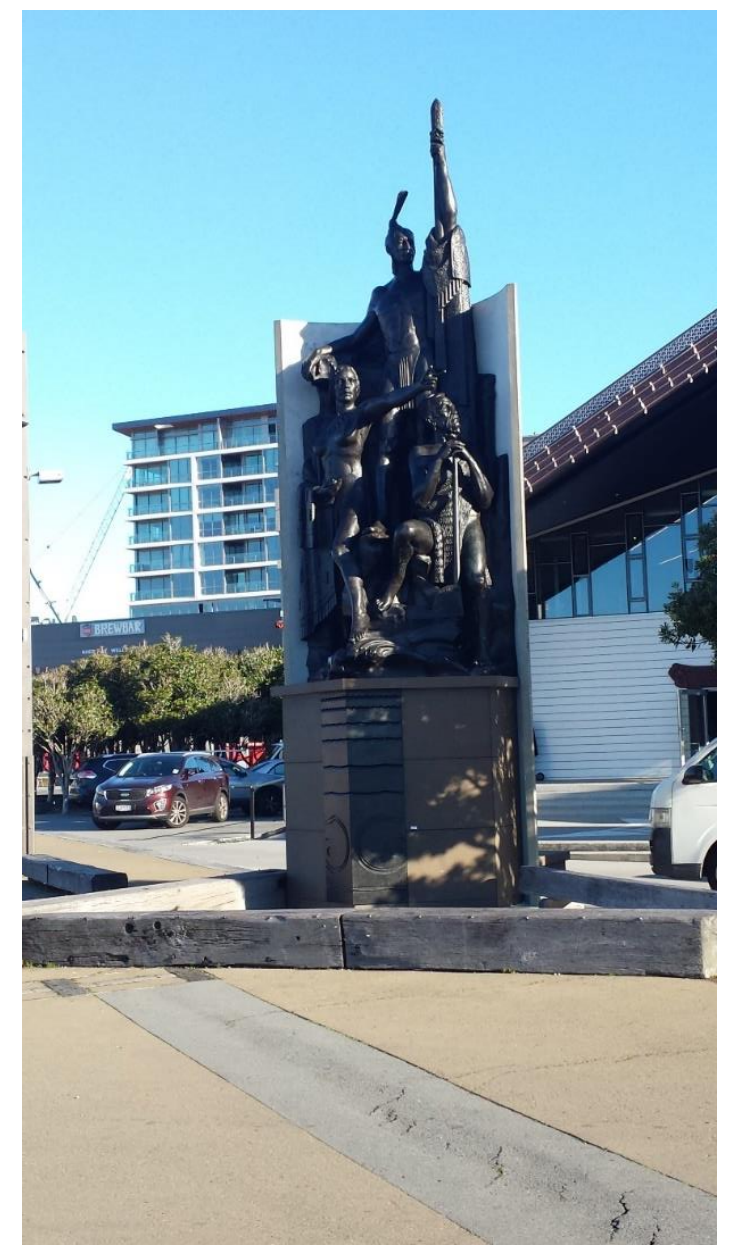

Figure 29: Kupe Group. Te Raukura is the building to the right: the Anthropocene Grove is behind and to the left. (10 August 2016.)

In his evidence to the resource consent submission, architect, Ian Athfield, describes the sculpture as marking "the transition between sea and land on the inner line of Taranaki Wharf" and he included it on his plans. ${ }^{102}$ Landscape architect, Wraight, describes the karaka grove as "company for Kupe." ${ }^{103}$ Representing the Tenths Trust on the Kupe Group Trust, Ngatata Love reportedly endorsed the sculpture as a means to "educate New Zealand about his people's heritage". 104 Elsewhere Kupe Group is described as being associated with neighbouring building $\mathrm{Te}$ Raukura $^{105}$, which was not named and opened until Waitangi Day, 6 February 2011, ${ }^{106}$ but plans for which had been in the air since at least 2001. ${ }^{107}$ In its waterfront framework report of April 2001, the Wellington City Council's Waterfront Leadership Group recommended that Māori cultural heritage should have a strong and "active" presence on the waterfront focusing on waka culture and identified Whairepo Lagoon as the site for a shelter to be built for ceremonial waka. ${ }^{108}$ Close to the original Te Aro Pā and the city's civic centre and with easy access to the water, the site was considered to potentially present a "living culture" with activities such as "waka construction, weaving decorative arts, building construction, carving and performing arts". ${ }^{09}$

\footnotetext{
${ }^{102}$ Lambton Harbour Management Limited. "Lambton Harbour Public Spaces Taranaki Wharf Stage 1." 7. ${ }^{103}$ Wraight interview.

${ }^{104}$ Rex Nicholls, "Submission to Resource Consent: Taranaki Wharf Area," (Wellington: Wellington City Council, 1999). 1.

105 Te Raukura was previously known as Te Wharewaka.

${ }^{106}$ Helen Lloyd, "William Trethewey, Kupe Group (1939)," Art in Context (2013), https://www.tepapa.govt.nz/sites/default/files/art_in_context.pdf. 42. And Cochran et al. Coastal Historic Heritage of the Wellington Region. 202.

107 Waterfront Leadership Group, "The Wellington Waterfront Framework".

${ }^{108}$ Ibid. 17. Waka of national and international importance were considered to be best moored near Te Papa.

109 Ibid. 36.
} 
Te Raukura (the Feather) ${ }^{110}$ was an initiative of Taranaki Whānui ki te Ūpoko o Te Ika (Taranaki Whānui $)^{111}$ and Wellington Waterfront Limited and is of special significance to descendants from Te Ātiawa, Taranaki, Ngāti Ruanui, Ngāti Tama and Ngāti Mutunga iwi. The building, with whakairo (carvings) and a korowai (cloak)-like covering, is in three parts: Te Wharewaka, the waka house designed to house two ceremonial waka taua (war canoes); Te Wharekai (dining hall, the very popular Karaka Café); and Te Whare Tapere (place for entertainment), conference and events venue and office of the Wellington Tenths Trust. Associated web sites place the building on the harbour frontage to Te Aro Pă,${ }^{112}$ some fragments of which were discovered in 2005 after the demolition of a building and subsequent earthworks for a new apartment complex at 39 Taranaki Street. The pā remains of three ponga structures and associated archaeological features were found under a building erected on the site in 1908 and are now preserved as a category one historic place by Heritage New Zealand. Toenga o Te Aro (remains of Te Aro Pa) are classified as being of:

outstanding archaeological, architectural, cultural, historical, social, and traditional significance due to their association with early Wellington and North Island iwi, the archaeological rarity of the site, the educational value of the place as an example of early Māori residential architecture, and their strong associations with figures of cultural and social importance to Māori and Pākehā New Zealanders. ${ }^{113}$

Considering together these four elements and their chronology demonstrates how varied they are - the Anthropocene Grove (planted in 1999; thriving in 2018), Kupe Group (first made in 1939; cast and relocated in 2000), Te Raukura (proposed in 2001; opened in 2011) and Toenga o Te Aro (first settled in the 1820s; uncovered and conserved in 2005). Despite their variations in form and age, however, they have strong heritage connections. The Port Nicholson Block Settlement Trust's (PNBST) ${ }^{114}$ web site places Te Raukura at the heart of

\footnotetext{
${ }^{110}$ The name refers to the passive resistance of the people of Parihaka in Taranaki to colonial troops in the $1880 \mathrm{~s}$. A white feather is the symbol still worn by their descendants.

${ }^{111}$ Taranaki Whānui ki te Ūpoko o Te Ika is a collective group of iwi including Te Ātiawa, Taranaki, Ngāti Ruanui, Ngāti Mutunga and other iwi from the Taranaki area. Part 1, Clause 8 of the Port Nicholson Block (Taranaki Whanui ki Te Upoko o Te Ika) Claims Settlement Bill 2008.

112 "Te Wharewaka O Poneke," http://www.wharewakaoponeke.co.nz/. And "Te Raukura," Port Nicholson Block Settlement Trust, http://www.pnbst.maori.nz/what-we-do/cultural-well-being/history/te-raukura/. Both accessed 14 March 2017.

113 “Toenga o Te Aro (remains of Te Aro Pa)," Heritage New Zealand, http://www.heritage.org.nz/the-listdetails/771. Accessed 15 March 2017.

114 The Port Nicholson Block Settlement Trust was established in August 2008 to receive and manage the Treaty settlement package for Taranaki Whanui ki te Ūpoko o Te Ika who have mana whenua (territorial rights) of the area. The trust's vision is: Ki te whakahou, whakapakari me te whakanikoniko i te ahurea papori, rangatiratanga o Taranaki Whānui ki te Ūpoko o te Ika. To restore, revitalise, strengthen and enhance the cultural, social and economic well-being of Taranaki Whānui ki te Ūpoko o te Ika.
} 
the Taranaki Wharf as the "fulfilment of a vision to return a Māori presence to Te Whanganui a Tara":

Previously the area where the building is located was harbour frontage to Te Aro Pa, one of the largest Maori communities in Wellington up until the 1880s. The building sees the reestablishment of a Maori presence on Taranaki Wharf, notably absent on the waterfront since that time. ${ }^{115}$

It would be easy to dismiss the recycled Kupe Group sculpture as a stereotypical and romantic image of early Māori fabricated by Pākehā, particularly in the light of the centennial's celebration of progress as discussed in Chapter Two. However, Taranaki Whānui have appropriated the statue as part of their "Māori presence". On its web site, the PNBST has rearticulated Kupe Group by linking it to the building through the placement of a colourful àtea (traditional Polynesian star compass) ${ }^{116}$ which is inlaid on the forecourt of Te Raukura. The web site describes the atea as the "cultural linkage between the Kupe statue and the building" adding that "Kupe could be seen as the external tauihi or 'prow' of the building which itself could be viewed as a waka". ${ }^{117}$ The trust has adopted the karaka grove as well by including a photograph of the grove taken at night on the web site, and describing it as making:

a connection to the history of Wellington's early inhabitants. It is said that Maori settlers brought the karaka seed with them on waka as they travelled to Aotearoa, so they could continue to harvest the karaka fruit. ${ }^{118}$

The relationships of the karaka grove with Kupe Group, Te Raukura and Toenga o Te Aro are, to some extent, serendipitous as are their relationships with the other heritage elements of the Taranaki Wharf assemblage. McCarthy has pointed out that despite the sometime dissonance between Māori values about the living past and Pākehā notions of history, in heritage practice "overlapping approaches to our entwined past open up constructive engagement rather than contested discourses". 119

This consideration of the contribution of the Anthropocene Grove to the heritage values of Taranaki Wharf has placed it in a broad context of both Māori and Pākehā settlement and the

\footnotetext{
115 http://www.pnbst.maori.nz/what-we-do/cultural-well-being/history/te-raukura/ Accessed 31 March 2017.

116 The ātea was designed by Eruera Te Whiti Nia of Rarotonga.

117 http://www.pnbst.maori.nz/what-we-do/cultural-well-being/history/te-raukura/ Accessed 31 March 2017. Cochran et al. note that Kupe Group has "an important resonance with the nearby Wharewaka". Cochran et al. "Coastal Historic Heritage of the Wellington Region.” 211.

118 http://www.pnbst.maori.nz/what-we-do/cultural-well-being/history/te-raukura/ Accessed 31 March 2017.

${ }^{119}$ Conal McCarthy, "Te Ara O Nga Tupuna Maori Heritage Trail/Te Aro Pa, 39 Taranaki St, Wellington,” New Zealand Journal of History 43, no. 1 (2009). 116.
} 
associated development of the waterfront. As a cultural heritage landscape with an assemblage of both Māori and Pākehā settlement signifiers, Taranaki Wharf works hard to contribute to the "collective memory" prescribed by Wraight as Table 5 demonstrates.

\begin{tabular}{|l|l|}
\hline Signifiers of Pākehā settlement & Signifiers of Māori settlement \\
\hline Star Boating Club (1885-6/1989) & Toenga o Te Aro (1820s/2005) \\
\hline Wharf bollards and timbers (c 1880s) & Karaka grove (planted 1999) \\
\hline Odlins Building (1907) & Kupe Group (1939/2000) \\
\hline Wharf gates (1907) & Te Raukura (2001/2011) \\
\hline Shed 22 (1921) & Forecourt ātea (2011) \\
\hline Hikitia (1925/1990) & \\
\hline Wellington Rowing Club (1931) & \\
\hline Wellington Free Ambulance Building (1931) & \\
\hline
\end{tabular}

Table 5: The heritage assemblage of Taranaki Wharf.

All of the artefacts listed under 'Pākehā settlement' plus Toenga o Te Aro listed under 'Māori settlement' in Table 5 qualify for 'official' heritage status of some form. Kupe Group, Te Raukura, the àtea and the Anthropocene Grove have attracted no official heritage acknowledgement as yet.

\section{Conclusion: Everyday Arboreal Heritage and the Intangible}

Chapter Two discussed the Cyberforest as a place of 'heritage trees' and concluded that it was an expression of the AAHD. This chapter has outlined the events leading to the existence of the Anthropocene Grove on Taranaki Wharf as a place of 'trees as heritage' and described its relationships with the other heritage elements of the Taranaki Wharf assemblage. In conclusion, this section situates the grove within the alternative heritage discourse - the UAHD - and discusses Harrison's 'counter-' approach as counter-heritaging in practice.

By considering together the Cyberforest in Chapter Two and the Anthropocene Grove in this chapter it is clear that the latter has little in common with the online register's existing entries which are, in general, large, old and/or rare trees. As a nineteen-year-old the Anthropocene Grove is unqualified also for inclusion in the general list held by New Zealand Heritage, "the leading national historic heritage agency" concerned with historic places and historic areas. ${ }^{120}$ Similarly it is unlikely to be classified by New Zealand Heritage as Māori Heritage Ngā

${ }^{120}$ http://www.heritage.org.nz/about-us. Accessed 8 March 2017. 
Taonga Tuku Iho nō Ngā Tūpuna (treasures handed down by our ancestors) either as an example of "physical/tangible heritage ... land-based places created, formed or shaped by earlier inhabitants"; "natural heritage places ... where no human activity is evident”; or "intangible heritage places where no visible feature or evidence is present". ${ }^{121}$

This thesis argues that, despite its inability to win a place in the AAHD a case can be presented for the Anthropocene grove as heritage - trees as heritage - achieved by counterheritaging which, Harrison argues, enables minority groups to "challenge some of the "takenfor-granteds' of heritage management but also encourages people to celebrate their experience of the everyday". ${ }^{122}$ While the establishment of the Anthropocene Grove is not devoid of professional input, in the form of the plans drawn up by Athfield Architects and Wraight Associates, its genesis is lodged in the community consultation brought about through the community's challenge of the "taken-for-granteds of heritage management" and achieved through the efforts of what Harrison describes as the "hybrid forum" of democratic decision-making. ${ }^{123}$ Counter-heritaging is similarly defined, in relation to the Anthropocene Grove, as the processes that challenge some of the assumptions of the AAHD and celebrate the everyday.
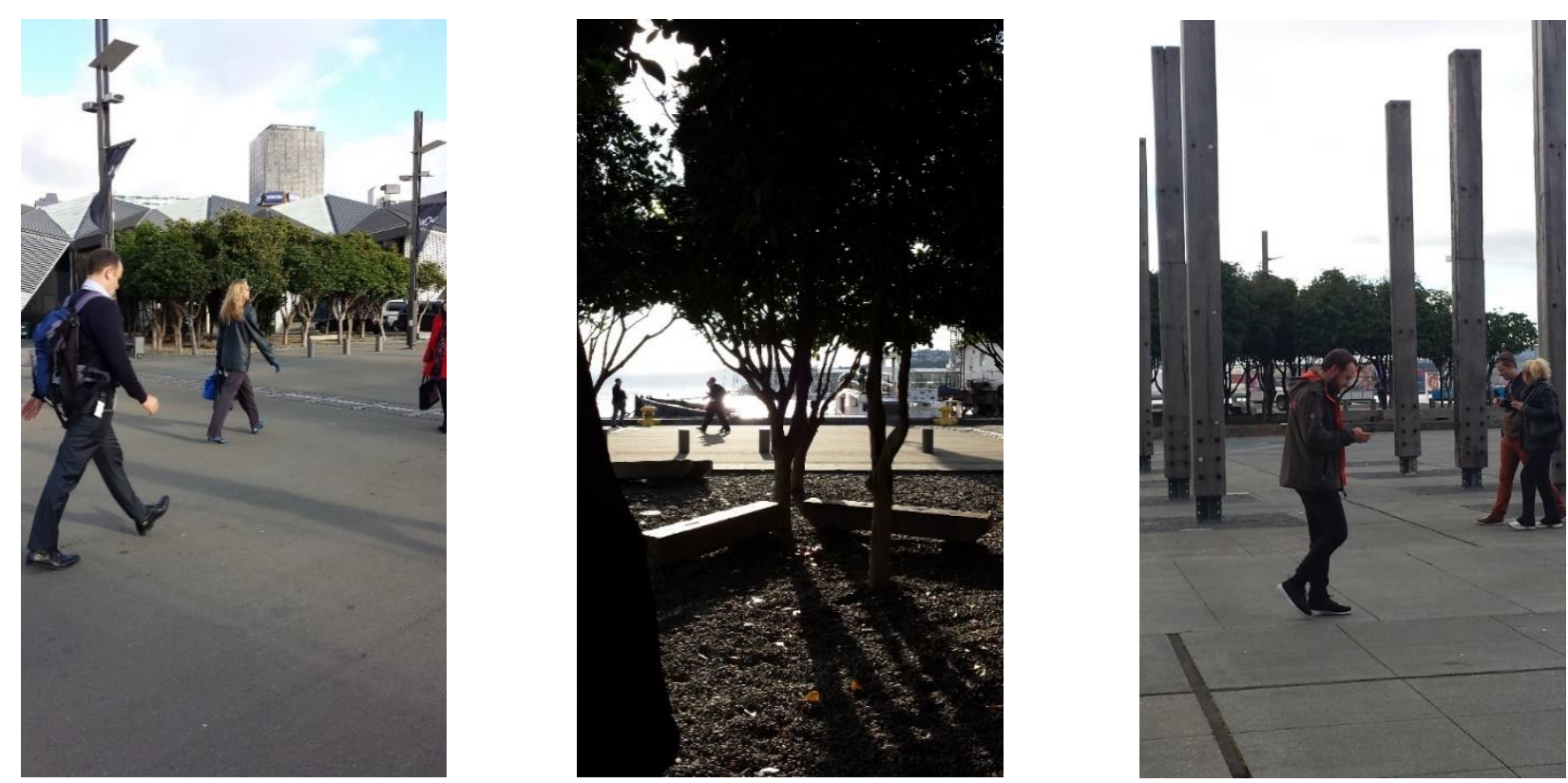

Figure 30: The Anthropocene Grove. Left: view west towards Te Raukura (28 September 2015). Middle: view east across the harbour; Right: view north from behind the timber garden (both 23 August 2016).

\footnotetext{
${ }^{121}$ http://www.heritage.org.nz/protecting-heritage/maori-heritage. Accessed 8 March 2017.

122 Harrison, "Counter-Mapping." 91.

${ }^{123}$ Harrison, Heritage: Critical Approaches. 229.
} 
The Anthropocene Grove - despite, or because of, its spiritual connections to Te Aro Pā; its association with the international development of waterfronts; and its role in the rehabilitation of Taranaki Wharf-is decidedly 'everyday'. Anecdotal evidence and personal observations demonstrate that few of the many Wellingtonians who regularly walk past the grove to and from work every day and the thousands of tourists who traverse Taranaki Wharf between the Civic Square and Te Papa each year might remark upon its presence or pause to ponder its existence. The grove has become part of Taranaki Wharf's furniture: as ubiquitous as the seagulls and the light standards. Within its larger, leafy context, all of which is almost completely dedicated to indigenous plants and encompasses Waitangi Park (to the east) and Frank Kitts Park (to the west) and neighbouring Te Papa's Bush City, the addition of a grove of native trees - particularly 'weed'-like karaka — was unlikely to excite much attention. The events leading up to the establishment of the grove, however, verify that it was not intended merely to 'soften' the Anthropocene landscape with some greenery and was certainly not the result of a value-neutral decision. The design plan commissioned by the $\mathrm{CCC}$, as a result of consultation, prompted by a groundswell of public interest in and agitation for ownership of the waterfront development, led to a conscious process of counter-heritaging. While Taranaki Wharf already possessed co-constituent, historic heritage elements in the form of its extant buildings and commercial wharf apparatus, to meet the instructions of the $\mathrm{CCC}$ to "include both pre- and post-European history" and acknowledge the "importance of the waterfront to Maori" additional, tangible elements were needed. ${ }^{124}$ The landscape required more heritage.

Taranaki Wharf's karaka grove is not the only specially fabricated Māori heritage element in Wellington. For example, the Māori heritage trail Te Ara o Ngā Tupuna (the path of our ancestors) is marked by a series of symbolic carved pou whenua (post markers of ownership) fabricated for the purpose. The trail was developed by the Wellington City Council, the Wellington Tenths Trust and Ngāti Toa in 1996 and was expanded in 2006 to include Waitangi Park and the rediscovered remains of Te Aro Pā. It is both a walking trailbeginning at modern Pipitea Pā, ${ }^{125}$ and taking in Toenga o Te Aro, a site identified as Te Aro kāinga and the former Waitangi (crying waters) Lagoon which was a traditional food source for Te Aro Pā inhabitants ${ }^{126}$ — and a driving trail—from Matairangi Mount Victoria to

\footnotetext{
${ }^{124}$ Community Consultative Committee, "Report on Lambton Harbour.” 47.

125 Pipitea Pā was built in the early 1980s as an urban marae for all Wellington's Māori population.

126 The lagoon was drained substantially when the 1855 earthquake raised the land.
} 
Owhiro Bay on the southern coast. The pou whenua (or dedicated rocks or interpretive panels in some places) guide trail participants to old pā, cultivations, historic sites, buildings and cultural landscapes. Pou whenua traditionally marked boundaries or places of significance: today, like the Anthropocene Grove, they acknowledge the association of tāngata (people) and whenua (land). In the busy, visually cluttered urban landscape of Wellington these small signposts, like the Anthropocene Grove, signify Māori historic heritage and have become part of the everyday experience. Despite the fact that many of the traditional Māori sites on the trail have been built over or destroyed and there is nothing left to observe except the pou themselves, the interpretive pamphlet states, their "strong spiritual presence" survives. ${ }^{127}$ In a world that has become increasingly virtual, standing on the real place where real history has been made can have strong affect. ${ }^{128}$

The Anthropocene Grove is not marked on Te Ara o Ngā Tupuna and, as reclaimed land, can lay no claim to the heritage measure of authenticity as an historic place, as discussed further in Chapter Five. It is entitled, however, to the acknowledgement that it contrives both a physical presence of hybrid living heritage rich in symbolism and a spiritual presence of another kind - an Anthropocene genius loci. The commitment to planting a grove of ecosourced trees in locally sourced aggregates is in line with Wellington City Council's encouragement of its people to strengthen the city's arboreal biodiversity by planting two million native trees by $2020 .{ }^{129}$ However, the Anthropocene Grove is more than just a feature of urban design or an addition to the city's indigenous arboreal inventory. Its location within the "memoryland"130 of Taranaki Wharf steeped in both Māori and non-Māori histories demanded a more thoughtful treatment of trees as living materiality and as heritage. As Hitchings' ANT definition explains, there is much “jostling” of people, objects, plants, animals and ideas going on here. ${ }^{131}$ In the Māori world view nature, people and the land are inextricably intertwined through a shared whakapapa. The establishment of the karaka grove may have had its genesis in an official committee-generated recommendation but it has achieved, through thoughtful, contemporary design and implementation, both tangible and intangible connections with the early Māori who first transported the food-bearing trees to the region from their natural northern home and trod the very soil the grove now thrives in-

\footnotetext{
${ }^{127}$ Matene Love, “Te Ara O Nga Tupuna," (Wellington City Council, 1996 [second edition 2006]). Np.

${ }^{128}$ McCarthy, "Te Ara O Nga Tupuna Maori Heritage Trail/Te Aro Pa, 39 Taranaki St, Wellington.” 115.

${ }^{129} \mathrm{http} / / / \mathrm{www}$.wellington.govt.nz/your-council/projects/two-million-trees. Accessed 10 March 2017.

${ }^{130}$ Term borrowed from Macdonald, Memorylands.

${ }^{131}$ Hitchings, "People, Plants and Performance." 100.
} 
albeit overlaid on reclaimed land. It is also a physical representation of what might have been in the urban landscape - be it cultural or natural — and is no longer there. This is not an overt statement of heritage - there is no interpretive panel nearby to inform the passer-by of the intentions of the CCC and the designer or the adoption of the trees by the PNBST. Within the context of Taranaki Wharf the Anthropocene Grove unobtrusively presents heritage as an “inalienable possession", to borrow Macdonald's term, "dense in history and symbolic significance" and tightly bound to the identity of Māori and all Wellington. ${ }^{132}$ As "trees as heritage' the grove's existence is the fruit of a counter-heritaging action that boldly challenges the assumptions of the AAHD and quietly celebrates the everyday.

\section{Being There}

The Anthropocene Grove, Monday 13 November 2017

This is another heritage tree site that I'm very familiar with having walked past it many times en route to my bus stop. In search of an alternative impression of the grove, I invite its architect Megan Wraight to join me and discuss it. She's always happy to talk about her trees, she says, and we agree to meet this morning at 7.00. There are only joggers and cyclists at their individual pursuits when I arrive, and I can hear the commands of the rowing coaches spinning across the waters of the harbour. It might be spring but there's a chilling southerly and nobody zooming past is pausing to admire the karaka. The standard lights on the wharf are still on and so are the security lights embedded in the ground below the trees. Peter Wohlleben writes that trees need rest and can suffer if they are subjected to light every night. ${ }^{133}$ I wonder when this grove manages to get some sleep. The small birds that settle in the warmth of the canopy in the evenings have already left to go about their urban business, and there are only a few city pigeons bustling around carrying out their after-the-weekenddetritus check of the ground. I move in with them to get out of the wind and find that under the canopy it's comfortably calm after the bustle and glare of the wharf. The dense canopy moves smoothly above us. There's a strong aroma of urine, and the freestanding bench-type seats are streaked with bird pooh. Visitors to the grove in summer frequently shift the benches around to create customised seating arrangements in the shade. The lower leaves of the canopy are pooh-streaked too, and amongst them hang heavy bunches of shiny green, unripe fruit. The pigeons aren't interested in karaka berries, though. They busily stocktake

\footnotetext{
${ }^{132}$ Ibid. 115. See also, Annette B. Weiner, “Inalienable Wealth,” American Ethnologist 12, no. 2 (1985).

${ }^{133}$ Peter Wohlleben, The Hidden Life of Trees: What They Feel, How They Communicate: Discoveries from a Secret World, trans. Jane Billinghurst (Melbourne: Black Inc., 2015). 226.
} 
the cigarette butts, drink cans and plastic cutlery among the fallen, yellowing leaves, and take little notice of me inspecting the environs.

At 7.15 the lights go out and there's still no sign of Megan but that's fine. For the first time, I'm really looking at this site, not just taking a few photographs or checking that the grove is still there and hurrying past.

A couple of metre-high taupata (Coprosma repens) have colonised the space and have seedlings springing up on the edges of the grove where they can find some light. A branch has been ripped off one of the karaka in the weekend and tossed aside. I try to count the trees-forty maybe thirty-eight. It's tricky because they seem random. I go to the other side of the wharf and try counting again—maybe thirty-nine? Their grey-brown trunks have been heavily pruned and the scars are arthritically knobbly. At 7.30 the Kai-to-Compost truck stops to pick up leftovers from the Karaka Café and a van delivers eggs. More vans come and go for pick-ups or deliveries, and cars cruise in bearing more rowers. Workers stride purposefully towards the city, with lanyards swinging. Café staff arrive and glance quizzically at me so I take some photographs to appear official. At 7.45 the sound of traffic nearby has built up, there's music and the smell of coffee drifting from the café and the sun is valiantly pushing aside some cloud. There are more black-clad office workers than athletes on the wharf now. At 8.00 I leave and, at a distance, I turn and watch the little grove swaying and shining its living presence within the urban, concrete desert of Taranaki Wharf.

Tuesday 14 November 20178.00 am An urgent telephone call from Megan. Where am I? She's at Taranaki Wharf and I've had a communications malfunction. I hitch a ride with a friend and find Megan shivering by the grove. The ground is much cleaner today. The wind has dispatched the litter and the air definitely smells sweeter. We walk in under the trees and gaze up into the canopy. It's just how she imagined it, she says, trees planted close together and a full canopy. There's only one gap - a single window to the sky, an unexpected bonus and "quite beautiful". She's concerned about the height of the security lights, though, and wishes she had a pair of secateurs in her back pocket to tidy up the shoots at the bases of some of the trees. The seats could do with a bit of a clean too, she says. The idea behind the design concept was to produce an assemblage of different spaces at Taranaki Wharf serving different purposes, she explains. The karaka grove is a closed space to frame the wharf: the timber grove on Odlin's Plaza is an open space. The sculpture of Kupe was a great addition, she says, but she's 
disappointed that people park their cars between Kupe and the grove, disrupting their association. She knew about the atea in the forecourt of Te Raukura and is pleased to learn that the café has been named after the grove. In the shadows cast by the trees, we watch the crowd of workers hurrying by. The trees create a stroboscopic effect. Now you see someone...now you don 't...now you do...now ... "It's good being in here," Megan says. “Everyone said the grove wouldn't grow-too much wind and right by the sea-but it's turned out to be exactly the same shape as in the sketches." The idea was inspired by the many extant cultural groves around Wellington's coast, and she hasn't designed karaka groves for any other parts of New Zealand. We cross the wharf to get a better impression of how the wind has shaped these trees and take in the city context. "I think the trunks are really lovely," she says. "Look at the way they support each other. They look like they're a crowd standing together." She doesn't remember how many karaka she specified for the space, she's amused that I've had trouble counting them, and she's pleased that they seem random. "That," she says, "is exactly how they were drawn".

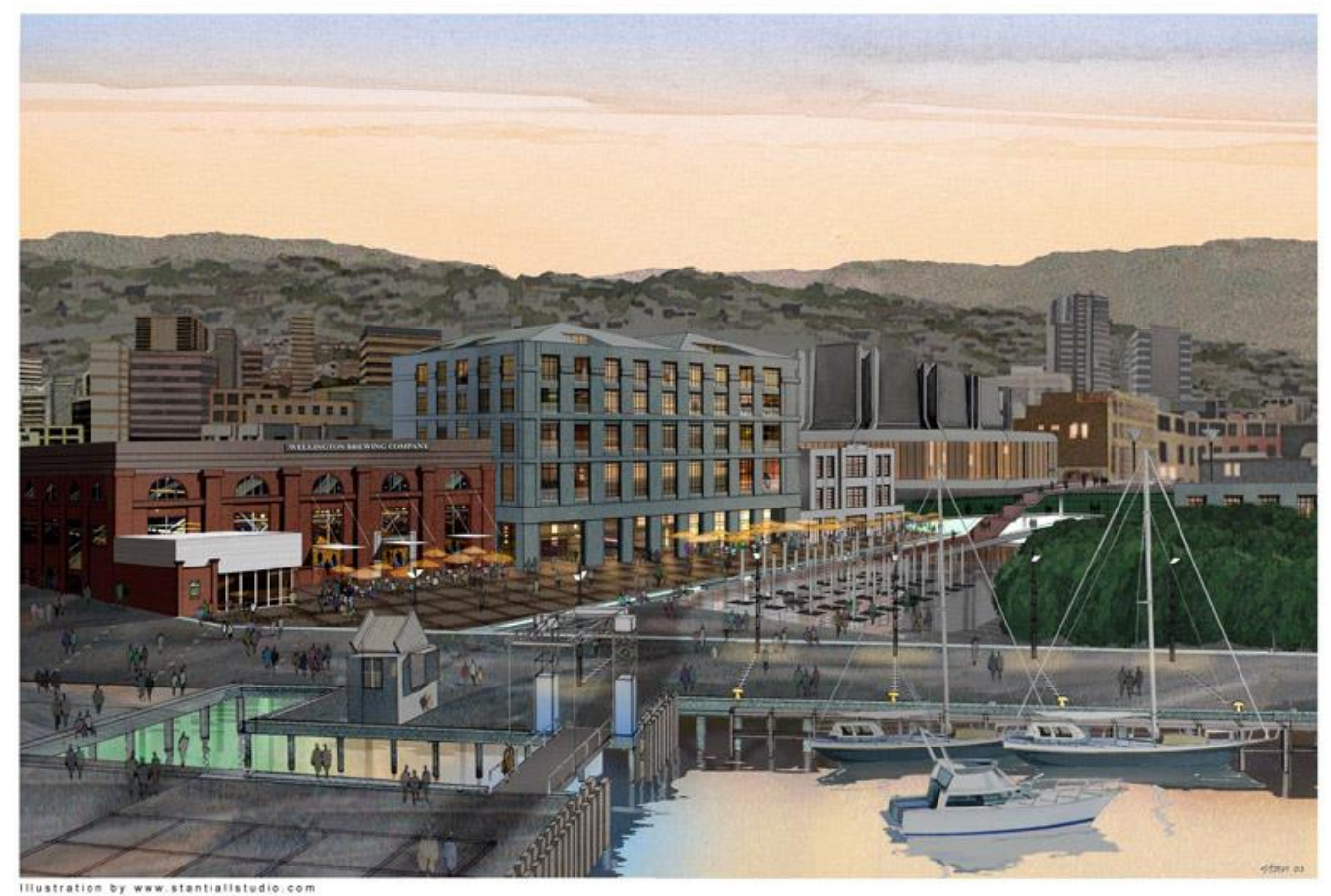

Figure 31: An early Taranaki Wharf proposal illustration showing the karaka grove to the right. The Odlins Plaza buildings are from left: Shed 22, the Odlins Building and the Wellington Free Ambulance Building. The marina shown here beyond the wharf was never established. Image: Stantiall's Studio. Reproduction permission courtesy of Wraight and Associates. 


\section{CHAPTER FOUR: THE DENDROGLYPH TREES: HERITAGE AS TREES}

\section{Introduction}

This third case study focuses on a heritage tree site situated at Lake Kohangapiripiri, within the Parangarahu Lakes area on Wellington's south-east coast. The heritage significance of these particular karaka trees relies on the presence of marks identified as dendroglyphs (engravings on the bark or sapwood of living trees), on their trunks, and the role of the trees as part of cultural redress within a Parliamentary Act. This case has several links with the Anthropocene Grove case described in Chapter Three. Both heritage tree sites are located in Wellington and they share history of Māori and Pākehā settlement, which has been described in detail in Chapter Three and, therefore, is not repeated here. Both heritage tree sites have roles within plans carried out by local authorities with considerable community input - the Anthropocene Grove as part of the heritaging of Taranaki Wharf by the Wellington City Council prompted by community consultation, and the Dendroglyph Trees as part of the environmental management of the Parangarahu Lakes Area by the Greater Wellington Regional Council (GWRC) and the PNBST representing the wishes of Taranaki Whānui ki Te Upoko o Te Ika (Taranaki Whānui) iwi. Neither site appears in the Cyberforest or has been evaluated by STEM. In this study of arboreal heritage, both the Anthropocene Grove and the Dendroglyph Trees are considered to be expressions of the UAHD, as distinct from the Cyberforest which is considered to be a manifestation of the AAHD.

This chapter is in four sections. Following this introduction, the second section (Heritage as Trees) explains the history and contemporary significance of Te Tiriti $\mathrm{O}$ Waitangi the Treaty of Waitangi as background to the passing of the Port Nicholson Block (Taranaki Whānui ki Te Ūpoko o Te Ika) Claims Settlement Act 2009, and its provision of the Dendroglyph Trees as cultural redress. The third section (Heritage, People and Place) introduces the long-term plans for the Parangarahu Lakes Area, situates the Dendroglyph Trees among other tree carvings recorded in New Zealand, describes the 1959 'discovery' of the Lake Kohangapiripiri carvings and the archaeological studies that followed, and concludes with a discussion of early settlement of the Parangarahu Lakes Area and an investigation into the possible origin of the Dendroglyph Trees. This third section also includes 'Being There' accounts of two trips undertaken to visit the Dendroglyph Trees and one trip to visit a nearby 
recorded site of tree carvings in Palliser Bay. The fourth section discusses the Dendroglyph Trees as taonga tuku iho (heirlooms, heritage).

\section{Heritage as Trees}

In Chapter Three the Anthropocene Grove is sub-titled 'Trees as Heritage' and describes how the grove of karaka has been fabricated as a contribution to the heritage nature of Taranaki Wharf. This Chapter is sub-titled 'Heritage as Trees' and the following discussion elaborates on the sub-title and demonstrates how, in something of a reverse action to the heritaging process carried out at the Anthropocene Grove, where heritage is achieved by a new planting of karaka, heritage has been officially attributed to two extant karaka trees at Lake Kohangapiripiri.

\section{Te Tiriti $O$ Waitangi the Treaty of Waitangi}

Te Tiriti O Waitangi the Treaty of Waitangi, first signed on 6 February 1840 at Waitangi in the Bay of Islands, is officially regarded as New Zealand's founding document. ${ }^{1}$ It is an agreement written in both Māori and English between the British Crown and an estimated 540 rangatira (chiefs) and lays down a broad statement of principles for the founding of a nation state and the establishment of government in New Zealand. In order to understand the values, meanings and understandings underlying the role of the Dendroglyph Trees as arboreal heritage it is important to be familiar with the background and principles of the Treaty. This section outlines some of the history of the Treaty and explains its contemporary application that led to the passing of the Port Nicholson Block (Taranaki Whānui ki Te Ūpoko o Te Ika) Claims Settlement Act 2009 and its relationship with the Dendroglyph Trees.

The English version of the Treaty states three articles: that Māori cede the sovereignty of New Zealand to Britain; that Māori give the Crown exclusive rights to buy land for sale and, in return, are guaranteed full rights of ownership of lands, forests, fisheries and other possessions; and that Māori receive the rights and privileges of British subjects. There are important and controversial differences, however, between the English and Māori language versions of the Treaty. These variations in meaning have been much studied, debated and

\footnotetext{
${ }^{1}$ https://nzhistory.govt.nz/politics/treaty/the-treaty-in-brief. Accessed 21 April 2017. Following information concerning the Treaty is taken largely from this source.
} 
challenged and have led, directly or indirectly, to many protests and land occupations most notably in the 1970s and early 1980s. 'Sovereignty', for example, was originally translated as 'kawanatanga' (authority, government) which some Māori understood to mean relinquishing the governance of their land but retaining the right to manage their own affairs; and whereas the English version guaranteed 'undisturbed possession' of all their properties', the Māori equivalent guaranteed 'tino rangatiratanga' (full authority) over 'taonga' (precious resources).

While the Treaty was generally respected during the early years of colonial rule, it carried less weight following the New Zealand Wars in the 1860s and its importance was not rediscovered until the mid-1980s. ${ }^{2}$ The Treaty is not considered to be part of New Zealand's domestic law, except where its principles are referred to in Acts of Parliament, and today it is more common to refer to the 'intention' or 'spirit' of the Treaty. The Waitangi Tribunal, a commission of inquiry established in 1975 to investigate alleged breaches of the Treaty by the Crown, receives claims from individual iwi and is the only body that has the right to determine the meaning of the Treaty. ${ }^{3}$

The claims of Taranaki Whānui iwi were lodged with the Waitangi Tribunal from 1987 onwards, ${ }^{4}$ and a district report was presented by the Waitangi Tribunal in 2003. In January 2004, the Crown recognised the mandate of the negotiating team that settled the claims, the terms of the negotiation were signed in the middle of the same year and the agreement in principle was signed in December 2007. An initial deed of settlement was signed in June 2008 which proceeded to the final deed of settlement signed at Pipitea Marae, Wellington, the following August, and on 23 September 2008 Michael Cullen, Minister in Charge of Treaty of Waitangi Negotiations, delivered the first reading of the Port Nicholson Block (Taranaki Whanui ki Te Upoko o Te Ika) Claims Settlement Bill in the House. ${ }^{5}$ There was much, Cullen pointed out, for the Crown to apologise for:

\footnotetext{
${ }^{2}$ David V. Williams, "The Treaty of Waitangi: Māori Magna Carta," in The Treaty on the Ground: Where We Are Headed and Why It Matters, ed. Rachael Bell, et al. (Auckland: Massey University Press, 2017). 32.

${ }^{3}$ For an explanation of the claims process see https://waitangitribunal.govt.nz. Accessed 21 April 2017

${ }^{4}$ The claim began as Wai 145.

${ }^{5}$ For a full account of the first reading see https://www.parliament.nz/en/pb/hansarddebates/rhr/document/48HansD_20080925_00000300/port-nicholson-block-taranaki-whanui-ki-te-upoko-o-te. Accessed 21 April 2017.
} 
The Crown's apology recognises that the Crown breached its obligations under the Treaty and its principles. This breach includes the Crown's failure to consistently protect Taranaki whānui's interests during the process by which the Crown and its agents acquired Taranaki whānui's interest in the Port Nicholson Block, the compulsory acquisition and endowment of their lands for public purposes, and various acts and omissions in relation to delays in the implementing of legislation and administration of the reserves. This significantly undermined the tino rangitiritanga of Taranaki Whānui ki Te Upoko o Te Ika, and this impacted upon their economic and social development. ${ }^{6}$

The actions, referred to by Cullen, include the Crown's assumption that Taranaki Whānui's title to the land covered by the Wakefield Deed ${ }^{7}$ (referred to in Chapter Three) had been fully extinguished despite knowing that the deed was seriously flawed. The Crown had actively encouraged the exchange of reserve lands around the harbour for inadequate alternative lands elsewhere, pressuring Taranaki Whānui to move away from their traditional lands, and denying them a role in administering the remaining reserves until $1985 .{ }^{8}$ The Bill recognised that delays in establishing proper administration of the tenths reserves; the appropriation and alienation of reserves land for public purposes; and the imposition of perpetual leases had undermined the tino rangatiratanga of Taranaki Whānui and curtailed their economic and social development. In addition, the harbour which had been an important trade and food resource for iwi had been polluted by urban and industrial development and significantly altered by reclamation.

The Port Nicholson Block (Taranaki Whānui ki Te Ūpoko o Te Ika) Claims Settlement Act 2009 came into force on September 2009. The Act made provisions for statutory acknowledgements of Taranaki Whānui's historical, cultural and spiritual association with various areas within the Port Nicholson Block; ${ }^{9}$ financial and commercial redress, including a financial settlement of approximately \$25 million and a one-hundred-year right of first

\footnotetext{
${ }^{6}$ Ibid.

${ }^{7}$ The private land settlement company, The New Zealand Company, negotiated the Port Nicholson/Wakefield Deed with Taranaki Whānui ki Te Ūpoko o Te Ika in 1839. The purpose of the deed signed on 27 September 1839 was the purchase of land at Port Nicholson and its environs known as 'The Port Nicholson Block'. The deed was drafted only in English. "It did not include a map or sketch plan of the boundaries and its description of the boundaries was very general. An interpreter explained the deed orally in Maori. His interpretation did not convey the meaning or consequences of the deed to Taranaki Whānui ki Te Upoko o Te Ika." New Zealand Government, "Port Nicholson Block (Taranaki Whanui Ki Te Upoko O Te Ika) Deed of Settlement," (Wellington: New Zealand Government, 2008). 8.

${ }^{8}$ These reserves were established by the New Zealand Company in the nineteenth century setting aside one tenth of the surveyed land for Māori purposes. This process is described in more detail in Chapter Three. The Wellington Tenths Trust took over the administration of the Tenths reserves in 1985.

9 The Port Nicholson Block is loosely defined as "the Wellington Harbour area". https://www.pnbst.maori.nz. Accessed 24 November 2017.
} 
refusal to purchase certain properties; amendment of various place names to incorporate Māori language versions; and cultural-redress vesting of properties of significance to Taranaki Whānui. Among the sites of cultural redress are the lakebeds ${ }^{10}$ and former esplanade reserves of Lake Kohangatera and Lake Kohangapiripiri (formerly known as lakes Fitzroy and Pencarrow) and a nearby site of karaka trees bearing dendroglyphs, all of which are contained within the Parangarahu Lakes Area which is owned by the GWRC and is managed as a recreation reserve. ${ }^{11}$ This case study focuses on these carved trees vested in the trustees of Taranaki Whānui as property of cultural redress.

\section{Heritage, People and Place}

Previously known as 'Pencarrow Lakes', the Parangarahu Lakes Area is located on Wellington's south-east coast behind Te Rae-akiaki (Pencarrow Head) bounded by the waters of Fitzroy Bay to the south and southwest and by private land to the north, northeast and southeast. The area is part of the East Harbour Regional Park and, although only 11 kilometres from central Wellington as the crow flies (over Wellington Harbour), the two lakes have received less scientific attention than other comparable lakes in the country. ${ }^{12}$ The area comprises land parcels of different legal status and under different ownership and management of different bodies. ${ }^{13}$ The lakes have formed in drowned valleys which have been blocked off from the sea by beach ridges formed by earthquake activity ${ }^{14}$ and are recognised as being rich in cultural features including pā, pits, terraces and middens, which

\footnotetext{
${ }^{10}$ The space occupied by water and air above the lakebeds, however, is maintained as a scientific reserve owned by the Crown and is managed by the Department of Conservation.

${ }^{11}$ New Zealand Government, "Port Nicholson Block (Taranaki Whanui Ki Te Upoko O Te Ika) Deed of Settlement," 24. The 507-square-metre-site of the karaka trees is in two parcels of land and is defined as a Māori reservation. The lake beds and former esplanade reserves are subject to conservation covenants under the Conservation Act 1987 and the Reserves Act 1977 with four objectives: for conservation purposes (the natural and historic qualities/resources of the area); preserving the reserve values (natural environment, landscape amenity, wildlife habitat and historic values); providing freedom of access to the public for their appreciation and recreational enjoyment; to provide for the enhancement and protection of Taranaki Whānui's ancient relationship with the land, and ensure that the land is held and appreciated in accordance with Taranaki Whānui tikanga (customs, correct procedures). The PNBST has the right to authorise Taranaki Whānui members to collect plants for medicinal and food purposes.

${ }^{12}$ George W. Gibbs, "Pencarrow Lakes: Conservation Values and Management," (Wellington: Department of Conservation, 2002). 4. As a result, the wetlands are in a relatively unmodified state.

13 These include: Port Nicholson Block Trust; Hutt City Council (sewer outfall and access road); Heritage New Zealand (archaeological sites and the historic Pencarrow Lighthouse); GWRC; and Department of Conservation (wildlife management). Other groups with interests in the lakes include: Te Ātiawa ki te Upoko o te Ika a Māui Pōtiki Trust (fisheries management); Fish and Game New Zealand Inc. Wellington Region; Royal Forest and Bird Protection Society Lower Hutt Branch; Mainland Island Restoration Operation Incorporated; Wellington Wildfowlers Club; adjacent landowners and Horokiwi Quarries Ltd.

${ }^{14}$ Lake Kohangapiripiri has been a freshwater lake for at least seven thousand years: the closing date from the sea of Lake Kohangatera is uncertain. Gibbs, "Pencarrow Lakes." 4.
} 
are considered to be evidence of early settlement of the area, ${ }^{15}$ and the dendroglyphs on karaka located near Lake Kohangapiripiri. In 2012 an advisory group Te Roopu Tiaki was set up, through a memorandum of understanding agreed between the PNBST and the GWRC, to develop a long-term vision for the Parangarahu Lakes Area.

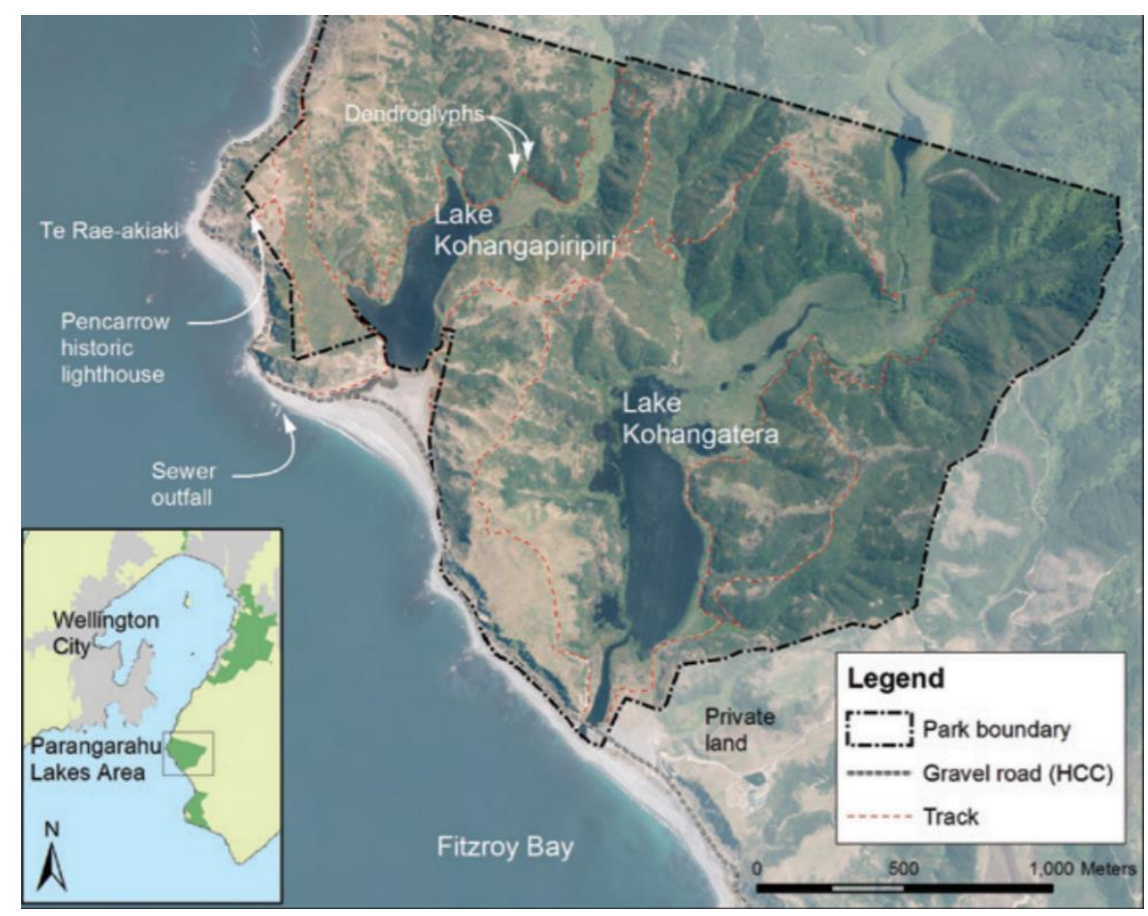

Figure 32: Parangarahu Lakes Area showing the site of the Dendroglyph Trees. Reproduction permission courtesy of the GWRC and the PNBST.

Te Roopu Tiaki considers the Parangarahu Lakes area to be taonga and, as such, to be conserved, protected and managed to the highest level ensuring that the land, lakes and wetlands can nurture life and well-being. ${ }^{16}$ The advisory group lists as one indicator of the success of its kaitiakitanga of the area the recording, preservation, protection and appropriate interpretation, including Taranaki Whānui kaitiaki guides, of the dendroglyphs on the karaka. ${ }^{17}$

\footnotetext{
${ }^{15}$ J. B. Palmer, "Maori Sites in Fitzroy Bay," New Zealand Archaeological Association Newsletter 6, no. 3 (1963). 128. B. G. McFadgen, "Maori Occupation of the Pencarrow Survey District as Recorded on Early Survey Records," ibid.

${ }^{16}$ Port Nicholson Block Settlement Trust and Greater Wellington Regional Council "Parangarahu Lakes Area Co-Management Plan: And Amendment to the Greater Wellington Regional Council Parks Network Plan," (Wellington: Port Nicholson Block Settlement Trust and Greater Wellington Regional Council, 2014). 11.

${ }^{17}$ Ibid. 14
} 


\section{Dendroglyphs in New Zealand}

Dendroglyphs, or tree carvings, are human-generated, representational markings in the bark or sapwood of living trees and, as all trees die naturally or are deliberately destroyed, are becoming increasingly rare. ${ }^{18}$ They occur in many places and for different purposes. In 1918, for example, Robert Etheridge, director of the Australian Museum, Sydney, classified the dendroglyphs of New South Wales variously as taphoglyphs, found beside aboriginal graves, and teleteglyphs, found at initiation grounds; ${ }^{19}$ carved trees in Sweden have been described as 'notice-boards' designating animal grazing areas; ${ }^{20}$ and in eastern North America dendroglyphs are described as sites that record Amerindian deeds and pass on information. ${ }^{21}$

The rākau momori (carved memorial trees) of Rēkohu (the largest land mass of the Chatham Islands) are the most numerous in New Zealand: much has been written about them and strenuous efforts to preserve them are under way. Archaeologists believe that the Moriori (indigenous people of Rēkohu) probably carved the mostly anthropomorphic representations on the living kōpi (karaka) before the arrival of Ngāti Mutunga and Ngāti Tama iwi from Aotearoa, but the purpose of the carvings remains unclear. ${ }^{22}$ It is generally recognised that the kōpi trees were brought to cool-climate Rēkohu from Aotearoa and planted in groves to replace tropical crops as a food resource. ${ }^{23}$ Wind exposure caused by nineteenth-century deforestation for farming; bark shedding; attacks by borer and honey fungus; and foot traffic over the kōpi trees' roots have all contributed to the deterioration of the trees. ${ }^{24}$ In January 2010, a team of Department of Conservation staff and University of Otago staff and students employed a 3D laser scanning technique to create accurate records of the dendroglyphs. ${ }^{25}$ The

\footnotetext{
${ }^{18}$ R. Andersson, L. Östlund, and R. Lundqvist, "Carved Trees in Grazed Forests in Boreal Sweden: Analysis of Remaining Trees, Interpretation of Past Land-Use and Implications for Conservation," Vegetation History and Archaeobotany 14, no. 2 (2005). Robert Etheridge, "The Dendroglyphs or 'Carved Trees' of New South Wales," Geological Survey of New South Wales: Memoir Ethnological Series No. 3 (1918).

${ }^{19}$ See also Frederick D. McCarthy, "The Carved Trees of New South Wales," The Australian Museum Magazine 7, no. 5 (1940). 161.

${ }^{20}$ Andersson, Östlund, and Lundqvist, "Carved Trees in Grazed Forests in Boreal Sweden.” 149-58.

${ }^{21}$ Fred E. Coy, "Native American Dendroglyphs of the Eastern Woodlands," in The Rock Art of Eastern North America: Capturing Images and Insight, ed. Carol Diaz-Granados and James R. Duncan (Tuscaloosa: University of Alabama Press, 2004). 3-16.

${ }^{22}$ Ian G. Barber, Justin Maxwell, and Richard Hemi, "Growing Images: Generating 3d Digital Models to Investigate Archaeological Moriori Carvings on Live Trees," World Archaeology 46, no. 1 (2014). 64.

${ }^{23}$ Leach and Stowe, "Oceanic Arboriculture at the Margins," The Journal of the Polynesian Society 114, no. 1 (2005); Ian G. Barber, Justin Maxwell, and Fiona Petchey, "A Radiocarbon Investigation of Moriori Forest Use on Rēkohu (Chatham Island), Southwestern Polynesia,” Journal of Archaeological Science: Reports 10 (2016); J. A. Costall et al., "The Endemic Tree Corynocarpus laevigatus (Karaka) as a Weedy Invader in Forest Remnants of Southern North Island, New Zealand," New Zealand Journal of Botany 44 (2006).

${ }^{24}$ http://blog.tepapa.govt.nz/category/conservation-2/. Accessed 27 April 2017.

${ }^{25}$ Nester, Richard, interview.
} 
resulting digital images are regarded as taonga by the Hokotehi Moriori Trust, the representative body of the Moriori people, and are treated with "great reverence". ${ }^{26}$ In recent years, carved trees at Rēkohu considered to be at risk of further deterioration have been harvested and conserved by Te Papa and the remaining trees are now managed to improve their health. ${ }^{27}$ Tree carvings have only rarely been identified and recorded on the main islands of New Zealand. The outline of a facial mask carved into one cabbage tree in a grove of forty trees in inland Patēa was described in $1957^{28}$ and was later considered possibly to have special significance as a nineteenth-century rāhui (device for separating people from things that are tapu). ${ }^{29}$ A 1968 field survey of the Te Anau region revealed a relief carving on a solitary rimū located in a large beech forest and described as originally representing a human face. ${ }^{30}$ In his summary of archaeology carried out in the Bay of Plenty, Law recorded a sole dendroglyph near Te Whaiti but did not identify the tree type. ${ }^{31}$ Two Te Mata Park, Hawke's Bay, karaka with possible dendroglyphs are recorded in the New Zealand Archaeological Association (NZAA) database with the comment that the engravings are "obviously old, but whether created by pre-European Māori or the work of someone since that time is at present impossible to determine". ${ }^{32}$ Two karaka on the Taranaki coast are reported to have trunks "scored with old tomahawk cuts, and an attempt at rude carving"; "Trees with carvings" have been recorded by an unknown person in a sketch plan of the eastern coast of Kapiti Island ${ }^{34}$ and dendroglyphs in south Wairarapa have been noted in a document by Robert Cairns ${ }^{35}$ both of which are held at the Alexander Turnbull Library in Wellington.

\footnotetext{
${ }^{26}$ Maui Solomon and Susan Thorpe, "Taonga Moriori: Recording and Revival," Journal of Material Culture 17, no. 3 (2012). 257.

${ }^{27}$ Balram interview.

${ }^{28}$ R. A. L. Batley, “A Dendroglyph from Inland Patea (Upper Rangitikei)," The Journal of the Polynesian Society 66, no. 2 (1957). 210. Batley describes the carving as bearing little resemblance to the Chatham Islands' dendroglyphs except for the heart-shaped outline of the face, and he concludes that the age of the dendroglyph remains uncertain. As is the case with karaka, the structure of the trunks of cabbage trees means that carvings are difficult to age.

${ }^{29}$ I. W. Keyes, "Dendroglyphs from Lake Kohanga-Piripiri, Eastern Wellington," New Zealand Archaeological Association Newsletter 11, no. 3 (1968). 103.

${ }^{30}$ Peter Coutts, “A Field Survey of Some Traditional Maori Sites in the Te Anau Region,” ibid.12, no. 4 (1969). 226. Coutts described the carving as "reasonably old" and probably made with steel tools. He reported that other tree carvings had been found in the general area.

${ }^{31}$ Garry Law, Archaeology of the Bay of Plenty (Wellington: Department of Conservation, 2008). 58.

${ }^{32}$ Elizabeth Pishief, "Te Mata Trust Park Historic Heritage Landscape Report," (Te Mata Trust Board, 2011). 13.

33 "New Zealand Trees: Some Interesting Observations," Hawera and Normanby Star, 4 November 1921. Reprinted in Ellesmere Guardian, 25 February 1922.

${ }^{34}$ MapColl-832.47eg/[18-?](1972)/Acc.37823, '[Creator unknown] : Tokakawau [Kapiti Island] [copy of ms map]. [1972]'.

35 88-070-20/25, 'Dendroglyphs and petroglyphs', and 88-070-20/24 'Dendroglyphs'.
} 


\section{The Lake Kohangapiripiri Dendroglyphs}

The marks on the karaka trees on the western side of Lake Kohangapiripiri first came under Pākehā attention through their 'discovery' ${ }^{36}$ by archaeology enthusiasts George Bull and George Leslie Adkin who visited the site on 27 September 1959. ${ }^{37}$ In his unpublished notebook, Adkin records that the observation could be regarded as "an event of considerable ethnologic importance and one opening up interesting problems of culture connection and symbolic significance". ${ }^{38}$ The two men returned to Fitzroy Bay with the Dominion Museum ethnologist, Terrence Barrow, and other interested people on 15 December in the same year, and, having identified more carvings than first observed by Adkin and Bull, took measurements, rubbings, photographs and colour slides of the five trees with dendroglyphs (one single tree "A" and a grove of four trees "B", "C", "D" and "E"). ${ }^{39}$ The recorded carvings include fish motifs, a cradle shape with serial notches and "shoe-heel" forms and two single Roman letters ' $\mathrm{N}$ ' and ' $\mathrm{A}$ '; vertical bark stripping is also noted. ${ }^{40}$ Barrow agreed with Adkin that: "(1) the dendroglyphs are archaic (certainly pre-European); (2) the motifs are characteristically primitive and in Polynesian style; (3) the designs have a symbolical, and perhaps, ritual, significance and purpose". ${ }^{41}$ Adkin's notebook includes a sketch plan of the site and sketches of the individual carvings.

\footnotetext{
${ }^{36}$ In his biography of Adkin, Dreaver described Adkin's “confident_-perhaps over-confident" ascription of an artefact as "characteristic of Adkin's ethnology". Anthony Dreaver, An Eye for Country: The Life and Work of Leslie Adkin (Wellington: Victoria University Press, 1997). 151.

${ }^{37}$ Adkin had been encouraged to explore the Pencarrow shore of Wellington Harbour by J. B. Palmer. Ibid. 221. 38 "Maori Notebook," (vol. 44). MS-Papers-6061-45. ATL. Page numbers are inconsistent and not noted here.

${ }^{39}$ Barrow respected Adkin as, "the man who brought together the considerable but scattered knowledge of Maori occupation in this part of New Zealand". Quoted in Dreaver, An Eye for Country. 252.

40 "Examples have been reported of trees partially stripped of bark in antiquity to make containers. The stripped portion dies and decay may affect the heart of the tree, but the unstripped portion continues to grow and a characteristic scar is left. Totara and karaka were commonly stripped in this way." T. Walton, ed. Archaeological Site Recording in New Zealand (New Zealand Archaeological Association, 1999). 73-74. Best records that both tōtara and mānuka were commonly used to make domestic vessels with bark from other trees used as alternatives if tōtara was unavailable. While "barking", and therefore damaging, fruit-bearing trees that provided food for birds appeared unlikely, Best points out, it was possible that male trees that did not bear fruit might be selected for the purpose. Best, Forest Lore of the Maori (Wellington: Te Papa Press, 2005). 103-4. 41 "Maori Notebook," (vol. 44).
} 


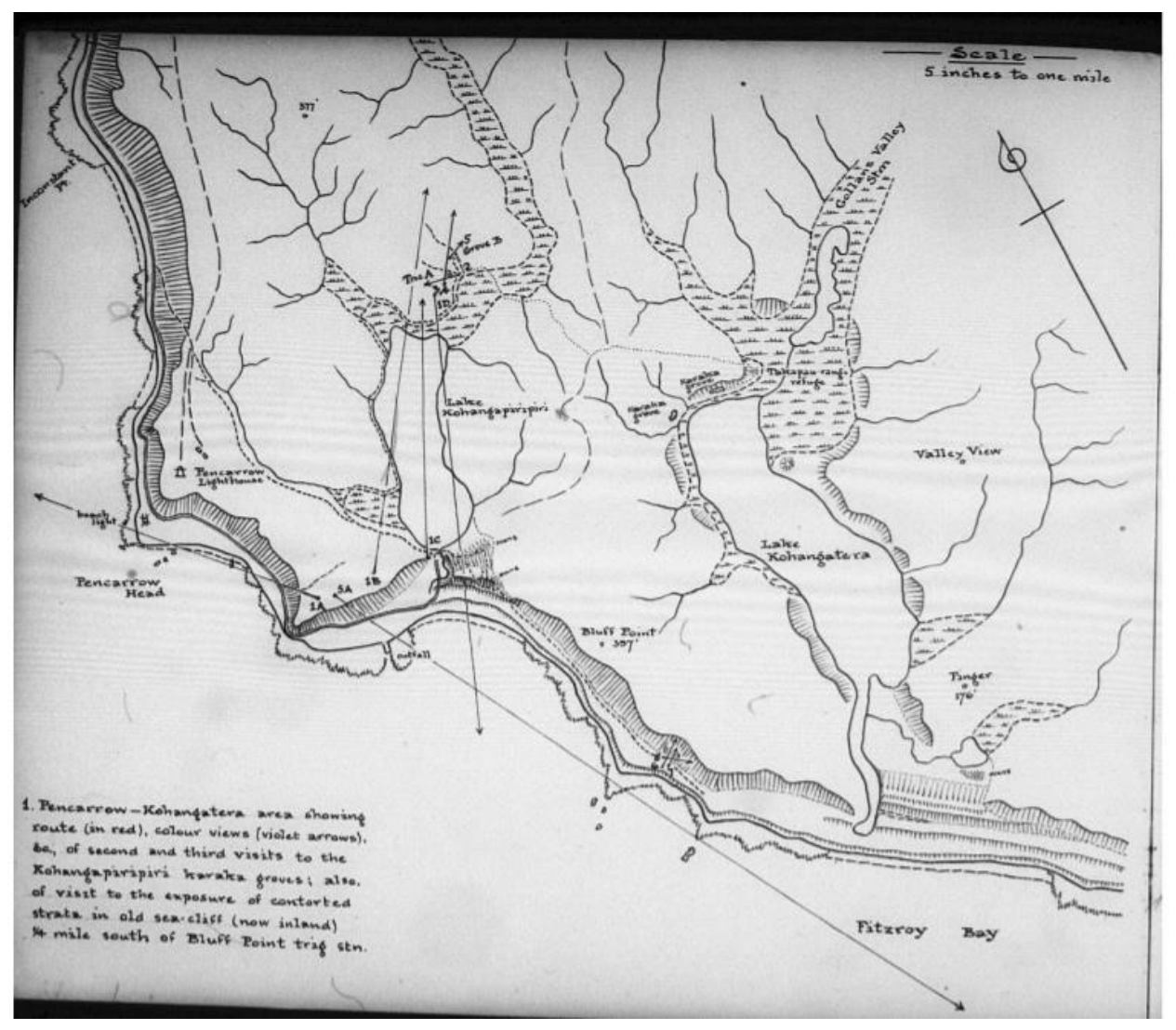

Figure 33: Adkin's map showing route of second and third visits to the Kohangapiripiri karaka groves and the locations of the Dendroglyph Trees. Ref: MS-Papers-6061-45 ATL.

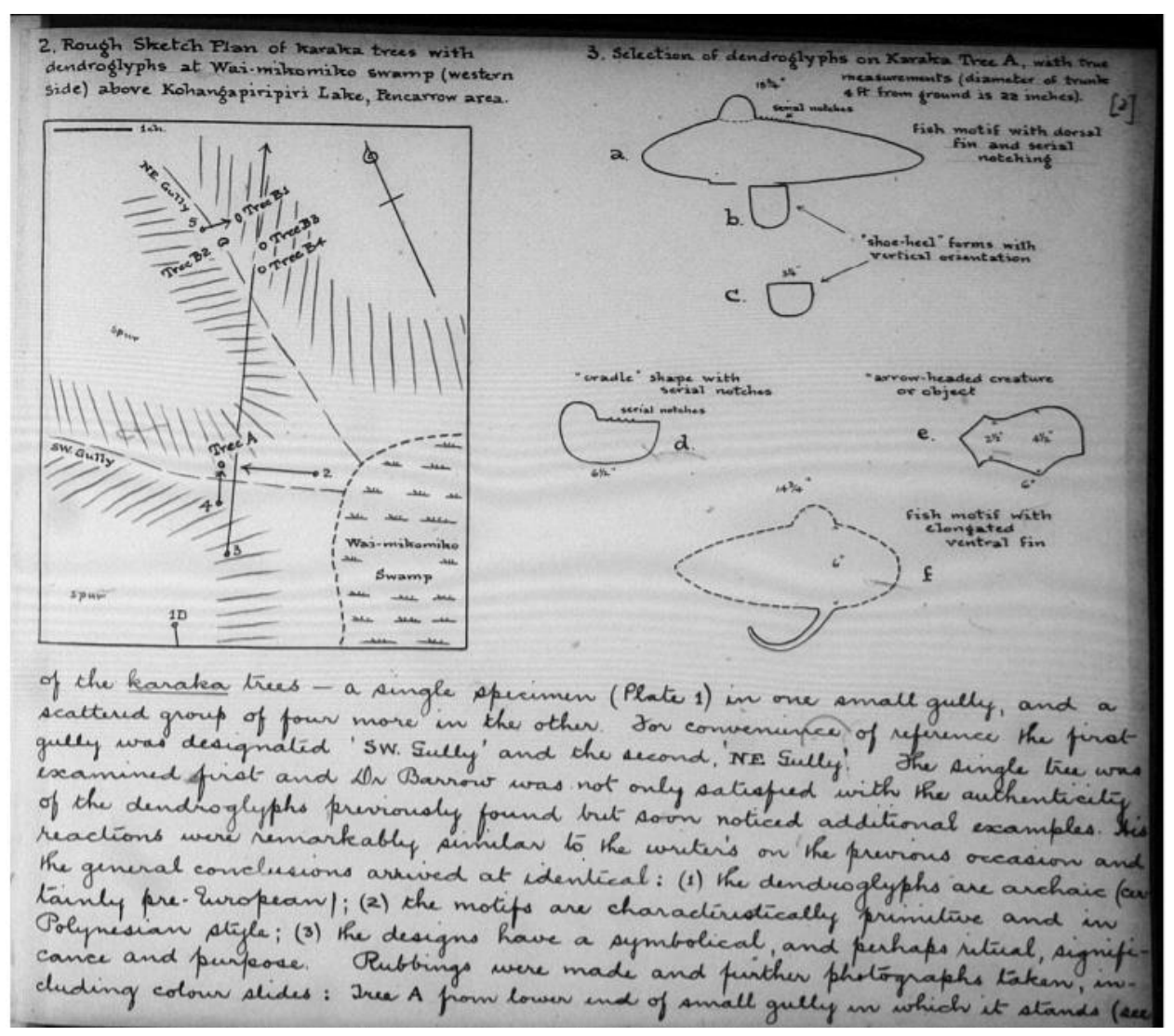

Figure 34: Adkin's Sketch plan of Lake Kohangapiripiri Dendroglyph Trees and sketches of dendroglyphs. Ref: MS-Papers-6061-45 ATL. 
Adkin's biographer, Anthony Dreaver, describes the event as a "remarkably staid and Pakeha occasion" that, nevertheless, "illustrated the growing acceptance of the importance of Maori culture in defining the identity of all New Zealanders". ${ }^{42}$ On a third visit to the Lake Kohangapiripiri site on 16 January 1960, Adkins and Bull accompanied Barrow and others with the purpose of making tracings of the carvings on Tree A as Adkins describes:

A sheet of stout brown paper was wrapped round the trunk of the tree to cover the upper dendroglyphs, fixed in position by drawing pins, and 'windows' cut in it to expose the respective designs. Tracing paper was used to cover these 'windows' and the glyphs were traced on to this. A second sheet of brown paper was wrapped below the first, slightly overlapping it, and the process described was repeated to cover the lower glyphs. By this means a complete record and coverage was obtained of the designs in their proper relative positions, and credit is due to Dr Barrow for his adroitness in working out this technique. ${ }^{43}$

The tracing process revealed additional, but less distinct, similarly shaped fish-form carvings in the bark of the tree and further details that had been overlooked previously, and Adkin amended his original fish-form drawing to incorporate the 'shoe-heel' below it as its fin. Unfortunately, a search by a Te Papa curator and my own search of Te Papa's archives in 2016 failed to turn up the original tracings or any record of their existence. ${ }^{44}$

The 'discovery' of the dendroglyphs was announced in The Dominion on 1 July 1961 based on information supplied by Adkin and Barrow. Under the headline 'N.Z.'s First Tree Carvings: Big Coast Discovery" the article describes the event as "one of the most significant discoveries in this country - a major step forward in the research into early New Zealand inhabitation". ${ }^{45}$ The article quotes Adkin as distinguishing three different ages of carvings: "Ancient (pre-European) fish and symbolical designs"; "Early European times, single Roman capital letters artistically done" and "European initials, in one place only, up to three in number and crudely cut". Barrow, the article continues, did not entirely agree that the designs were as old as Adkin believed:

"Though authentic, I do not believe it possible to determine the exact period of workmanship of the carvings", he [Barrow] explained yesterday. "The outline of the fish and the curious notches along the edges are typically Maori, probably early Maori. The ' $N$ ' and ' $A$ ' do not discredit the Maori origin of the dendroglyphs as they probably post-date the fish designs. Then we have quite modern initials which are

\footnotetext{
${ }^{42}$ Dreaver. An Eye for Country. 233.

43 "Maori Notebook," (vol. 44).

${ }^{44}$ Dougal Austin, Curator Taonga Tuturu, Museum of New Zealand Te Papa Tongarewa, email 3 July 2016. Personal search of archive carried out on 22 July 2016.

45 “N.Z.'s First Tree Carvings: Big Coast Discovery," The Dominion, 1 July 1961.
} 
heavy and unattractive." Dr Barrow said that dendroglyphs are very well known in the Chatham Islands but are completely different from these in Wellington. Many are on display at the museum. "It is difficult to preserve the local tree", he concluded, "but we hope to make a plaster cast and replica of the design for display". ${ }^{46}$

In 1968 Ian Keyes described the engravings as "subtle features" compared with damage to the bark brought about by falling rocks, breaking branches, grazing stock and "the inevitable assortment of modern European carved initials". ${ }^{47}$ An outline of each motif, he writes, had been carved through the bark and into the sap-wood and the area of bark outlined had been removed. The scars had healed with new bark growth but the original carving had remained about 5 millimetres below the trunk surface in comparison with "more modern mutilations" which showed no sign of re-growth. He concluded that the dendroglyphs suggested "considerable age". ${ }^{48}$ Keyes sketched eleven glyphs he observed on three trees and suggests that further, less obvious examples might be found but could be difficult to distinguish from natural scars showing similar regrowth. He also notes bark stripping which appeared to be "an old feature and may date from the period of the dendroglyph carving". ${ }^{49} \mathrm{He}$ describes the carvings as representing aquatic animals with three identified as possibly representing whales or dolphins, perhaps commemorating the catching or stranding of the mammals and potentially being of ritualistic importance. ${ }^{50}$ Archaeological assessments of karaka trees have concluded that it is difficult to assess their age, ${ }^{51}$ however Keyes proposes that the Kohangapiripiri trees were no more than about 170 years old at the time of writing (1968). ${ }^{52}$ He theorises that the two ' $A$ ' and 'N' capital letters were carved by Māori at a time between the engraving of the aquatic glyphs and the marks of vandalism, and hypothesises that the glyphs were possibly carved by members of Ngāti-Ira or Ngāti-Awa iwi. While the trees were adjacent to the wetland ("Wai-mikomiko swamp") in 1968, it was highly probable, he concludes, that when the dendroglyphs were carved they were at the water's edge which would place them chronologically before the 1855 earthquake and uplift.

\footnotetext{
${ }^{46}$ Ibid.

${ }^{47}$ Keyes, "Dendroglyphs from Lake Kohanga-Piripiri, Eastern Wellington,” 104.

${ }^{48}$ Ibid.

49 Ibid. 108.

${ }^{50}$ Ibid. 109.

${ }^{51}$ Ibid. B. Mitcalfe, "The Significance of Karaka in an Assessment of Pre-European Land Utilisation in New Zealand," ibid.12, no. 4 (1969). 184. Twenty-first-century coring technology may be able to determine the age of the Kohangapiripiri and Kohangatera trees.

52 Keyes, "Dendroglyphs from Lake Kohanga-Piripiri, Eastern Wellington.” 109. Walton and McFadgen reported in 1998 that Tree 1 survived in poor condition and with at least one glyph. Based on Keyes' information they estimate the glyph to be less than about two hundred years old. Anthony Walton and B. G. McFadgen, "Fitzroy Bay: A Further Archaeological Survey," New Zealand Archaeological Association: Archaeology in New Zealand 31, no. 3 (1988). 162.
} 
These dendroglyphs appear to be of authentic Maori origin and were probably executed in times immediately prior to major European contacts in the area. The portrayal of sea mammals in the motifs conforms to concepts typical of Polynesian art, but their true significance appears to be ritualistic as well as just the recording of the possible capture of sea mammals. ${ }^{53}$

In 2012 and 2013 archaeologist Ian Barber ${ }^{54}$ researched and visited the Lake Kohangapiripiri dendroglyphs at the request of the GWRC and concludes, in an unpublished report, that there is "no unequivocal evidence that East Harbour karaka trees were deliberately carved" but concedes that "they do at least represent a cultural connection to the past". 55

Māori introduced karaka to the lower North Island and South Island for the food value of the tree's nutritious drupes. Karaka tree locations can serve as important reminders of the patterns of earlier settlement and food production management in this region. The moderate size of the remaining Kohangapiripiri trees allows for the possibility of a nineteenth century age at least. ${ }^{56}$

Notwithstanding the findings of the Barber report Te Roopu Tiaki prize the karaka trees and dendroglyphs as "special and unique" and as "taonga tuku iho, cultural heritage and a resource important to Māori". ${ }^{57}$ They have decided that the "ambiguity of their origin and meaning should be embraced" and intend to encourage "ongoing korero [discussion] and debate to add to the mana [spiritual power] of the site". ${ }^{58}$ The Hutt City District Plan has registered the dendroglyphs as significant archaeological resources and notes their New Zealand Archaeological Association map sheet and site number (R27/62). Heritage New Zealand in its Fire Safety and Heritage Places guide warns that at Lake Kohangapiripiri "there are ancient dendroglyphs (tree carvings) recorded as archaeological sites that could be lost forever by wildfire" 59 and the Department of Conservation recognises them as "unique on [the] New Zealand mainland". ${ }^{60}$ The trees are not noted, however, on the New Zealand Tree Register or in Burstall's Great Trees of New Zealand.

\footnotetext{
${ }^{53}$ Keyes, "Dendroglyphs from Lake Kohanga-Piripiri, Eastern Wellington.” 110.

${ }^{54}$ Ian Barber is associate professor in the Department of Anthropology and Archaeology at the University of Otago and has researched and written extensively on the dendroglyphs of the karaka trees of Rēkohu Chatham Island.

${ }^{55}$ Ian G. Barber, “Archaeological Assessment of Reported Carvings on Karaka (Corynocarpus laevigatus) Trees (Dendroglyphs), East Harbour Regional Park,” (Greater Wellington Regional Council, 2013). Quoted in Port Nicholson Block Settlement Trust and Greater Wellington Regional Council, "Parangarahu Lakes Area CoManagement Plan.” 26.

56 Ibid.

${ }^{57}$ Port Nicholson Block Settlement Trust and Greater Wellington Regional Council, "Parangarahu Lakes Area Co-Management Plan.” 26.

${ }^{58}$ Ibid.

${ }^{59}$ Robert McClean, Fire Safety and Heritage Places, Sustainable Management of Historic Heritage Guidance Series (Wellington: New Zealand Historic Places Trust, 2012). 6.

${ }^{60}$ Gibbs, "Pencarrow Lakes." 4.
} 


\section{The Origin of Local Karaka}

The purpose of this thesis is to examine the values, meanings and understandings, and human and non-human forces that shape Aotearoa New Zealand's arboreal heritage today and, therefore, the authenticity of the Lake Kohangapiripiri dendroglyphs is not in question. What is of greater interest here is the relationship between Taranaki Whānui and their engraved karaka trees. Researchers generally agree that Māori used karaka berries as a supplementary source of food after intensive preparation of the kernels to remove the poisonous karakin. ${ }^{61}$

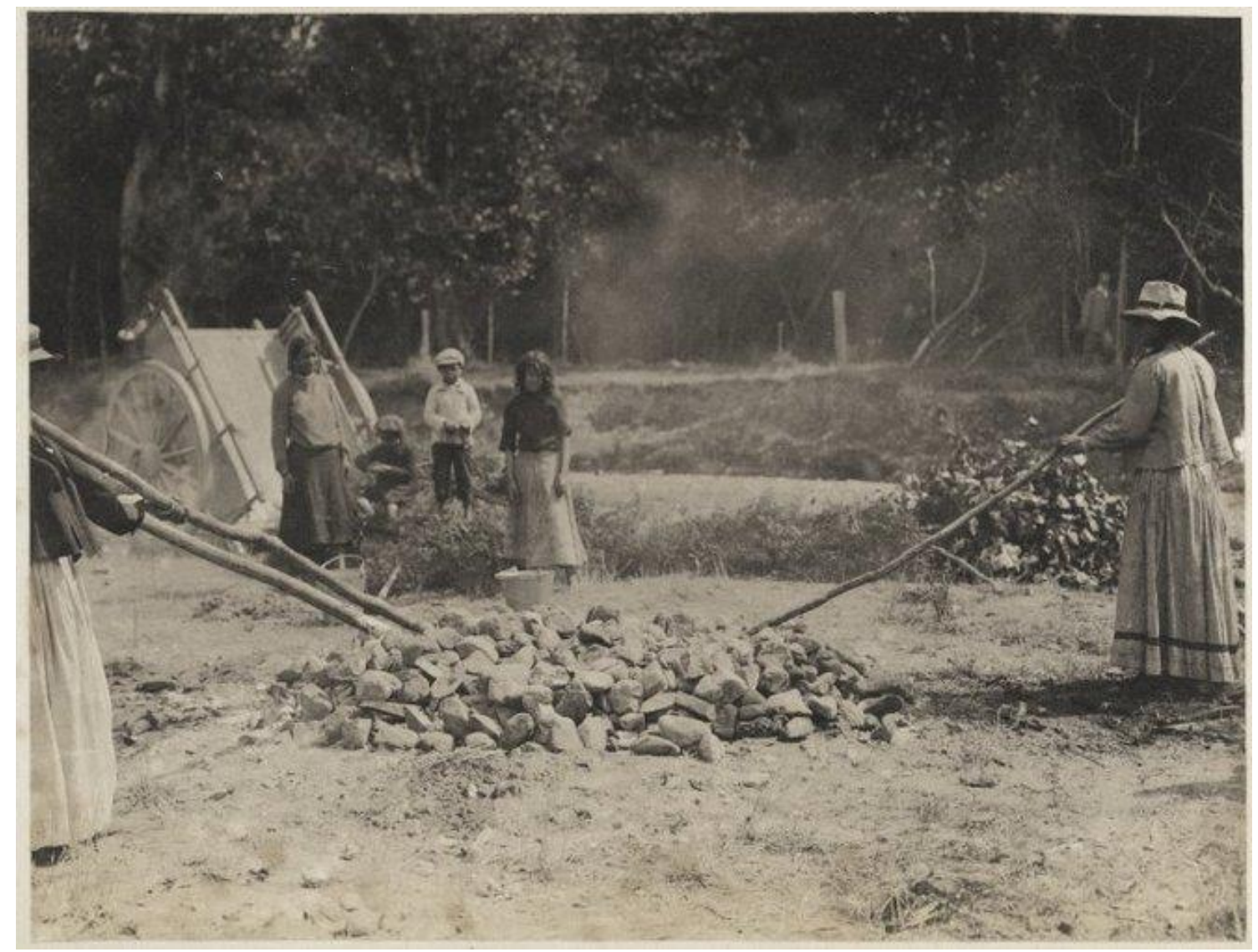

Figure 35: Māori group roasting karaka berries at Whakarongotai, Waikanae. 1908. Ref: PAI-o-229-48-4. ATL.

Extant groves of karaka are often regarded as potential signposts of early settlement sites and the New Zealand Archaeological Association's monograph advising on methods of site recording points out that karaka trees:

may be an indication of a possible adjacent site or be a clue to past settlement and subsistence patterns, particularly when found beyond their natural range which is confined to the north of the North Island. The trunks should be examined for dendroglyphs. ${ }^{62}$

\footnotetext{
${ }^{61}$ John Sawyer, Bruce McFadgen, and Paul Hughes, "Karaka (Corynocarpus laevigatus J.R. Et G. Forst.) in Wellington Conservancy (Excluding Chatham Islands)," in DOC Science Internal Series 101 (Wellington: Department of Conservation, 2003). 7. ${ }^{61}$ Leach and Stowe, "Oceanic Arboriculture at the Margins." 13. ${ }^{62}$ Walton, Archaeological Site Recording in New Zealand. 73.
} 
What is less readily agreed, however, is the extent to which Māori cultivated this food source. Are the groves found near settlement sites more likely to be the result of opportunistic nurturing of a natural resource (natural karaka) or were they orchards deliberately planted from material sourced elsewhere and actively gardened (cultural karaka)? As this thesis seeks to understand the thoughts and actions that join the tangible remains of the past with contemporary heritage meanings and practices, the origin of these particular karaka trees and their Parangarahu Lakes Area context are considered here through accounts of Māori occupation ${ }^{63}$ and more recent Pākehā observations.

While I have found no accounts of Polynesian explorer Kupe stopping at Parangarahu during his discovery of Aotearoa New Zealand a thousand years ago, given his progress through Te Whanganui-a-Tara Wellington Harbour ${ }^{64}$ it is feasible that he may have sighted the entrances to the lakes Kohangapiripiri and Kohangatera before entering the harbour at Te Rae-akiaki. ${ }^{65}$ In Kupe's wake, the first settlers in the Parangarahu and Wellington areas were Whatonga and his sons Tara-ika and Tautoki. Tara's people (Ngāi Tara) occupied the harbour and western and southern parts of Wellington: Tautoki's people lived in the Wairarapa but maintained a fort which was the first pā at Parangarahu and was located strategically at the eastern end of Fitzroy Bay with commanding views of the bay and access both to the eels in the lakes Kohangapiripiri and Kohangatera and to seafood. ${ }^{66}$ Ngāti Ira, who migrated from Tolaga Bay, intermarried with the descendants of Whatonga and Ngāi Tara and, along with Ngāti Kahungungu, were the tangata whenua of the eastern shores of Wellington harbour for more than ten years from 1820. An oral history account connects the two iwi with the Parangarahu area through the killing of a Ngāti Kahungungu chief by Ngāti Ira in a location just east of Te Rae-akiaki in which a valuable greenstone mere was lost and has never been

\footnotetext{
${ }^{63}$ The source of much of the information concerning early Māori occupation that is recorded here is Port Nicholson Block Settlement Trust and Greater Wellington Regional Council, "Parangarahu Lakes Area CoManagement Plan.”

${ }^{64}$ Kupe's progress is summarised as "from Castlepoint (Rangi-whakaoma) he reached Cape Palliser (Te Kawakawa and Matakitaki-a-Kupe); thence to Seatoun (Te Turanga-o-Kupe); on to Sinclair Head (Rimurapa, and Pariwhero nearby); onward to Porirua Harbour (Pari-rua), and Mana Island (Te Mana-o-Kupe-ki-Aotearoa); thence he turned the prow of his canoe southward, crossed Cook Strait (Raukawa) and reached Arahura on the West Coast of the South Island (Te Wai-pounamu) in G. Leslie Adkin, The Great Harbour of Tara: Traditional Maori Place-Names and Sites of Wellington Harbour and Environs (Christchurch: Whitcombe and Tombs, 1959). 5-6.

${ }^{65}$ Port Nicholson Block Settlement Trust and Greater Wellington Regional Council, "Parangarahu Lakes Area Co-Management Plan.” 15.

${ }^{66}$ Ibid.
} 
found. ${ }^{67}$ Ngāti Mutunga defeated Ngāti Ira sometime in the 1830s and took over the pā site and cultivations at Parangarahu before handing them over to Te Ātiawa and Taranaki before leaving, with Ngāti Tama, for Rēkohu the Chatham Islands in $1835 .{ }^{68}$ Te Ātiawa have maintained ahi kā (rights of occupation) of Te Whanganui-a-Tara Wellington Harbour since that time.

William Colenso visited "Parangarehu" 69 on 25 March 1845 and described it as "a nice little village containing several natives", ${ }^{70}$ and in his journal of 6 March 1846 observed that the "forty residents of this little village had already threshed eighty bushels of wheat". ${ }^{71}$ Charles Rooking Carter, in May 1853 on his first trip to the Wairarapa, travelled by boat from the Wellington pilot station to the eastern shores of the harbour then walked along a rough track passing "two pretty sheets of water" (lakes Kohangapiripiri and Kohangatera) to arrive at "a dry stone wall about 300 feet long [91.4 m], 3ft. 6-in. high [1.1 m], and 2 feet thick [0.6 m], enclosing a plot of cultivated ground, and evidently erected by the natives". ${ }^{72}$ Nearby, Carter found "about a dozen huts" inside which were the "usual Maori utensils, some fishing gear, and some provisions, but not a soul to be seen — not even a dog to bark". ${ }^{73}$ Carter concluded that Parangarehu was a fishing village. These early nineteenth-century observations by both Colenso and Carter establish Parangarehu as a Māori settlement sufficiently permanent to warrant the construction of a dry-stone wall and as an environment suitable for the cultivation of food. Palmer's archaeological field surveys carried out in Fitzroy Bay, beginning in $1950,{ }^{74}$ support these early observations concluding that since "cultural material typical of the Archaic Period has been found in the bay, it is certain that settlement had taken place at an early date". ${ }^{75}$ His survey revealed oven areas, middens, pits, terraces, fragments of adzes in varying stages of production and more remnants of the wall, originally noted by Carter, measuring a little over half a mile $(0.8 \mathrm{~km})$ and extending between two occupation sites. The

\footnotetext{
${ }^{67}$ Journal of the Polynesian Society, "History and Traditions of the Taranaki Coast (Continued)," The Journal of the Polynesian Society 18, no. 4 (72) (1909). 174.

${ }^{68}$ New Zealand Government, "Port Nicholson Block (Taranaki Whanui Ki Te Upoko O Te Ika) Deed of Settlement," 4.

${ }^{69}$ Also written as 'Para-ngarehu' in some early sources.

${ }^{70}$ A. G. Bagnall and G. C. Petersen, William Colenso, Printer, Missionary, Botanist, Explorer, Politician: His

Life and Journeys (Wellington: A. H. and A. W. Reed, 1948). 215.

${ }^{71}$ Ibid. 227.

${ }^{72}$ Charles Rooking Carter, Life and Recollections of a New Zealand Colonist Written by Himself, 3 vols., vol. 2 (London: Printed by R. Madley, 1866-1875). 85.

${ }^{73}$ Ibid.

${ }^{74}$ Palmer's description includes references to notes made by H. B. Fell during 1936-7. Palmer was a lecturer at Wellington Teachers' College.

75 Palmer, "Maori Sites in Fitzroy Bay." 128.
} 
cultivation flat was identified as extending from the wall towards the sea. Palmer makes no mention of the karaka with dendroglyphs.

Research into the distribution of karaka shows that its original natural range is the northern regions of the North Island, ${ }^{76}$ however, descriptions of nineteenth-century Wellington suggest that karaka was well established in the region at that time. In his examination of survey recording of Māori occupation in the Pencarrow survey district, McFadgen quotes the R.P. 372 entry of 1859 , the earliest survey of the Wainuiomata River including part of the Orongorongo River and the coast from Fitzroy Bay to Palliser Bay and showing the bushed area of the Pencarrow Survey District (the eastern land from Eastbourne to Palliser Bay):

In the Wainuiomata Valley prior to and during 1859, the standing bush consisted of Rimu, Titoki, Kahikatea, Rewa Rewa, Maire, Rata, Hinau, "abundant” Tawa, Totara, and "other pines of the finest description". At a distance of about two and a half miles [4 km] up the Wainuiomata Valley, the bush gradually gave way to a large grove of Karakas, extending for about half a mile $[0.8 \mathrm{~km}]$. These eventually gave way to "small fern and fine grass".

The floor of the Orongorongo Valley was for the most part covered in shingle and scrub. There was however, a Karaka grove just over a mile $[1.6 \mathrm{~km}]$ from the coast alongside section $4 .^{77}$

In an edited version of his notes on the south-western Wellington coast, Peter Beckett describes karaka growing "at any suitable spots along the coast" in 1890 and records a grove of trees west of the stream in Red Rocks Bay, "covering about a quarter of an acre [0.1 ha]" and another "about half a mile $[0.8 \mathrm{~km}]$ along the ridge north of Red Rocks" where "in a basin at the head of a gully falling westward to the Red Rocks stream, was an area of about fifteen acres [6 ha] of dense growth of trees. They were a mass of gold fruit-a sight never to be forgotten. ${ }^{78}$

Beckett reaches no conclusion on the origin of the trees. A clue to whether the karaka trees at Lake Kohangapiripiri are 'natural' or 'cultural,' however, may lie in both the archaeological status and the climate of the Parangarahu Lakes Area. In describing wild plants domesticated in Polynesia, Yen cites karaka as one New Zealand example of the exploitation of local flora. "In an environment that was only marginally amenable to those tropical food plants

\footnotetext{
${ }^{76}$ Leach and Stowe, "Oceanic Arboriculture at the Margins,"; Barber, "Archaeological Assessment of Reported Carvings on Karaka (Corynocarpus laevigatus) Trees (Dendroglyphs), East Harbour Regional Park."

${ }^{77}$ McFadgen, "Maori Occupation of the Pencarrow Survey District as Recorded on Early Survey Records.” 120.

${ }^{78}$ Beckett, "Some Notes on the Western Wellington Cook Strait Coast." 139. Beckett's original notes were edited by John Daniels.
} 
introduced by the first New Zealanders ... a move towards domestication within the native flora is unsurprising". ${ }^{79}$ The traditional techniques of planting karaka for harvesting fruit, he writes, remain common knowledge among rural Māori. ${ }^{80}$ Exploring Yen's theory that karaka was domesticated by Māori, Leach and Stowe propose that it is possible to "define on climatic grounds the conditions under which karaka reproduce themselves in lowland forests". ${ }^{81}$ If Māori were moving and cultivating karaka both within and beyond the natural range, they argue, these specimens are likely to occur in association with archaeological sites. "Specimens occurring in areas where climatic conditions were suitable for unaided reproduction, and where archaeological sites are absent, are more likely to be natural components of the vegetation". ${ }^{82}$ By plotting karaka trees on maps alongside the New Zealand Archaeological Association's data base of archaeological sites in the North and South Islands Leach and Stowe have demonstrated that 84 per cent of cultural occurrences of karaka have occurred with one or a combination of pā (22\%), midden (23\%), terraces $(21 \%)$ and pits (18\%), and were most frequently found in sunnier, drier and windier locations closer to the coast than sites hosting natural karaka ${ }^{83}$ Furthermore, Leach and Stowe claim that:

taken together, these results suggest that before human intervention, karaka was restricted to the northern North Island, with human cultivation and translocation extending its natural range to the lower North Island and the upper South Island. ${ }^{84}$

General consensus is that Fitzroy Bay presents a challenging climate for settlement. Most of the bay is exposed to wind rendering it a sunny, dry and windy site borne out in the names 'Kohangatera' interpreted as "a nest basking in the sun" and 'Kohangapiripiri' as "a strongly clinging nest". ${ }^{85}$ In a note to Colenso's report of wheat threshing at Parangarahu in 1846 Bagnall and Petersen comment that the "present-day visitor to the attractive ruggedness of

\footnotetext{
79 D. E. Yen, "Wild Plants and Domestication in Pacific Islands," in Recent Advances in Indo-Pacific Prehistory: Proceedings of the International Symposium Held at Poona, December 19-21, 1978, ed. Virenda N. Misra and Peter S. Bellwood (Leiden: E. J. Brill, 1985). 322.

${ }^{80}$ Other examples of domestication of native plants described by Yen are flax, cabbage tree and bracken fern (Pteridium esculentum).

${ }^{81}$ Leach and Stowe, "Oceanic Arboriculture at the Margins." 15.

${ }^{82}$ Ibid.

${ }^{83}$ Ibid. $18-20$.

${ }^{84}$ Ibid. 20. See also See also Bruce Molloy, "The Origin, Relationships, and Use of Karaka or Kopi (Corynocarpus laevigatus)," in Nga Mahi Maori O Te Wao Nui a Tane: Contributions to an International Workshop on Ethnobotany, Te Rehua Marae, Christchurch, New Zealand, 22-26 February 1988, ed. Warwick Harris and Promila Kapoor (Christchurch: Botany Division, DSIR, 1990). 52.

${ }^{85}$ Adkin, The Great Harbour of Tara. 30-31; Port Nicholson Block Settlement Trust and Greater Wellington Regional Council, "Parangarahu Lakes Area Co-Management Plan." 11. An alternative interpretation suggested by the 1847 deed of sale of the Parangarahu Block is also referred to in the Management Plan. The deed records the names of the lakes as 'Whangatera' and 'Whangapiripiri' without the prefix 'ko'. It is suggested that 'whanga' could be interpreted as bay, inlet or harbour and thereby support the geological evidence that the lakes were formerly marine inlets.
} 
Fitzroy Bay might justifiably wonder where on that uncompromising littoral anyone might raise one bushel of wheat". ${ }^{86}$ In discussing karaka as a food source able to be preserved and stored, Best highlights its usefulness "more especially in certain districts where cultivated food-products formed no real part of the food-supply, as, for example, the rugged coastline from Wellington northward to Castle Point". ${ }^{87}$ The exposure of the site to harsh weather, Palmer concludes, would have governed the length of settlement in Fitzroy Bay and necessitated types of potentially long-lasting food resources and means of food storage for times of bad weather. "It is known that parts of the flat were cultivated so that permanent settlement could have been possible. Evidence of food supply suggests that several food items could have been dried during the summer months and stored for later use, so that the limitations of food gathering may have been overcome during prolonged wet and windy periods." $" 88$

That karaka was a useful food source for the early inhabitants of Fitzroy Bay and the greater Wellington area seems generally agreed. Jerningham Wakefield describes a trip north from Waikanae in 1840 in a canoe provisioned with cold cooked potatoes and fish, and "large baskets of the kernel of the karaka berry" the kernel of which, he explains, formed "an important article of native food". ${ }^{89}$ As the prepared kernels required no further cooking, Wakefield records, "The natives use them extensively in travelling". ${ }^{90}$ Colenso, in 1845 near Waimimiha (south of Castlepoint, now 'Waimimi') shared a meal with Māori who were baking karaka kernels "gathered from one of the precious coastal groves", 91 and in 1848 describes his communications with Māori as "backed all the time by the seasonal scarcity of food". ${ }^{92}$ A wedding feast at Mataikona, (north of Castlepoint), comprised "nine pigs, with only dried karaka kernels as a substitute for the more palatable maize or potatoes". ${ }^{93}$ Keyes, in reporting on a "range of small site types which attest to past occupation" recorded by the Wellington Archaeological Society, (and referencing Palmer 1963 and Best 1942), concludes that a plentiful food supply of karaka berries, birds and eels available in the Kohangapiripiri and Kohangatera lakes area supports the belief that the lakes were "important sites for

\footnotetext{
${ }^{86}$ Bagnall and Petersen, William Colenso, Printer, Missionary, Botanist, Explorer, Politician. 232.

${ }^{87}$ Best, Forest Lore of the Maori. 45.

${ }^{88}$ Palmer, "Maori Sites in Fitzroy Bay." 127.

${ }^{89}$ Wakefield, Adventure in New Zealand. 233.

90 Ibid.

${ }^{91}$ Quoted in Bagnall and Petersen, William Colenso, Printer, Missionary, Botanist, Explorer, Politician. 212.

92 Ibid. 280.

93 Ibid.
} 
seasonal occupation" in the prehistory of Wellington. ${ }^{94}$ The role of Parangarahu karaka as a food source is borne out by the description of berry harvesting in the vicinity recorded in evidence given in the Native Land Court on 13 September 1889:

Saw Mu at Parangarahu he went with us. Did not see Wikiriwha and ka Mangaringa at Parangarahu. He lived at Pitoone. When the people went to Parangarahu to get Berries Mu and others went there. Many people went there to get Berries who had no right there. The persons who had cultivated previously were [list of 27 names]. ${ }^{95}$

Not all observers have supported the arguments of Yen, Leach and Stowe regarding 'cultural' karaka groves. Investigating the distribution of karaka in relation to occupation sites on 48 miles [77 km] of the Wairarapa coast from Cape Palliser to Flat Point (east of Fitzroy Bay), Mitcalfe found a high correlation of karaka groves and gardens, and pā or village sites. He concludes, however, that while evidence that the trees were left standing to provide food and shelter and to attract birds for snaring indicates that Māori valued karaka, it does not prove that they deliberately planted them. Mitcalfe carried out experiments testing whether traditionally prepared soaked and dried berries remained viable after treatment. The tests resulted in the germination of three out of one hundred berries which, he concludes, demonstrates that "accidental germination [is] a feasible cause of the karaka associated with living sites". ${ }^{96}$ Mitcalfe provides no answer to the question of whether or not Māori deliberately planted karaka but deduces that "their deliberate protection by the early Maori seem unquestionable for they are growing beside well used tracks and pits where young trees would inevitably have been destroyed without nurture". ${ }^{97}$ Walton and McFadgen, carried out an archaeological survey of the area in 1987 and identified the dendroglyphs on one of the remaining Kohangapiripiri trees. ${ }^{98}$ They note, however, that karaka trees were scattered around the margins of both lakes and along the coastal platform, and report "some doubt about whether karaka trees are a useful indication of human activity" but conclude that, regardless of whether they were deliberately planted or not, the trees would have been a valuable food supply in the Fitzroy Bay area. ${ }^{99}$

\footnotetext{
${ }^{94}$ Keyes, "Dendroglyphs from Lake Kohanga-Piripiri, Eastern Wellington," 104. On 17 November 1845 Colenso observed Maori just north of Parangarehu "with live huias caught on the karakas near by". Quoted in Bagnall and Petersen, William Colenso, Printer, Missionary, Botanist, Explorer, Politician. 225.

${ }^{95}$ The evidence was provided by Henare te Puni and others to identify entitlement in an application to the court for the partition of the Parangarahu block into eight parcels. Cited in Port Nicholson Block Settlement Trust and Greater Wellington Regional Council, "Parangarahu Lakes Area Co-Management Plan." 34.

${ }^{96}$ Mitcalfe, "The Significance of Karaka in an Assessment of Pre-European Land Utilisation in New Zealand." 187.

${ }^{97} \mathrm{Ibid}$

${ }^{98}$ McFadgen interview.

${ }^{99}$ Walton and McFadgen, "Fitzroy Bay." 167.
} 


\section{Regeneration of Parangarahu Lakes Area}

The Parangarahu Lakes Area Co-Management Plan which was developed under the guidance and leadership of Te Roopu Tiaki, was published by the GWRC and the PNBST in 2014. It was the first collaboration of its kind for the GWRC and concerned a largely neglected area of the region. ${ }^{100}$ The moemoea (vision) that underlies the plan is that "the combined catchments of the lakes and the wetlands and lakes themselves will be recognised and sought after as a place for nurturing biodiversity, for regenerating life, and for sustaining human well-being". ${ }^{101}$ The Parangarahu Lakes Area has been severely modified by deforestation and farming and, as a result, little indigenous vegetation remains. Nevertheless, eleven groups of karaka near Lake Kohangatera were entered into the New Zealand Archaeological Association's Site Recording Scheme in 1963: the site of the Dendroglyph Trees was recorded in the scheme in 1987. The co-management plan recognises these remnant groves beside the wetlands and both lakes as an indication of Māori occupation sites and cultivation, and Taranaki Whānui regard them as a significant part of their history and an important part of the cultural landscape. ${ }^{102}$ The area was retired from grazing in 2004 and gorse (Ulex europaeus), tauhinu (Ozothamnus leptophyllus) and mānuka (Leptospermum scoparium) now dominate the land but members of the community group Mainland Island Restoration Operation (MIRO) have begun planting fenced nodes of native plants in the southern area of the two lakes. The intention is that the nodes will provide a seed source that birds will naturally disperse across the greater area, thereby helping with the regeneration.

On 17 July 2016, I joined a planting day at the Parangarahu Lakes Area with people from Taranaki Whānui, GWRC and MIRO at a site just north of the Pencarrow Lighthouse and just west of the dendroglyph sites. The GWRC provided tools and transport to the area which had been fenced in preparation for the day.

We planted the same native trees and shrubs that in the nineteenth century had been cut down and burnt; we listened to Jason Fox, then chief executive of the PNBST, describe the Trust's vision for the area; ${ }^{103}$ we shared lunch and climbed the lighthouse steps to admire the view

\footnotetext{
${ }^{100}$ Porteous interview.

${ }^{101}$ Port Nicholson Block Settlement Trust and Greater Wellington Regional Council, "Parangarahu Lakes Area Co-Management Plan.” 11. This includes restoration of the eel and native fisheries in the lakes and regeneration of customary resources for weaving, carving and rongoā.

102 Rauhina-August interview.

${ }^{103}$ Jason Fox resigned as chief executive in April 2017.
} 
from the top. There were no karaka among the young natives we planted but the cultural revitalisation and reforestation programmes planned for the area may include the reestablishment of groves or "orchards" in the future. ${ }^{104}$ Nobody walked the track that day to visit the Dendroglyph Trees.

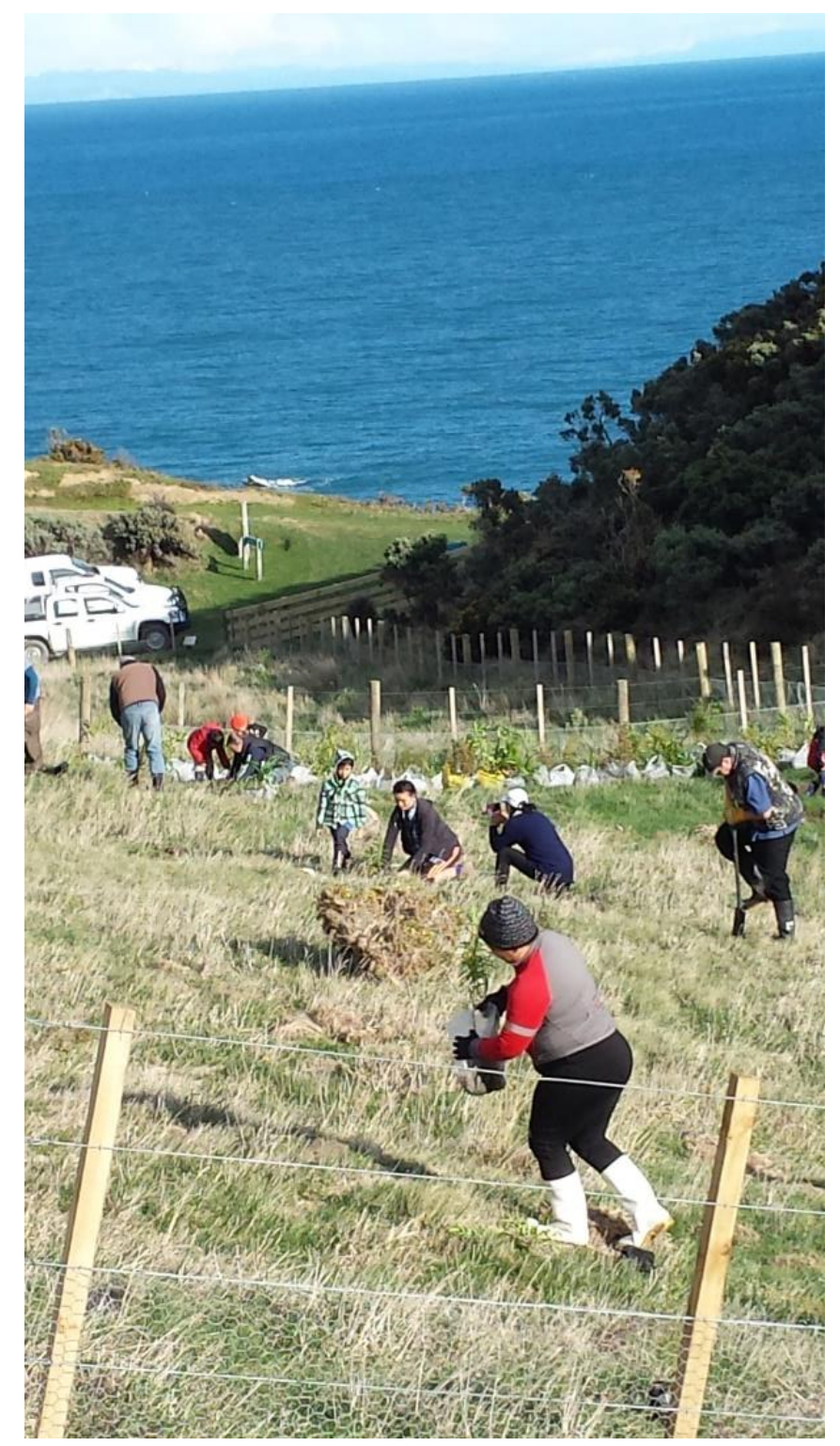

Figure 36: Planting Day at the Parangarahu Lakes Area. (17 July 2016.)

\footnotetext{
${ }^{104}$ Port Nicholson Block Settlement Trust and Greater Wellington Regional Council, "Parangarahu Lakes Area
} Co-Management Plan.” 34. 


\section{Being There}

The Dendroglyph Trees, 30 April 2016

Lake Kohangapiripiri is not much visited, friends tell me, and most walkers and cyclists end their journeys along the metal coast road at the Pencarrow Lighthouse (about two hours walking from Burdans Gate). With my daughter and a friend, and armed with Adkin's maps and dendroglyph drawings, I cycle into the southerly. At the lighthouse we pedal on around Te Rae-akiaki (Pencarrow Head), past a sewer outfall and stop at a locked gate. We climb a stile and take the track along the western side of the sea outlet then alongside the lake and enter a calm and quiet valley. The Dendroglyph Trees (Trees A and B4 on Adkin's map) are unmissable—solitary, glossy flags of former occupation in small, adjacent gullies, surrounded by a monochromatic matte-dull tangle of rank grass, gorse, mānuka, tauhinu and clumps of flax. Several other karaka punctuate the hillside behind but they're not part of today's investigation plan. The two in our sights are modest, wind sculpted trees; fenced separately by barriers that are more gesture than deterrent. We clamber up to Tree A on the first site, find the fish form on the rough bark, run our fingers over its indentations (no white gloves required), I photograph it (cameras permitted): we examine the tree on the second site, struggle to identify its markings, peer into its hollow trunk and photograph it for the record.
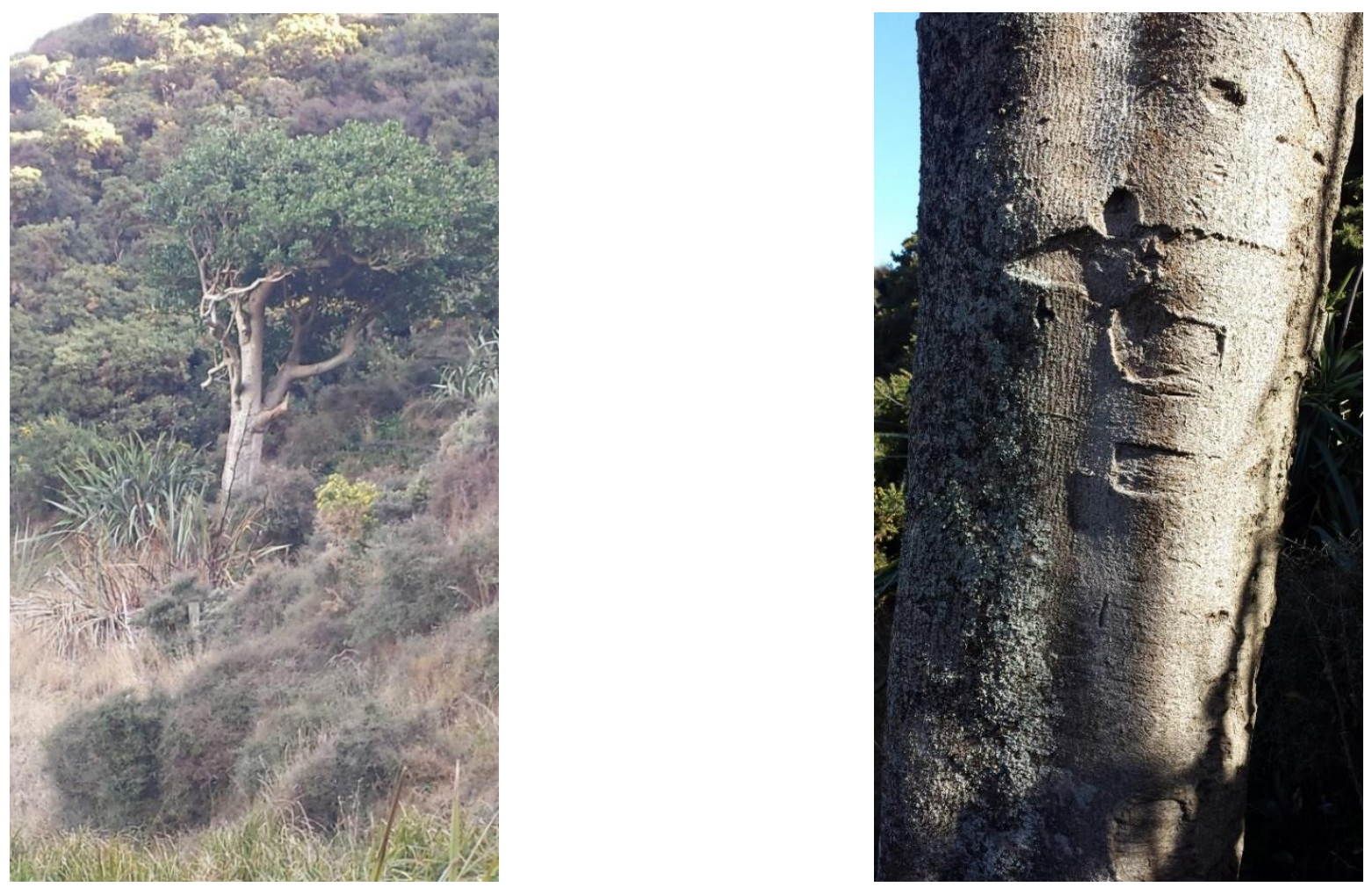

Figure 37: Lake Kohangapiripiri Dendroglyph Tree. Left: Tree marked as 'A' on Adkin's map. Right: the fish form on the trunk of the tree. (30 April 2016.) 


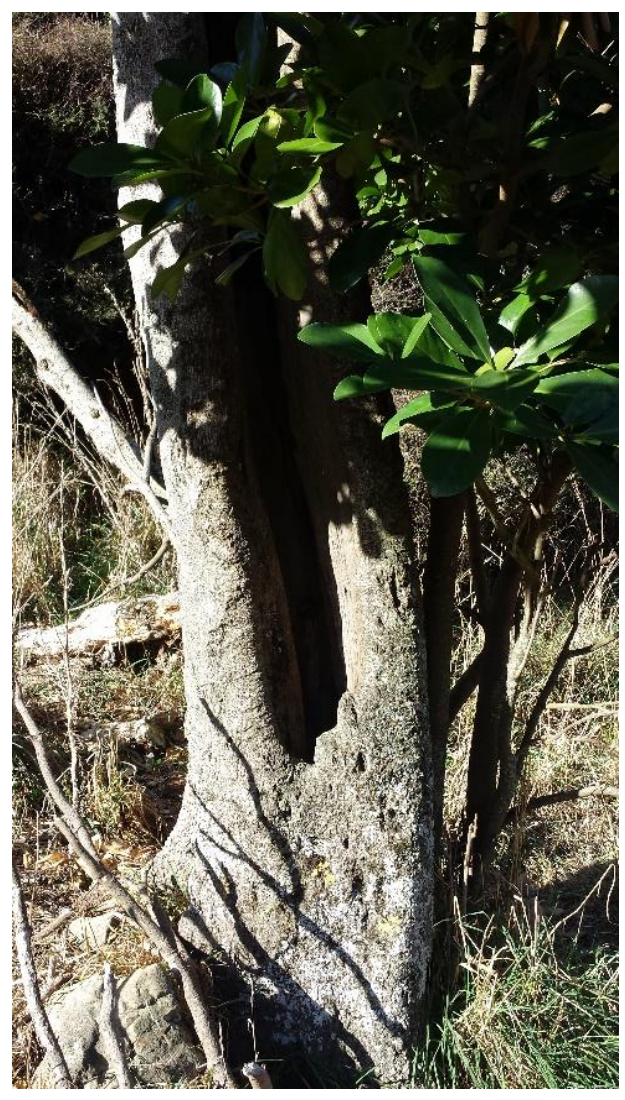

Figure 38: Lake Kohangapiripiri Dendroglyph Tree, marked as ' $B$ ' on Adkin's map, showing the hollow trunk. (30 April 2016.)

It's exhilarating to be right on the spot where Māori once raised a karaka orchard (probably) and carved a fish to commemorate an event (possibly); and where Adkin and Barrow enthusiastically wrapped a tree in brown paper and traced its glyphs (apparently). For Adkin and Bull this would have been a newfound site of heritage, exciting, numinous and real: for Taranaki Whānui, as kaitiaki, this is taonga tuku iho. We walk further up the valley alongside the wetland to look at the trees from another perspective, then quite suddenly the sun deserts the valley, the shine slips from the karaka leaves and the trees merge into the shadows of the hillside. The show is over. We cycle homeward with the southerly at our backs. 


\section{The Karaka of Palliser Bay}

Included at the back of Adkin's notebook are: a sketch plan of Turikirae, the western section of Palliser Bay (south-east of Fitzroy Bay) showing the location of ten karaka groves between Hurupi Stream in the west and Te Roro Stream in the east; a detailed plan of the Te Roro Stream area showing karaka groves; and drawings of "possible dendroglyphs" on the Te Roro Stream trees. ${ }^{105}$ Adkin's survey records are dated 28 December 1959, nine days after the second visit to the Kohangapiripiri trees and nineteen days before the third visit. No field notes are included to support the sketches so it is unclear whether he carried out the survey alone or whether he discussed the find with Bull or Barrow. The drawings of the carvings are appended "as noted by G. L. A.": the depth of topographical and archaeological detail recorded on the sketches suggests he visited the site on more than one occasion. Adkin recorded five karaka groves on his Te Roro Stream sketch plan-grouped as thirteen trees; two trees; five trees; thirty-eight trees; and two trees. ${ }^{106}$ The "possible" dendroglyphs were identified on the grove of thirteen trees (three carvings) and on one of the groves of two trees (one carving). The tree carvings noted include a "symbolic motif", "canoe-shaped grooves", "circular and elliptical 'cut-outs"” and a "cradle' motif inverted" similar to the glyph identified and recorded at Fitzroy Bay.

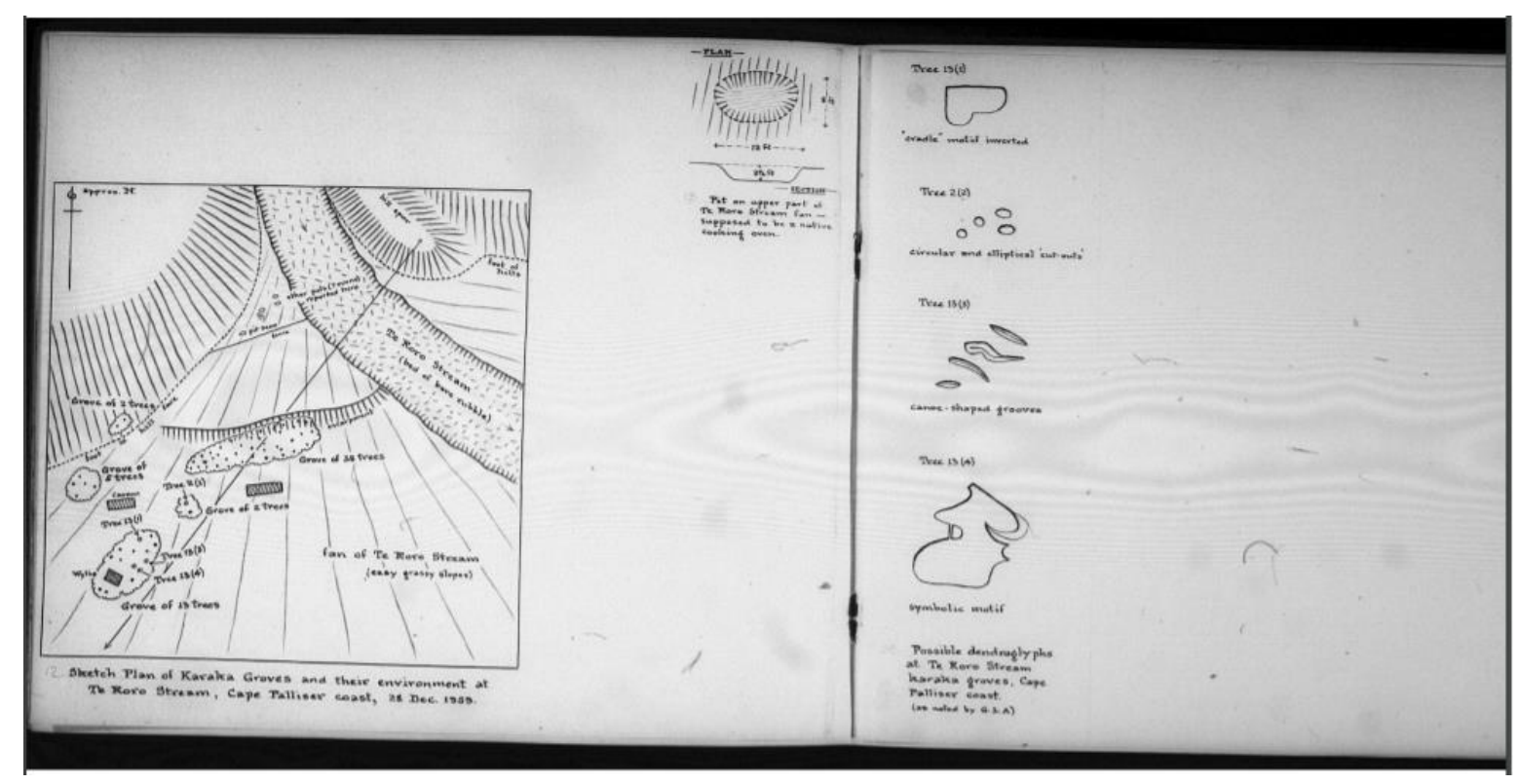

Figure 39: Adkin's "Sketch Plan of Karaka Groves and their environment, Cape Palliser coast, 28 December 1959.” Ref: MS-Papers-6061-45 ATL.

\footnotetext{
105 "Maori Notebook," (vol. 44).

${ }^{106}$ Adkin also identified on his maps: ancient stone walls; ancient burials; an ancient lookout; native pits; charcoal refuse; former kāinga and native terraces.
} 


\section{Being There}

Palliser Bay, 2 July 2016

This trip is a quest to find the "possible" dendroglyphs at Te Roro Stream recorded in Adkin's Maori notebook (vol 44). With the notebook's Palliser Bay Road map showing from Waimeha Creek to Waiarakeke Stream (Figure 40); the sketch plan of the environment of Te Roro Stream; and the dendroglyph drawings (Figure 39); I drive with my husband towards Cape Palliser (Matakitaki-a-Kupe, the gazing of Kupe). On the inland farms, between the Hurupi Stream and the Cape Palliser Lighthouse, we spot five of the ten karaka groves that Adkins noted on his coast road map. They shine in the paddocks and foothills and are surrounded by scrub and often by grazing animals.

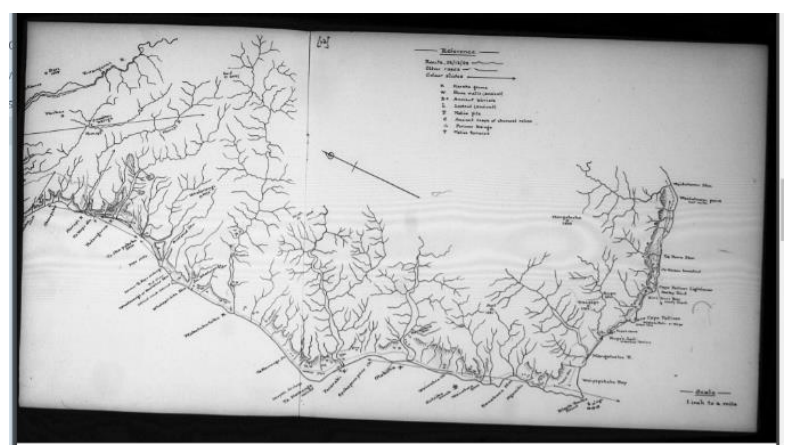

Figure 40: Adkin's map of the route taken on 28 December 1959, showing the karaka groves. Ref: MS-Papers-6061-45 ATL

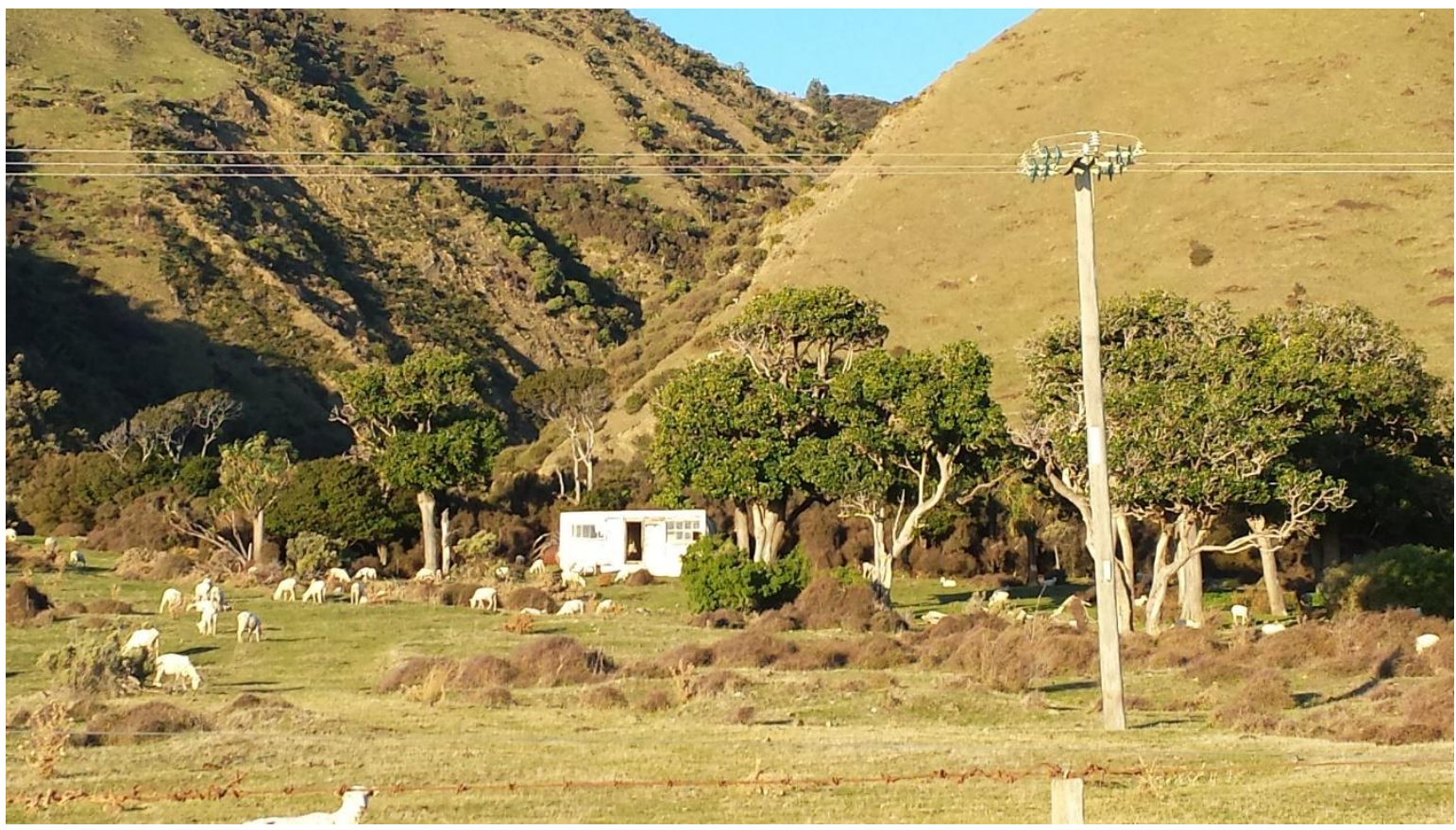

Figure 41: One of the extant karaka groves identified on Adkin's 1959 Palliser Bay Road map. (2 July 2016.) 
Just past the lighthouse, Te Roro Stream proves to be no more than a shingle bed, and the surrounding area has graduated to become the Aorangi Forest Park, a recreational hunting area managed by an eponymous trust. In 1959 Adkin mapped five karaka groves on the broad, sweeping slopes: in 2016 we walk alongside the beach and veer up the largely barren hillside and sight a few isolated karaka splendent amongst scrub high above. The two karaka groves lower down (thirteen trees and two trees) noted by Adkin as the site of "possible" dendroglyphs have disappeared. We find the grove of thirty-eight karaka, however, by an escarpment as he described and note that it has been reduced to thirteen trees, some with initials carved into their trunks.

These trees are in a small area of regenerating bush which, I later learn, has been fenced and protected with pest traps by local Queen Elizabeth II National Trust members to conserve the karaka, a small group of rengarenga (Arthropodium cirratum) believed to have been introduced to the site by early Māori, and new plantings of rare coastal plant species. The trees are now part of a large restoration project by Ngäti Hinewaka to restore the coastal forest to their land. ${ }^{107}$

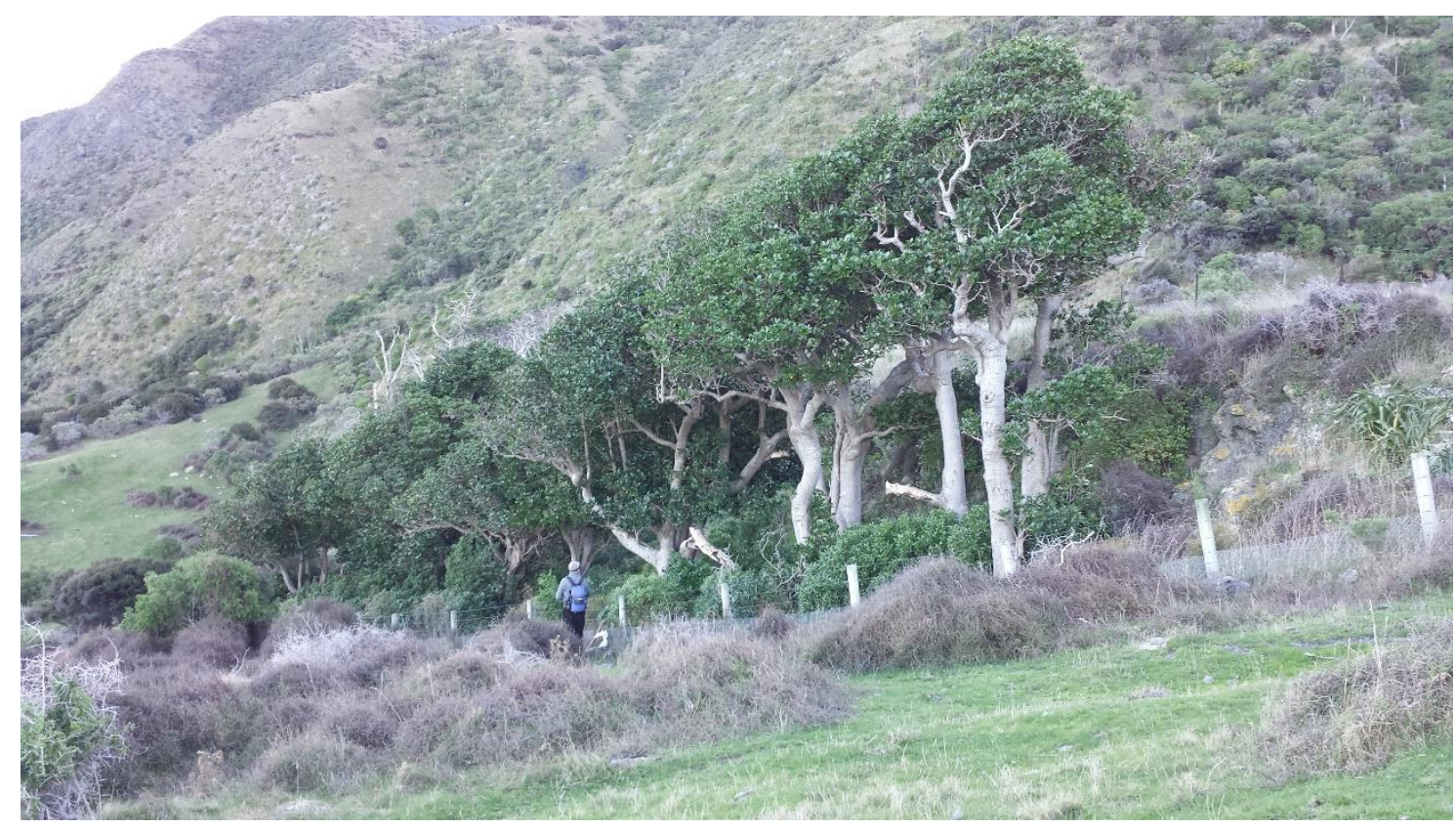

Figure 42: The remaining thirteen karaka of a grove of thirty-eight trees identified by Adkin at Te Roro Stream in 1959. (2 July 2016.)

${ }^{107}$ Email correspondence with Trevor Thompson, Queen Elizabeth II National Trust, 29 July 2016. The project is supported by the Queen Elizabeth II National Trust; GWRC; the local branch of Forest and Bird; Taratahi Agricultural Training Centre and the Norfolk Road Native Nursery. 


\section{Being There}

Lake Kohangapiripiri and Lake Kohangatera, 6 July 2016

I'm invited to visit Lake Kohangapiripiri and Lake Kohangatera with two anthropologists,

Bruce McFadgen (Victoria University of Wellington) and Justin Maxwell (University of Otago) who are identifying possible settlement sites for Maxwell's work on Barber's Marsden project, "Pushed to the Limits: investigating the significance of agricultural transfers and innovation in southern Polynesian colonisation". Maxwell has also worked with Barber on the Rēkohu Chatham Islands' kōpi projects. He has a key to Burdans Gate so we drive to the stile. We trudge up the eastern side of Lake Kohangatera (a nest basking in the sun) and enter thick groves of karaka rising greenly from lush undergrowth.

These are the New Zealand Archaeological Association-registered sites and are convincingly orchard-like in their numbers and groupings. The massed trees are straight and tall, forming their own breaks against the coastal wind and providing a dense canopy which filters sunlight onto healthy saplings thriving below.

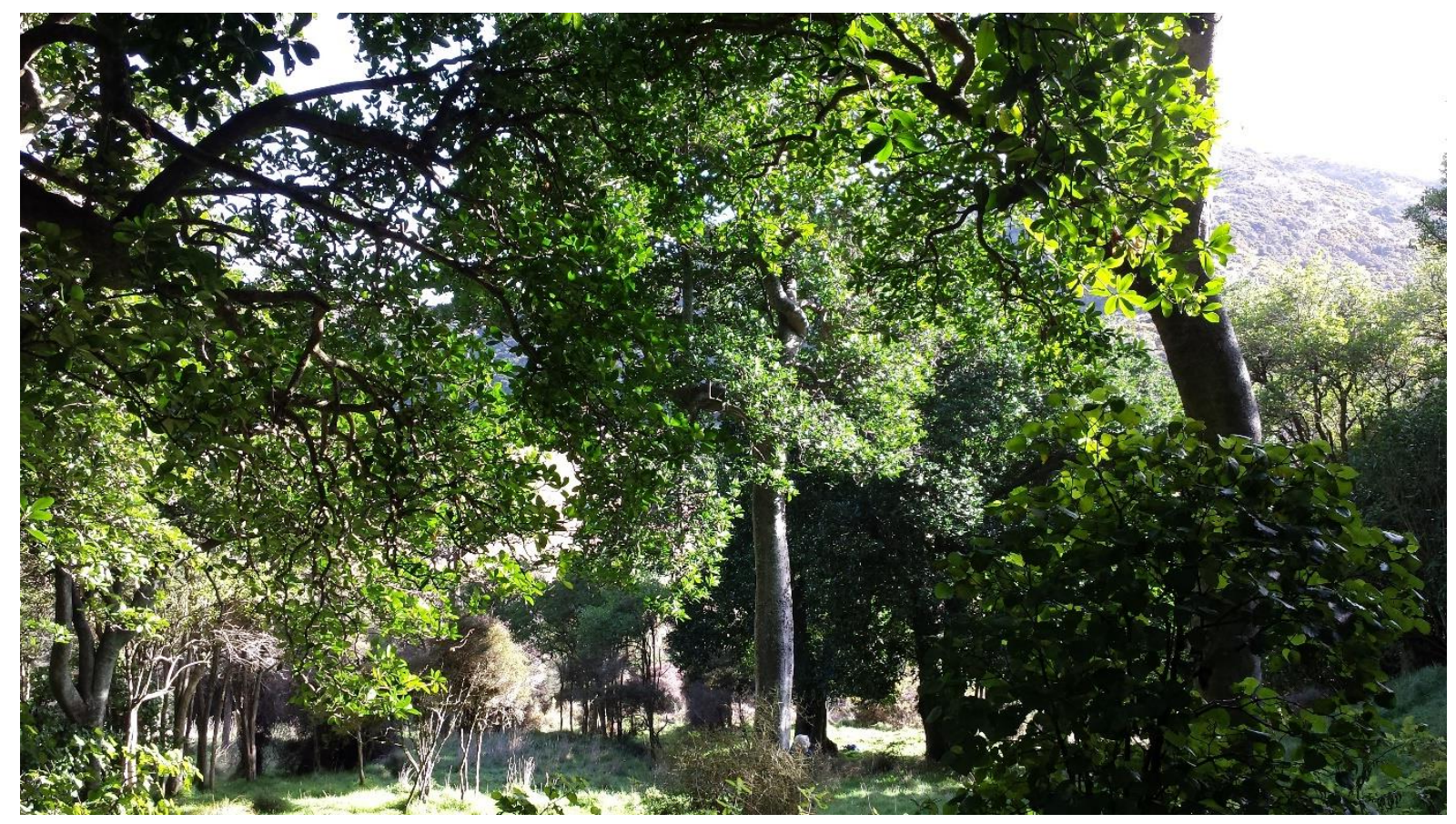

Figure 43: Lake Kohangatera karaka grove. (6 July 2016.) 
We return to the beach, turn right and walk up the more exposed western side of Lake Kohangapiripiri (a strongly clinging nest) to the two Dendroglyph Trees and living proof that the height of mature karaka trees is determined as much by their environment as by their age. The Dendroglyph Trees are much smaller than their more numerous and sheltered Lake Kohangatera neighbours, but the mystery of their marked surfaces, their courage and persistence in the face of all the challenges that deforestation, isolation, farming and harsh weather have thrown at them render them the more heroic survivors.

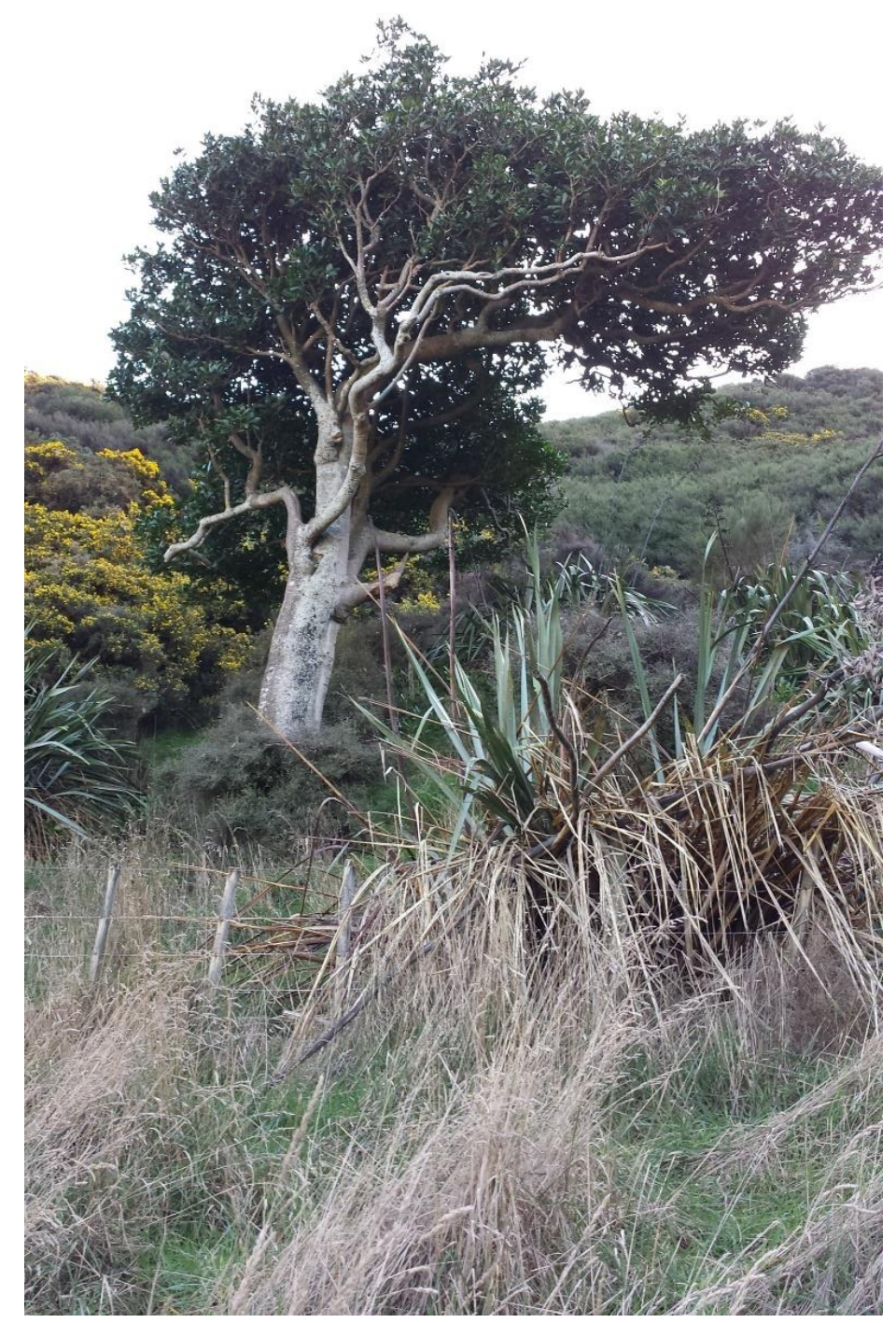

Figure 44: Lake Kohangapiripiri Dendroglyph Tree identified By Adkin as Tree 'A'. (6 July 2016.) 


\section{Conclusion: Trees as Taonga Tuku Iho}

In his lecture "The Art of Taonga" at City Gallery, Wellington, Paul Tapsell describes taonga as "time-travellers":

They made real not only the ancestors, but also their surrounding landscapes by burying a sense of ancestral belonging deep into our living core. These taonga were present during tribe-defining moments of crisis; they played key roles alongside key ancestors. In time, such taonga do not just represent ancestors, they become those ancestors. ${ }^{108}$

They carried "life-lessons and poignant ancestral reminders of a once omnipresent, maraedefined value system based on kin belonging", Tapsell argues. Colonial intervention and contemporary redefinition of resources, with associated legislation, have changed the role of marae, "So where are those taonga today that once represented the art of marae relationships - past, present, future? Who is (re)defining them? Who is telling their stories?"109

Te Roopu Tiaki's acknowledgement of Kohangapiripiri’s carved trees as taonga tuku iho, their decision to embrace the "ambiguity of their origin and meaning" and their encouragement of "ongoing korero and debate to add to the mana of the site"110 might be seen as one such example of the redefinition and story-telling Tapsell calls for. ${ }^{111}$ In a world of rapid change (changed leadership of the PNBST has introduced new ideas and aspirations to the co-management plan) it seems a pragmatic approach. Although, as pointed out earlier, the authenticity of the carvings as Māori artefacts is not a primary concern of this thesis (this is discussed further in Chapter Five) and the "ambiguity of their origin and meaning" has been adopted by Taranaki Whānui as their kaitiaki, it does remain something of an 'elephant in the room'. Liz Mellish, a founding member of Te Roopu Tiaki, reportedly said that she believed the dendroglyphs had been carved "by one of our ancestors in the 1820 s or 1840 s", ${ }^{112}$ however Barber, in his archaeology report, argued that there was no evidence that

\footnotetext{
108 Tapsell's lecture was delivered on 25 November and was published the following year as: Paul Tapsell, The Art of Taonga, Gordon H. Brown Lecture (Wellington Art History, Victoria University of Wellington, 2011). 10 .

${ }^{109}$ Ibid. 12-13.

${ }^{110}$ Port Nicholson Block Settlement Trust and Greater Wellington Regional Council, "Parangarahu Lakes Area Co-Management Plan.” 26.

${ }^{111}$ Ibid.

112 Quoted in Rachel Buchanan, "Re-Making Memory on Matiu and Other "Settlement" Sites," Memory Connection 1, no. 1 (2011). 292.
} 
the trees were deliberately carved. ${ }^{113}$ How then can the trees claim the status of taonga tuku iho when the "ambiguity of their origin and meaning" remains unresolved? Is it essential to know who marked the trees - or even if the markings are cultural rather than natural—-for them to be considered heritage? Is it important to determine the age of the markings or what they represent? Do any of these questions matter?

In an essay describing the evolving nature of Māori art and the contemporary importance of taonga for Māori, Ngarino Ellis proposes a way of thinking about taonga tuku iho that transcends questions like these and, at the same time, provides some answers. Taonga, she writes, are often considered as living beings and part of the whakapapa and history of the land and the communities with which they are associated. "Māori do not consider taonga able to be owned, but rather, as with the whenua, we are here to look after them until we can pass them on to the next generation. ${ }^{114}$ Ellis's method of inquiry advocates the construction of 'biographies' of taonga — names, materials, forms, and makers — that "allows a multifaceted approach to taonga tuku iho, animating the treasure and bringing it to life". ${ }^{115}$ The method has its limitations when applied to the living Kohangapiripiri trees which, unlike many portable treasures, are not known to be named after a specific ancestor and, because they are literally rooted in the ground, have no known history of mobile tribal or familial circularity and the layers of stories that would result from this. They do, however, possess a rich biography of materials. As living treasures, taonga retain the mauri (life force) of the materials from which they are made. ${ }^{116}$ Tree carvings, therefore, retain the mauri of the host trees whose whakapapa stretches back in time via the people who first introduced karaka to Wellington from the north of New Zealand to the creation myth of Ranginui (Sky Father and husband of Papatūānuku) and Papatūānuku (Earth Mother and wife of Ranginui) and Tāne Mahuta (god of the forest and birds, and son of Ranginui and Papatūānuku) who separated his parents. The Kohangapiripiri trees reach forward in time, too: from their introduction to the area; through nineteenth-century Pākehā settlement; the 'sale' of land under the Port Nicholson Deed; the subsequent deforestation and farming of the area; ongoing human and natural threats to their survival; 'discovery' of their carvings; twenty-first-century

\footnotetext{
${ }^{113}$ Cited in Port Nicholson Block Settlement Trust and Greater Wellington Regional Council, "Parangarahu Lakes Area Co-Management Plan.” 25.

${ }^{114}$ Ngarino Ellis, "Te Ao Hurihuri O Ngā Taonga Tuku Iho: The Evolving Worlds of Our Ancestral Treasures," Biography 39, no. 3 (2016). 443.

115 Ibid. 444.

116 Ibid. 445.
} 
acknowledgement through an act of Parliament; to their contemporary role in the cultural revitalisation of the Parangarahu Lakes Area. Shifting between worlds, Ellis writes, "along with the shifting of ancestors and generations, is a challenge for many to conceptualizetracing tidy genealogical lines of descent and matching them up to time periods is impossible". ${ }^{117}$ The findings of archaeologists who have studied the Lake Kohangapiripiri Dendroglyph Trees, as described above, are largely inconclusive and the dates they provide are somewhat contradictory. Read together, however, they form a heritage biography of their own that firmly links the trees with people and place.

Like the Anthropocene Grove ('trees as heritage'), the Dendroglyph Trees ('heritage as trees') present heritage itself as an inalienable possession rich in history and symbolism. The primary value of inalienability, Weiner states, lies in "the power these objects have to define who one is in a historical sense". 118 "The object acts as a vehicle for bringing past time into the present, so that the histories of the ancestors, titles, or mythological events become an intimate part of a person's present identity. To lose this claim to the past is to lose part of who one is in the present." 119

\footnotetext{
${ }^{117}$ Ibid. 446.

${ }^{118}$ Weiner, "Inalienable Wealth.” 210.

119 Ibid.
} 


\section{CHAPTER FIVE: CASE STUDY DISCUSSION}

\section{Introduction}

This chapter is a cross-case analysis of the three cases studied - the Cyberforest, the Anthropocene Grove and the Dendroglyph Trees. Some conclusions specific to the three discrete case studies have already been drawn and spelt out within chapters Two, Three and Four, which are self-contained research entities. Case study research is not sampling research and, in order to understand the contemporary function of the three cases, the individual development of each case has been studied in isolation of the others. ${ }^{1}$ This chapter does not deal with the cases on an individual basis as previously, however, but builds on the evidence of chapters Two, Three and Four in a cross-case analysis.

My literature review examines the concept of the AHD and discusses in depth its characteristics, in particular, of monumentality, time depth, expert judgement and listing. It identifies notions of otherness, agency, intangible natural heritage, affective nature and the ethical mindfulness turn plus a counter-AAHD approach (UAHD) as useful means of reconsidering New Zealand's arboreal heritage. ANT has provided an appropriate theoretical perspective for my discussion of relationships between human and non-human actants and for determining the agency exhibited by karaka in the case studies. In order to test my differentiation of AAHD and UAHD this chapter discusses the differences and similarities between the cases and considers them in relation to seven 'domains' - clearly defined areas of knowledge extrapolated from the data and applied here specifically to arboreal heritage, rather than heritage in general - which are not intended to evaluate arboreal heritage but to provide a platform for discussion. They are:

Species specificity

Origins (cultural or natural)

Agency

Authenticity (claims to)

Social and political change

Monumentality

Materiality

My decision to focus on one tree species for this study is a response to the need for boundedness in the research. I consider that a multiple case study of a number of different

\footnotetext{
${ }^{1}$ Robert E. Stake, The Art of Case Study Research (Thousand Oaks: Sage Publications, 1995). 8.
} 
species is too diffuse and can result in a proliferation of diluted data that demonstrates much uniqueness of the cases but little commonality. On the other hand, concentrating on a single species poses the risk of too much commonality and little uniqueness but, in the event, has turned out to be surprisingly apposite. Inevitably some intersections in the case studies have occurred as the result of the research focus on a single tree species as sole representation of arboreal heritage, however, these have not proved to be as predictable or as wholesale as one might expect. Table 6 summarises the data of this cross-case analysis.

\section{Species Specificity}

Species specificity refers to the properties that are characteristic to a particular species and differentiate one species from another. Botanical references to karaka customarily note the form of its foliage, the presence and traditional use of its fruit, its estimated height and its tolerance of coastal conditions as properties that distinguish the species and, therefore, are part of that particular tree type's specificity. The Māori name 'karaka' refers to the tree, the fruit and the fruit's orange colour. As demonstrated in previous chapters, karaka's fruit has been an important source of food for Māori who have traditionally nurtured it in cultural groves and deliberately distributed it through a large part of New Zealand. This characteristic of food provision, therefore, is one trait that might be anticipated to resonate throughout the study as an ingredient of the tree sites' 'heritageness'. As noted in Chapter Four, few other New Zealand indigenous plants can claim to be domesticated by the first Māori arrivals when faced with a climate unsuited to growing their customary tropical food plants. Despite this fact, which might elevate karaka as a tree with inherent heritage qualities and considerable agency, karaka as food for human consumption features in only two of the tree sites studied here and can be assumed in a third.

The first is the Cyberforest's Palmerston North tree site where the interpretation panel explains that the conserved grove provides physical and spiritual links with the history of the Rangitāne people and once provided them with food and shelter. Native plants in the gardens outside the grove have been selected in order to illustrate the historic relationships of Māori with plants. However, this connection with karaka as human food is not confined to the contemporary interpretation of the heritage grove. Prior to the refurbishment of the site, the original pou that marked the grove since 1984 was in the style of a pātaka (storehouse). These old and new, written and figurative representations of karaka as a food source contrast with the identified properties of the other two karaka tree sites registered in the Cyberforest. It 
was the stature of the tree and its fecundity rather than any culinary potential that earned the New Plymouth tree its early place in the Register. As Allan remarked, when sizing it up in 1940, the tree was "a magnificent specimen fruiting freely". The Te Awanga karaka is listed as part of an indigenous tree collection of note for its unconventional suburban character rather than the stature or fruiting capability of the tree. Of the three Cyberforest tree sites only the Palmerston North entry refers directly to karaka's potential as food for humans.

The second tree site that acknowledges the human-food property of karaka-albeit metaphorically - is the Anthropocene Grove. Initially intended to provide Taranaki Wharf with a sense of historic Māori presence by means of a figurative orchard, the grove mustered further layers of meaning with the arrival of the Kupe sculpture and the commandeering of the image of karaka-as-food by neighbouring Te Raukura in both the naming of its café and its promotional texts. An associated representation of karaka as food is derived from the seemingly random placement of single karaka trees on the bank of nearby Whairepo Lagoon as though distributed by kererū that have feasted on the Taranaki Wharf orchard.

The third tree site that has connections to karaka's ability to provide food for humans is on the opposite side of Wellington Harbour where the two Dendroglyph Trees are distinguished primarily by their human-generated carvings. The evidence presented in Chapter Four, however, establishes their environs as a traditional berry-harvesting area. Adkin noted in 1959 that a single carved karaka was located in one gully while dendroglyphs were observed in the "rather widely spaced group of four karaka trees in the adjoining gully" suggesting that the trees at one time could have been part of a larger grove. ${ }^{2}$ The flourishing karaka groves at neighbouring Lake Kohangatera are described in archaeological records as cultural, and archaeological evidence of settlement at Parangarahu combined with the exposed situation of Fitzroy Bay, which poses serious challenges for the cultivation of most other crops for food production, suggest that further karaka orchards could have been planted before the area was farmed and the land grazed. This data suggests that while it is not determined that they have been purposefully planted the two trees are closely related to what was known traditional karaka orchard practice.

\footnotetext{
${ }^{2}$ Maori Notebook (vol. 44).
} 


\section{Origins (Cultural or Natural)}

A second feature of karaka's production of fruit is its suitability as nourishment for some birds and the tree's consequent conscription of kererū as a willing agent of seed distribution. This means of colonising has led to much speculation among archaeologists as to whether the groves being investigated are of cultural or natural origin. ${ }^{3}$ Of the five heritage tree sites under the microscope here the Palmerston North site is formally interpreted as being of cultural origin (derived from an original circa 1800 planting), and the Te Awanga site and the Anthropocene Grove are known to be planted by human hands in the twentieth century (circa 1950 and 1999 respectively). However, as pointed out above, whether the two Dendroglyph Trees are of natural or cultural origin is not accounted for as part of their heritage significance, which relies instead on the cultural practice of tree carving, but they are closely associated with neighbouring karaka of presumed cultural origin. The New Plymouth site's entry in the Cyberforest makes no mention of whether the tree is of natural or cultural origin and, presumably, is thought to be part of original indigenous forest of the area. An unattributed and undated chronology of Brooklands Park provided to me by the NPDC refers to "age-old bush"; and includes an 1896 quote describing "a backdrop of original bush" in the area occupied by the karaka. However, it also notes that there was a "Maori clearing" in the centre of the block of land at the time of its purchase by ballot in June 1842 but makes no mention of any karaka groves. Governor General Lord Bledisloe when opening Brooklands Park in 1934 reportedly referred to its "magnificent environment of pure native bush" 4 and the guide to the park hints at the tree's venerable age, describing the karaka as "one of the biggest recorded in New Zealand". 5

Considered together these findings related to karaka as food for humans and for birds, as illustrated by the five tree sites, demonstrate that arboreal heritage is largely defined in terms of its cultural significance despite its obvious affiliation with nature. Three of the tree sites have attained heritage status on the grounds of their cultural origins (Palmerston North, Te Awanga and Anthropocene Grove); and one on its cultural modifications and association with traditional practice (Dendroglyph Trees). The remaining site (New Plymouth) while generally

\footnotetext{
${ }^{3}$ Although kererū are known to be the dominant avian consumers of karaka fruits they are not the only providers of its seed transport in this area. Ornithologist David Medway reports that blackbirds (Turdus merula) also distribute karaka by carrying whole fruit in their bills and consuming the flesh in a safer environment. David Medway, "Karaka Fruits as a Source for Birds in Pukekura Park and Brooklands," Magazine of the Friends of Pukekura Park 5, no. 3 (2010). 12.

4 “Gift to Citizens: New Plymouth Reserve: Opened by Lord Bledisloe," Auckland Star, 12 March 1934.

${ }^{5}$ Ron Lambert, Pukekura Park and Brooklands: A Guide to Walks (New Plymouth: Puke Ariki, 2007$) .29$.
} 
perceived to be arboreal heritage of natural origin is noted as originating in land modified by Māori in the early nineteenth century.

\section{Agency}

In association with and in contrast to the preceding discussion is the topic of the non-human agency (rather than cultural determination) exercised by karaka itself —or the tree's part in what Pollan calls the "coevolutionary drama" that links humans and non-humans to the betterment of both. ${ }^{6}$ This moves the discussion into the territory of Latour's actor network theory and ways of understanding how nature and society - in this case specifically nature and heritage - relate. In an ANT world 'actants' mediate in order to make others do things. ${ }^{7}$ In the world of arboreal heritage, as demonstrated in this section and discussed in preceding chapters, karaka assumes many roles as a non-human mediator within both formal and domestic assemblages, and of both tangible and intangible heritage. As already described, these mediating activities include the species' ability to ensure its distribution and continuance by means of its fruit as human sustenance and bird fodder and through its employment of another non-human actant in the form of the alimentary canal of kererū. Previous chapters have highlighted complex examples of the forging of mutualistic karakahuman relationships by virtue of the species' cosmogonic and mythical values, its aesthetic and affective properties, its endemicity, its adaptability to environments beyond its natural range and its ability to flourish in tough coastal conditions, all of which have contributed to its utilisation and place in arboreal heritage.

The agency of the natural component in any heritage assemblage is often overlooked but in this consideration of the values, meanings and understandings attached to arboreal heritage the notion is very relevant. It is important to reiterate here that understanding the machinations of arboreal heritage requires a move away from the idea that human agency is "separate, privileged and ontologically unique" and to acknowledge that trees exercise their own peculiar form of agency within a symbiotic relationship. ${ }^{8}$ It is worth noting here as well that the fact that the five tree sites are included in this study of arboreal heritage demonstrates at first hand that none of them is made up of passive entities. First, all the tree sites have earned their places as arboreal heritage by exercising their own peculiar tangible and

\footnotetext{
${ }^{6}$ Pollan, The Botany of Desire.

${ }^{7}$ Latour, Reassembling the Social. 107.

${ }^{8}$ Jones and Cloke, Tree Cultures. 54.
} 
intangible qualities; cementing themselves as part of the mental landscape and architecture of each space, be it formal, domestic or wild. Second, considered together the five tree sites mediate to form a single non-hierarchical natural landscape, as advocated by Cronon, that includes the city, the suburb and the wild. ${ }^{9}$ Third, equally with humans, to borrow from Jones and Cloke once more, and taking an ANT perspective, the sites are "embedded in a vast range of cultural, social, technological and economic networks". ${ }^{10}$

The first section of this chapter describes species specificity as referring to properties that are characteristic to a particular species. This study of the five tree sites demonstrates that they can exhibit agency independent of their species specificity - as individual agency as distinct from their more typical collective agency. Individual agency is demonstrated by two of the tree sites included here. The New Plymouth tree site has secured its place in the Cyberforest by means of its impressive longevity and stature, rather than its peculiar karaka characteristics. While these attributes have ensured it a measure of human protection as arboreal heritage within the context of Brooklands Park they do not distinguish this karaka from a tree of any other species that is of similarly admirable age, height and breadth. ${ }^{11}$ It is its individual agency, rather than its collective agency shared by the species, that has enabled this tree site to be part of the Cyberforest where, in reality, it engages in vigorous replication, as demonstrated by the crowd of saplings and mature trees that have sprung up around it and reinforced by Allan's remark of 1940 that it was "fruiting freely". The Te Awanga karaka in its domestic situation provides a further example of individual — but tenuous — agency as a member of a group of indigenous trees rather than as karaka per se. Along with two pōhutukawa and single pūriri, tawhai, rewarewa and kahikatea trees the karaka has entered the Cyberforest as a native tree and could be replaced by any other karaka without disturbing the heritage value of the group. There is little opportunity here for the karaka to make more copies of itself given the densely populated suburban nature of its context and the constraints imposed on it by both the occupants of the neighbouring property and the rules of its local council.

\footnotetext{
${ }^{9}$ Cronon, "The Trouble with Wilderness."

${ }^{10}$ Jones and Cloke, Tree Cultures. 54.

${ }^{11}$ A neighbouring pūriri in Brooklands Park is noted in the park guide as "one of the largest of its species in New Zealand" and was estimated in 1913 to have been approximately two thousand years old. Lambert, Pukekura Park and Brooklands. 29.
} 
Of the five heritage tree sites studied here, it is the Palmerston North grove, the Anthropocene Grove and the Dendroglyph Trees that exhibit collective agency primarily through the species' ability to provide food which in turn ensures their protection and continuance by humans for mutual benefit. Significantly these are also the tree sites most closely linked to Māori tradition and history which are connected through relationships with land. As noted in the Introduction, while the land has special meanings for both Māori and Pākehā and provides each people with a sense of belonging and a sense of place these values do not take the same shape. The intertwining of nature and the land within a shared whakapapa and the stitching of heritage into the landscape are part of Māori tradition and contemporary Māori life. These values are highlighted by the various pou of the Palmerston North tree site, the stewardship of the Dendroglyph Trees by Taranaki Whānui and the inclusion of the Anthropocene Grove in the narrative of Te Raukura. The essentially Pākehā "progressive pioneer tradition", on the other hand, that has laid waste in the past to much of the country's indigenous forest and is alive and well in today's urban intensification establishes 'belonging' and 'place' by means of modification (an action more consequential than the importation of trees from northern New Zealand), and is unlikely to ascribe agency to trees that might be in the way. ${ }^{12}$ Nor is it likely to acknowledge karaka's robust viability as anything other than the characteristic of a weed.

Jones and Cloke argue that contemporary understanding of the relationships between nature and culture recognises that "nature is not merely inscribed upon by human culture and practice. Rather, nature 'pushes back' with its own vitality which is manifest in specific material processes". ${ }^{13}$ As demonstrated by this discussion of the agency of karaka all of the five tree sites studied here "push back" in some way to establish themselves as arboreal heritage. What was not expected until this cross-case analysis determined the sites' similarities and differences was that these purposive actions could be defined as either individual or collective. Nor was it previously realised that within this thesis, focused on karaka, collective agency and individual agency could be directly related respectively to Māori and Pākehā relationships with land.

\footnotetext{
12 Byrnes, Boundary Markers. 2.

${ }^{13}$ Jones and Cloke, Tree Cultures. 6.
} 


\section{Authenticity}

Another thread that weaves through the cases studied here is the slippery heritage term 'authenticity' which theorists tend to replace with notions such as "actualities and virtualities" ${ }^{14}$ or bury within discussions of "performance and performativity ${ }^{15}$ or demote to the everyday as in "almost everything shows elements of authenticity". ${ }^{16}$ Despite this trend of authenticity reductionism in the heritage discourse, the presence or absence of authenticity can be of genuine interest to visitors who are curious to know whether or not the material/the style/the place/the function of the heritage site they are viewing is actually 'real'. ${ }^{17}$ West defines authenticity as "a measure of the extent to which a thing might be considered to be the remains of the original" and which carries an ethical connotation that differentiates it from "“fake' or 'sham', both of which assume deception". ${ }^{18}$ Rather than discussing whether or not the heritage tree sites in this study are authentic, this section considers how the three cases, on their own behalf, lay claim to authenticity or some "remains of the original".

The Anthropocene Grove which, on the surface, appears to be a very inauthentic heritage site, as a group of nursery-raised trees planted at the very cusp of the current millenium on reclaimed land, in fact, tries very hard to assemble some authentic attributes to achieve the "veneer of pastness" expected of a heritage site. ${ }^{19}$ The trees are eco-sourced, from (possibly) cultural karaka orchards in the vicinity, as is the aggregate in which they grow, and karaka is a customary tree in many of Wellington's coastal settlements. Visitors to Taranaki Wharf, who are unfamiliar with native flora, can confidently assume that the karaka are authentically indigenous trees because they also appear in Te Papa's outdoor exhibition Bush City ${ }^{20}$ to the east and at Whairepo Lagoon to the west and because they are a comfortable aesthetic fit in their location between the Kupe sculpture and Te Raukura. Observers who recognise the grove's trope of orchardness might recognise the limbing up of the trees for practical reasons and the initial replacement of the few young trees that were unsuccessful as examples of authentic orchard practice.

\footnotetext{
${ }^{14}$ Kirshenblatt-Gimblett, "Theorizing Heritage.” 375

${ }^{15}$ Crouch, "The Perpetual Performance and the Emergence of Heritage." 57.

${ }^{16}$ Howard, Heritage. 226.

${ }^{17}$ Goldsmith, "Turning over Old Ground." 82-83.

18 West, Understanding Heritage in Practice. 313.

${ }^{19}$ Graeme Davison, "Heritage: From Patrimony to Pastiche," in The Heritage Reader, ed. Graham Fairclough, et al. (London: Routledge, 2008). 32.

${ }^{20}$ https://www.tepapa.govt.nz/visit/whats-on/exhibitions/bush-city. Accessed 18 July 2017.
} 
The Dendroglyph Trees, on the other hand, have no need to expend energy proving their authenticity in order to ensure heritage recognition. As the hosts of perceived dendroglyphs of considerable age they enjoy statutory acknowledgement and guaranteed protection as cultural redress despite the aura of mystery surrounding the origins of the carvings. While the two trees are indisputably old and sited in an archaeologically authenticated place of early Māori settlement their actual age has not been officially established. Knowing how old the trees are could be the key that unlocks the mystery of whether or not the carvings were made by Māori, when they were executed and what their purpose might be. However, although archaeologist Justin Maxwell is keen to determine the trees' age by core sampling, ${ }^{21}$ Taranaki Whānui have so far resisted any such action which they believe might threaten the health of the trees for which they are kaitiaki. ${ }^{22}$ Possessing heritage is a civil right as is the right to determine the form that it takes ${ }^{23}$ and in considering the Dendroglyph Trees' claims to authenticity it is important to remember their social and political context. As detailed above, the Waitangi Tribunal awarded Taranaki Whānui the beds and esplanades of lakes Kohangapiripiri and Kohangatera and the two Dendroglyph Trees as cultural redress for many years of suffering through devious land deals. Within Wellington's broad cultural landscape of history and heritage, whether or not the markings on the trees are authentic seems a very minor detail.

A discussion of authenticity of another kind arose during a meeting of Te Roopu Tiaki at which I was invited to present an account of my research into the Dendroglyph Trees. ${ }^{24}$ The dialogue which followed my presentation veered off into a consideration of further tree planting in the area and prompted a question from a Te Roopu Tiaki representative to a GWRC representative as to whether or not the council planned to plant more karaka. The answer 'no' came swiftly and unequivocally as karaka, he pointed out, was a weed and not part of Parangarahu's biodiversity, that is, not considered to be authentic indigenous flora of the region.

\footnotetext{
${ }^{21}$ The anatomy of karaka's wood makes it impossible to age the trees by growth rings. Burstall and Sale estimated that a Hawke's Bay karaka was "more than 500 years". Burstall and Sale, Great Trees of New Zealand. 134. Leach and Stowe recorded in 2003 that a tree on Lady Alice Island in the Hen and Chicken Islands, "may be older than 600 years". "Corynocarpus laevigatus (Karaka)," Centre for Agriculture and Biosciences International, http://www.cabi.org/isc/datasheet/59069. Accessed 24 July 2017.

${ }^{22}$ Meeting with Te Roopu Tiaki, 25 May 2017.

${ }^{23}$ Eriksen, From Antiquities to Heritage. 149.

${ }^{24}$ Meeting with Te Roopu Tiaki, 25 May 2017.
} 
Neither the Anthropocene Grove nor the Dendroglyph Trees can approach anywhere near the heights of self-proclaimed authenticity boasted by the Cyberforest and manifested in its register. Any list, by asserting its right to select and reject, presents its contents as incontestable and its methods as unquestionable. Selected and maintained by experts employing an objective system based on set criteria the New Zealand Tree Register, along with its local government clones, exerts a hegemony of expertise that rebuts any accusations of 'fake' or 'sham'. There is, however, a hint of 'deception' attached to the Cyberforestthough not through any contemporary intention of its own. This is derived from the Register's historical mission to protect trees by means of listing them in an 'official' list and has persisted through the misconception of the general public that once a tree is listed it will be protected, despite NZNTT's admission that its primary purpose is one of collection rather than protection. ${ }^{25}$ There is also an element of bluff in the Register's name which claims national breadth and depth but whose selection process, in the light of the analysis in Chapter Two, is dependent on local involvement, remains tethered to its original categories of size, age, rarity or association with someone/something famous - "the usual suspects" of the $\mathrm{AHD}^{26}$ - and records significantly more exotics than natives. There is no room in the Cyberforest for the Anthropocene Grove or the Dendroglyph Trees and, despite Burstall's documented observations, Rēkohu's carved kōpi or any other trees do not appear in the list. ${ }^{27}$

\section{Social and Political Change}

One striking link between all three cases studied here is their independent evolution from various networks of social and political change. The Cyberforest traces its origins to a government-sponsored national conference aimed at mitigating the effects of both historic and contemporary indigenous forest clearance on the environment and, consequently, the economy of the country. It grew as the flagship of the RNZIH's persistent lobbying as it struggled to secure government support for the protection of what the institute believed best represented the country's tree heritage. It was the introduction of the RMA in 1991 that relieved the RNZIH of its responsibility to secure the protection of trees—by passing the

\footnotetext{
${ }^{25} \mathrm{http} / / /$ www.notabletrees.org.nz. Accessed 28 June 2017.

${ }^{26}$ Smith, Uses of Heritage 11.

${ }^{27}$ Burstall's 1973 mensuration report notes, "Karaka (called kopi in the Chathams) was formerly common in this forest type and was the favoured species for the tree-carvings of the original Polynesian inhabitants. The carvings can still be seen in some places". S. W. Burstall, "Forest Mensuration Report No. 22 Historic and Notable Trees of New Zealand: North Canterbury, South Canterbury and Chatham Islands" (New Zealand Forest Service, Forest Research Institute, 1973 [unpublished]). 53.
} 
conservation baton to local authorities - and enabled it to concentrate on documenting a collection of trees considered important and, finally, establishing its Cyberforest.

The Anthropocene Grove germinated from a heady brew of challenge and destruction including the nineteenth-century suppression of Te Aro Pā and the twentieth-century demolition of historic buildings, a stock market crash, and vigorous battles between community groups, developers and the local council. The case study demonstrates how the Local Government Act 1974 then the Town and Country Planning Act 1977 enabled communities to have a far greater say in local affairs through public consultation and the right of individuals and groups to object to planning applications. Most significant to the later development of the Anthropocene Grove was the Town and Country Planning Act's directive to local authorities to acknowledge a new assemblage of culture, traditions and relationships of Māori with their ancestral land, a principle reflected in the 1991 RMA and in the Wellington CCC's 1996 report that underpinned the Taranaki Wharf development and is now ingrained in public planning policy.

Parliamentary recognition of the Dendroglyph Trees as historic heritage is founded on the nineteenth-century inglorious acquisition of land from Māori by the New Zealand Company and the failure of the Treaty of Waitangi to protect Taranaki Whānui from extortion and social and economic exclusion. The Dendroglyph Trees' roots run deep in political soil and in its 2008 deed of settlement with Taranaki Whānui the government acknowledged and apologised for breaching the obligations it had undertaken one hundred and sixty-eight years earlier.

\section{Monumentality}

Throughout the research for this thesis the phrase 'natural monuments' has served as its working title. Borrowed from Sanderson's 1940 plea for the protection of trees as "natural monuments" of a "biological nature" it smacks of an old-world appeal that contrasts neatly with the digital form of the Cyberforest which was the first case study under examination here. With the development of the next two case studies, the Anthropocene Grove and the Dendroglyph Trees, the working title, rather than seeming anachronistic when applied to further twenty-first-century matters, took on new depth and resonance as the work became progressively focused on the employment of trees as representations of heritage. The phrase 'natural monuments' has gained its faded charm because the term 'monuments', like 
'antiquities', 'vestiges' and 'relics', has been supplanted by the contemporary, more generalised term 'heritage'. ${ }^{28}$ The title of this thesis with its sub-title, 'rethinking arboreal heritage for twenty-first-century Aotearoa New Zealand', describes the temporal scope of the research that takes in nineteenth-century background, twentieth-century activities to protect 'natural monuments' and progresses to a close reading of arboreal heritage as it is perceived today. The term 'monumentality' is used here in accordance with Loukaki's definition as a social construct that provides "symbolism and abstraction, stimulation of the imagination of social agents, narrativization of the human experience and mythopoesis". ${ }^{29}$ This section considers each of the tree sites independently exploring the concept of trees-as-monuments and asking the question 'monuments to what or to whom?

In the Cyberforest the spare prose of the Register, with its devotion to measurements, location and categorisation and with the constraints of its taxonomy and matrix, affords little room for a detailed discussion of a tree's symbolism or mythopoesis. However, where a tree is known to have been associated with a person or an event from the past its commemorative value is narrated in the section titled 'general notes'.

The Palmerston North grove whose monumentality has been ensured by layers of heritaging actions, beginning with its early protection from farm activities, followed by the erection of a commemorative pou and culminating in the refurbishment and interpretation of the site, is described briefly in the notes of its register entry as being "of significance to the Manawatu region", "established by local tribes to provide a food source" and "the site of Maori conflict prior to European settlement". The Cyberforest lists the approximate planting date of the grove as 1800 which projects back not to its later protection from farm activities as a powerful living monument to both people and a dramatic event but to its practical domestic use by iwi for food and shelter, thereby highlighting, what Riegl describes as, its "age value", ${ }^{30}$ and its association with tradition, and grounding it in deep time.

The entry for the New Plymouth tree notes no such association with people or events, relying instead on its spatiality and temporality for its inclusion in the Register. The tree was first officially observed in 1969 by Burstall and Fuller who recorded no estimate of its age. With

\footnotetext{
${ }^{28}$ Eriksen, From Antiquities to Heritage. 2.

${ }^{29}$ Loukaki, Living Ruins, Value Conflicts. 47.

${ }^{30}$ Riegl, "The Modern Cult of Monuments."
} 
no approximate date hazarded since — although Burstall referred to it later as "a veteran karaka"-its presumed antiquity is concomitant with its considerable size and the history of Brooklands Park. ${ }^{31}$ The Cyberforest's aerial photograph locates the tree deep in dense native bush in a corner of the park and the entry reveals that there were difficulties measuring the height of the tree with a clinometer but, nevertheless, records it at 21 metres with a crown spread of 22 metres in 2010. The measurements demonstrate that this is a giant karaka: ${ }^{32}$ but these are virtual numbers and the tree's impressiveness as a monument to stature and longevity is communicated only in actuality. The true expansiveness of the New Plymouth tree is defined not only by itself but also by its relationship with its context which can be experienced only in person-its neighbouring trees are equally towering and exuberantly healthy but with none of the capaciousness of the two massive trunks and the vastness of the leafy canopy boasted by the registered tree. With all the boxes ticked for measurements, location and categorisation and no association with a person or event to be acknowledged the entry's general notes describe the tree site in Burstall's sober words of 1973 as "a healthy colourful tree".

The third and youngest karaka in the Cyberforest is the only intentional monument in this group. Like the New Plymouth tree, the Te Awanga tree lacks historic associations and relies on spatiality defined by its context to achieve monumentality. As part of a bold, out-ofcontext, suburban statement, the Te Awanga tree is a domestic monument to indigeneity. Defiantly breaking the rules of suburbia — where no tree should shade or shed excessively or interfere in any way with the neighbouring property - the tree is a privately devised abstraction of native forest flourishing on highly modified land. No reference is made in the Register to why the tree site is there, its relationship to its owners or what effect its presence might have except to categorise it as 'notable tree-local interest'. All the required details are provided in the entry, the aerial photograph situates the tree site in its suburban setting and the general notes record the various species included in the group.

Liberated from the limits imposed by registration and digitisation the remaining two casesthe Dendroglyph Trees and the Anthropocene Grove-assume different characteristics of

\footnotetext{
${ }^{31}$ Burstall and Sale, Great Trees of New Zealand. 144.

${ }^{32}$ For purposes of comparison: Metcalf, Salmon and Cave and Paddison describe karaka as a medium-sized tree growing up to 15 metres tall. Metcalf, The Cultivation of New Zealand Trees and Shrubs. 104; Salmon The Native Trees of New Zealand. 227; The Gardener's Encyclopaedia of New Zealand Native Plants. 197.
} 
monumentalism. Unlike the Cyberforest, these two cases show no interest in measurements and experience of them can only be real rather than virtual.

Whether the Dendroglyph Trees conform to Riegl's definition of 'intentional' monuments (the carvings have symbolic meaning) or 'unintentional' monuments (the carvings are pictorial rather than symbolic or are merely marks generated by natural causes) is unclear. Regardless of this uncertainty, however, they are secure in their heritage value. In understanding the significance of the two trees, it is important to recognise that they are located near other groves of karaka assumed to be of cultural origin at Lake Kohangatera but not included in the Cyberforest. What sets them apart from these neighbours is their additional layer of cultural capital, that is their ability to connect people with the past, which is inherent in the carvings and is the reason for their preferential treatment. It is important to remember too that the tree carvings existed before Adkin's 'discovery' of them in 1959 and before they became part of the Waitangi Tribunal settlement package. As part of twenty-firstcentury cultural redress, as much as signifying arboreal heritage, the trees represent a contemporary need to identify heritage in order to define and strengthen the group to which it belongs. Consequently, the two trees play an unassailable role as monuments that commemorate both the people who affiliate to them and the traditions of their shared past.

The Anthropocene Grove also commemorates people and events but in a very different public, manufactured and contemporary form. Like the Te Awanga site the grove is a youthful, intentional monument to indigeneity_-but this time to human indigeneity rather than the arboreal kind. Its purpose is to represent past Māori presence in a contemporary urban setting in a carefully crafted and aesthetically pleasing way. When initially planted the grove contributed a 'green' aspect to Taranaki Wharf that otherwise paid homage to the built monuments of Pākehā industry or maritime history. With Kupe Group, Te Raukura, the forecourt ātea and Toenga o Te Aro, the grove today tells a chapter of the narrative about traditional Māori culture and presence, transition and change which is continued by exhibitions inside neighbouring Te Papa.

\section{Reliance on Materiality}

One question that arose in my literature review was whether or not a tree's heritageness relied on its materiality. It's a complex question when applied to living entities that are destined to grow and literally die of either natural or unnatural causes. The 3D-scanning of the Rēkohu 
trees with the subsequent ascription of taonga status to the resultant images and the digitisation of the New Zealand Tree Register suggest that to some degree materiality is not essential to their heritage existence - at least in a virtual sense. A similar argument could be put for a library or museum catalogue where articles and artefacts can be viewed online. The sense of touching or seeing the real thing or being in the actual place, as described in the 'Being There' sections in this thesis, both by myself and by the invited participants, and alluded to above in relation to monumentality, contributes to an emotional and sensory experience that cannot be replicated on a screen. The question might be better rephrased: 'does heritageness rely on the living materiality of the trees?'

Certainly, the Cyberforest's New Plymouth tree as heritage relies completely on its living presence in Brooklands Park. As described above, the heritageness of this tree site is inherent in its spatiality and (associated) temporality. Some of the neighbouring karaka may appear to be as tall but none has the heft of the double trunk form or the magnificent span of the registered tree's canopy: none achieves the stature that earned it an early place in Allan's 1940 list. The Te Awanga karaka, however, makes a different claim to its heritageness. Rather than relying on temporality or spatiality and without any known association with a noteworthy event or person, the tree banks on its performance as part of a small, daring indigenous forest in a suburb to ensure its continuing existence. It is the species of tree and its indigeneity, rather than the particular tree itself, that determines the heritageness of this group of trees. Accordingly, the existing tree could be cut down and replaced by the same species planted in the exact space and the heritageness of the tree site, as experienced today, would remain intact and its living materiality would be transferred. The relationship between materiality and heritageness at the third tree site in the Cyberforest is more complex. The Register records the establishment date of the Palmerston North grove as 1800 but none of the trees is singled out as being original. This grove is an extended arboreal whānau. It comprises a gathering of young and old, tall and small karaka that, presumably, share the same DNA which has been passed on for more than two hundred years. Replacement of trees from another source, therefore, would disrupt this family line: the heritageness of the Palmerston North trees is deeply embedded in their materiality and on the place where they grow.

Not so, however, in the Anthropocene Grove. While the karaka on Taranaki Wharf have been locally sourced and are in, but not on, local soil they have nothing of the sense of permanence 
that comes with a spontaneous springing from the earth. While they are clearly living heritage they cannot be defined as purely natural heritage but instead are a form of hybrid heritage which creates its own sense of place and tells its own narrative. If Anthropocene Grove trees die they can be (and have been) replaced from the Wellington City Council's nursery of ecosourced trees and the living materiality of the grove will grow on.

The Dendroglyph Trees, in contrast, are treasured as both physical trees and taonga tuku iho which are qualities that tie them both to the ground they grow on and to the whakapapa and history of the land and their people. These trees cannot be replaced. Their physical form can be scanned and recorded and ascribed a new value as taonga - as has been carried out for the trees of Rēkohu — but their sensory presence on their windswept hillside and their relationship to tangata and whenua and their role as longtime witnesses are unable to be replicated.

All heritage is vulnerable and subject to damage and destruction and the three cases studied here are no exception. Te Roopu Tiaki are especially concerned about the safety of their Dendroglyph Trees in their remote location and as kaitiaki are mindful of their responsibility to hand them on to a future generation. ${ }^{33}$ In parallel with the duties of kaitiakitanga is Taranaki Whānui's anxiety about the implications of improved access for kaumātua (elders persons of status) and the introduction of interpretation which might either protect the trees through visitor knowledge or attract vandalism by drawing attention to them. Paradoxically it is the urban location of the Anthropocene trees that might lead to damage not only through potential vandalism but also through change of use. During most weekdays Odlins Plaza is a pedestrian route between the city and Te Papa but in weekends, some evenings and during holidays it is a preferred location for festivals, fan-zones, a temporary ice-skating rink and commercial displays. As a result, the karaka grove becomes incidental to the main activity and is frequently obscured by temporary shipping containers, signs and hoardings. As a person-made place of leafy heritage the Anthropocene Grove is dependent on the whim of the city and, just as it grew out of social and political change, it could equally fall out of favour if its original purpose no longer had contemporary relevance and it found no champions of its sheltering and aesthetic values. Of the three cases, the Cyberforest is the least subject to mortal change. Despite the removal of the Te Awanga tree from the HDC's list of 'outstanding trees' and the disappearance of the New Plymouth tree from the NPDC's list of

\footnotetext{
${ }^{33}$ Meeting with Te Roopu Tiaki, 25 May 2017.
} 
'notable trees' the karaka themselves remain materially alive for now and the existence of all three tree sites in digital form is guaranteed in perpetuity for the life of the Cyberforest. ${ }^{34}$

\section{Conclusion}

The purpose of this cross-case analysis is to identify intersection and divergence of the three cases and to use this evidence to determine their distinctive characteristics and their relationships with the AAHD and the UAHD. In Chapter Two I have argued that the Cyberforest is positioned within the AAHD primarily by virtue of its nomination and topdown evaluation and selection processes which began informally with Allan's early lists and are now formalised within the digitised New Zealand Tree Register. In contrast I have presented the Anthropocene Grove and the Dendroglyph Trees as being situated within the UAHD as the products of hybrid forums of decision-making and idiosyncratic processes of heritaging. This chapter has analysed the cases according to seven domains of arboreal heritage, and Table 6 summarises the results. A ticked box signifies that the tree site possesses the required characteristics to qualify for a place in the domain. Boxes marked 'by default as Cyberforest' indicate that the Cyberforest case study itself qualifies for the appropriate domain according to the discussion above and, therefore, the embedded tree sites qualify by association.

\footnotetext{
${ }^{34}$ Some other trees on record in the Cyberforest no longer exist. http://www.notabletrees.org.nz. (Accessed 28 June 2017). Flook's intention in the 1994 forerunner to the Cyberforest was to remove dead trees but retain trees "vandalised or killed by malpractice" as reminders of "the vulnerability of our great New Zealand trees". Flook, An Introduction to the Notable Trees of New Zealand. 8.
} 


\begin{tabular}{|c|c|c|c|c|c|c|c|}
\hline Tree sites & $\begin{array}{l}\text { Recognition of } \\
\text { species } \\
\text { specificity }\end{array}$ & $\begin{array}{l}\text { Origins } \\
\text { (natural/ } \\
\text { cultural) }\end{array}$ & $\begin{array}{l}\text { Recognition } \\
\text { of agency } \\
\text { (collective/ } \\
\text { individual) }\end{array}$ & $\begin{array}{l}\text { Claims to } \\
\text { authenticity }\end{array}$ & $\begin{array}{l}\text { Evolution } \\
\text { from social/ } \\
\text { political } \\
\text { change }\end{array}$ & $\begin{array}{l}\text { Monumentality } \\
\text { to what/whom? }\end{array}$ & $\begin{array}{l}\text { Reliance on } \\
\text { materiality }\end{array}$ \\
\hline $\begin{array}{l}\text { Palmerston } \\
\text { North }\end{array}$ & $\sqrt{ }$ & cultural & collective & $\begin{array}{l}\text { By default as } \\
\text { Cyberforest }\end{array}$ & $\begin{array}{l}\text { By default as } \\
\text { Cyberforest }\end{array}$ & $\begin{array}{l}\text { unintentional } \\
\text { Māori and } \\
\text { tradition }\end{array}$ & $\begin{array}{l}\text { (assured } \\
\text { by presence } \\
\text { in the } \\
\text { Cyberforest) }\end{array}$ \\
\hline New Plymouth & & $\begin{array}{l}\text { natural/ } \\
\text { cultural }\end{array}$ & individual & $\begin{array}{l}\text { By default as } \\
\text { Cyberforest }\end{array}$ & $\begin{array}{l}\text { By default as } \\
\text { Cyberforest }\end{array}$ & $\begin{array}{l}\text { unintentional } \\
\text { size and age }\end{array}$ & $\begin{array}{l}\sqrt{\text { (assured }} \\
\text { by presence } \\
\text { in the } \\
\text { Cyberforest) }\end{array}$ \\
\hline Te Awanga & & cultural & individual & $\begin{array}{l}\text { By default as } \\
\text { Cyberforest }\end{array}$ & $\begin{array}{l}\text { By default as } \\
\text { Cyberforest }\end{array}$ & $\begin{array}{l}\text { intentional } \\
\text { arboreal } \\
\text { indigeneity }\end{array}$ & $\begin{array}{l}\text { (assured by } \\
\text { presence in } \\
\text { the } \\
\text { Cyberforest) }\end{array}$ \\
\hline $\begin{array}{l}\text { Anthropocene } \\
\text { Grove }\end{array}$ & $\sqrt{ }$ & cultural & collective & $\begin{array}{l}\text { eco-sourcing } \\
\text { familiarity } \\
\text { association } \\
\text { orchardness }\end{array}$ & $\sqrt{ }$ & $\begin{array}{l}\text { intentional } \\
\text { Māori and } \\
\text { tradition }\end{array}$ & $\sqrt{ }$ \\
\hline $\begin{array}{l}\text { Dendroglyph } \\
\text { Trees }\end{array}$ & $\sqrt{\text { (assumed) }}$ & $\begin{array}{l}\text { natural/ } \\
\text { cultural }\end{array}$ & collective & $\begin{array}{l}\text { cultural } \\
\text { redress }\end{array}$ & $\sqrt{ }$ & $\begin{array}{l}\text { un/intentional } \\
\text { Māori and } \\
\text { tradition }\end{array}$ & $\sqrt{ }$ \\
\hline
\end{tabular}

Table 6: Comparison of tree sites according to core domains of arboreal heritage.

Rather than revealing sameness this cross-cutting of case study research highlights how nuanced arboreal heritage can be. Hitchings' defines ANT as “people, objects, plants, animals and ideas" jostling against each other and shaping society and our understanding of it. ${ }^{35}$ Table 6 demonstrates that the tree sites studied here similarly exhibit 'jostling', and are too lively to be neatly and firmly bundled into one category or another but, instead, can spring out of the taxonomic constraints I have proposed for them to form new and unexpected bonds in an ANT-like manner. In the above section, which discusses the various claims to authenticity made by the three cases, I suggested that as there was no room in the Cyberforest for the Anthropocene Grove or the Dendroglyph Trees it was because the Cyberforest was situated in the AAHD and both the Anthropocene Grove and the Dendroglyph Trees rightfully belonged in the UAHD. Table 6, however, demonstrates that these assemblages are fluid. The Palmerston North tree site, while located in the Cyberforest, has more in common with the Anthropocene Grove and the Dendroglyph Trees than with the other two Cyberforest tree sites and, therefore, might readily find a place in the UAHD. In addition, consideration of the relationship between the Cyberforest's three tree sites and their separate socio-political backgrounds adds further obfuscation to the division of the AAHD and the UAHD.

\footnotetext{
${ }^{35}$ Hitchings, "People, Plants and Performance." 100.
} 
Four of the columns in Table 6, when considered cumulatively, differentiate the Anthropocene Grove and the Dendroglyph Trees as UAHD and enable the Palmerston North Trees to skip across the AAHD-UAHD boundary. First is the column relating to monumentality which demonstrates the focus on people and tradition shared by all three tree sites. These are not measurable qualifications, as required by the intended objectivity of the AAHD, but lie at the heart of the heritageness of the Palmerston North grove, the Anthropocene Grove and the Dendroglyph Trees. Second, the column demonstrating shared species specificity shows a similar human focus in its concentration on the relationship of people with karaka and the tree's ability to provide food and is similarly unable to be quantified. The third differentiation is evidenced by the column that demonstrates karaka's agency. In the AAHD world registration relies on a scale that calculates uniqueness and has no room for the collective nature of agency shown here which, in contrast, sits comfortably within the UAHD. The fourth column that differentiates the AAHD from the UAHD is the one demonstrating the influence of social and political change. While I have written above that all three cases studied here have been influenced by social and political change and I have noted in Table 6 that the three Cyberforest tree sites qualify for a place in this domain by default, a closer examination of the embedded tree sites reveals subtle differences. I have shown how the Cyberforest grew from a twentieth-century concern for the environment and, consequently, the economy of the country and developed through the lobbying efforts of the RNZIH and, notably, the introduction of the RMA. Within the Register, the New Plymouth tree site appears to have been unaffected by any particular political or social influence of its own, earning its place as a result of its standing within its own arboreal sphere as a very large and very old specimen of karaka. Reading between the lines, however, the Te Awanga and Palmerston North sites tell different stories that rely in part on their individual dates of registration.

The Cyberforest records the first observation of the New Plymouth tree site as 1969 but its presence as a registered heritage tree stretches back to the 1940 entry by Allan. The New Plymouth karaka, therefore, appears at the very foundation of the New Zealand Tree Register. In contrast, the Te Awanga site was first observed for the Cyberforest in 2000 and the Palmerston North site was first observed in 2013 making the latter the youngest tree-site-asheritage studied in this thesis and qualifying both as twenty-first-century arboreal heritage sites. Given the shortage of native trees in the Register, as demonstrated by Table 3 in Chapter Two, the presence of the Te Awanga entry as a group of trees whose sole claim to 
notability is a celebration of arboreal indigeneity in a region (Hawke's Bay) with the greatest disparity in exotic (159) and native (6) entries (Table 3 in Chapter Two), seems highly improbable. Equally perplexing is the tardiness of the registration of the Palmerston North site which has been maintained as a heritage site by its current owners since 1926 and was interpreted by pou and signage in 1987 but took a further twenty-six years to enter the national tree heritage register in 2013 . The answer to both these puzzles lies in the political and social contexts out of which their registration has evolved and which aligns them more closely with the Anthropocene Grove and the Dendroglyph Trees than with the New Plymouth tree site. One thread of the solution is derived from Sisson's description of a "systematisation of Maori tradition" that draws primarily on te reo Māori (Māori language) but refers also to Māori ceremony, art and crafts, beliefs and values and is implemented by a raft of State endorsements and the inclusion of Māori practices in government entities and official events. ${ }^{36}$ Sissons' notion is useful for this rethinking of arboreal heritage in the twenty-first century because it provides some background for what might be described as the systematisation of another form of language - the idiom of indigenous arboreal heritage. I argue here that the heritaging of the Palmerston North, Te Awanga, Anthropocene Grove and Dendroglyph Tree sites draws from both the systematisation of Māori tradition described by Sisson and a second thread of its continuous nurturing by Māori, and that it expresses a national rhetoric of arboreal indigeneity that has transcended the AAHD and UAHD boundaries, as illustrated by Table 6 .

The concept of a systematised indigenous arboreal heritage explains, in part, why it took so long for the Palmerston North and Te Awanga tree sites to enter the Cyberforest, why it was imperative that a Māori presence was represented on Taranaki Wharf by a grove of trees and why two trees were considered worthy as cultural redress at Parangarahu. This language of indigenous arboreal heritage is further communicated through the perennial actions of local authorities throughout the country who have translated exotic amenity plantings into native ones, declaim the importance of maintaining indigenous biodiversity, champion the ecosourcing of plants and encourage native tree planting as a measure to combat climate change.

The second thread of the answer is derived from an expression, or acknowledgement, of kaitiakitanga and the agency and performativity of karaka itself. It resides in Tapsell's

\footnotetext{
${ }^{36}$ Sissons, "The Systematisation of Tradition." 101. See also, Kawharu, "Measuring Progress."
} 
definition of taonga as "time travellers" 37 and Ellis" explanation of taonga as living beings integral to the land and its communities. ${ }^{38}$ It relies on the concepts of whakapapa and personification of natural phenomena, inalienable wealth and, in particular, the intergenerational fostering of Māori tradition and is related to the 1991 Wai 262 Waitangi Tribunal claim to protect and preserve indigenous flora and fauna and associated cultural and intellectual heritage.

The twenty-first-century inclusion of the Te Awanga and Palmerston North tree sites in the Cyberforest; the planting of the Anthropocene Grove in 1999 and the acknowledgement of the Dendroglyph Trees by Treaty settlement in 2008 have each appropriated karaka in different ways but share these social and political imperatives. It is the medium, here, that is the message. Consciously or unconsciously each of these four tree sites has, to borrow from Sissons again, rearticulated karaka as a hyper-symbolic expression of indigenous arboreal heritage. ${ }^{39}$

\footnotetext{
37 Tapsell, "The Art of Taonga". 10.

${ }^{38}$ Ellis, "Te Ao Hurihuri O Ngā Taonga Tuku Iho". 444.

${ }^{39}$ This phrase is borrowed from Sissons' conclusion that cultural forms "already symbolic, were systemically rearticulated as hyper-symbolic expressions of Maori identity". Sissons, "The Systematisation of Tradition." 113.
} 


\section{CONCLUSION: RETHINKING ARBOREAL HERITAGE FOR THE TWENTY-FIRST CENTURY}

The multiple case study of a single tree species carried out in this thesis research has provided a framework to survey arboreal heritage in Aotearoa New Zealand from three very different perspectives. The three cases examined in the research have provided archival, documentary and empirical evidence of some ways in which New Zealanders have acknowledged their tree heritage in the past and continue to do so at present. Chapter Five considered the similarities and differences between the cases. This chapter takes another tack by considering the cases as a group in order to answer the individual thesis questions and presents a set of principles for negotiating the acknowledgement and protection of arboreal heritage in practice.

\section{What is Arboreal Heritage in Aotearoa New Zealand?}

The first question 'what is arboreal heritage in Aotearoa New Zealand?' has proved to be the most difficult to answer. The standard answer-and the one most people offered me when asked - concerns trees that are particularly old, large, rare or associated with a well-known person or event. These are the qualities that people generally equate with arboreal heritage and they are the qualifications for the trees that they expect will be safely listed by some authority and protected from any incursion of disease, vandalism or destruction. These are the trees people have suggested that I visit and include in this thesis, a characteristic response that has contributed to my contention that the commonly-held expectations of selection, management and preservation of tree heritage by experts are based on a narrow conceptual understanding of arboreal heritage itself - the AAHD.

New expressions of tree heritage have emerged in the twenty-first century that reflect contemporary issues and attitudes that differ from those reflected by this popular concept of tree heritage. These new iterations are not necessarily included in proprietary registers. I have employed - and customised - critical heritage theory in differentiating between examples that belong to the AAHD and those that find a home in the UAHD. I have stated that the first is characterised by a top-down selection of tree sites by experts for inclusion in a list or register by employing an evaluation system that equates, in general terms, to sites of the old, large, rare or historically significant trees described by my interviewees. I defined the second as a discourse determined by a community-derived, social or cultural imperative and, while also 
possibly qualifying as old, large, rare or associated with history, immune from definitive evaluation.

At the beginning of my study my argument that tree sites could be neatly categorised according to the AAHD (the Cyberforest) and the UAHD (the Anthropocene Grove and the Dendroglyph Trees) appeared to be cogent. While the Cyberforest requests nominations for registration from members of the public who have an interest in trees, the final entry is moderated by NZNTT. ${ }^{1}$ Local authorities tend to solicit the advice of arborists and commonly apply STEM or customised versions of the evaluation method. The Anthropocene Grove and the Dendroglyph Trees, on the other hand, are not listed in the Cyberforest and their existence as heritage is derived from hybrid decision-making forums and, according to my definition, qualify as part of the UAHD. However, the subsequent cross-case analysis of the research data in Chapter Five shows that the boundary between the AAHD and UAHD categories is not fixed. Where it might be expected that all three karaka heritage tree sites within the Cyberforest might be ensconced comfortably within the confines of the AAHD, in fact the two sites which were first registered in the twenty-first century (Te Awanga and Palmerston North) exhibit qualities that qualify them for inclusion in the UAHD as well.

Rather than being able to be constrained by rigid evaluation systems, arboreal heritage has proved to be a dynamic notion that is influenced by the circumstances of the times in which it exists. This finding is reinforced by the historical backgrounds to all three cases and the chronological accounts of their development as heritage, all of which demonstrate how they have been shaped by any one or more of economic, environmental, cultural, historical, scientific, political and personal concerns. In further support of this, the cross-case analysis has introduced the notion of a contemporary national rhetoric of indigenous arboreal heritage that represents an evolution in arboreal heritage in New Zealand. This notion bolsters my argument that the Anthropocene Grove and the Dendroglyph Trees, as examples of tree heritage, operate in a manner 'counter' to the AAHD and helps to explain why the Palmerston North and Te Awanga tree sites were able to blur the boundary between the AAHD and the UAHD in Table 6. This time-related mutability of arboreal heritage is well illustrated by the corresponding changes in the language used to discuss it. While in 1938 The Canterbury branch of the NZIH calls for the preservation of the trees "planted by our

\footnotetext{
${ }^{1}$ Cadwallader interview.
} 
pioneers on estates throughout the Dominion", 2 in 2014 the GWRC and the PNBST refer to the Dendroglyph Trees as "taonga tuku iho". ${ }^{3}$ It is unlikely that either expression would be employed should the years be swapped.

In conclusion, my research shows that, like other forms of heritage, tree heritage reflects not only the past but the contemporary values that select and maintain it and the attitudes and issues that are prevalent at the time. While it can be loosely divided into two categories, defined by either an authorised or unauthorised arboreal heritage discourse, this differentiation is flexible. What sets it apart from most other forms of heritage is the fact that the 'artefacts' in tree heritage are living which introduces additional contemporary values, attitudes and issues which are discussed further in this chapter.

\section{How do Trees become Arboreal Heritage?}

This second question has also proved challenging because the means by which tree sites become arboreal heritage and the qualifications for their heritageness are manifold. As a method of reflecting this variability within the cases studied I have subtitled the cases 'heritage trees'(the Cyberforest), 'trees as heritage'(the Anthropocene Grove) and 'heritage as trees'(the Dendroglyph Trees). The early lists of tree sites by Allan, Burstall and Flook were selected by experts in their field aided by enthusiasts knowledgeable about the trees in their respective geographical regions. The Cyberforest which grew from these early lists maintains much the same process in collecting and assessing its entries for registration. Members of the public are invited to nominate tree sites for inclusion and the potential additions are moderated by the Notable Trees Registration Committee before being added to the list. Heritage tree lists maintained by local authorities on their ratepayers' behalf are similarly subject to expert opinion, and both the national and regional lists are founded on evaluation systems. However, while Allan, Burstall and Flook's lists were designed to protect the country's heritage trees, the Cyberforest does not make the same claim. Instead, it presents a collection of trees considered to be both an important national resource and an attraction for international tourists and evaluates its physically largest specimens in order to measure up to international comparison. The duty of care intended by the early lists has become the responsibility of local authorities since the introduction of the RMA in 1991.

\footnotetext{
2 "Remit no, 8," Minutes of the Fifteenth Annual Meeting of the New Zealand Institute of Horticulture, (1938). ${ }^{3}$ Port Nicholson Block Settlement Trust and Greater Wellington Regional Council, "Parangarahu Lakes Area Co-Management Plan.” 26.
} 
And here's the rub. Many New Zealanders believe that by achieving local authority registration heritage trees will be safe from developers and their chainsaws and from changes to district plans - as illustrated by the protests against potential tree destruction in Auckland described in Chapter One, and the Christchurch efforts to achieve or reinstate registration related in Chapter Two. The findings of the research, however, demonstrate that this is not necessarily the case. How trees cease to be arboreal heritage is as significant a question as how they become arboreal heritage in the first place. The removal of the Te Awanga tree site from the HDC's Outstanding Trees List, the disappearance of the New Plymouth tree site from the NPDC's list of Notable Trees, the post-earthquake Christchurch hearing and Auckland's loss of trees following the introduction of its Unitary Plan show that these lists are fluid.

My study of the Cyberforest in Chapter Two reveals several points that contribute to understanding how tree sites become recognised as what is popularly understood to be arboreal heritage. First, the research demonstrates that arboreal heritage is a very locallyoriented concept which is guided by the aspirations and enthusiasms of its community. Table 3 demonstrates significant disparity in the numbers of trees registered in the Cyberforest according to the regions in which they are located. These figures range from 165 entries in Hawke's Bay to four entries in Coromandel. It is important to restate here that these numerical comparisons are not representative of the actual numbers of trees in the individual regions but only signify the number of registrations. Nominations are invited for consideration by the Notable Trees Registration Committee and a full set of criteria for entry is provided for the convenience of potential contributors. Therefore, it is reasonable to assume that the difference in regional numbers of registrations can be attributed to the difference in the numbers of nominations and, by association, the varying levels of energy and commitment of tree enthusiasts in the nineteen regions. The Cyberforest acknowledges that it is not a complete list of heritage trees by continuing to solicit nominations for its "growing list of some of our finest trees on current record". ${ }^{4}$

\footnotetext{
${ }^{4}$ https://www.notabletrees.org.nz. Accessed 28 June 2017.
} 
Second, although the Cyberforest is now an "open register", the place secured by trees in the list is dependent on how rigorously the tree site conforms to its set requirements. ${ }^{5}$ Flook's standard tree evaluation method had its genesis in a seminar in 1984 and a report prepared by a working party that advocated, among other things, a system that awarded monetary value to listed notable trees according to set criteria. The system was devised essentially as a tool for protecting the trees in the event of any legal dispute over their destruction. Flook writes in his author's note to the publication explaining his method that while still in draft STEM had been used in three court cases and was "effective in gaining costs and decisions for tree retention". ${ }^{6}$ While the Cyberforest includes STEM scores when provided with tree nominations, holds the copyright for STEM and regards it as a useful tool for benchmaking and comparison of trees nationwide, it does not evaluate tree entries by this method. NZNTT is considering "tightening up" STEM to avoid subjective decision-making and removing valuation from the method. ${ }^{7}$

Local authorities commonly use STEM to compile and maintain the tree lists in their district plans, and, in some instances, have customised the original method to suit their individual local requirements. Flook's original intention was to design an uncomplicated, standardised tree evaluation method that could be adapted to various geographic conditions, was readily understood, easy to use in the field and would give "conservative results". ${ }^{8}$ In the assessment of an organic object, he writes, "the essential ingredient is objectivity". ${ }^{9}$ Objectivity, however, is an elusive quality when deciding the worth of a heritage tree site, as demonstrated by some of the comments reported in news media and documented later in this chapter. As Bowker and Star point out, the classifications employed in evaluating will either advantage or disadvantage each of the objects under consideration for a list and curatorial decisions on standards and categories amount to matters of ethical choice. ${ }^{10}$ Tables 2,3 and 4 compare the numbers of native and exotic trees listed and suggest that indigenous trees are the ones disadvantaged by the nominators' preferences and evaluation methods used in the lists studied and echo the mid- twentieth-century sentiments expressed by McCaskill that

\footnotetext{
${ }^{5}$ Cadwallader interview.

${ }^{6}$ Flook, STEM: A Standard Tree Evaluation Method. 7.

${ }^{7}$ Cadwallader interview.

${ }^{8}$ Flook, STEM: A Standard Tree Evaluation Method. 14.

${ }^{9}$ Ibid.

${ }^{10}$ Bowker and Star, Sorting Things Out. 5-6.
} 
New Zealanders have traditionally preferred to live amongst the trees of Europe and North America, as described in Chapter Two.

A third point revealed by my study of the Cyberforest is that trees require champions if they are to attain the official status of heritage and, crucially, maintain it. The determined crusade for trees that had fallen off the Christchurch City Council's list, related in Chapter Two, is a case in point. Successful long-term championing is exemplified by Massey University's recognition, maintenance and development of the Palmerston North karaka site which has been critical to its longevity and earned it places in both the Cyberforest and the list of its local authority. The well-publicised occupation by Michael Tavares, described in Chapter One, garnered considerable public support, stayed the chainsaws threatening the West Auckland kauri and rimū for private land development and called to account the property's owners and local authority. Official heritage status, however, requires official heritage recognition as shown by the fortunes of the Te Awanga tree site. The removal of the trees from their local authority list of outstanding trees, despite spirited resistance by their owners, was in response to a neighbour's complaints which had been lodged with the HDC over an eleven-year period. While the petitioning neighbour might appear on the surface to have won the battle, it was, in fact, the system that determined the trees' dismissal from the list. The comments of Darryl Judd in his commissioned report to the council are telling. Although he considers the trees to be valuable to the local community as part of its streetscape, he writes, measuring them according to STEM, as required, precludes them from reaching a score that ensures their protection. ${ }^{11}$ The council consequently decided that the trees did not meet the criteria required by the district plan and removed them from the list.

To anyone persuaded that the term 'heritage' means only big, old, rare or association with famous people or events, the Anthropocene Grove and the Dendroglyph Trees might seem unlikely subjects for critical heritage study as they do not bask in the popularly recognised aura of 'heritageness' bestowed by entry in the Cyberforest and are not subject to evaluation by STEM. The trees of the Anthropocene Grove are not old nor is the ground they grow in original: the carvings on the Dendroglyph Trees may or may not be the work of people or the effects of weather and their age is unknown. While they have not found a place in the Cyberforest as members of New Zealand's "rich arboreal heritage" they undeniably qualify

\footnotetext{
${ }^{11}$ Hastings District Council, "Hastings District Plan Hearings Committee Meeting." 35.
} 
for Kirshenblatt-Gimblett's's definition of heritage as "a mode of cultural production in the present that has recourse to the past". ${ }^{12}$ Unlike the heritage tree sites in the Cyberforest, the Anthropocene Grove and the Dendroglyph Trees have not been cherry-picked for listing by tree enthusiasts but have grown out of topical, twenty-first-century circumstances and are heritage by virtue of the actions and ambitions of their respective communities. While the Cyberforest remains a curated collection of 'heritage trees' considered to be worthy of note, the Anthropocene Grove, employing 'trees as heritage' and the Dendroglyph Trees, establishing 'heritage as trees' have connected the past, the present and the future in distinctive ways that transcend the received heritage evaluation methods of the AAHD.

The contrast in means by which the New Plymouth, Te Awanga and Palmerston North tree sites have entered the Cyberforest, and the Anthropocene Grove and Dendroglyph Trees have been defined as 'arboreal heritage' is at the heart of my differentiation of the AAHD and the UAHD and is the crux of my answer to the question 'how do trees become arboreal heritage?' The first three have been nominated, evaluated, found to be worthy of selection, categorised and catalogued: the second two have grown as heritage out of the needs and aspirations of their communities. Despite their different origins, they do share some characteristics. The Cyberforest entries are also community inspired, in the sense that they have been nominated for inclusion by their regions before being moderated by experts, and all five tree sites have, at some time, been championed by their communities. The most striking difference revealed in the heritaging of the Cyberforest, as distinct from the Anthropocene Grove and Dendroglyph Trees, is in the application of evaluation methods in the listing process.

In her argument for improving the ecological and ethical relationships between humans and nature, Plumwood questions the ethics of the anthropocentric position traditionally taken by humans in deciding which living things can be included within the human sphere and which belong to a 'lower' sphere and therefore can be excluded and treated as resources for exploitation. ${ }^{13}$ Heritage listing operates by establishing a set of criteria by which artefacts are measured and judged suitable or unsuitable for inclusion: heritage lists are made up of the selected artefacts. If, as Plumwood argues, a methodology of exclusion rather than inclusion

\footnotetext{
${ }^{12}$ Kirshenblatt-Gimblett. "Theorizing Heritage.” 370.

${ }^{13}$ Plumwood, Environmental Culture.
} 
should be applied when addressing the natural world then, by extension, the onus of proof for attaining the status of arboreal heritage might be shifted from inclusion to exclusion as well. In other words, rather than listing trees according to set criteria of heritageness, all trees might be regarded as potentially 'heritage' unless proved otherwise. The effect of such a paradigm is profound. The commonly held belief that experts should select and maintain an official list of tree heritage is disrupted, the received methodology of selection is found wanting and the means by which trees 'officially' become recognised as arboreal heritage in local authority lists throughout New Zealand is called into question.

\section{What Values, Meanings and Understandings, and Human and Non-human Forces have Shaped and Continue to Shape Aotearoa New Zealand's Arboreal Heritage Today?}

To answer this third question, I return to the suburban drama recounted in the Introduction in which the lead character was a beleaguered, self-sown pōhutukawa tree. The incident illustrates how trees represent different meanings for different people and that trees themselves are far from passive in the engagement but, instead, actively form relationships with people and prompt contrasting reactions. Of particular interest is my neighbour's description of the sapling as "not a real tree". At the time, I assumed she meant that because it was self-propagated it was not 'real' in the sense that it was not deliberately planted by a human. Now, at the end of my study and having learnt more about karaka and arboreal heritage I am no longer sure that my initial assumption was correct. Was her conclusion reached on the basis of the tree species rather than the manner of its birth? Did she perhaps consider a pōhutukawa to be a weed? If, for instance, the tree had been a pretty, self-sown Taiwanese cherry (Prunus campanulata) would her judgment have been different? Perhaps so.

The ascribing of values, meanings and understandings to trees falls partly under the umbrella of intangible natural heritage. The presence of the Anthropocene Grove on Wellington's waterfront and the inclusion of the Dendroglyph Trees as cultural redress within a Parliamentary Act signal overt recognition that human relationships with natural phenomena actively shape heritage. Taranaki Wharf required trees as heritage: Taranaki Whānui required heritage as trees. Both tree sites are deeply rooted in the history of their locations and communities and it is their intangible values that link people and place. The provenances of these two tree sites might be ambiguous but, rather than diluting the strength of their relationships, the symbolic nature of the fabricated Anthropocene Grove within the built 
heritage assemblage of Taranaki Wharf and the mystery and meanings surrounding the tree carvings' origins at remote Lake Kohangapiripiri enhance their spiritual power. However, while the heritage values at these two sites resides in the physical presence of trees this research demonstrates that contemporary heritage meanings are not necessarily reliant on the tangibility of trees themselves. The 3D laser scanning of rākau momori on the kōpi of Rèkohu to obtain digital taonga tuku iho, and the retention of entries of deceased trees in the Cyberforest indicate that materiality is not always essential to arboreal heritage. Nor is authenticity. For example, karaka that have failed to thrive in the Anthropocene Grove have been replaced by new trees. None of these actions threatens the heritage value of the tree sites with which they are associated; it is their intangible values that are most important here. Furthermore, this study shows that it is not only human forces that shape arboreal heritage. The case studies and cross-case analysis have described many instances where karaka has actively mediated its place in arboreal heritage by means of its food provision capabilities, its cosmogonic and mythical values, its aesthetic and affective properties, its indigeneity, its enlisting of kererū and its adaptability - tangible and intangible qualities that differ from the more conventional human-generated heritage measures of size, age, rarity or cultural association.

It is largely the tangible values of trees, however, that are shaping arboreal heritage as we increasingly understand how trees can help meet the challenges of climate change. In 2016, New Zealand's combined local authorities planted one million native trees and set a target for planting another 4.7 million native trees in 2017 “one for every New Zealander". ${ }^{14}$ My own local authority has plans to plant two million trees in Wellington by $2020,{ }^{15}$ and in their 2017 coalition agreement the New Zealand Labour Party and the New Zealand First Party committed to a priority goal of "planting 100 million trees per year in a Billion Trees Planting programme". ${ }^{16}$ Arboreal heritage has its own important part to play in this regard in the recommendations of native trees and, despite popular belief that young trees are more vigorous than their older counterparts, in the conclusions of recent international studies that larger and older trees grow more quickly than younger ones and accumulate carbon more

\footnotetext{
${ }^{14} \mathrm{http} / / / \mathrm{www} . l g n z . c o . n z /$ news-and-media/local-wins/a-million-native-trees-planted-by-local-government-lastyear. Accessed 21 July 2017.

${ }^{15} \mathrm{https} / / /$ wellington.govt.nz/your-council/projects/two-million-trees. Accessed 10 March 2017.

${ }^{16} \mathrm{https} / / / \mathrm{www}$. nzdoctor.co.nz/sites/default/files/2017-

10/Labour\%20and\%20New\%20Zealand\%20First\%20\%20Coalition\%20Agreement.pdf. Accessed 3 November 2017.
} 
rapidly. ${ }^{17} \mathrm{We}$ are beginning to look at trees anew and our definition of 'real' trees might be about to change.

We exhibit conflicting attitudes and values regarding the worth of trees and our relationships with them and, significantly, most of these arise from our own viewpoint as humans. Whether a 'real' tree or not, the pōhutukawa sapling described above formed its own relationships with its cohabitants of the neighbourhood. Trees have their own agency. Some people might view this as a tree-hugger's hypothesis but it is a statement supported by significant, multidisciplinary research ${ }^{18}$ and is critical to the future stewardship of arboreal heritage in this country. This is a timely investigation that engages critical heritage studies in an interdisciplinary, theoretical discussion of the relationships between humans and non-humans and the importance of nature to human life and well-being, and promotes arboreal heritage as a topic for further critical heritage study. While this research is focused on a single tree species and is carried out exclusively in New Zealand its findings have broad application to critical heritage studies and provide a basis for further research. In New Zealand or elsewhere this might include a comparative study of heritage sites associated with other indigenous tree species, further inquiry into the relationship of native and exotic tree species in other heritage lists or a close examination of the heritage listing process in general.

\section{Principles for the Acknowledgement and Protection of Arboreal Heritage in Aotearoa}

\section{New Zealand}

My occasional survey of New Zealand media reports between 2012 and 2018 dealing with the potential felling of trees illustrates the emotions experienced by heritage tree supporters, local authorities and developers alike. Engagement with authorities is variously described as "a stoush", "unconscionable", "a day of shame", "a fight", "an impasse”, "beyond shameful" and causing "conflict and division", and the process is described as "not community friendly", "stressful”, causing "outrage", "sadness and anger”, and making people "enraged", "shocked" "utterly devastated", "furious" and "disheartened". Constrained by district plans, STEM and its council clones, authorities "received a few complaints [...and...] put a hold on

\footnotetext{
${ }^{17}$ N. L. et al Stephenson, "Rate of Tree Carbon Accumulation Increases Continuously with Tree Size," Nature 507, no. 7490 (2014). 90-93; Becky Oskin, "Old Trees Grow Faster Than Young Ones, New Study Shows," http://www.huffingtonpost.com/2014/01/16/big-trees-grow-faster-young_n_4609096.html. Accessed 7 September 2017.; Wohlleben, The Hidden Life of Trees. 97.

${ }^{18}$ Bennett, "The Force of Things."; Harrison, Heritage; Hawkins, "The Politics of Bottled Water."; Hitchings, "People, Plants and Performance."; Jones and Cloke, Tree Cultures; Latour, "On Recalling ANT."; Law, "After ANT."; Nader, "Up the Anthropologist."; Plumwood, Environmental Culture.
} 
things, "have no legal mandate to revoke", are "reviewing the process", are "looking at all options" and "ways to resolve the matter", noting "the level of abuse directed at [...them...] on social media", seeking "legal advice", "going to go over our procedures", and "unable to comment on the issue". Developers "believed the tree was a safety risk", "did "thoroughly consider' corrective pruning, but the cost was prohibitive", understood "conflicting needs and different opinions, but to resolve these you need good systems and processes", "have been trying to come up with solutions where no-one loses everything but we all compromise, and [this] is something new and hopeful that looks forward and not backward", requested "fair compensation for our land and efforts to date as we have not broken the law", and "did not expect invitations to future street parties". Each of these comments expresses the person's inability to successfully engage with arboreal heritage. There is passion, aggression, sadness and frustration all bound together over the issue of whether to destroy or protect heritage trees.

While Galway's version of a suitable national "tree sense" for the 1930s, quoted in the Introduction, might be old fashioned, the sentiment itself remains apposite and, equally, has relevance for a new heritage tree sense that is appropriate for today. ${ }^{19}$ In answering the three thesis questions, this chapter has put forward ideas to form the basis of a twenty-first-century heritage tree sense. These ideas and the preceding research are brought together in Table 7 as ten principles for communities, local authorities and heritage practitioners when negotiating the acknowledgement and protection of arboreal heritage in New Zealand.

19 “Conserving Native Bush,” Evening Post, 2 April 1937. 


\begin{tabular}{|l|}
\hline Principles for Arboreal Heritage in Practice \\
\hline $\begin{array}{l}\text { Arboreal heritage can be manifest in many forms over and above age, size, rarity and } \\
\text { association with prominent people or events }\end{array}$ \\
\hline $\begin{array}{l}\text { Listing is only one tool for recognition of arboreal heritage and is often more applicable to } \\
\text { collection rather than protection }\end{array}$ \\
\hline In the twenty-first century trees have important additional environmental value \\
\hline $\begin{array}{l}\text { All trees have the potential to be arboreal heritage, therefore, operating from a standpoint } \\
\text { of exclusion rather than inclusion is appropriate }\end{array}$ \\
\hline Arboreal heritage requires champions in order to thrive \\
\hline $\begin{array}{l}\text { A partnership of non-professional and professional arboreal heritage values will be } \\
\text { stronger than one or the other }\end{array}$ \\
\hline $\begin{array}{l}\text { All trees have agency and it is important to identify and consider the significance of that } \\
\text { agency in decision-making about protection/destruction }\end{array}$ \\
\hline $\begin{array}{l}\text { Effective communication and open discussion of principles for decision-making will foster } \\
\text { a contemporary local, regional and national heritage tree sense }\end{array}$ \\
\hline $\begin{array}{l}\text { Arboreal heritage might have different meanings and values according to whether the trees } \\
\text { are indigenous or exotic and this difference should be taken into consideration } \\
\text { and management, and avoid conflict in negotiating acknowledgement and protection. }\end{array}$ \\
\hline
\end{tabular}

Table 7: Principles for the acknowledgement and protection of arboreal heritage in Aotearoa New Zealand

Arboreal heritage is much more than lists of trees that we might want to keep because they are big, rare, old or associated with historical people or events. These listed trees do matter, of course, but the lists are devised from an anthropocentric standpoint that is currently being tested by new attitudes towards the natural world. Today, we face complicated environmental and societal challenges, and more than ever before we need to work in partnership with nature rather than dictating our own terms. To do justice to the arboreal heritage of Aotearoa New Zealand we need to review the ways in which the fate of trees is negotiated and decided. The principles listed above are designed to contribute to this rethinking of arboreal heritage for the twenty-first century. 


\section{BIBLIOGRAPHY}

\section{Primary sources}

Alexander Turnbull Library, Wellington

88-070-20/25, 'Dendroglyphs and petroglyphs', and 88-070-20/24 'Dendroglyphs'.

MapColl-832.47eg/[18-?](1972)/Acc.37823, ‘[Creator unknown] : Tokakawau [Kapiti

Island] [copy of ms map]. [1972]'.

MS-Papers-1132-286 "J. W. A. Heenan Collection: Trees" (Alexander Turnbull

Library, 1943).

MS-Papers-6061-45, 'Maori notebook (vol 44)'.

Museum of New Zealand Te Papa Tongarewa

MU000002/057/0007: Maori Ethnology: General; 1931-1964

MU000002/059/0002, Maori Ethnology: Identifications and information; 1958-1965

MU000002/063/0002, Maori Ethnology: Archaeology: general; 1949-1975

MU000002/063/0013, Ethnology: Identifications and information; 1953-1975

MU000002/059/0006, Maori Ethnology: Maori carvings: information; 1943-1965

Royal New Zealand Institute of Horticulture

Royal New Zealand Institute of Horticulture Archive, Lincoln University (uncatalogued)

Heritage New Zealand

Heritage New Zealand General-Trees 22004-001 vols. 1, 2, 3, 4, 5, 6 and 7.

City Archives (Wellington)

“City Shaper”, Box 87

"City Shaper", Box 107

Wellington City Library

2010/47:21:1215/14 Pt4, Council and standing committees - Maori Committee

2010/47:21:1215/14 Pt5, Council and standing committees - Maori Committee 
Web sites

http://environmentalhistory-a-nz.org

http://portal.unesco.org

http://www.cabi.org

http://www.colloquy.monash.edu.au

http://www.huffingtonpost.com

http://www.labour.org.nz

http://www.lgnz.co.nz

http://www.mana.co.nz

http://www.massey.ac.nz

http://www.nzfoa.org.nz

http://www.pnbst.maori.nz

http://www.productivity.govt.nz

http://www.teara.govt.nz

http://www.tekau.maori.nz

http://www.unesco.org

http://www.wellington.govt.nz

http://www.wellingtoncivictrust.org

http://www.wellingtoncivictrust.org

http://www.wharewakaoponeke.co.nz

https://nzhistory.govt.nz

https://stamps.nzpost.co.nz

https://waitangitribunal.govt.nz

https://www.auckland.ac.nz

https://www.mpi.govt.nz

https://www.notabletrees.org.nz

https://www.nzdoctor.co.nz

https://www.parliament.nz

https://www.pncc.govt.nz

https://www.stuff.co.nz.

https://www.tepapa.govt.nz

www.newplymouthnz.com 
Newspapers

Akaroa Mail and Banks Peninsula Advertiser

Auckland Star

Christchurch Press

Christchurch Star Sun

Cook Strait News

Ellesmere Guardian

Evening Post

Hawera and Normanby Star

Nelson Evening Mail

New Zealand Gazette and Wellington Spectator

New Zealand Herald

The Dominion

The Dominion Post

The National Business Review

Official publications

Appendix to the Journal of the House of Representatives

Interviewees

Nirmala Balram, Museum of New Zealand Te Papa Tongarewa

6 January 2016

Brad Cadwallader, NZNTT

28 August 2018

George Fuller, formerly NPDC

13 March 2015

Paul Mahoney, Department of Conservation

10 April 2015

Bruce McFadgen, Victoria University of Wellington

30 June 2016

Richard Nester, Department of Conservation

1 March 2016

Tim Porteous, GWRC

26 April 2016

Lee Rauhina-August, PNBST

29 November 2016

Sven Schroeder, Department of Conservation

10 April 2015

Megan Wraight, Wraight Associates

29 July 2016.

Transcripts from the shorthand notes of the interviews are held by the author and can be made available to bona fide researchers, subject to permission being granted by interviewees. 


\section{Secondary sources}

Acting Inspector General, Post and Telegraph Department. "The Centennial Postage-Stamp Issue: No. 2. The Fourpenny and the One Shilling Stamps." New Zealand Centennial News, no. 8 (19 April 1939): 8-9.

Adkin, G. Leslie. The Great Harbour of Tara: Traditional Maori Place-Names and Sites of Wellington Harbour and Environs. Christchurch: Whitcombe and Tombs, 1959.

Allan, H. H. "Historic Trees." Journal of the Royal New Zealand Institute of Horticulture 12, no. 3 (December 1942). 54.

- "Historic Trees in New Zealand." Journal of the Royal New Zealand Institute of Horticulture 10, no. 1 (June 1940): 19.

- "Historic Trees in New Zealand." Journal of the Royal New Zealand Institute of Horticulture 10, no. 2 (September 1940): 42-46.

. "Historic Trees in New Zealand." Journal of the Royal New Zealand Institute of Horticulture 11, no. 1 (June 1941): 13.

_. "Historic Trees in New Zealand: Consolidated List from Journals of Royal N.Z. Institute of Horticulture June and September, 1940, June 1941." In MS-Papers-1132-286 "J. W. A. Heenan Collection: Trees", 13: Alexander Turnbull Library, 1943.

Anderson, Atholl. "A Fragile Plenty: Pre-European Maori and the New Zealand Environment." In Making a New Land: Environmental Histories of New Zealand, edited by Eric Pawson and Tom Brooking, 35-51. Dunedin: Otago University Press, 2013.

Andersson, R., L. Östlund, and R. Lundqvist. "Carved Trees in Grazed Forests in Boreal Sweden: Analysis of Remaining Trees, Interpretation of Past Land-Use and Implications for Conservation." Vegetation History and Archaeobotany 14, no. 2 (July 2005): 149-58.

Arnold, Rollo. "British Settlers and the Land." In Te Whenua Te Iwi: The Land and the People, edited by Jock Phillips, 27-41. Wellington: Allen and Unwin and Port Nicholson Press, 1987.

Attfield, Robin. "The Good of Trees." The Journal of Value Inquiry 15, no. 1 (1981): 35-54.

Bagnall, A. G., and G. C. Petersen. William Colenso, Printer, Missionary, Botanist, Explorer, Politician: His Life and Journeys. Wellington: A. H. and A. W. Reed, 1948.

Baker, Richard St Barbe. Famous Trees of New Zealand. Wellington: Reed, 1965.

Ballara, Angela. "Te Whanganui-a-Tara: Phases of Maori Occupation of Wellington Harbour C. 1800-1840." In The Making of Wellington 1800-1914, edited by David Hamer and Roberta Nicholls, 9-34. Wellington: Victoria University Press, 1990.

Barber, Ian G, Justin Maxwell, and Fiona Petchey. "A Radiocarbon Investigation of Moriori Forest Use on Rēkohu (Chatham Island), Southwestern Polynesia.” Journal of Archaeological Science: Reports 10 (2016): 96-109.

Barber, Ian G. "Archaeological Assessment of Reported Carvings on Karaka (Corynocarpus laevigatus) Trees (Dendroglyphs), East Harbour Regional Park.” Greater Wellington Regional Council, 2013. 
Barber, Ian G., Justin Maxwell, and Richard Hemi. "Growing Images: Generating 3d Digital Models to Investigate Archaeological Moriori Carvings on Live Trees." World Archaeology 46, no. 1 (2014): 63-77.

Barber, Ian, and Justin Maxwell. "Evaluating New Radiocarbon Dates from Midden Deposits near Moriori Tree Carvings, Rēkohu (Chatham Island)." The Journal of the Polynesian Society 121, no. 1 (March 2012): 33-50.

Bardsley, Dianne. In the Paddock and on the Run. Dunedin: Otago University Press, 2009.

Barrowman, Rachel. "Heenan, Joseph William Allan." Te Ara-the Encyclopedia of New Zealand, https://teara.govt.nz/en/biographies/4h24/heenan-joseph-william-allan.

_ . "History and Romance: The Making of the Centennial Historical Surveys." In Creating a National Spirit: Celebrating New Zealand's Centennial, edited by Bill Renwick, 161-77. Wellington: Victoria University Press, 2004.

Batley, R. A. L. "A Dendroglyph from Inland Patea (Upper Rangitikei).” The Journal of the Polynesian Society 66, no. 2 (June 1957): 210.

Beattie, James. "Growing Chinese Influences in New Zealand: Chinese Gardens, Identity and Meaning." New Zealand Journal of Asian Studies 9, no. 1 (2007): 38-61.

Beattie, James John, and Katie Holmes. "Reflections on the History of Australasian Gardens and Landscapes." Studies in the History of Gardens and Designed Landscapes 31, no. 2 (2011): 75-82.

Beckett, Peter. "Some Notes on the Western Wellington Cook Strait Coast." New Zealand Archaeological Association Newsletter 6, no. 3 (September 1963): 135-39.

Bedford, Yukiko Numata. "The 'Peace Gardens', Featherston, South Wairarapa and the Chor-Farmer." http://environmentalhistory-a-nz.org/wpcontent/up[loads/2011/01/ENNZ_2010_v5_n2.

Belich, James. Making Peoples: A History of the New Zealanders from Polynesian Settlement to the End of the Nineteenth Century. Auckland: Allen Lane, the Penguin Press, 1996.

Bennett, Jane. The Enchantment of Modern Life: Attachments, Crossings, and Ethics. Princeton: Princeton University Press, 2001.

. "The Force of Things: Steps Towards an Ecology of Matter." Political Theory 32, no. 3 (2004): 347-72.

Benson, Frank L. "Public/Private Sector Partnerships: The Custom House Docks-a Case Study." In Waterfronts: A New Frontier for Cities on Water, edited by Rinio Bruttomesso, 76-83. Venice: International Centre Cities on Water, 1993.

Best, Elsdon. Forest Lore of the Maori: With Methods of Snaring, Trapping, and Preserving Birds and Rats, Uses of Berries, Roots, Fern-Root, and Forest Products, with Mythological Notes on Karakia Used Etc. Wellington: Te Papa Press, 2005. 1942. 
Blackley, Roger. “Alfred Sharpe.” In Art at Te Papa, edited by William McAloon, 96. Wellington: Te Papa Press, 2009.

Bouma, Gary D. The Research Process. Melbourne: Oxford University Press, 1993.

Bowker, Geoffrey C., and Susan Leigh Star. Sorting Things Out: Classification and Its Consequences. Cambridge, Massachusetts: MIT Press, 2000.

Bradbury, Matthew, ed. A History of the Garden in New Zealand. Auckland: Viking, 1995.

Brooking, Tom, and Eric Pawson. "The Contours osf Transformation." In Seeds of Empire: The Environmental Transformation of New Zealand, edited by Tom Brooking and Eric Pawson, 13-33. London: I. B. Tauris and Co. Ltd, 2011.

Buchanan, Rachel. "Re-Making Memory on Matiu and Other 'Settlement' Sites." Memory Connection 1, no. 1 (December 2011): 283-300.

Burke, Rebecca. "'Friendly Relations between the Two Races Were Soon Established'?: Pakeha Interactions with Maori in the Planned Settlements of Wellington, Nelson and New Plymouth, 1840-1860.” PhD, Victoria University of Wellington, 2014.

Burns, Patricia. Fatal Success: A History of the New Zealand Company. Auckland: Heinemann Reed, 1989.

Burstall, S. W. "Forest Mensuration Report No. 18 (Revised) Historic and Notable Trees of New Zealand: Poverty Bay, Hawke's Bay." Rotorua: New Zealand Forest Service, Forest Research Institute, 1974 (unpublished).

_. "Forest Mensuration Report No. 19 Historic and Notable Trees of New Zealand: Taranaki, Wanganui, Rangitikei, Central North Island.” Rotorua: New Zealand Forest Service, Forest Research Institute, 1973 (unpublished).

—. "Forest Mensuration Report No. 22 Historic and Notable Trees of New Zealand: North Canterbury, South Canterbury and Chatham Islands." Rotorua: New Zealand Forest Service, Forest Research Institute, 1973 (unpublished).

- "Forest Mensuration Report No. 23 Historic and Notable Trees of New Zealand:

Otago and Southland." Rotorua: New Zealand Forest Service, Forest Research Institute, 1970 (unpublished).

- "Historic and Notable Trees of New Zealand: Reports 16, 17, 18, 18 (Revised), 19, 20, 21, 22, 23." Rotorua: New Zealand Forest Service, Forest Research Institute 1970-74 (unpublished).

Burstall, S. W., and E. V. Sale. Great Trees of New Zealand. Wellington: A. H. \& A. W. Reed in association with the New Zealand Forest Service, 1984.

Byrne, Denis, and Gro Birgit Ween. "Bridging Cultural and Natural Heritage." In Global Heritage: A Reader, edited by Lynn Meskell. Chichester: Wiley Blackwell, 2015.

Byrnes, Giselle. Boundary Markers: Land Surveying and the Colonisation of New Zealand. Wellington: Bridget Williams Books, 2001.

Cadwallader, Brad. "The New Zealand Notable Trees Trust Online Database." New Zealand Garden Journal 12, no. 2 (2009): 15-17. 
Carter, Charles Rooking. Life and Recollections of a New Zealand Colonist Written by Himself. 3 vols. Vol. 2, London: Printed by R. Madley, 1866-1875.

Cave, Yvonne, and Valda Paddison. The Gardener's Encyclopaedia of New Zealand Native Plants. Auckland: Godwit, 2003. 1999.

Choay, Francoise. The Invention of the Historic Monument. Translated by Lauren M. O'Connell. Cambridge: Cambridge University Press, 2001.

Christchurch Independent Hearings Panel. "Decision 44: Chapter 9: Natural and Cultural Heritage (Part). Topic 9.4-Significant Trees." Christchurch: Independent Hearings Panel, Christchurch Replacement District Plan, 2016.

Clifford, Sue. "Local Distinctiveness: Everyday Places and How to Find Them." In Local Heritage, Global Context: Cultural Perspectives on Sense of Place, edited by John Scholfield and Rosy Szymanski, 13-32. Surrey: Ashgate, 1988.

Cloke, Paul, and Owain Jones. "Grounding Ethical Mindfulness for/in Nature: Trees in Their Places.” Ethics, Place \& Environment 6, no. 3 (2003): 195-213.

Cloke, Paul, and Eric Pawson. "Memorial Trees and Treescape Memories." Environment and Planning D: Society and Space 26, no. 1 (2008): 107-22.

Cochran, Chris, Russell Murray, Michael Kelly, and Andy Dodd. "Coastal Historic Heritage of the Wellington Region: Survey for the Coastal Plan Review." Wellington, 2012 updated 2014.

Commission for the Environment and Royal New Zealand Institute of Horticulture. "Notable and Historic Trees: A National Scheme to Promote and Register New Zealand's Notable and Historic Trees." Wellington: Commission for the Environment and Royal New Zealand Institute of Horticulture, 1985.

Community Consultative Committee. "Report on Lambton Harbour.” Wellington, 1996.

Costall, J. A., R. J. Carter, Y. Shimada, D. Anthony, and G. L. Rapson. "The Endemic Tree Corynocarpus laevigatus (Karaka) as a Weedy Invader in Forest Remnants of Southern North Island, New Zealand." New Zealand Journal of Botany 44 (2006): 5-22.

Coutts, Peter. "A Field Survey of Some Traditional Maori Sites in the Te Anau Region." New Zealand Archaeological Association Newsletter 12, no. 4 (1969): 224-27.

Coy, Fred E. "Native American Dendroglyphs of the Eastern Woodlands." In The Rock Art of Eastern North America: Capturing Images and Insight, edited by Carol Diaz-Granados and James R. Duncan, 3-16. Tuscaloosa: University of Alabama Press, 2004.

Cronon, William. "Introduction: In Search of Nature." In Uncommon Ground: Toward Reinventing Nature, edited by William Cronon, 23-56. New York: W. W. Norton, 1995. —. "The Trouble with Wilderness: Or, Getting Back to the Wrong Nature." In Out of the Woods: Essays in Environmental History, edited by Char Miller and Hal Rothman, 28-50. Pittsburgh: University of Pittsburgh Press, 2014. 
Crouch, David. "The Perpetual Performance and the Emergence of Heritage." In Culture, Heritage and Representation: Perspectives in Visuality and the Past, edited by Emma Waterton and Steve Watson, 57-71. Surrey: Ashgate, 2010.

Cumberland, Kenneth B. "A Century's Change: Natural to Cultural Vegetation in New Zealand.” Geographical Review 31, no. 4 (1941): 529-54.

Dargavel, John. "More to Grief Than Granite: Arboreal Remembrance in Australia." Journal of Australian Studies 24, no. 64 (2000): 187-95.

Davison, Graeme. "Heritage: From Patrimony to Pastiche." In The Heritage Reader, edited by Graham Fairclough, Rodney Harrison, John Jameson and John Schofield, 31-41. London: Routledge, 2008.

Dawson, Bee. A History of Gardening in New Zealand. Auckland: Random House, 2010.

de Castro, Eduardo Viveiros. "Exchanging Perspectives: The Transformation of Objects into Subjects in Amerindian Ontologies.” Common Knowledge 10, no. 3 (2004): 463-84.

de Groot, Jerome. "Historiography and Virtuality." In Culture, Heritage and Representation: Perspectives on Visuality and the Past, edited by Emma Waterton and Steve Watson, 91-103. Surrey: Ashgate, 2010.

de Vries, B. F. “A Site for a Planned Settlement.” In Wellington Prospect: Survey of a City 1840-1970, edited by N. L. McLeod and B. H. Farland, 18-26. Wellington: Hicks Smith and Sons, 1970.

Dorfman, Eric. "Foreword." In Intangible Natural Heritage: New Perspectives on Natural Objects, edited by Eric Dorfman, xi-xiv. New York: Routledge, 2012.

- ed. Intangible Natural Heritage: New Perspectives on Natural Objects. New York: Routledge, 2012.

Dorfman, Eric, and Janet Carding. "Discussion: Towards a Unified Concept of Intangible Natural Heritage." In Intangible Natural Heritage: New Perspectives on Natural Objects, edited by Eric Dorfman, 160-77. New York: Routledge, 2012.

Dreaver, Anthony. An Eye for Country: The Life and Work of Leslie Adkin. Wellington: Victoria University Press, 1997.

Duff, Gowan. "Preface." In Great Trees of New Zealand, edited by S. W. Burstall and E. V. Sale. Wellington: A. H. \& A. W. Reed in association with the New Zealand Forest Service, 1984.

Duff, Oliver. New Zealand Now. 2nd ed. London: George Allen and Unwin, 1956.

Eisenberg, Evan. The Ecology of Eden. New York: Alfred A. Knopf, 1998.

Ellis, Ngarino. "Te Ao Hurihuri O Ngā Taonga Tuku Iho: The Evolving Worlds of Our Ancestral Treasures." Biography 39, no. 3 (Summer 2016): 438-60. 
Elsner, Jaś. "Iconoclasm and the Preservation of Memory." In Monuments and Memory, Made and Unmade, edited by Robert S Nelson and Margaret Olin, 209-31. Chicago: Chicago University Press, 2003.

Eriksen, Anne. From Antiquities to Heritage: Transformations of Cultural Memory. New York: Berghahn, 2014.

Etheridge, Robert. "The Dendroglyphs or 'Carved Trees' of New South Wales." Geological Survey of New South Wales: Memoir Ethnological Series No. 3 (1918).

Fairburn, Miles. "Wakefield, Edward Gibbon." Te Ara-the Encyclopedia of New Zealand, http://www.teara.govt.nz/en/biographies/1w4/wakefield-edward-gibbon.

Flook, Ron. "Annual Report to the Royal New Zealand Institute of Horticulture.” edited by Notable Trees New Zealand: Royal New Zealand Institute of Horticulture, 2001.

\section{- An Introduction to the Notable Trees of New Zealand. Nelson: Copy Press, 1994.}

—. "Report for the R.N.Z.I.H. Executive and A.G.M. Christchurch 2003." Royal New

Zealand Institute of Horticulture 2003.

—. "Report to the Royal New Zealand Institute of Horticulture Executive from Notable Historic Trees Committee.” Royal New Zealand Institute of Horticulture, 1986.

-. STEM: A Standard Tree Evaluation Method. Nelson: self-published, 1996.

- Tree Registration Manual: For National and Local Authority District Plan Heritage Listings. Nelson: Royal New Zealand Institute of Horticulture, 2001. 2003.

Galbreath, Ross. "Allan, Harry Howard Barton.” Te Ara-the Encyclopedia of New Zealand, http://www.TeAra.govt.nz/en/biographies/5a5/allan-harry-howard-barton.

_. "Sanderson, Ernest Valentine." Te Ara-the Encyclopedia of New Zealand, http://www.teara.govt.nz/en/biographies/4s4/sanderson-ernest-valentine.

Gass, William H. "I've Got a Little List." Salmagundi Winter-Spring, no. 109/110 (1996): $20-38$.

Gatley, Julia, and Paul Walker. Vertical Living: The Architectural Centre and the Remaking of Wellington. Auckland: Auckland University Press, 2014.

Gell, Alfred. "The Technology of Enchantment and the Enchantment of Technology." In Anthropology Art and Aesthetics, edited by Jeremy Coote and Anthony Shelton, 40-63.

Oxford: Clarendon Press, 1992.

Gentry, Kynan Harley. "Associations Make Identities: The Origins and Evolution of Historic Preservation in New Zealand, 1870-1954.” PhD, University of Melbourne, 2009.

Gibbs, George W. "Pencarrow Lakes: Conservation Values and Management." Wellington: Department of Conservation, 2002.

Goldsmith, Susette. "Turning over Old Ground: Investigating Garden Heritage in Aotearoa New Zealand.” MA, Victoria University of Wellington, 2014. 
Goody, Jack. The Domestication of the Savage Mind. Cambridge: Cambridge University Press, 1977.

Graham, Brian, G. J. Ashworth, and J. E. Tunbridge. A Geography of Heritage: Power, Culture and Economy. London: Arnold, 2000.

Graham, Rob, Paul Kenny, Shane Moohan, Cory Smith, Nicky Woolford, Ross Boardman, John Reid, et al. "The Notable Trees of New Zealand." Arboricultural Journal: The International Journal of Urban Forestry 34, no. 2 (2012): 83-90.

Grant, Nick. "Stihl's Global Boss Calls 'Bullshit' on Govt's Climate Change Response." The National Business Review (26 February 2016): 8.

Gustafson, Barry. "Parry, William Edward." Te Ara-the Encyclopedia of New Zealand, http://www.teara.govt.nz/en/biographies/3p12/parry-william-edward.

Guthrie Smith, Herbert. "The Changing Land.” In Making New Zealand : Pictorial Surveys of a Century, edited by E. H. McCormick. Wellington: New Zealand Government, 1940.

Halbwachs, Maurice. The Collective Memory. New York: Harper \& Row, 1980.

Hall, Peter. "Waterfronts: A New Urban Frontier." In Waterfronts: A New Frontier for Cities on Water, edited by Rinio Bruttomesso, 12-19. Venice: International Centre Cities on Water, 1993.

Hamer, David. New Towns in the New World: Images and Perceptions of the NineteenthCentury Urban Frontier. New York: Columbia University Press, 1990.

. "Wellington on the Urban Frontier." In The Making of Wellington 1800-1914, edited by David Hamer and Roberta Nicholls, 227-54. Wellington: Victoria University Press, 1990.

Hamer, David, and Roberta Nicholls. "Introduction." In The Making of Wellington 1800 1914, edited by David Hamer and Roberta Nicholls, 1-7. Wellington: Victoria University Press, 1990.

Harrison, Rodney. “'Counter-Mapping' Heritage, Communities and Places in Australia and the United Kingdom.” In Local Heritage, Global Context: Cultural Perspectives on Sense of Place, edited by John Scholfield and Rosy Szymanski, 79-98. Surrey: Ashgate, 1988.

-. Heritage: Critical Approaches. London: Routledge, 2013.

- "What Is Heritage?". In Understanding the Politics of Heritage, edited by Rodney Harrison, 5-42. Manchester: Manchester University Press, 2010.

Hastings District Council, "Hastings District Plan Hearings Committee Meeting: Outstanding Trees at 28 Kuku Street, Te Awanga." Hastings: Hastings District Council, 2015.

"Proposed Hastings District Plan: Decision Report: Outstanding Trees at $28 \mathrm{Kuku}$ Street, Te Awanga.” Hastings: Hastings District Council, 2015.

Hawkins, Gay. "The Politics of Bottled Water: Assembling Bottled Water as Brand, Waste and Oil." In Assembling Culture, edited by Tony Bennett and Chris Healy, 177-89. London: Routledge, 2011. 
Hayden, Dolores. The Power of Place: Urban Landscapes as Public History. Cambridge, Massachusetts: MIT Press, 1997.

Heenan, J. W. 'New Zealand's Greatest Book 'Tutira' by H. Guthrie-Smith: A Talk During Author's Week." 1936.

Heerwagen, Judith H., and Gordon H. Orians. "Humans, Habitats and Aesthetics." In The Biophilia Hypothesis, edited by Stephen R. Kellert and Edward O. Wilson, 138-72.

Washington DC: Island Press, 1993.

Hitchings, Russell. "People, Plants and Performance: On Actor Network Theory and the Material Pleasures of the Private Garden." Social and Cultural Geography 4, no. 1 (2003): 99-113.

Holcroft, Monte H. The Deepening Stream: Cultural Influences in New Zealand. Christchurch: The Caxton Press, 1940.

Holmes, Katie. "Growing Australian Landscapes: The Use and Meanings of Native Plants in Gardens in Twentieth-Century Australia." Studies in the History of Gardens and Designed Landscapes 31, no. 2 (2011): 121-30.

Howard, Peter. Heritage: Management, Interpretation, Identity. London: Continuum, 2005.

Hunter, Michael. "The Fitful Rise of British Preservation.” In Preserving the Past: The Rise of Heritage in Modern Britain, edited by Michael Hunter, 1-16. Phoenix Mill: Alan Sutton Publishing, 1996.

Johnson, David. Wellington Harbour. Wellington: Wellington Maritime Museum Trust, 1996.

Jones, Owain, and Paul Cloke. Tree Cultures: The Place of Trees and Trees in Their Place. Oxford: Berg, 2002.

Journal of the Polynesian Society. "History and Traditions of the Taranaki Coast (Continued)." The Journal of the Polynesian Society 18, no. 4(72) (December 1909): 157204.

Kahn, Peter H. Jr. The Human Relationship with Nature: Development and Culture. Cambridge, Massachusetts: MIT Press, 2001.

Kaplan, R., and S. Kaplan. The Experience of Nature: A Psychological Perspective. Cambridge: Cambridge University Press, 1989.

Kawharu, Margaret. "Measuring Progress: Reflections on the Ground". In The Treaty on the Ground: Where We Are Headed, and Why It Matters, edited by Rachael Bell, Margaret Kawharu, Kerry Taylor, Michael Belgrave and Peter Meihana, 297-310. Auckland: Massey University Press, 2017. 
Kellert, Stephen R. "The Biological Basis for Human Values of Nature.” In The Biophilia Hypothesis, edited by Stephen R. Kellert and Edward O. Wilson, 42-69. Washington DC: Island Press, 1993.

Kelly, Michael. “Old Shoreline: Heritage Trail.” Wellington: Wellington City Council, 2005.

Kerridge, Donna. "Rongoa Maori: The Mighty Karaka." http://www.mana.co.nz/heritage/rongoa-maori-the-mighty-karaka.html.

Keyes, I. W. "Dendroglyphs from Lake Kohanga-Piripiri, Eastern Wellington.” New Zealand Archaeological Association Newsletter 11, no. 3 (1968): 103-10.

Kirshenblatt-Gimblett, Barbara. “Theorizing Heritage.” Ethnomusicology 39, no. 3 (1995): 367-80.

Klinac, D., R. A. Benton, and S. Rentoul. "Karaka Nuts: A 'New' New Zealand Nutcrop." (Wellington: Ministry of Agriculture and Fisheries, 2009).

Klinac, David. “Karaka: A Traditional New Zealand Nutcrop.” Indigena (2007): 19-21.

Krebs, Angelika. Ethics of Nature: A Map. Berlin: Walter de Gruyter, 1999.

Lambert, Ron. Pukekura Park and Brooklands: A Guide to Walks. New Plymouth: Puke Ariki, 2007.

Lambton Harbour Management Limited. "Lambton Harbour Public Spaces Taranaki Wharf Stage 1: Applications for Resource Consent." Wellington: Lambton Harbour Management, 1999.

Larsen, S. E. “Is Nature Really Natural?”. Landscape Research 17, no. 3 (1992): 116-23.

Latour, Bruno. "On Recalling Ant." In Actor Network Theory and After, edited by John Law and John Hassard, 16-25. Oxford: Blackwell, 1999.

_. "Politics of Nature: East and West Perspectives." Ethics and Global Politics 4, no. 1 (2011): 71-80.

- Reassembling the Social: An Introduction to Actor-Network-Theory. Oxford:

Oxford University Press, 2005.

Law, Garry. Archaeology of the Bay of Plenty. Wellington: Department of Conservation, 2008 .

Law, John. "After Ant: Complexity, Naming and Topology." In Actor-Network-Theory and After, edited by John Law and John Hassard, 1-15. Oxford: Blackwell, 1999.

Leach, Helen. 1000 Years of Gardening in New Zealand. Wellington: Reed, 1984.

_. "Analysing Change in the New Zealand Home Garden-by Style or Element." New Zealand Garden Journal 1, no. 2 (1996): 12-18. 
Leach, Helen, and Chris Stowe. "Oceanic Arboriculture at the Margins - the Case of the Karaka (Corynocarpus laevigatus) in Aotearoa." The Journal of the Polynesian Society 114, no. 1 (2005): 7-28.

Lenzerini, Federico. "Intangible Cultural Heritage: The Living Culture of Peoples." European Journal of International Law 22, no. 1 (2011): 101-20.

Lloyd, Helen. "William Trethewey, Kupe Group (1939).” Art in Context (2013): 42. https://www.tepapa.govt.nz/sites/default/files/art_in_context.pdf.

Loukaki, Argyro. Living Ruins, Value Conflicts. Aldershot: Ashgate, 2008.

Love, Matene. “Te Ara O Nga Tupuna.” Wellington City Council, 1996 (second edition 2006).

Love, Morris. "Te Ati Awa of Wellington." Te Ara-the Encyclopedia of New Zealand, http://www.teara.govt.nz/en/te-ati-awa-of-wellington.

Low, Tim. The New Nature. Camberwell, Australia: Viking, 2002.

Lowenthal, David. "Natural and Cultural Heritage." International Journal of Heritage Studies 11, no. 1 (2006): 81-92.

"Natural and Cultural Heritage." In The Nature of Cultural Heritage and the Culture of Natural Heritage: Northern Perspectives on a Contested Patrimony, edited by Kenneth R. Olwig and David Lowenthal, 80-90. London: Routledge, 2006.

Macdonald, Sharon. Behind the Scenes at the Science Museum. Oxford: Berg, 2002.

- Memorylands: Heritage and Identity in Europe Today. London: Routledge, 2013. . "Reassembling Nuremberg, Reassembling Heritage." Journal of Cultural Economy

2, no. 1-2 (2009): 117-34.

Maclean, Chris, Jock Phillips, and Debbie Willis. The Sorrow and the Pride: New Zealand War Memorials. Wellington: New Zealand Department of Internal Affairs: Historical Publications Branch, 1990.

Malouf, David. Being There. Sydney: Random House, 2016.

Maloy, Andrew. "Ronald Richard Flook AHRIH: 14 September 1932-9 January 2006." New Zealand Garden Journal 9, no. 1 (2006): 20-22.

McCarthy, Conal. "Te Ara O Nga Tupuna Maori Heritage Trail/Te Aro Pa, 39 Taranaki St, Wellington.” New Zealand Journal of History 43, no. 1 (April, 2009 2009): 114-17.

McCarthy, Frederick D. "The Carved Trees of New South Wales." The Australian Museum Magazine 7, no. 5 (1 June 1940): 161-66.

McCaskill, L. W. "Celebration of the Centennial in Schools: A National Scheme for the Growth and Study of Native Plants." New Zealand Centennial News, no. 2 (15 September 1938): 8. 
McClean, Robert. Fire Safety and Heritage Places. Sustainable Management of Historic Heritage Guidance Series. Wellington: New Zealand Historic Places Trust, 2012.

—. "Sustainable Management of Historic Heritage: Discussion Paper No. 3: Heritage Landscape Values." Wellington: New Zealand Historic Places Trust 2007.

McClellan, Andrew. The Art Museum from Boullée to Bilbao. Berkeley: University of California Press, 2008.

McEldowney, Dennis, ed. An Absurd Ambition: Autobiographical Writings: E. $H$. McCormick. Auckland: Auckland University Press, 1996.

McFadgen, B. G. "Maori Occupation of the Pencarrow Survey District as Recorded on Early Survey Records." New Zealand Archaeological Association Newsletter 6, no. 3 (1963): 11825.

McLean, Gavin. "Where Sheep May Not Safely Graze: A Brief History of New Zealand's Heritage Movement 1890-2000." In Common Ground?: Heritage and Public Places in New Zealand, edited by Alexander Trapeznik, 25-44. Dunedin: University of Otago Press, 2000.

McLintock, A. H. "The Forest." In Making New Zealand: Pictorial Surveys of a Century, edited by McCormick E. H. Wellington: New Zealand Government, 1939.

Medway, David. "Karaka Fruits as a Source for Birds in Pukekura Park and Brooklands." Magazine of the Friends of Pukekura Park 5, no. 3 (2010): 12.

Merchant, Carolyn. Reinventing Eden: The Fate of Nature in Western Culture. London: Routledge, 2004.

Metcalf, L. J. The Cultivation of New Zealand Trees and Shrubs. Auckland: Reed, 1991. 1972.

Millar, David P. "Reclamations." In Wellington Prospect: Survey of a City 1840-1970, edited by N. L. McLeod and B. H. Farland, 40-45. Wellington: Hicks Smith and Sons, 1970.

Miller, Char, and Hal Rothman. "Introduction." In Out of the Woods: Essays in Environmental History, edited by Char Miller and Hal Rothman, xi-xvi. Pittsburgh: University of Pittsburgh Press, 2014.

Miller, John. Early Victorian New Zealand: A Study of Racial Tension and Social Attitudes 1839-1852. Wellington: Oxford University Press, 1974. 1958.

Mirmohamadi, Kylie. "Designing Bush Landscapes: History and Place in Eltham and Castlecrag." Studies in the History of Gardens and Designed Landscapes 31, no. 2 (2011): 131-38.

_. "Talking About Native Plants." (2006).

http://www.colloquy.monash.edu.au/issue12/mirmohamadi.pdf.

Mitcalfe, B. "The Significance of Karaka in an Assessment of Pre-European Land Utilisation in New Zealand." New Zealand Archaeological Association Newsletter 12, no. 4 (1969): 184-88. 
Mitchell, W. J. T. "Canon.” In New Keywords: A Revised Vocabulary of Culture and Society, edited by Tony Bennett, Lawrence Grossberg and Meaghan Morris, 20-22. Oxford: Blackwell Publishing, 2005.

_. "Imperial Landscape." In Landscape and Power, edited by W. J. T. Mitchell, 5-34. Chicago: University of Chicago Press, 1994.

Molloy, Bruce. "The Origin, Relationships, and Use of Karaka or Kopi (Corynocarpus laevigatus)." In Nga Mahi Maori O Te Wao Nui a Tane: Contributions to an International Workshop on Ethnobotany, Te Rehua Marae, Christchurch, New Zealand, 22-26 February 1988, edited by Warwick Harris and Promila Kapoor, 48-53. Christchurch: Botany Division, DSIR, 1990.

Mulgan, Alan. The City of the Strait: Wellington and Its Province, a Centennial History. Wellington: A. H. and A. W. Reed, 1939.

Muller-Wille, Staffan, and Isabelle Charmantier. "Lists as Research Technologies." Isis 103, no. 4 (2012): 743-52.

Munjeri, Dawson. "Tangible and Intangible Heritage: From Difference to Convergence." In Cultural Heritage: Critical Concepts in Media and Cultural Studies, edited by Laurajane Smith, 323-30. London: Routledge, 2004.

Nader, Laura. "Up the Anthropologist: Perspectives Gained from Studying Up." In Reinventing Anthropology, edited by Dell Hymes, 284-311. New York: Vintage Books, 1972.

Nelson, Robert S., and Margaret Olin. "Destruction/Reconstruction." In Monuments and Memory, Made and Unmade, edited by Robert S. Nelson and Margaret Olin, 205-07.

Chicago: Chicago University Press, 2003.

- . "Introduction." In Monuments and Memory, Made and Unmade, edited by Robert S. Nelson and Margaret Olin, 1-10. Chicago: University of Chicago Press, 2003.

New Zealand Government. "Centennial Tree-Planting by Schools: A Widespread Programme of Progress.” New Zealand Centennial News, no. 10 (27 July 1939): 20.

- "Centennial Tree-Planting for Posterity: A National Appeal." New Zealand

Centennial News, no. 1 (15 August 1938): 4.

_. "Summary of Centennial Organization." New Zealand Centennial News, no. 1 (15

August 1938): 2.

_. "Port Nicholson Block (Taranaki Whanui Ki Te Upoko O Te Ika) Claims Settlement Bill: First Reading.” 19144. Wellington: New Zealand Parliament, 2008.

3. . "Desirable Memorials." New Zealand Centennial News, no. 1 (15 August 1938): 2

_. "Trees to Save the Country." New Zealand Centennial News, no. 14 (15 August 1940): 26.

New Zealand Productivity Commission. "Research Note: A History of Town Planning." Wellington: New Zealand Productivity Commission.

www.productivity.govt.nz/sites/default/files/using-land-draft-report-research-note.pdf. 
Nicholls, Rex. "Submission to Resource Consent: Taranaki Wharf Area.” Wellington: Wellington City Council, 1999.

Nora, Pierre. "Between Memory and History: Les Lieux De Mémoire." Representations 26 (1989): 7-24.

O'Sullivan, M. J. History of the Royal New Zealand Institute of Horticulture. Wellington: Royal New Zealand Institute of Horticulture, 1952.

Olwig, Kenneth R. "Introduction: The Nature of Cultural Heritage, and the Culture of Natural Heritage-Northern Perspectives on a Contested Patrimony." In The Nature of Cultural Heritage and the Culture of Natural Heritage: Northern Perspectives on a Contested Patrimony, edited by Kenneth R. Olwig and David Lowenthal, 1-5. Oxford: Routledge, 2006.

Opie, Anne. "Unstructured Interviewing." In Social Science Research in New Zealand: Many Paths to Understanding, edited by Martin Tolich and Carl Davidson, 220-30. Auckland: Longman, 1999.

Oskin, Becky. "Old Trees Grow Faster Than Young Ones, New Study Shows." http://www.huffingtonpost.com/2014/01/16/big-trees-grow-faster-young_n_4609096.html.

Palmer, J. B. "Maori Sites in Fitzroy Bay." New Zealand Archaeological Association Newsletter 6, no. 3 (September 1963): 125-34.

Park, Geoff. Ngā Uruora: The Groves of Life. Wellington: Victoria University Press, 1995. - Theatre Country: Essays on Landscape and Whenua. Wellington: Victoria University Press, 2006.

Parr, Joy. Sensing Changes: Technologies, Environments, and the Everyday, 1953-2003. Vancouver: UBC Press, 2010.

Parry, Ross. "The End of the Beginning: Normativity in the Postdigital Museum." Museum Worlds: Advances in Research 1(2013): 24-39. Published electronically 2013. doi:10.3167/armw.2013.010103.

Parry, W. E. “All Together for the Centennial.” New Zealand Centennial News, no. 9 (29 May 1939): 1. —. "Centennial Tree-Planting." New Zealand Centennial News, no. 8 (29 April 1939): 1.

_. "Centennial Tree-Planting: Careful Preparations Necessary." New Zealand Centennial News, no. 7 (30 March 1939): 5.

_. "An Opportunity for All." New Zealand Centennial News, no. 2 (15 September 1938): 1 .

Pawson, Eric. "The Memorial Oaks of North Otago: A Commemorative Landscape." In Glimpses of a Gaian World, edited by Geoff Kearsley and Blair Fitzharris, 115-31. Dunedin: University of Otago, 2004. 
Pawson, Eric, and Tom Brooking, eds. Making a New Land: Environmental Histories of New Zealand. Dunedin: Otago University Press, 2013.

_. "Introduction." In Seeds of Empire: The Environmental Transformation of New

Zealand, edited by Tom Brooking and Eric Pawson, 1-12. London: I. B. Tauris and Co. Ltd, 2011.

Petre, Henry William. An Account of the Settlements of the New Zealand Company: From Personal Observation During a Residence There. Christchurch: The Caxton Press, 1842, 1971.

Phillips, Jock. "Afterword: Reading the 1940 Centennial." In Creating a National Spirit: Celebrating New Zealand's Centennial, edited by Bill Renwick, 272-83. Wellington: Victoria University Press, 2004.

- ed. Te Whenua Te Iwi — the Land and the People. Wellington: Stout Research Centre, 1987.

Phillips, Ruth B. "Settler Monuments, Indigenous Memory: Dis-Membering and ReMembering Canadian Art History." In Monuments and Memory, Made and Unmade, edited by Robert S. Nelson and Margaret Olin, 281-304. Chicago: University of Chicago Press, 2003.

Pickles, Katie. "Mapping Memorials for Edith Cavell on the Colonial Edge." New Zealand Geographer 62 (2006): 13-24.

Pishief, Elizabeth. “Te Mata Trust Park Historic Heritage Landscape Report.” Te Mata: Te Mata Trust Board, 2011.

Plumwood, Val. Environmental Culture: The Ecological Crisis of Reason. London: Routledge, 2002.

Pollan, Michael. The Botany of Desire: A Plant's-Eye View of the World. New York: Random House, 2002.

Pope, F. S. "President's Address.” Wellington: Royal New Zealand Institute of Horticulture, 1939.

Port Nicholson Block Settlement Trust and Greater Wellington Regional Council, "Parangarahu Lakes Area Co-Management Plan: And Amendment to the Greater Wellington Regional Council Parks Network Plan.” Wellington: Port Nicholson Block Settlement Trust and Greater Wellington Regional Council, 2014.

Reinfeld, Mahinekura, Leonie Pihama, and Naomi Singer, eds. Matarakau: Nga Korero Mo Nga Rongoa O Taranaki: Healing Stories of Taranaki. Taranaki: self-published, 2007.

Renwick, Bill. "Making New Zealand: Pictorial Surveys of a Century." In Creating a National Spirit: Celebrating New Zealand's Centennial, edited by Bill Renwick, 178-92. Wellington: Victoria University Press, 2004.

Reps, John W. Cities of the American West: A History of Frontier Urban Planning. New Jersey: Princeton University Press, 1979. 
Riegl, Alois. "The Modern Cult of Monuments: Its Character and Its Origin.” Translated by Kurt W. Foster and Diane Ghirardo. In Cultural Heritage, edited by Laurajane Smith, 11442. London: Routledge, 2007.

Rival, Laura. "Trees, from Symbols of Life and Regeneration to Political Artefacts." In The Social Life of Trees: Anthropological Perspectives on Tree Symbolism, edited by Laura Rival, 1-36. Oxford: Berg, 1998.

Roberts, Mere, Waerete Norman, Nganeko Minhinnick, Dell Wihongi, and Carmen Kirkwood. "Kaitiakitanga: Maori Perspectives on Conservation." Pacific Conservation Biology 2 (1995): 7-20.

Roche, Michael. "An Interventionist State: 'Wise Use' Forestry and Soil Conservation.” In Making a New Land: Environmental Histories of New Zealand, edited by Eric Pawson and Tom Brooking, 209-25. Dunedin: Otago University Press, 2013.

Rolston, Holmes III. "Ethics on the Home Planet." In An Invitation to Environmental Philosophy, edited by Anthony Weston, 107-39. Oxford: Oxford University Press, 1999.

Rountree, Kathryn, and Tricia Laing. Writing by Degrees: A Practical Guide to Writing Theses and Research Papers. Auckland: Longman, 1996.

Royal New Zealand Institute of Horticulture. "Historic Trees." edited by Publications Committee. Wellington: Royal New Zealand Institute of Horticulture, 1964.

_. "Notable and Historic Trees: A National Scheme to Register and Promote New Zealand's Notable and Historic Trees." Wellington: Royal New Zealand Institute of Horticulture, 1977.

—. "Notable and Historic Trees." Wellington: Royal New Zealand Institute of Horticulture, 1985.

—. "Notable Trees New Zealand ... New Directions." Wellington: Royal New Zealand Institute of Horticulture, 2002. . "Report to Executive Committee Members." Wellington: Notable Trees Committee Royal New Zealand Institute of Horticulture, 1987.

Royal, Te Ahukaramā Charles, ed. The Woven Universe: Selected Writings of Rev. Māori Marsden. Ōtaki: Estate of Rev. Māori Marsden, 2003.

Saint, Andrew. "How Listing Happened." In Preserving the Past: The Rise of Heritage in Modern Britain, edited by Michael Hunter, 115-33. Phoenix Mill: Alan Sutton Publishing, 1996.

Salmon, John T. The Native Trees of New Zealand. Auckland: Reed, 1981. 1980.

Salmond, Anne. "Maori Epistemologies." In Reason and Morality, edited by J. Overing, 24063. London: Tavistock, 1985.

-. "Ontological Quarrels: Indigeneity, Exclusion and Citizenship in a Relational World." Anthropological Theory 12, no. 2 (2012): 115-41.

Sarajevs, Vadims. "Street Tree Valuation Systems." Forestry Commission (UK), 2011. 
Sawyer, John, Bruce McFadgen, and Paul Hughes. "Karaka (Corynocarpus laevigatus J.R. Et G. Forst.) in Wellington Conservancy (Excluding Chatham Islands)." In DOC Science Internal Series 101. Wellington: Department of Conservation, 2003.

Scheers, Peter. "Human Interpretation and Animal Excellence." In Is Nature Ever Evil?

Religion, Science and Value, edited by Willem B. Drees, 56-64. London: Routledge, 2003.

Schrader, Ben. "City Planning." Te Ara-the Encylopedia of New Zealand, http://www.teara.govt.nz/en/city-planning.

Schuster, J. Mark. "Making a List and Checking It Twice: The List as a Tool of Historic Preservation." In Biannual Conference of the Association for Cultural Economics International. Rotterdam, 2002.

Schwarz, Bill. "Heritage." In New Keywords: A Revised Vocabulary of Culture and Society, edited by Tony Bennett, Lawrence Grossberg and Meaghan Morris, 154-56. Malden, USA: Blackwell, 2005.

Searle, Graham. Rush to Destruction: An Appraisal of the New Zealand Beech Forest Controversy. Wellington: A. H. \& A. W. Reed, 1975.

Sexson, Lynda. "Isaac and the Elk: Nature's Unnatural Acts." In Sacred Landscapes and Cultural Politics: Planting a Tree, edited by Philip P. Arnold and Ann Grodzins Gold, 3-26. Aldershot: Ashgate, 2001.

Short, John Rennie. "Alternative Geographies: From Cosmography to Geography." In Sacred Landscapes and Cultural Politics: Planting a Tree, edited by Philip P. Arnold and Ann Grodzins Gold, 27-34. Aldershot: Ashgate, 2001.

Simpson, Philip. Pohutukawa and Rata: New Zealand's Iron-Hearted Trees. Wellington: Te Papa Press, 2005.

\section{7.}

Sissons, Jeffrey. "The Systematisation of Tradition: Maori Culture as a Strategic Resource." Oceania 64, no. 2 (December 1993): 97-116.

Skipworth, M. R. "Roadside Beautification in New Zealand." edited by the Royal New Zealand Institute of Horticulture, 1939.

Smith, Jill, and Peter Smith. Making Connections: John Bevan Ford, Maori Artist. Wellington: Gilt Edge Publishing, 2001.

Smith, Laurajane. "General Introduction." In Cultural Heritage: Critical Concepts in Media and Cultural Studies, edited by Laurajane Smith, 1-21. Oxford: Routledge, 2007.

-. Uses of Heritage. London: Routledge, 2006.

Smith, Philip. "Genius Loci: Identity and the New Zealand Garden." New Zealand Garden Journal 7, no. 1 (2004): 12-16. 
Solomon, Maui, and Susan Thorpe. "Taonga Moriori: Recording and Revival." Journal of Material Culture 17, no. 3 (2012): 245-63.

Stake, Robert E. The Art of Case Study Research. Thousand Oaks: Sage Publications, 1995.

Star, Paul, and Lynne Lochhead. "Children of the Burnt Bush: New Zealanders and the Indigenous Remnant, 1880-1930." In Making a New Land: Environmental Histories of New Zealand, edited by Eric Pawson and Tom Brooking, 141-57. Dunedin: Otago University Press, 2013.

Stephens, John. "Remembrance and Commemoration through Honour Avenues and Groves in Western Australia." Landscape Research 34, no. 1 (2009): 125-41.

Stephenson, Janet, Mick Abbott, and Jacinta Ruru, eds. Beyond the Scene: Landscape and Identity in Aotearoa New Zealand. Dunedin: Otago University Press, 2010.

Stephenson, N. L. et al. "Rate of Tree Carbon Accumulation Increases Continuously with Tree Size.” Nature 507, no. 7490 (March 2014): 90-93.

Tapsell, Paul. The Art of Taonga. Gordon H. Brown Lecture. Wellington Art History, Victoria University of Wellington, 2011.

Taylor, Ken, and Jane Lennon. "Cultural Landscapes: A Bridge between Culture and Nature?”. International Journal of Heritage Studies 17, no. 6 (2011): 537-54.

Thomson, A. P. "Lancelot William McCaskill: An Appreciation." The New Zealand Journal of Forestry 30, no. 1 (1985): 7-13.

Tolich, Martin, and Carl Davidson. Starting Fieldwork: An Introduction to Qualitative Research in New Zealand. Melbourne: Oxford University Press, 1999.

Tonk, Rosemarie. “"A Difficult and Complicated Question': The New Zealand Company's Wellington, Port Nicholson, Claim." In The Making of Wellington 1800-1914, edited by David Hamer and Roberta Nicholls, 35-59. Wellington: Victoria University of Wellington, 1990.

Trapeznik, Alexander, ed. Common Ground: Heritage and Public Places in New Zealand. Dunedin: University of Otago Press, 2000.

Turnbull, Michael. The New Zealand Bubble: The Wakefield Theory in Practice. Wellington: Price Milburn and Company, 1959.

Ulrich, Roger S. "Biophilia, Biophobia, and Natural Landscapes." In The Biophilia Hypothesis, edited by Stephen R. Kellert and Edward O. Wilson, 73-137. Washington DC: Island Press, 1993.

UNESCO, "Recommendation Concerning the Protection, at National Level, of the Cultural and Natural Heritage." http://portal.unesco.org/en/ev.phpURL_ID=13087\&URL_DO=DO_TOPIC\&URL_SECTION=201.html. 
Urry, J. The Tourist Gaze. London: Sage, 1990.

Visak, Tatjana. "The Moral Relevance of Naturalness." In Is Nature Ever Evil? Religion, Science and Value, edited by Willem B. Drees, 41-44. London: Routledge, 2003.

Wade, Richard C. The Urban Frontier: Pioneer Life in Early Pittsburgh, Cincinnati, Lexington, Louisville, and St. Louis. Chicago: University of Chicago Press, 1976.

Waitangi Tribunal, "Te Whanganui a Tara Me Ona Takiwa: Report on the Wellington District: Wai 145.” Wellington: Waitangi Tribunal, 2003.

Wakefield, Edward Jerningham. Adventure in New Zealand. Vol. 1, London: J. Murray, 1845.

Wakeling and Associates, Survey of Notable Trees for Palmerston North City Council: District Plan Review 2011: Report and Recommendations, 9 June 2011.

Walton, Anthony, and B. G. McFadgen. "Fitzroy Bay: A Further Archaeological Survey." New Zealand Archaeological Association: Archaeology in New Zealand 31, no. 3 (September 1988): 159-68.

Walton, T., ed. Archaeological Site Recording in New Zealand: New Zealand Archaeological Association, 1999.

Warren-Findley, Jannelle. "Human Heritage Management in New Zealand in the Year 2000 and Beyond." Wellington: Fulbright New Zealand, 2001.

Waterton, Emma, and Steve Watson, eds. Culture, Heritage and Representation:

Perspectives in Visuality and the Past. Surrey: Ashgate, 2010.

Watson, Steve, and Emma Waterton. "Introduction." In Culture, Heritage and Representation: Perspectives in Visuality and the Past, edited by Emma Waterton and Steve Watson, 1-16. Surrey: Ashgate, 2010.

Weiner, Annette B. “Inalienable Wealth.” American Ethnologist 12, no. 2 (May 1985): 210227.

Wellington City Council. "Wellington City District Plan.” Wellington: Wellington City Council, 2000, amended 2012.

Wellington Civic Trust, "On the Waterfront: A Report and Commentary on the Lambton Harbour Forum Held at the Events Centre, Lambton Harbour Sunday 19 May 1996." Wellington: Wellington Civic Trust, 1996.

Wellington, Shannon, and Gillian Oliver. "Reviewing the Digital Heritage Landscape: The Intersection of Digital Media and Museum Practice." In The International Handbooks of Museum Studies: Museum Practice, edited by Conal McCarthy, 577-96. Chichester: Wiley Blackwell, 2015. 
Waterfront Leadership Group, "The Wellington Waterfront Framework: Report of the Waterfront Leadership Group.” Wellington: Wellington City Council, 2001.

West, Susie, ed. Understanding Heritage in Practice. Manchester: Manchester University Press, 2010.

Weston, Anthony. "Introduction." In An Invitation to Environmental Philosophy, edited by Anthony Weston, 1-15. Oxford: Oxford University Press, 1999.

—. "Is It Too Late?". In An Invitation to Environmental Philosophy, edited by Anthony Weston, 43-68. Oxford: Oxford University Press, 1999.

White, Richard. "Discovering Nature in North America." The Journal of American History 79, no. 3 (1992): 874-91.

Williams, David V. "The Treaty of Waitangi: Māori Magna Carta." In The Treaty on the Ground: Where We Are Headed and Why It Matters, edited by Rachael Bell, Margaret Kawharu, Kerry Taylor, Michael Belgrave and Peter Meihana, 29-50. Auckland: Massey University Press, 2017.

Williams, Malcolm. Making Sense of Social Research. London: Sage, 2003.

Williams, P. M. E. Te Rongoa Maori: Maori Medicine. Auckland: Reed, 1996.

Wilson, Edward O. Consilience: The Unity of Knowledge. New York: Alfred A. Knopf, 1998.

Wittman, Richard K. "Local Memory and National Aesthetics: Jean Pagès's EarlyEighteenth-Century Description of the 'Incomparable' Cathedral of Amiens." In Monuments and Memory: Made and Unmade, edited by Robert S. Nelson and Margaret Olin, 259-79. Chicago: University of Chicago Press, 2003.

Wohlleben, Peter. The Hidden Life of Trees: What They Feel, How They Communicate: Discoveries from a Secret World. Translated by Jane Billinghurst. Melbourne: Black Inc., 2015.

Wood, John. Twelve Months in Wellington, Port Nicholson; or Notes for the Public and the New Zealand Company. London: Pelham Richardson, 1843.

Yen, D. E. "Wild Plants and Domestication in Pacific Islands." In Recent Advances in IndoPacific Prehistory: Proceedings of the International Symposium Held at Poona, December 19-21, 1978, edited by Virenda N. Misra and Peter S. Bellwood, 315-26. Leiden: E. J. Brill, 1985.

Yin, Robert. Case Study Research: Design and Methods. London: Sage, 1994.

Young, David. Our Islands Our Selves: A History of Conservation in New Zealand. Dunedin: Otago University Press, 2004.

Young, John. The Life of John Plimmer, Father of Wellington, with Selections from His Writings. Wellington: Printed by the New Zealand Times Co., 1901. 
Young, Liam Cole. "Un-Black Boxing the List: Knowledge, Materiality, and Form." Canadian Journal of Communication 38 (2013): 497-516. 